\title{
Development of an Analytical Model for Organic-Fluid Fouling
}

\section{Energy Systems Division} Argonne National Laboratory

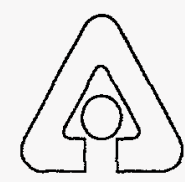

Operated by The University of Chicago, under Contract W-31-109-Eng-38, for the United States Department of Energy 


\section{Argonne National Laboratory}

Argonne National Laboratory, with facilities in the states of Illinois and Idaho, is owned by the United States Government, and operated by the University of Chicago under the provisions of a contract with the Department of Energy.

This technical memo is a product of Argonne's Energy Systems (ES) Division. For information on the division's scientific and engineering activities, contact:

Director, Energy Systems Division

Argonne National Laboratory

Argonne, Illinois 60439-4815

Telephone (708) 252-3724

Presented in this technical memo are preliminary results of ongoing work or work that is more limited in scope and depth than that described in formal reports issued by the ES Division.

Publishing support services were provided by Argonne's Information and Publishing Division.

\section{Disclaimer}

This report was prepared as an account of work sponsored by an agency of the United States Government. Neither the United States Government nor any agency thereof, nor any of their employees, makes any warranty, express or implied, or assumes any legal liability or responsibility for the accuracy, completeness, or usefulness of any information, apparatus, product, or process disclosed, or represents that its use would not infringe privately owned rights. Reference herein to any specific commercial product, process, or service by trade name, trademark, manufacturer, or otherwise, does not necessarily constitute or imply its endorsement, recommendation, or favoring by the United States Government or any agency thereof. The views and opinions of authors expressed herein do not necessarily state or reflect those of the United States Government or any agency thereof.

Available to DOE and DOE contractors from the Office of Scientific and Technical Information, P.O. Box 62, Oak Ridge, TN 37831; prices available from (615) $576-8401$

Available to the public from the National Technical Information Service, U.S. Department of Commerce, 5285 Port Royal Road, Springfield, VA 22161. 


\section{DISCLAIMER}

Portions of this document may be illegible in electronic image products. Images are produced from the best available original document. 


\section{Development of an Analytical Model for Organic-Fluid Fouling}

by C.B. Panchal and A.P. Watkinson*

Energy Systems Division,

Argonne National Laboratory, 9700 South Cass Avenue, Argonne, Illinois 60439

October 1994

Work sponsored by United States Department of Energy,

Assistant Secretary for Energy Efficiency and Renewable Energy,

Office of Industrial Technologies

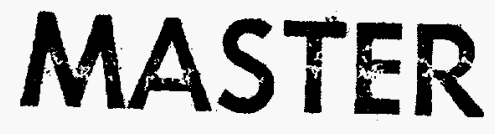

"Watkinson is affiliated with the Department of Chemical Engineering, University of British Columbia. 


\section{Contents}

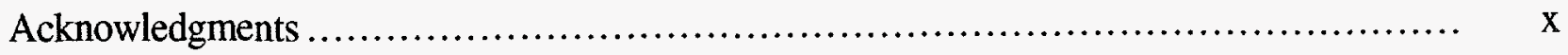

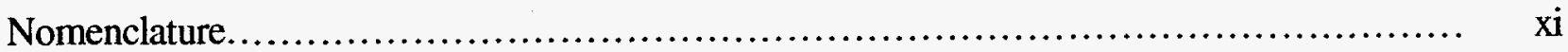

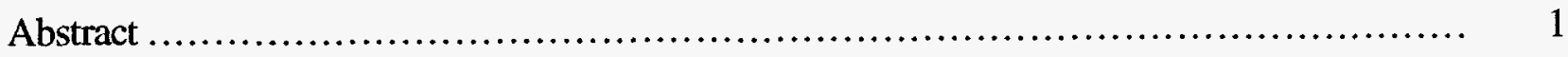

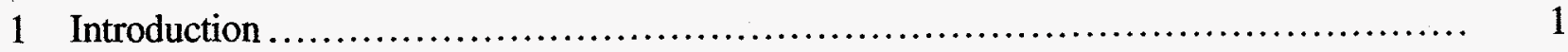

2 Literature Models of Fouling ............................................. 5

3 Physical Model............................................................ 9

4 Mathematical Model for Local Deposition .................................. 17

4.1 Precursor Generation in Bulk........................................... 18

4.2 Precursor Generation in Boundary Layer.................................. 20

4.3 Precursor Generation at Wall ........................................ 25

5 System Simulation...................................................... 27

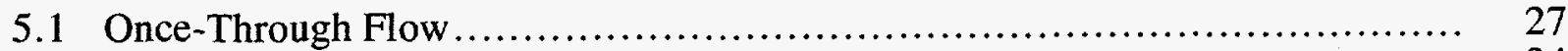

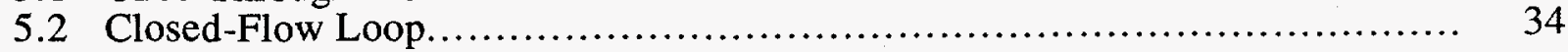

6 Experimental Apparatus and Procedure ..................................... 39

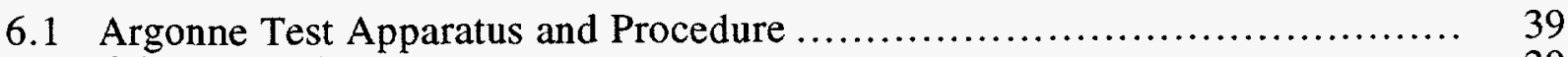

6.1 .1 Test Apparatus .................................................... 39

6.1.2 Instrumentation of the Data-Acquisition System..................... 43

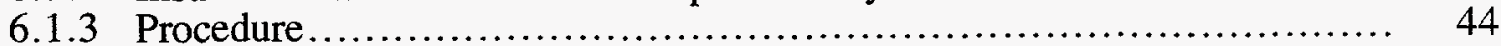

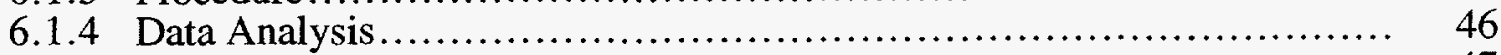

6.2 UBC Test Apparatus..................................................... 47

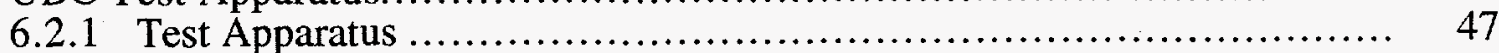

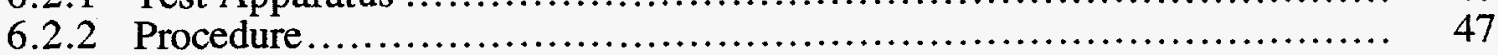

6.2.3 Data Analysis ........................................................ 50

7 Validation of the Model................................................... 51

7.1 Determination of Kinetic Data......................................... 51

7.2 Effects of Physical Parameters............................................... 60

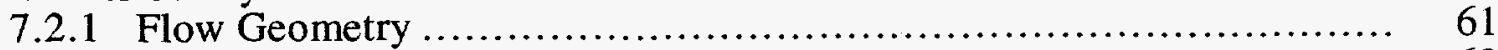

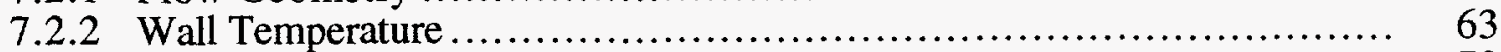

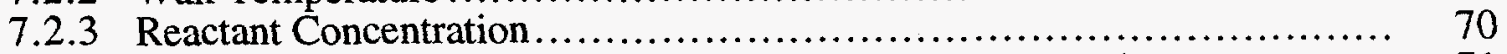

7.2 .4 Fluid Bulk Temperature ......................................... 71

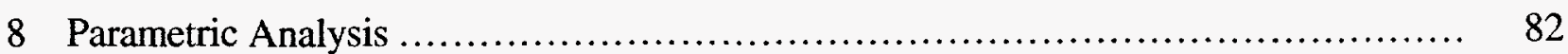

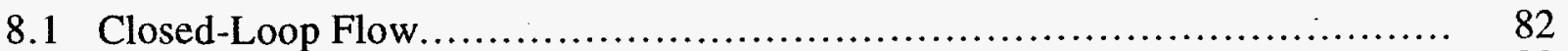

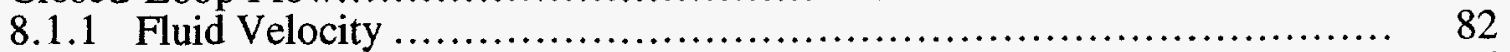

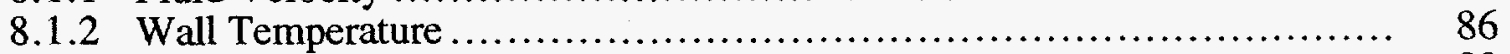

8.1 .3 Bulk Temperature ................................................ 89 


\section{Contents (Cont.)}

8.1.4 Indene Concentration............................................... 94

8.1.5 Oxygen Concentration............................................. 95

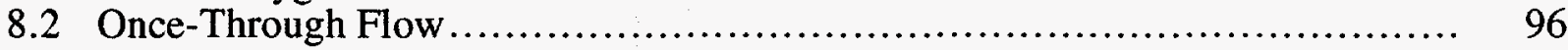

9 Computer Program ............................................................... 103

9.1 Calculation Algorithms ........................................................ 103

9.2 Physical Properties ........................................................ 107

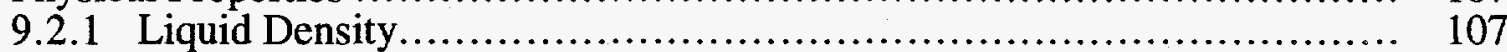

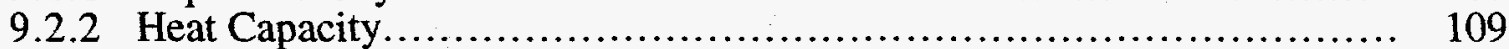

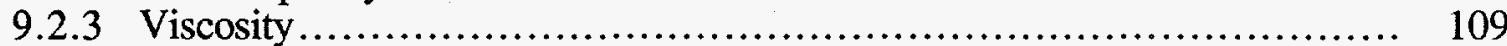

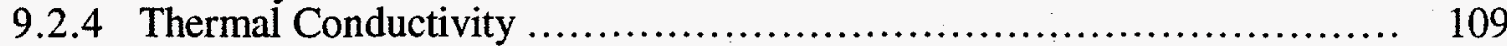

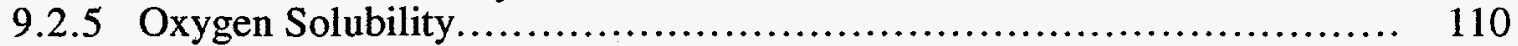

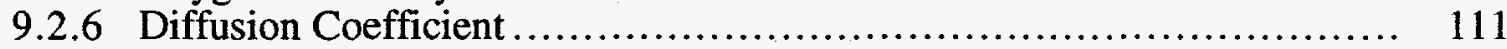

10 Conclusions and Recommendations.......................................... 112

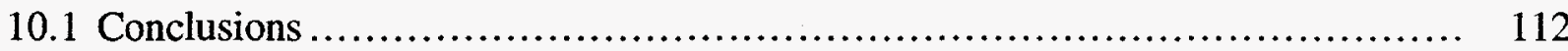

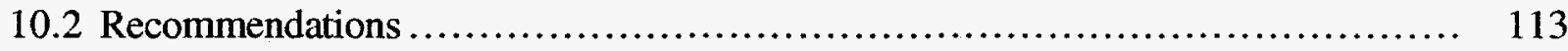

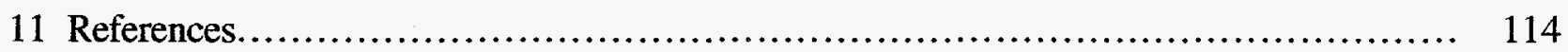

Tables

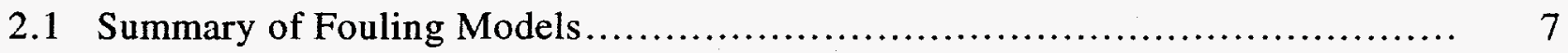

6.1 List of Instrumentation for the Argonne Fouling Apparatus..................... 42

6.2 Design Specifications for Fouling Probes.................................... 49

6.3 Instrumentation for the UBC Fouling Apparatus.............................. 49

7.1 Batch-Reaction Data and Calculated Reaction Results ........................... 52

7.2 Average Test Conditions and Physical Parameters for the Baseline

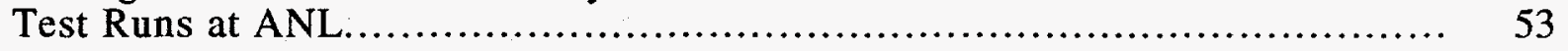

7.3 Average Test Conditions and Physical Parameters for the Baseline Test Runs at UBC....

7.4 Test Conditions for ANL Experiments to Determine the Effects of Interface Temperature

7.5 Test Conditions for ANL Experiments to Determine the Effects of Reactant Concentration .

7.6 Test Conditions for ANL Experiments to Determine the Effects of Fluid Temperature 


\section{Tables (Cont.)}

8.1 Baseline Test Conditions for the Parametric Analysis for

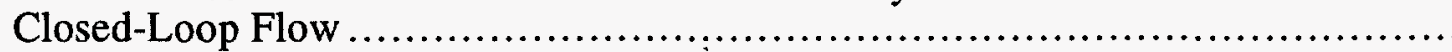

8.2 Baseline Test Conditions for the Parametric Analysis for Once-Through Flow

9.1 Input Parameter List for Once-Through-Flow System......................... 105

9.2 Input Parameter List for Closed-Flow-Loop System ........................... 106

9.3 Reaction Parameters.......................................................... 107

9.4 Predicted and Experimental Viscosities ................................... 110

9.5 Predicted and Experimental Thermal Conductivities ............................ 110

\section{Figures}

1.1 Four-Step Approach to OFF Research ....................................... 2

3.1 Schematic Diagram of the OFF Model...................................... 12

4.1 Concentration and Temperature Profiles for the Film Theory ................... 21

4.2 Concentration and Temperature Profiles for the Film Theory under Limiting-

Case Uniform Temperature in the Diffusion-Boundary Layer

4.3 Concentration and Temperature Profiles for the Film Theory under Limiting-

Case Uniform Concentration in the Thermal-Boundary Layer...

4.4 Concentration and Temperature Profiles for the Film Theory, Showing the Incremental Boundary Layer....

5.1 Control Volume for the Case 1 Fouling Models

5.2 Control Volume for the Case 2 Fouling Model............................. 32

5.3 Control Volume for the Case 3 Fouling Model............................... 33

5.4 Flow Schematic Diagram for the ANL Fouling Apparatus .................... 34

5.5 Flow Schematic Diagram for the UBC Fouling Apparatus ..................... 35

6.1 Process and Instrumentation Diagram for the ANL Fouling Apparatus: Evaporator Section

6.2 Process and Instrumentation Diagram for the ANL Fouling Apparatus: Cooler Section 


\section{Figures (Cont.)}

6.3 Schematic Diagram of the ANL Fouling Monitor............................. 41

6.4 Flow Diagram for the UBC Fouling Apparatus................................ 48

7.1 Fouling Resistance for HTM\#1 for Baseline Conditions and Comparison with the Case 2 Prediction ........................................................

7.2 Fouling Resistance for HTM\#2 for Baseline Conditions and Comparison with the Case 2 Prediction

7.3 Fouling Resistance for HTM\#3 for Baseline Conditions

7.4 Fouling Resistance for HTM\#1 for Baseline Conditions and Comparison with Case 1a Prediction ........................................................

7.5 Fouling Resistance for HTM\#2 for Baseline Conditions and Comparison with Case la Prediction

7.6 Effect of Foulant Particulate Size on the Fouling Resistance at $15 \mathrm{~h}$ for Case $1 b$

7.7 Fouling Resistance for HTM\#1 for Baseline Conditions and Comparison with the Case 3 Prediction

7.8 Fouling Resistance for HTM\#2 for Baseline Conditions and Comparison with the Case 3 Prediction

7.9 Comparison of the Fouling Resistance for In-Tube and Annular Flow Monitors and Comparison with the Case la Prediction

7.10 Comparison of the Fouling Resistance for In-Tube and Annular Flow Monitors and Comparison with the Case 2 Prediction

7.11 Comparison of the Fouling Resistance for In-Tube and Annular Flow Monitors and Comparison with the Case 3 Prediction

7.12 Effect of Interface Temperature for HTM\#1 in ANL Experiments and Comparison with the Case 1a Prediction

7.13 Effect of Interface Temperature for HTM\#2 in ANL Experiments and Comparison with the Case 1a Prediction

7.14 Effect of Interface Temperature for HTM\#1 in ANL Experiments and Comparison with the Case 2 Prediction

7.15 Effect of Interface Temperature for HTM\#2 in ANL Experiments and Comparison with the Case 2 Prediction

7.16 Effect of Interface Temperature for HTM\#1 in ANL Experiments and Comparison with the Case 3 Prediction 


\section{Figures (Cont.)}

7.17 Effect of Interface Temperature for HTM\#2 in ANL Experiments and Comparison with the Case 3 Prediction

7.18 Effect of Interface Temperature for UBC Experiments and Comparison with the Case 1a Prediction

7.19 Effect of Interface Temperature for UBC Experiments and Comparison with the Case 2 Prediction

7.20 Effect of Interface Temperature for UBC Experiments and Comparison with the Case 3 Prediction

7.21 Effect of Oxygen Concentration for HTM\#1 in ANL Experiments and Comparison with the Case la Prediction

7.22 Effect of Oxygen Concentration for HTM\#2 in ANL Experiments and Comparison with the Case 1a Prediction

7.23 Effect of Oxygen Concentration for HTM\#1 in ANL Experiments and Comparison with the Case 2 Prediction

7.24 Effect of Oxygen Concentration for HTM\#2 in ANL Experiments and Comparison with the Case 2 Prediction

7.25 Effect of Oxygen Concentration for HTM\#1 in ANL Experiments and Comparison with the Case 3 Prediction

7.26 Effect of Oxygen Concentration for HTM\#2 in ANL Experiments and Comparison with the Case 3 Prediction

7.27 Effect of Indene Concentration for HTM\#1 in ANL Experiments and Comparison with the Case 1a Prediction

7.28 Effect of Indene Concentration for HTM\#2 in ANL Experiments and Comparison with the Case la Prediction

7.29 Effect of Indene Concentration for HTM\#1 in ANL Experiments and Comparison with the Case 2 Prediction

7.30 Effect of Indene Concentration for HTM\#2 in ANL Experiments and Comparison with the Case 2 Prediction

7.31 Effect of Indene Concentration for HTM\#1 in ANL Experiments and Comparison with the Case 3 Prediction

7.32 Effect of Indene Concentration for HTM\#2 in ANL Experiments and Comparison with the Case 3 Prediction

7.33 Effect of Bulk Fluid Temperature for HTM\#1 in ANL Experiments and Comparison with the Case 1a Prediction 


\section{Figures (Cont.)}

7.34 Effect of Bulk Fluid Temperature for HTM\#2 in ANL Experiments and Comparison with the Case la Prediction

7.35 Effect of Bulk Fluid Temperature for HTM\#1 in ANL Experiments and Comparison with the Case 2 Prediction

7.36 Effect of Bulk Fluid Temperature for HTM\#2 in ANL Experiments and Comparison with the Case 2 Prediction

7.37 Effect of Bulk Fluid Temperature for HTM\#1 in ANL Experiments and Comparison with the Case 3 Prediction

7.38 Effect of Bulk Fluid Temperature for HTM\#2 in ANL Experiments and Comparison with the Case 3 Prediction

8.1 Effect of Fluid Velocity on the Fouling Resistance at $15 \mathrm{~h}$ as Predicted by Case 1 a....

8.2 Effect of Fluid Velocity on the Fouling Resistance at $15 \mathrm{~h}$ as Predicted by Case $1 b$

8.3 Effect of Fluid Velocity on the Fouling Resistance at $15 \mathrm{~h}$ as Predicted by Case 2

8.4 Effect of Fluid Velocity on the Fouling Resistance at $15 \mathrm{~h}$ as Predicted by Case 3

8.5 Effect of HTM Wall Temperature on the Fouling Resistance at $1.5 \mathrm{~h}$ as Predicted by Case 1a

8.6 Effect of HTM Wall Temperature on the Fouling Resistance at $15 \mathrm{~h}$ as Predicted by Case 1b

8.7 Effect of HTM Wall Temperature on the Fouling Resistance at $15 \mathrm{~h}$ as Predicted by Case 2

8.8 Effect of HTM Wall Temperature on the Fouling Resistance at $15 \mathrm{~h}$ as Predicted by Case 3

8.9 Effect of HTM Wall Temperature on the Fouling Resistance at $15 \mathrm{~h}$ as Predicted by Case 1a, Presented as an Arrhenius Plot.

8.10 Effect of HTM Wall Temperature on the Fouling Resistance at $15 \mathrm{~h}$ as Predicted by Case 2, Presented as an Arrhenius Plot

8.11 Effect of HTM Wall Temperature on the Fouling Resistance at $15 \mathrm{~h}$ as Predicted by Case 3, Presented as an Arrhenius Plot...

8.12 Effect of Fluid Temperature on the Fouling Resistance at $15 \mathrm{~h}$ as

Predicted by Case $1 \mathrm{a}$ 


\section{Figures (Cont.)}

8.13 Effect of Fluid Temperature on the Fouling Resistance at $15 \mathrm{~h}$ as

Predicted by Case $1 \mathrm{~b}$

8.14 Effect of Fluid Temperature on the Fouling Resistance at $15 \mathrm{~h}$ as

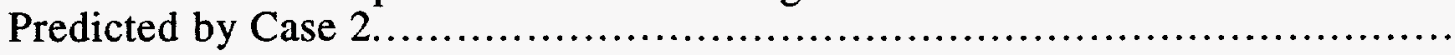

8.15 Effect of Fluid Temperature on the Fouling Resistance at $15 \mathrm{~h}$ as

Predicted by Case 3

8.16 Effect of Indene Concentration on the Fouling Resistance at $15 \mathrm{~h}$ as

Predicted by the Three Fouling Cases

8.17 Effect of Oxygen Concentration on the Fouling Resistance at $15 \mathrm{~h}$ as

Predicted by the Three Fouling Cases

8.18 Distribution of the Fouling Resistance along the Heat-Exchanger Length at $15 \mathrm{~h}$ as Predicted by the Three Fouling Cases: Zero Precursor Concentration at the Inlet.

8.19 Distribution of the Fluid Temperature along the Heat-Exchanger Length at Time 0 and $15 \mathrm{~h}$ as Predicted by the Three Fouling Cases: Zero Precursor Concentration at the Inlet.

8.20 Distribution of the Interface Temperature along the Heat-Exchanger Length at Time 0 and $15 \mathrm{~h}$ as Predicted by the Three Fouling Cases: Zero Precursor Concentration at the Inlet.

8.21 Fouling Resistance at the Outlet as a Function of Time as Predicted by the Three Fouling Cases: Zero Precursor Concentration at the Inlet.

8.22 Distribution of the Fouling Resistance along the Heat-Exchanger Length at $15 \mathrm{~h}$ as Predicted by the Three Fouling Cases: Inlet Precursor Concentration of $0.01 \mathrm{kmol} / \mathrm{m}^{3}$

8.23 Distribution of the Fluid Temperature along the Heat-Exchanger Length at Time 0 and $15 \mathrm{~h}$ as Predicted by the Three Fouling Cases: Inlet Precursor Concentration of $0.01 \mathrm{kmol} / \mathrm{m}^{3}$

8.24 Distribution of the Interface Temperature along the Heat-Exchanger Length at Time 0 and $15 \mathrm{~h}$ as Predicted by the Three Fouling Cases: Inlet Precursor Concentration of $0.01 \mathrm{kmol} / \mathrm{m}^{3}$....

8.25 Fouling Resistance at the Outlet as a Function of Time as Predicted by the Three Fouling Cases: Inlet Precursor Concentration of $0.01 \mathrm{kmol} / \mathrm{m}^{3}$

9.1 Overall Structure of the Computer Program for the Fouling Model 104 


\section{Acknowledgments}

The present work was supported by the U.S. Department of Energy, Office of Industrial Technologies, Thermal Sciences Program, of which EhrPing HuangFu is the program manager. The authors wish to thank G. Zhang of the University of British Columbia and J. Falkenberg of Argonne National Laboratory for conducting experiments. The authors wish to acknowledge Valerie Davis and Vicki Skonicki for word processing and Ellen Hathaway for editing. 


\section{Nomenclature}

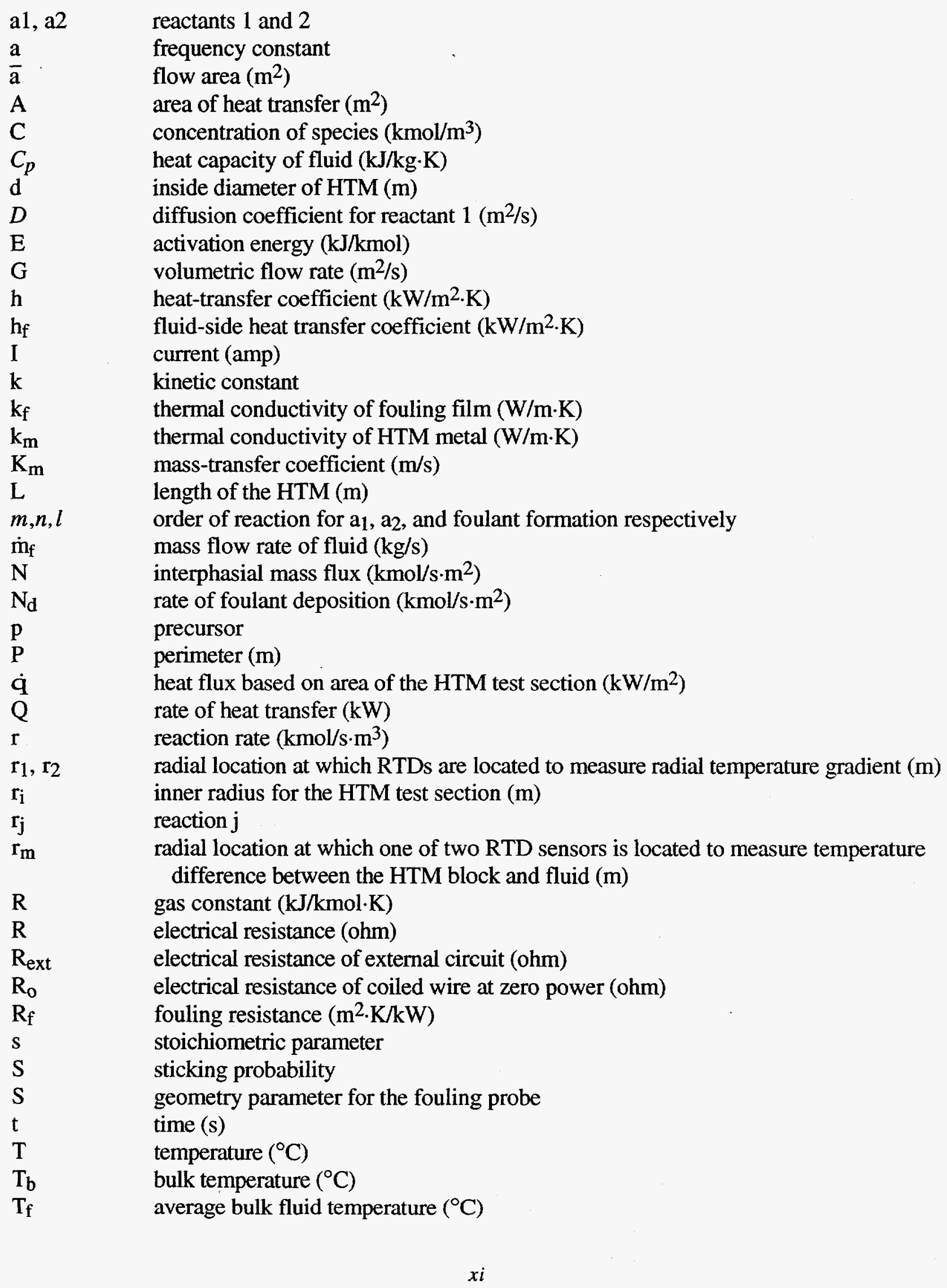




$\begin{array}{ll}\mathrm{T}_{\mathrm{i}} & \text { fluid temperature at wall/fluid interface }\left({ }^{\circ} \mathrm{C}\right) \\ \mathrm{T}_{\mathrm{S}} & \text { surface temperature }\left({ }^{\circ} \mathrm{C}\right) \\ \mathrm{T}_{\mathrm{W}} & \text { metal wall temperature beneath surface }\left({ }^{\circ} \mathrm{C}\right) \\ \mathrm{V} & \text { voltage power for } \mathrm{HTM}(\mathrm{V}) \\ \mathrm{Vo} & \text { volume of the cooler/reservoir }\left(\mathrm{m}^{3}\right) \\ \mathrm{V}_{\mathrm{Z}} & \text { axial fluid velocity }(\mathrm{m} / \mathrm{s}) \\ \mathrm{x} & \text { distance in the boundary layer } \\ \mathrm{x}_{\mathrm{f}} & \text { fouling film thickness }(\mathrm{m}) \\ \mathrm{Z} & \text { distance along the flow channel }\end{array}$

\section{Greek Letters}

$\alpha \quad$ temperature coefficient of resistance (ohm/K)

$\rho \quad$ fluid density $\left(\mathrm{kg} / \mathrm{m}^{3}\right)$

$\rho_{\mathrm{c}} \quad$ concentration density $\left(\mathrm{kmol} / \mathrm{m}^{3}\right)$

$\rho_{\mathrm{f}} \quad$ density of film deposition $\left(\mathrm{kg} / \mathrm{m}^{3}\right)$

$\mu \quad$ viscosity (Pa.s)

$\Delta \mathrm{H}_{\mathrm{rj}} \quad$ heat of reaction for reaction $\mathrm{j}(\mathrm{kJ} / \mathrm{kmol})$

$\Delta \mathrm{P} \quad$ pressure difference $(\mathrm{Pa})$

$\Delta \mathrm{t} \quad$ time increment (s)

$\Delta \mathrm{T} \quad$ temperature difference $\left({ }^{\circ} \mathrm{C}\right)$

$\Delta \mathrm{T}_{1} \quad$ temperature difference between radius locations $\mathrm{r}_{1}$ and $\mathrm{r}_{2}\left({ }^{\circ} \mathrm{C}\right)$

$\Delta \mathrm{T}_{2} \quad$ temperature difference between radius location $\mathrm{r}_{\mathrm{m}}$ and test fluid $\left({ }^{\circ} \mathrm{C}\right)$

$\Delta \mathrm{T}_{\mathrm{f}} \quad$ change in fluid temperature as it flows through HTM $\left({ }^{\circ} \mathrm{C}\right)$

$\Delta \mathrm{T}_{\mathrm{m}} \quad$ change in fluid temperature between radius locations $\mathrm{r}_{\mathrm{m}}$ and $\mathrm{r}_{\mathrm{i}}\left({ }^{\circ} \mathrm{C}\right)$

$\Delta \mathrm{T}_{\mathrm{mtd}} \quad$ mean temperature difference $\left({ }^{\circ} \mathrm{C}\right)$

\section{Subscripts}

1,2 reactions 1 and 2 , respectively

a1, a2 reactants 1 and 2, respectively

b bulk

f foulant

i interface

p precursor 


\title{
Development of an Analytical Model for Organic-Fluid Fouling
}

\author{
by
}

\author{
C.B. Panchal and A.P. Watkinson
}

\begin{abstract}
The research goal of this project is to determine ways to effectively mitigate fouling in organic fluids: hydrocarbons and derived fluids. The fouling research focuses on the development of methodology for determining threshold conditions for fouling. Initially, fluid containing chemicals known to produce foulant is analyzed; subsequently, fouling of industrial fluids is investigated. The fouling model developed for determining the effects of physical parameters is the subject of this report. The fouling model is developed on the premise that the chemical reaction for generation of precursor can take place in the bulk fluid, in the thermalboundary layer, or at the fluid/wall interface, depending upon the interactive effects of fluid dynamics, heat and mass transfer, and the controlling chemical reaction. In the analysis, the experimental data are examined for fouling deposition of polyperoxide produced by autoxidation of indene in kerosene. The effects of fluid and wall temperatures for two flow geometries are analyzed. The results show that the relative effects of physical parameters on the fouling rate differ for the three fouling mechanisms. Therefore, to apply the closed-flow-loop data to industrial conditions, the controlling mechanism must be identified.
\end{abstract}

\section{Introduction}

Organic-fluid fouling (OFF) is a costly problem for chemical, petroleum, and other industries that produce, refine, prepare, and use organic chemicals. An Exxon study showed that, for a typical refinery of $100,000 \mathrm{bbl} / \mathrm{d}$ capacity, the fouling-related cost can be as much as $\$ 10$ million (1981 dollars) per year, of which nearly half is spent for energy (Van Nostrand et al. 1981). The U.S. Department of Energy (DOE) sponsored a study by Rebello that showed significant energy losses due to fouling in the chemical and petroleum industries (1987). The effects of fouling can be summarized as follows:

- Thermal energy loss,

- Productivity loss, and 
- Loss of opportunity to use advanced process equipment (e.g., compact heat exchangers, enhanced surfaces, and such integrated units as reactor and separator).

The four-step approach shown in Figure 1.1 is used for the OFF research. Initially, the basic mechanism of organic-fluid fouling is investigated by means of a nonfouling test fluid doped with a known amount of fouling-causing chemicals. Subsequently, a generalized approach can be developed for complex fluids where several reactions may occur simultaneously. The objective is to develop an analytical tool(s) for determining threshold conditions. The research will then lead to effective means of mitigating fouling with existing and new techniques.

A critical review of OFF was carried out as part of the Thermal Sciences Program at Argonne National Laboratory (ANL) to establish the present status of knowledge in this field and to identify a number of key areas where detailed information is lacking (Watkinson 1988). One area lacking detailed information is the mathematical description of the OFF processes taking place in heat-exchange equipment. A mechanistic description of the fouling process is essential to identifying the controlling mechanism(s) and determining the effects of physical parameters. It may not be possible to develop a detailed chemical-reaction model for many complex fluid systems; however, a basic model can be used to identify the rate-controlling step, thereby facilitating the application of laboratory data to industrial conditions. The fouling model can serve as an analytical

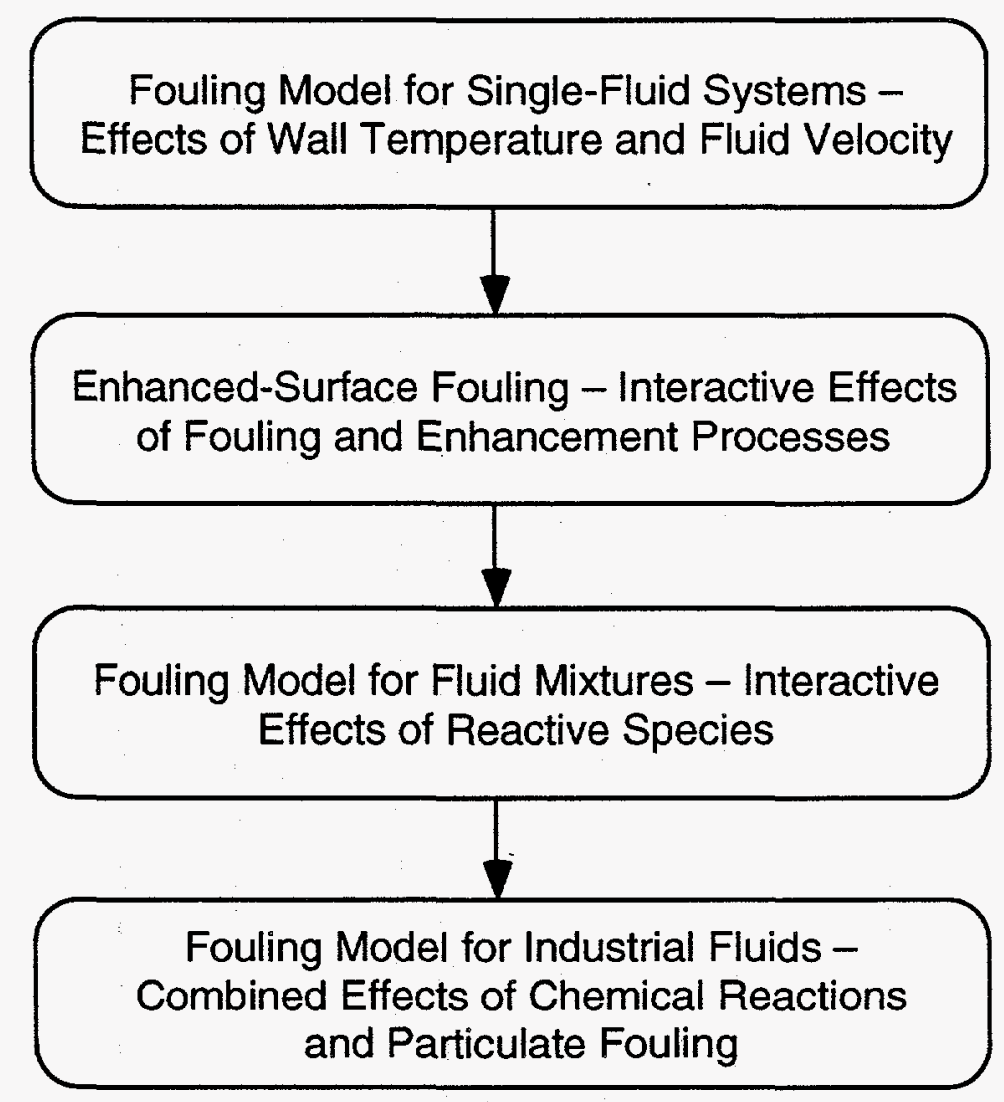

FIGURE 1.1 Four-Step Approach to OFF Research 
tool for determining the interactive effects of the chemical and physical processes associated with OFF.

Until recently, OFF has been treated as a system-specific problem, and no general solution was anticipated. However, with better understanding of the chemical and physical processes associated with fouling and the classification of the fouling mechanisms, it is believed that OFF, also recognized as chemical-reaction fouling, can be formulated to identify the rate-governing process. Such mathematical models should include a description of the fluid dynamics, heat transfer, and chemical-reaction processes that give rise to the presence of fouling precursors and their subsequent reaction to form insoluble deposits. The major objectives of the present work are to develop a physical model that describes the fouling process and to derive the mathematical model that represents the physical and chemical steps of the overall fouling process. The fouling model discussed in this report will have the following functions:

- Prediction of the trend of fouling (for a chemically defined system),

- Determination of the effects of physical parameters,

- Extrapolation of the experimental data to field conditions, and

- Determination of threshold conditions for significant fouling.

The physical model and the mathematical analysis provide insight into the fouling mechanism. However, a comprehensive approach is required to analyze the following technical issues associated with the fouling process:

- Chemical kinetics,

- Transport mechanisms,

- Solubility criteria for foulant,

- Interactive effects of chemical and physical processes, and

- Fouling-film characterization.

A fundamental problem in the mathematical description of OFF is identifying specific precursors and obtaining the kinetic data for their generation and reaction to form insoluble deposits. However, the critical review identified several general reaction pathways that lead to the formation of foulant in many process applications (Watkinson 1988). The scope of the model 
development task is based on certain key assumptions that are justified on the basis of experimentally observed results.

The scope of the report is to document the fouling model and to discuss its capability for predicting fouling. The experimental data obtained during fiscal year 1992 at ANL and at the University of British Columbia (UBC) are used to illustrate the fouling model. The model development task was carried out jointly by ANL and UBC. 


\section{Literature Models of Fouling}

It is generally believed that no simple fouling deposition model can be used for OFF. The classical model proposed by Kern and Seaton (1959), shown as Equation 2.1, is commonly used to correlate particulate and water-scaling (crystallization) fouling:

$$
R_{f}=R_{f}^{*}\left\{1-e^{\left(-t / t_{c}\right)}\right\}
$$

where

$$
\begin{aligned}
R_{\mathbf{f}} & =\text { fouling resistance at time } t \\
R_{\mathbf{f}}^{*} & =\text { asymptotic fouling resistance, } \\
t & =\text { time starting from clean surface, and } \\
t_{c} & =\text { time constant. }
\end{aligned}
$$

The Kern-Seaton equation was developed on the basis of the following assumptions:

1. No chemical reaction is involved,

2. Net deposition is the result of deposition minus fouling removal,

3. Fouling removal increases with mass of deposition, and

4. Rate of deposition is independent of mass of deposition.

Equation 2.1 was later modified by Taborek et al. (1972) to include an appropriate term for fouling-film removal. The Kern-Seaton equation can be treated as a lumped-parameter model for correlating the experimental data in a given range of operating conditions. It is believed that this model would not correlate the data where chemical reaction is involved, such as in OFF, biofouling, and corrosion fouling.

Since the original fouling model was proposed by Kern and Seaton, several investigators have tried to formulate the fouling process for different fouling mechanisms. Crittenden et al. (1987) provided a general review of models for the chemical-reaction fouling (organic and corrosion fouling) reported in the literature. Corrosion-fouling models in particular were reviewed by Somerscales (1981). A general conclusion can be derived from these studies that no 
comprehensive effort has been carried out to develop a fouling model for OFF to provide the functional capability of predicting the fouling trend, the effects of physical parameters, and fouling under industrial conditions. The complexity of the fouling process and the need for a multidisciplinary approach are the principal reasons generally offered by investigators for simplifying the fouling analysis. Nevertheless, the previous studies provide useful information for the development of a comprehensive fouling model. Some of the selected analyses that are closely applicable to OFF are summarized in Table 2.1. Other models have been developed for the coking process for gas streams. These fouling models were used to correlate a particular set of experimental data; therefore, they may not have the general characteristics required for understanding the controlling fouling mechanism. Also, these models did not include the timedependent generation of precursor in a closed-loop experimental system. As a result, application of these models to other experimental systems and to field conditions may introduce unknown levels of uncertainty.

Of the fouling models presented in Table 2.1, the model developed by Crittenden et al. (1987) provides an approach to a generalized fouling model in which chemical reaction and transport phenomena are properly integrated. They formulated a fouling model by using a mechanistic approach for determining styrene deposition from kerosene. Although no specific assumptions are discussed in the original paper, it can be interpreted that the analysis was based on the following set of assumptions:

1. Foulant formation is a single-step chemical reaction, from styrene to insoluble foulant,

2. Reaction occurs at the wall/fluid interface,

3. Foulant has finite solubility in fluid,

4. Turbulent mass transfer is applicable at low Reynolds numbers (in the range of 1000 to 5000 ), and

5. Concentration of precursor (styrene) remains constant and equal to the initial value, and concentration of foulant remains zero, although the experimental system is a closed loop.

The rate of fouling-film buildup developed by Crittenden et al. is given by the following equation:

$$
\frac{\mathrm{dx}_{\mathrm{f}}}{\mathrm{dt}}=\frac{1}{\rho_{\mathrm{f}}}\left(\mathrm{N}_{\mathrm{p}}-\mathrm{N}_{\mathrm{f}}\right)
$$


TABLE 2.1 Summary of Fouling Models

Model Basic Assumptions

$\begin{array}{ll}\text { Watkinson and Epstein (1970) } & \begin{array}{l}\text { Precursor present in bulk } \\ \text { Insoluble foulant formed in bulk } \\ \text { Sticking probability inversely proportional to velocity }\end{array} \\ \text { Paterson and Fryer (1988) } & \begin{array}{l}\text { Zero-order reaction kinetics } \\ \text { No mass-diffusion resistance } \\ \text { Based on original analysis by Nelson (1934) }\end{array} \\ \text { Crittenden et al. (1987) } & \begin{array}{l}\text { Precursor present in bulk } \\ \text { Foulant formation occurs at wall surface } \\ \text { Finite solubility of foulant }\end{array} \\ \text { Back-diffusion of foulant } \\ \text { Nijsing (1964) } & \begin{array}{l}\text { Diffusion term included } \\ \text { Instantaneous first-order reaction near wall } \\ \text { Rapid deposition of foulant }\end{array}\end{array}$

Equation 2.2 can be expanded by inserting appropriate rate equations:

$$
\frac{d r_{f}}{d t}=\frac{d\left(x_{f} / k_{f}\right)}{d t}=\frac{1}{\rho_{f} / k_{f}}\left\{\frac{C_{p b}}{1 / K_{p}+1 / k}-K_{f} C_{f i}\right\} .
$$

where $K_{p}$ and $K_{f}$ are constants.

Equation 2.3 does not necessarily represent the overall fouling process, covering all possible cases. Nevertheless, such an analysis provides insight into the fouling mechanism and helps to determine the rate-controlling step. Crittenden et al. applied this analysis to determine polystyrene deposition from a dilute solution of styrene in kerosene by assuming the reaction zone to be at the wall surface. The predicted rate of deposition was significantly greater than the experimental data - by a factor of up to four - without considering the back-diffusion of foulant. The fouling data were used to calculate the interface concentration for computing back-diffusion of foulant. The analysis, however, did not differentiate between soluble precursor and insoluble foulant. As a result, combined effects were incorporated into back-diffusion of foulant. In order to extend the analysis, Crittenden et al. proposed to include the film-removal model of Kern and Seaton that was originally proposed for particulate fouling, where the rate of removal of the fouling deposits due to the turbulent intensity is proportional to the mass deposited on the wall surface. A further assumption was made that the film is made up of two layers: (1) a tarry and mobile layer near the interface and (2) a coke-type film near the wall surface. The experimental data, including the ANL and UBC data, support the above assumption, in particular for extended test runs in which the film aging process becomes significant. 
In the analysis by Paterson and Fryer (1988), an effective kinetic constant was calculated by integrating the reaction rate constant over the thermal-boundary layer, assuming a linear temperature profile. Paterson and Fryer did not distinguish between thermal-, momentum-, and mass-diffusion boundary layers. Their approach was based on a concept proposed by Nelson (1934). They used the analysis for correlating the fouling data in milk processing. However, they indicated that such an analysis should be applicable to OFF. Nijsing developed a set of equations for organic coolant in nuclear reactors, assuming an instantaneous first-order reaction at the wall surface that would produce an insoluble foulant. Note that Nijsing's analysis is based on an assumption that mass transfer is a controlling step. 


\section{Physical Model}

Analyses of the literature models discussed in Section 2 indicate that, for the development of the fouling model, it is essential to build a physical model to show possible steps taking place in the overall fouling process. The critical review by Watkinson (1988) shows that OFF, particularly hydrocarbon fouling, includes a two-step chemical reaction mechanism: generation of precursor followed by formation of foulant, as illustrated below for two typical process systems.

Fouling in the production process of ethylene and propylene

\begin{tabular}{|c|c|c|c|c|c|c|}
\hline & catalyst & & polymerization & & oxygen & \\
\hline $\begin{array}{l}\text { nitial } \\
\text { ydrocarbons }\end{array}$ & & $\begin{array}{l}\text { Cyclic } \\
\text { intermediates }\end{array}$ & $\Delta$ & $\begin{array}{l}\text { High molecular } \\
\text { hydrocarbons }\end{array}$ & $\longrightarrow$ & $\begin{array}{l}\text { Deposition } \\
\text { fouling }\end{array}$ \\
\hline
\end{tabular}

Crude-oil fouling by deposition of asphaltenes

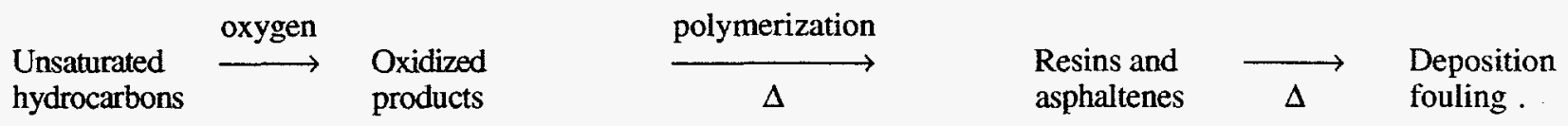

Some of the intermediate steps can be grouped into a predominant reaction that produces soluble or sparingly soluble precursors. The final reaction step would then be formation of insoluble foulant. Some of the initial steps have been studied in detail, because these reactions are used for production of derived chemicals (i.e., production of partially oxidized or sulfonated hydrocarbons). However, the chemical reaction responsible for formation of insoluble foulant has not been commonly studied, because it is not important from the standpoint of the product; formation of insoluble foulant would be small compared to production of the main product. However, a small amount of foulant formed in the heat-exchange equipment can accumulate on the surface over a period of time and develop into a significant fouling deposition.

The heat-exchanger tube acts as a tubular reactor, where the two-step reaction leading to the formation of insoluble foulant takes place. However, in conventional tubular reactors, the main reaction generally occurs in bulk. For wall-catalyzed reactions, the main reaction occurs at the wall surface. Organic-fluid fouling is a strong function of temperature. Because axial and radial temperature distributions prevail in heat-exchange equipment, the interactive effect of the chemical reaction with the temperature distribution plays an important role in OFF. Depending on the combination of conditions (i.e., temperature and reactant concentration), the chemical reaction leading to foulant formation can occur in bulk, in the thermal-boundary layer, or at the wall surface. Therefore, it is essential to determine the reaction zone where precursor and foulant are formed and to develop a fouling prediction model to represent the correct fouling phenomena. In addition, a better understanding of the physical parameters of the fouling film is necessary to develop a model accounting for the adhesion characteristics of the deposit. The film adhesiveness 
may depend on the chemical makeup of the film; however, it is believed that generalized foulingfilm characteristics can be developed for a given class of chemicals (e.g., olefins).

In summary, the fouling model analysis requires understanding of the following:

1. Chemical kinetics for generation of the soluble precursor and subsequent formation of the insoluble foulant,

2. Characterization of the molecular structure of the precursor,

3. Solubility criteria for the foulant in a given fluid,

4. Calculation of transport of the insoluble foulant, if the foulant formation occurs in bulk,

5. Probability factor and adhesion criteria for foulant sticking, and

6. Foulant-removal mechanism.

The kinetic data are available for selected foulant-forming autoxidation reactions. The adhesion criteria used for scaling and particulate fouling can be extended to OFF by estimation or experimental determination of an appropriate constant. Most of the previous analyses did not develop any solubility criteria with respect to the fouling process; therefore, the ANL fouling research may need to include foulant-solubility criteria in the analysis; a detailed approach will be developed at a later time. To summarize, initial information and a basic understanding of OFF exist, and it should be possible to initiate a comprehensive model analysis. If necessary, required information and analysis can be incorporated into the model during various stages of the model development.

At present, the mechanistic model is being developed on the basis of the two-step process, as shown below, of the foulant formation described earlier (Section 2):

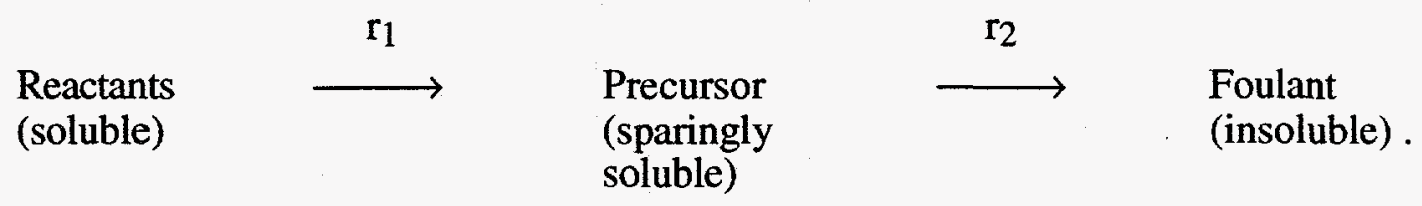

Reaction 1 leads to generation of the precursor, and reaction 2 leads to formation of the insoluble foulant. The reaction step representing the aging process will be included later. In the present approach, only the initial rate of fouling will be considered, so the aging process will not contribute to the overall fouling mechanism. 
In the overall reaction mechanism, chemical reactants responsible for the foulant formation are soluble in the parent fluid. In some cases, intermediate compounds, categorized as precursors, can form (first reaction step). They may be soluble or sparingly soluble; therefore, they themselves may not cause a major fouling deposition. The second reaction step contributes to the formation of foulant that may eventually deposit on the surface of the heat-exchange system before fluid exits. A third reaction (not shown) represents the aging process that continues after deposition of the high-molecular-weight foulant. In some applications where constant heat flux is applied, the wall temperature rises due to the added thermal resistance. The higher temperature causes the reaction in the fouling film close to the wall surface to accelerate, forming hard coke that is difficult to remove. In the present technical approach, the aging process will not be considered, because it could be specific to the system and because it requires a separate set of laboratory experiments to study the long-term kinetics associated with aging.

The interactive effects of the chemical reaction and the physical processes may bring about three different cases, depending on the reaction zone where precursor formation occurs. The overall process associated with OFF is summarized in Figure 3.1. The physical process varies depending on the limiting conditions, as shown below:

Case 1. Reaction zone for $r_{1}$ in bulk; low activation energy and high bulk-fluid temperature, or precursor is already present.

Case 1a. Reaction $r_{2}$ occurs at wall surface. Corresponding steps are

1. Formation of precursor in fluid,

2. Transfer of soluble precursor to wall surface,

3. Reaction $r_{2}$ at wall surface,

4. Possible removal, and

5. Aging.

Case $1 b$. Reaction $\mathbf{r}_{2}$ occurs in the bulk fluid. Corresponding steps are

1. Formation of precursor in fluid,

2. Formation of foulant in fluid,

3. Transfer of insoluble foulant to surface, 
Reaction Mechanism:

Reactant $\mathrm{A} \longrightarrow$ Precursor $\mathrm{B} \longrightarrow$ Foulant $\mathrm{C}$

Case 1: Precursor Generation in Bulk

Case 1a Molecular Transfer

Case $1 \mathrm{~b} \mathrm{~B}-\mathrm{C}$ C sticks on wall

Particulate Transport

Case 2: Precursor Generation in Boundary Layer

Molecular Transfer

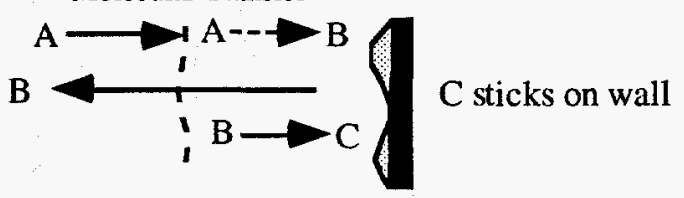

Case 3: Precursor Generation on Wall Surface

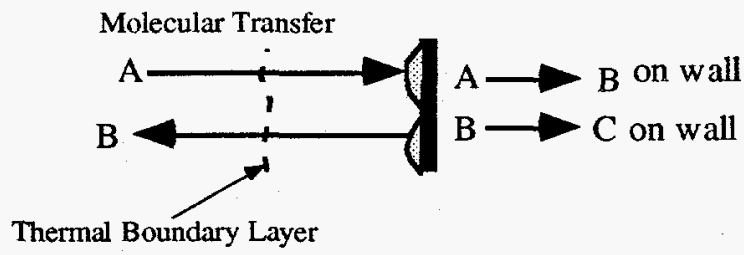

FIGURE 3.1 Schematic Diagram of the OFF Model

4. Attachment,

5. Possible removal, and

6. Aging.

Case 2. Reaction zone for $r_{2}$ in the thermal-boundary layer; activation energy is in the intermediate range, and temperature gradient is sharp (i.e., high heat flux):

Case 2a. Reaction $r_{1}$ occurs in boundary layer, but $r_{2}$ occurs at wall surface. Corresponding steps are

1. Simultaneous mass transfer and reaction in boundary layer to generate precursor,

2. Transfer of soluble precursor to surface and back-diffusion,

3. Formation of foulant at surface, 
4. Possible removal, and

5. Aging.

Case $2 b$. Reactions $r_{1}$ and $r_{2}$ occur in boundary layer. Corresponding steps are

1. Simultaneous mass transfer, including back-diffusion of precursor, and reactions to generate both precursor and insoluble foulant,

2. Deposition of foulant,

3. Possible removal, and

4. Aging.

Case 3. Reaction zone is at the wall surface; activation energy is relatively high, and bulk-fluid temperature is low. Corresponding steps are

1. Transfer of reactants to surface,

2. Formation of precursor on surface,

3. Formation of foulant on surface,

4. Possible removal, and

5. Aging.

Experimental data and supporting analyses are required to determine the controlling mechanisms for the three cases discussed above. However, possible simplifications do exist, and if experiments can reveal the controlling steps of fouling, the understanding of the fouling mechanism can be significantly improved.

The chemical reaction rate is generally expressed in terms of temperature and concentration of reactants. For example, the following reaction equation represents the reaction of two components to form a product that is typical of autoxidation of olefins:

$$
\mathrm{r}=\mathrm{k} \mathrm{C}_{\mathrm{a} 1}^{m} \mathrm{C}_{\mathrm{a} 2}^{n}
$$

where $\mathrm{k}=$ reaction constant $=\mathrm{a} \exp (-\mathrm{E} / \mathrm{RT})$. 
For hydrocarbon fluids at low to medium temperatures, autoxidation has been identified as the controlling reaction mechanism for the formation of precursor in reaction $r_{1}$. For some of the impurities found in hydrocarbon-fluid streams, frequency factor a, activation energy $\mathrm{E}$, and orders of reaction $\mathrm{m}$ and $\mathbf{n}$ are known from batch-reactor experiments. However, it is necessary to identify the chemical structures for precursor(s), so that the appropriate kinetic model can be used. Once the precursor is identified, the subsequent chemical step can be formulated. In general, the reaction may be controlled by the limiting reactant(s). For example, in oxygenated fluid systems, the concentration of peroxide formed by oxygen is rate limiting for formation of foulant at the surface. The reaction could be instantaneous under normal conditions, and the concentration of reactant tends to be zero at the interface. Therefore, there are two possible limiting cases. In one case, where the reactant concentration at the interface is zero, mass transfer is the limiting step. In the other case, where the interfacial concentration is the same as the bulk value, the reaction rate at the interface is the limiting step, and the rate of deposition is controlled by the reaction rate (Equation 3.1). In real situations, however, it may not be possible to simplify the fouling model as described above. Both the chemical reaction and the mass-transfer process may be important, and it may not be possible to distinguish whether the reaction takes place at the interface, in the bulk, or in the thermal-boundary layer.

The kinetic model is developed on the basis of knowledge of the possible reaction mechanism and the chemical structure of reactants and products, although the chemical kinetics can be better determined by batch-reactor experiments. In the experimental approach, fluid with known concentrations of reactants is allowed to react in the batch reactor, which is maintained at uniform temperature by constant stirring. Fluid samples are analyzed as a function of time, and kinetic constants are calculated by varying temperature and reactant concentration. In the first part of the ANL program, a known chemical system will be used for the development of the analysis. In the later part of the fouling research for prototype fluid mixtures, fouling experiments will be supported by a selected number of batch-reaction experiments.

The physical mechanisms associated with the fouling process are summarized below.

\section{Transport of Reactants and Soluble Precursor}

In the fouling process, mass diffusion plays a key role. Estimation of the diffusion coefficient and corresponding mass-transfer coefficient may not be difficult. The major difficulty is in identifying the rate-limiting chemical compound for which the mass-transfer coefficient needs to be calculated. For most cases of low- to medium-temperature fouling, thermophoretic diffusion may not be important. The diffusion equation can be expressed as

$$
N=K_{m}\left(C_{b}-C_{i}\right)
$$

For soluble species with known chemical structure, it is possible to estimate the diffusivity in a given parent fluid. The mass-transfer coefficient can then be calculated using the heat-transfer correlation and the Colburn analogy. The major problem in calculating the rate of mass transfer for an intermediate species is characterizing the precursor. The chemical analysis results for the fluid, 
along with the possible chemical reaction steps, will provide the information necessary to characterize the precursor and calculate the mass-transfer step. For diffusion and reaction occurring in the thermal-boundary layer, the simplified mass-flux equation given by Equation 3.2 is not valid, and a second-order diffusion equation needs to be solved with appropriate boundary conditions at the fluid/fouling-film interface and in the bulk.

\section{Transportation of Insoluble Foulant}

It is difficult to determine the key parameters that can be used to correlate the effective transfer coefficient for insoluble foulant. The major uncertainty associated with the prediction method is how to characterize the diffusing species in terms of size, shape, and coalescence. The scanning electron microscope (SEM) analysis can provide particle sizes of the fouling film deposited on the surface, from which the transport coefficient can be calculated. A detailed numerical analysis developed on the basis of the turbulent flow field system can determine the rate of deposition of the insoluble foulant formed in the bulk fluid. If the foulant formation step occurs at the wall surface or in the boundary layer, this transport step may play only a small role in the overall fouling process. Identification of reaction zones for foulant formation is a key research objective of the present program.

\section{Attachment of Foulant}

If the fouling process follows the chemical mechanism route shown by case $1 b$ or case $2 b$, it can be characterized as particulate fouling. In this fouling mechanism, attachment of foulant on the wall is a key step. Various mechanisms have been studied for the attachment of particulate fouling (but not for OFF), including surface forces and the interface stickiness factor. Considering the gummy nature of foulant in hydrocarbon fluids, it may be appropriate to assume a high value of the stickiness factor, which would give deposition of all foulant reaching the surface. Experimental confirmation is required to make such an assumption. It should be noted that in the ANL experimental setup, two heat-transfer monitors (HTMs) are installed in series. The first HTM, installed in the upstream location, is operated at high heat flux, giving wall temperatures comparable to that in industrial heat exchangers. It is followed by the second HTM, which is operated at very low heat flux to simulate isothermal conditions at the wall. The first HTM simulates formation of foulant in the bulk or boundary layer that is possibly carried downstream, while the second HTM measures the possible downstream deposition of foulant.

\section{Removal}

Removal of the fouling film is opposite to the deposition process, and in some cases, it is also recognized as a reentrainment process. Epstein (1987) has summarized the previous studies and proposed two basic mechanisms of fouling-film removal. Fouling film can be removed by the action of turbulent flow or by dissolution of the film in the fluid. The turbulent flow can reach to the interface and remove loosely attached particulates or part of the fouling film, although the foulant could redeposit downstream. There is a hypothesis that the so-called turbulent burst phenomenon is responsible for removal of loosely attached fouling film (Epstein 1987). However, 
individual particulates that are not strongly attached to the surface can be removed by the simple shear-stress gradient at the interface. These theories have been applied to particulate fouling; however, for OFF, it is believed that removal of the fouling film by such a mechanism is negligible. The major process of film or precursor removal from the fluid/wall interface is by dissolution and back-diffusion. In some cases, the precursor forms at the surface (case 3) at relatively high temperatures; however, before the second reaction can proceed to form the insoluble foulant, the precursor diffuses back to the bulk. The resulting rate of fouling is much less than that predicted by assuming no back-diffusion of precursor in the parent fluid.

Aging

Aging of the film for OFF includes continuous changes in chemical and physical parameters for the fouling film. Chemical reactions, in general, continue, and the film composition changes with time. It has been observed that a long-exposed fouling film shows two distinct layers, each possibly with different physical and chemical characteristics. As stated earlier, the initial effort is emphasizing formation and deposition of foulant; the aging process will be studied later in the program. 


\section{Mathematical Model for Local Deposition}

The analysis of the mathematical model is an evolving process; therefore, the analysis discussed in this report can be used as a framework for the development. The detailed analysis will be developed during the course of the program, especially after initial experimental data are available to verify the basic assumptions. In general, the analysis consists of two fundamental steps: calculation of the local rate of fouling and integration of local fouling along the flow channel. The local calculation of the fouling rate requires knowledge of the following:

- Bulk composition, including precursor if it exists from upstream reaction,

- Bulk temperature,

- Wall temperature or heat flux,

- Fluid velocity,

- Correlations to calculate the heat- and mass-transfer coefficients,

- Known chemical reactions (reactants to precursor to foulant),

- Solubility criteria, and

- Model for surface deposition or adhesiveness.

As discussed earlier, it may not be possible to estimate all parameters necessary to calculate the rate of deposition for comparison with the experimental data. Therefore, it is necessary to conduct experiments under controlled conditions, where certain steps can either be eliminated or the effects of these steps minimized. The mathematical analysis discussed here is a general approach based on the three fouling cases discussed in Section 3.

The basic assumptions used in the development of the mathematical model for OFF are summarized below:

1. Reaction mechanism consists of a two-step process,

Reaction 1: $\quad$ reactant $1+$ reactant $2 \longrightarrow$ precursor

Reaction 2: $\quad$ presursor $\longrightarrow$ foulant 
Reactants a1 and a2 form soluble precursor in the first reaction, and precursor forms insoluble foulant in the second reaction. This sequence is the typical reaction for autoxidation of olefins that produce soluble gum, leading to fouling deposition.

2. Heat of reaction is negligible; therefore, the temperature profile in the thermalboundary layer is governed by the heat-transfer process.

3. Properties of the fluid mixture do not change significantly during formation of precursors.

4. Heat-transfer coefficient is not affected by the fouling-film surface. In other words, the measured fouling resistance represents the conduction resistance of the fouling film.

5. Reaction leading to coke formation does not continue in the fouling film. As a result, the physical properties of the fouling film remain constant during the initial fouling period.

In this section, the formulation of equations for the local rate of deposition are described. The analysis can be used for determination of the local rate of fouling for a given set of bulk-fluid conditions and wall temperature (or heat flux). In Section 5, equations for the local rate of fouling will be incorporated into mass- and heat-balance equations for the heat exchanger and for the fluid reservoir, which is treated as a batch reactor.

\subsection{Precursor Generation in Bulk}

In Case 1a, reaction 1 occurs in fluid, but reaction 2 occurs at the interface. Precursor formed in reaction 1 diffuses to the wall interface, where reaction 2 occurs to form insoluble foulant. The reaction and diffusion steps happen in series; therefore, they can be individually expressed in terms of variables.

Step 1. Formation of precursor in fluid

$$
\mathrm{r}_{1}=\mathrm{k}_{1} \mathrm{C}_{\mathrm{a} 1 \mathrm{~b}}^{m} \mathrm{C}_{\mathrm{a} 2 \mathrm{~b}}^{n}
$$

where $\mathrm{k}_{1}=$ reaction constant $=\mathrm{a}_{1} \exp \left(-\mathrm{E}_{1} / \mathrm{RT}_{\mathrm{b}}\right)$. 
Step 2. Transfer of soluble precursor to wall surface

$$
\mathrm{N}_{\mathrm{p}}=\mathrm{K}_{\mathrm{mp}}\left(\mathrm{C}_{\mathrm{pb}}-\mathrm{C}_{\mathrm{bi}}\right) \text {. }
$$

Step 3. Reaction 2 at wall surface

$$
\mathrm{r}_{2}=\mathrm{k}_{2 \mathrm{i}} \mathrm{C}_{\mathrm{pi}}^{l}
$$

where $k_{2 i}=$ reaction constant for reaction 2 at interface $=a_{2} \exp \left(-E_{2} / R_{i}\right)$.

Terms associated with the removal and aging steps are not included in the analysis. The three sets of equations are solved simultaneously. Moreover, in cases of reactions occurring in bulk, the mass balance has to be integrated over the entire test loop for a cumulative effect of the precursor generation. A series of experiments will be conducted with no heat flux, and the rate of generation of precursor will be determined as a function of time. Since no back-diffusion of foulant is assumed, the mass flux of precursor is equal to the rate of foulant formation by reaction 2 .

In Case $1 \mathrm{~b}$, reactions 1 and 2 occur in bulk, and insoluble foulant is transported to the wall surface to form the fouling film.

Step 1. Formation of precursor is same as for case 1a (shown in Equation 4.1).

Step 2. Formation of foulant

$$
\mathrm{r}_{2}=\mathrm{k}_{2 \mathrm{~b}} \mathrm{C}_{\mathrm{pb}}^{l}
$$

where $k_{2 b}=$ reaction constant for reaction 2 at bulk conditions $=a_{2} \exp \left(-E_{2} / R_{b}\right)$.

The reaction rate equation is the same as shown in case la (Equation 4.3). However, to calculate the concentration of foulant at time $t$, both reaction rate equations must be integrated over the test loop. Moreover, the rate of deposition may or may not be a function of heat flux. Therefore, the foulant deposition can occur anywhere in the flow loop. It would be difficult to conduct experiments and analyze the data for this case. However, this case can be easily simulated for industrial application for once-through flow systems:

Step 3. Transfer of insoluble foulant

$$
\mathrm{N}_{\mathrm{f}}=\mathrm{K}_{\mathrm{mf}} \mathrm{C}_{\mathrm{fb}}
$$


The mass-transfer coefficient $\mathrm{K}_{\mathrm{mf}}$ is calculated by

$$
\mathrm{K}_{\mathrm{mf}}=\frac{\mathrm{V}_{\mathrm{z}}(\mathrm{f} / 8)^{1 / 2}}{11.8 \mathrm{Sc}^{2 / 3}}
$$

where the Schmidt number $(\mathrm{Sc})$ is calculated by using diffusivity of the particulate with diameter $d_{p}$. In the present analysis, Stokes's equation was used for calculating the particulate diffusivity (see Section 9.2).

Step 4. Attachment

$$
\mathrm{N}_{\mathrm{d}}=\mathrm{SN}_{\mathbf{f}} \text {. }
$$

Due to the gummy nature of the deposition, it was assumed that all of the foulant reaching the surface would attach. Consequently, a sticking probability of one was assumed.

\subsection{Precursor Generation in Boundary Layer}

There are two approaches to modeling the simultaneous mass transfer and chemical reaction in the boundary layer: (1) film theory and (2) turbulent flow. Film theory is assumed in the present approach for the development of the mathematical analysis. It provides a simple physical model by which the fouling mechanism can be understood. However, it should be noted that the effective film thickness for mass, momentum, and heat transfer differs, depending upon the Prandtl and Schmidt numbers. The basic approach is described below for the generalized case and two limiting cases.

\section{Generalized Case}

A detailed analysis is used to account for diffusion and temperature profile in the boundary layer. This treatment may be necessary for the system where the Prandtl and Schmidt numbers are comparable. A similar approach is commonly used for modeling gas absorption with chemical reaction. The expected temperature and concentration profiles are shown in Figure 4.1. The notable feature of this model is that the turbulent-flow transport phenomena are represented by individual boundary layers for the momentum, thermal, and mass diffusion processes. 


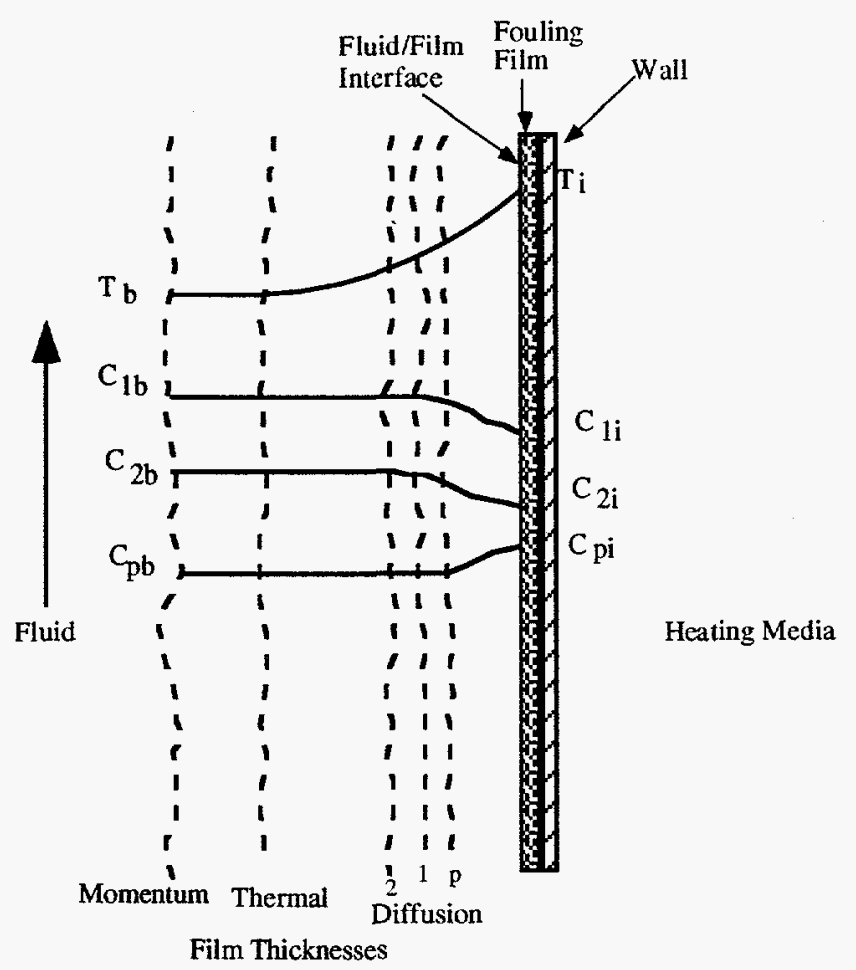

FIGURE 4.1 Concentration and Temperature Profiles for the Film Theory

\section{Limiting Cases}

a. For Schmidt number very much greater than Prandtl number, one can assume uniform temperature in the mass boundary layer. In this case, the temperature in the boundary layer is equal to the interface temperature. Figure 4.2 shows expected temperature and concentration profiles for this case.

b. The analysis can be further simplified by assuming uniform concentration in the diffusion boundary layer. The boundary layer can then be treated as a microreactor. The volume of the microreactor is directly proportional to the boundary layer thickness. Note that the analysis by Paterson and Fryer (1988) assumes this approach. The assumption in this approach can be justified when reaction 1 is a controlling step, giving uniform concentration profiles for both reactants. However, it is necessary to include back-diffusion of precursor. Figure 4.3 illustrates the physical model for this case.

The mathematical model for the case of a boundary-layer reaction zone is more difficult than the other two cases. Nevertheless, sufficient research information exists for the gas/fluid and fluid/fluid reaction systems for the development of the analysis. Therefore, a generalized model will be developed and limiting cases will be studied. An outline of the mathematical model analysis is shown here for the purpose of understanding the basic approach. 


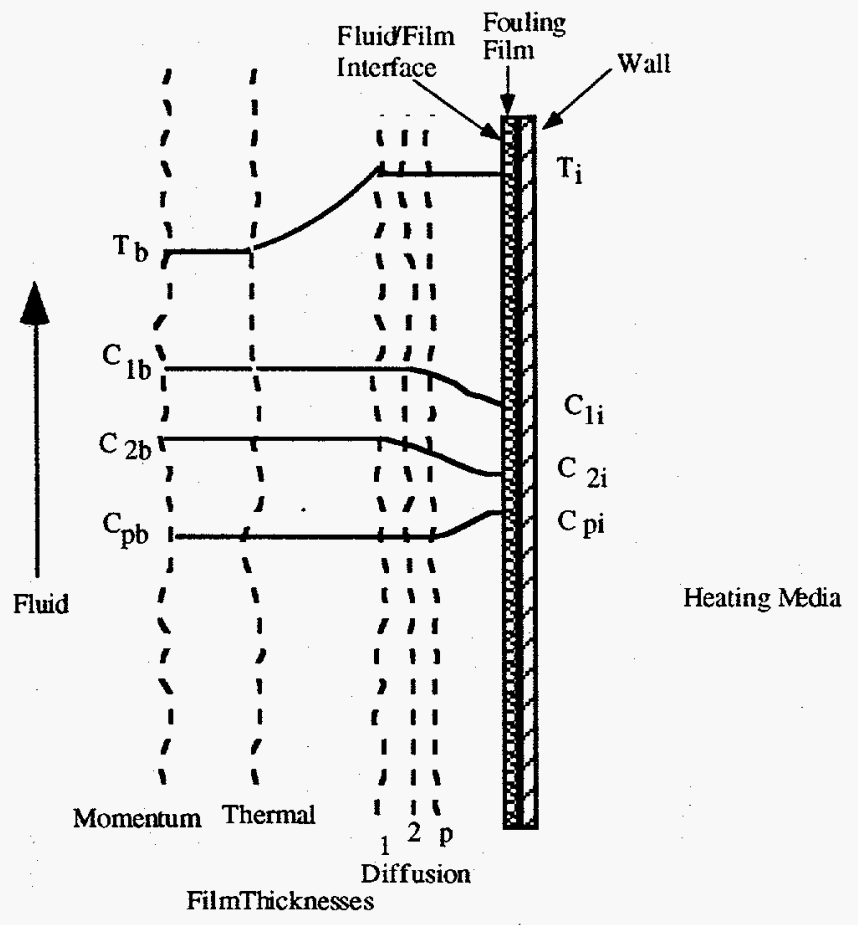

FIGURE 4.2 Concentration and Temperature Profiles for the Film Theory under LimitingCase Uniform Temperature in the DiffusionBoundary Layer

\section{Formulation for Generalized Case}

Formation of precursor in fluid for incremental boundary layer thickness (see Figure 4.4 for incremental section of boundary layer) can be expressed as

$$
\mathrm{dr}_{1}=\mathrm{s}_{\mathrm{a} 1} \mathrm{k}_{1}(\mathrm{~T}) \mathrm{C}_{\mathrm{a} 1}^{m} \mathrm{C}_{\mathrm{a} 2}^{n} \mathrm{dx}
$$

where

$$
\begin{aligned}
\mathrm{k}_{1}(\mathrm{~T}) & =\text { reaction constant at local temperature in boundary layer } \\
\mathrm{x} & =\text { distance in the boundary layer. }
\end{aligned}
$$

Applying the mass balance across the differential boundary layer and rearranging terms, the following equation is formulated:

\section{Reactant 1}

$$
\rho_{\mathrm{c}} D_{\mathrm{a} 1} \frac{\mathrm{d}^{2} \mathrm{C}_{\mathrm{a} 1}}{\mathrm{dx}^{2}}-\mathrm{s}_{\mathrm{a} 1} \mathrm{k}_{1}(\mathrm{~T}) \mathrm{C}_{\mathrm{a} 1}^{m} \mathrm{C}_{\mathrm{a} 2}^{n}=0
$$




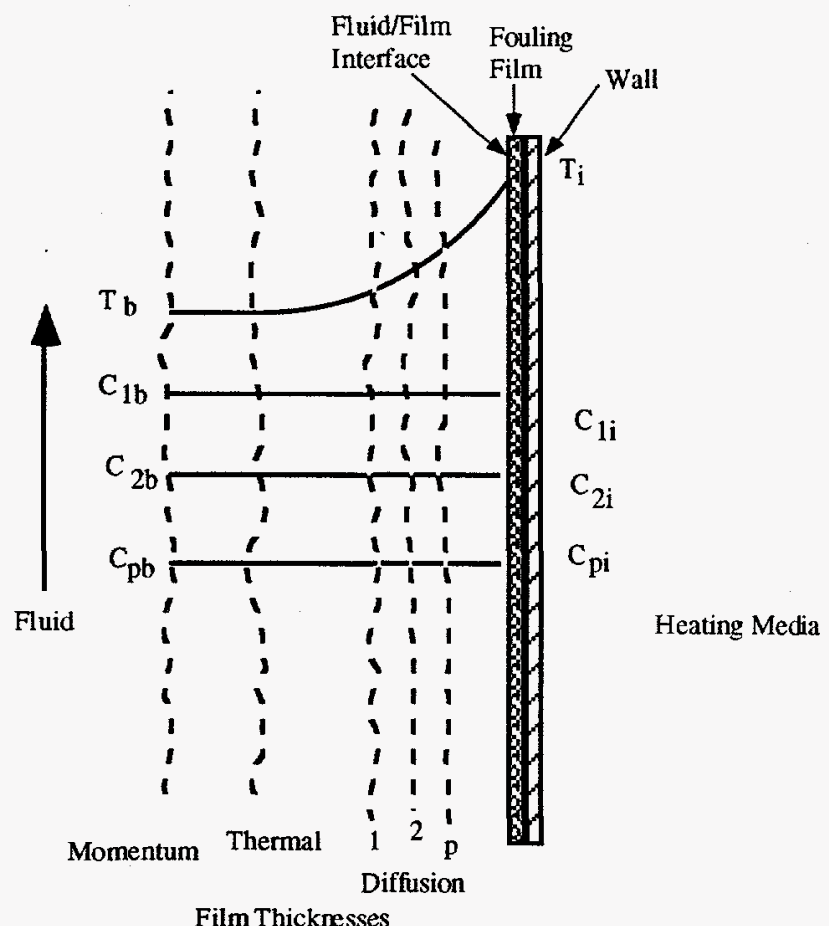

FIGURE 4.3 Concentration and Temperature Profiles for the Film Theory under LimitingCase Uniform Concentration in the ThermalBoundary Layer

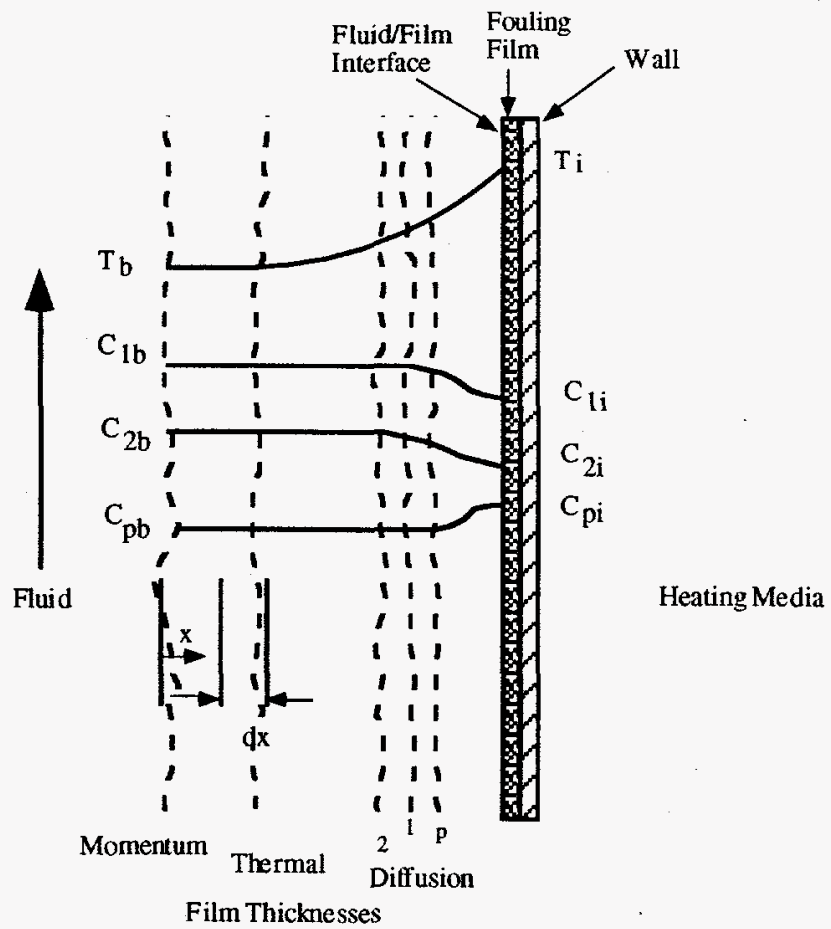

FIGURE 4.4 Concentration and Temperature Profiles for the Film Theory, Showing the Incremental Boundary Layer 
Similar equations can be developed for reactant 2 and precursor, as shown below:

Reactant 2

$$
\rho_{\mathrm{c}} D_{\mathrm{a} 2} \frac{\mathrm{d}^{2} \mathrm{C}_{\mathrm{a} 2}}{\mathrm{dx}^{2}}-\mathrm{s}_{\mathrm{a} 2} \mathrm{k}_{1}(\mathrm{~T}) \mathrm{C}_{\mathrm{a} 1}^{m} \mathrm{C}_{\mathrm{a} 2}^{n}=0
$$

Precursor

$$
\rho_{\mathrm{c}} D_{\mathrm{p}} \frac{\mathrm{d}^{2} \mathrm{C}_{\mathrm{p}}}{\mathrm{dx}^{2}}+\mathrm{s}_{\mathrm{p}} \mathrm{k}_{1}(\mathrm{~T}) \mathrm{C}_{\mathrm{a} 1}^{m} \mathrm{C}_{\mathrm{a} 2}^{n}-\mathrm{s}_{\mathrm{f}} \mathrm{k}_{2}(\mathrm{~T}) \mathrm{C}_{\mathrm{p}}^{l}=0
$$

This set of equations is simultaneously solved along with the heat-transfer equation. However, for simplicity, one could assume a linear temperature profile in the thermal-boundary layer. Appropriate concentration boundary conditions can be applied at the two edges of the boundary layer as shown in Equations 4.12 and 4.13. The boundary layer thicknesses should be different for each component.

At the bulk/boundary-layer interface,

$$
\mathrm{C}_{\mathrm{a} 1}, \mathrm{C}_{\mathrm{a} 2}, \mathrm{C}_{\mathrm{p}}=\text { bulk values. }
$$

At fluid/fouling-film interface,

$$
\frac{\mathrm{dC}_{\mathrm{al}}}{\mathrm{dx}}=\frac{\mathrm{dC}_{\mathrm{a} 2}}{\mathrm{dx}}=\frac{\mathrm{dC}_{\mathrm{p}}}{\mathrm{dx}}=0
$$

The boundary layer thicknesses should be different for each component.

\section{Formulation for Limiting Cases}

The two limiting cases can be analyzed by simplifying Equations 4.9-4.11. For example, a constant temperature can be assumed for case a, and the mass-diffusion equation can be solved with given bulk concentrations of reactants 1 and 2. On the other hand, an effective reaction constant can be calculated by assuming uniform concentration for limiting case b. A simplified analytical solution can be determined to represent the varying value for the reaction constant, as was done by Paterson and Fryer (1988). A numerical analysis should not be difficult to develop for a computerized analysis. 
It should be noted that the foulant-formation step is not included in the set of Equations 4.9 through 4.13. As indicated earlier, there are two possible cases for the formation of insoluble foulant, (1) in the boundary layer or (2) at the fluid/solid interface. In the first case, the foulantforming reaction step should be solved simultaneously with the rate-governing equations (Equations 4.9-4.11). The surface would then be coated with foulant following the particulatefouling mechanism. Some foulant could be transported into the fluid, which could coat the downstream surface. However, considering the foulant to be formed in the boundary layer in the vicinity of the surface, one could assume that the rate of deposition is equal to the rate of formation with minimum back-diffusion of insoluble foulant into the bulk of the fluid.

If the foulant is formed at the surface, then the reaction constant for reaction 2 is calculated by substituting the bulk temperature for the interface temperature. The precursor concentration at the interface is calculated by solving the diffusion equation, Equation 4.11. The boundary condition for the precursor at the fluid/solid interface can be expressed as

$$
-D_{\mathrm{p}} \frac{\mathrm{dC}_{\mathrm{p}}}{\mathrm{dx}}=\mathrm{k}_{2}\left(\mathrm{~T}_{\mathrm{i}}\right) \mathrm{C}_{\mathrm{pi}}^{l}
$$

where $k_{2}\left(T_{i}\right)=$ reaction constant for reaction 2 calculated at interface temperature $T_{i}$.

\subsection{Precursor Generation at Wall}

The case of precursor generation at the wall is the simplest of the three cases for the development of the mathematical model. Diffusion of reactant 1 can be expressed as follows:

$$
\mathrm{N}_{\mathrm{aj}}=\mathrm{K}_{\mathrm{maj}}\left(\mathrm{C}_{\mathrm{ajb}}-\mathrm{C}_{\mathrm{aji}}\right) \quad \mathrm{j}=1,2 .
$$

Reactions 1 and 2 occur at the interfacial temperature and concentration, as shown below:

$$
\mathrm{r}_{\mathrm{j}}=\mathrm{s}_{\mathrm{j}} \mathrm{k}_{\mathrm{j}}(\mathrm{T}) \mathrm{C}_{\mathrm{a} 1}^{m} \mathrm{C}_{\mathrm{a} 2}^{n} \quad \mathrm{j}=1,2
$$

Equations 4.15 and 4.16 are solved by using an iterative technique to determine the interfacial conditions. Once the interfacial conditions for the reactants are known, the precursor concentration at the interface can be determined. It is, however, necessary to account for backdiffusion of precursor, as shown below:

$$
\begin{array}{ll}
\text { Rate of formation of precursor: } & \mathrm{r}_{\mathrm{p}}=\mathrm{s}_{\mathrm{p}} \mathrm{k}_{1}\left(\mathrm{~T}_{\mathrm{i}}\right) \mathrm{C}_{\mathrm{a} 1}^{m} \mathrm{C}_{\mathrm{a} 2}^{n} \\
\text { Rate of back-diffusion of precursor: } & \mathrm{N}_{\mathrm{p}}=\mathrm{K}_{\mathrm{mp}}\left(\mathrm{C}_{\mathrm{pi}}-\mathrm{C}_{\mathrm{pb}}\right)
\end{array}
$$


Rate of foulant formation: $\quad \mathrm{r}_{\mathrm{f}}=\mathrm{s}_{\mathrm{f}} \mathrm{k}_{2}\left(\mathrm{~T}_{\mathrm{i}}\right) \mathrm{C}_{\mathrm{pi}}^{l}$

At steady state, the three rate equations are related by

$$
r_{p}=N_{p}+\frac{r_{f}}{s_{f}}
$$

When the individual terms have been substituted, Equation 4.20 is also nonlinear, and an iterative method is required to determine the interfacial condition. Once the interfacial concentration for precursor is obtained, the rate of formation of foulant is calculated by Equation 4.19. 


\section{System Simulation}

The rate equations formulated in Section 4 are incorporated into the heat- and mass-balance equations to calculate the rate of deposition and, hence, the fouling resistance. The fouling process is time-dependent, and calculation of the fouling resistance requires assumption of quasi-steadystate conditions to avoid an elaborate numerical solution of multivariable partial differential equations. In the present analysis, quasi-steady-state conditions were assumed in which the set of rate equations was solved for a given time to determine the rate of foulant deposition. The accumulated deposited mass was then calculated by multiplying the rate of deposition by the given time increment. Therefore, the local foulant-mass accumulation at time $t$ is given by the following equation:

$$
m_{f}(t)=m_{f}(t-\Delta t)+N_{f} \Delta t
$$

where

$$
\begin{aligned}
\mathrm{m}_{\mathrm{f}}(\mathrm{t}) & =\text { mass of foulant accumulated per unit area at time } \mathrm{t} \text {, and } \\
\mathrm{m}_{\mathrm{f}}(\mathrm{t}-\Delta \mathrm{t}) & =\text { mass of foulant accumulated per unit area at time }(\mathrm{t}-\Delta \mathrm{t}) .
\end{aligned}
$$

The fouling resistance $R_{\mathrm{f}}$ is given by

$$
R_{f}=m_{f}(t) / \rho_{f} k_{f} .
$$

The quasi-steady-state assumption allows $\mathrm{N}_{\mathrm{f}}$ to be constant during the time increment $\Delta t$. A detailed numerical analysis could be used for solving the multivariable partial differential equations; however, such a method could become quite complex without gaining significant accuracy, especially for prototype heat-exchanger flow channels. The present analysis is intended to analyze the initial stage of fouling, where the time-dependent variation in the bulk concentration of reactants and precursors and the physical properties of the fouling film are expected to vary slowly. Therefore, the quasi-steady-state assumption does not impose any significant limitation on the present analysis for determination of the initial rate of fouling.

\subsection{Once-Through Flow}

The once-through flow analysis discussed in this section represents the fluid stream inside a heat-exchanger channel. Although the inlet conditions may stay constant for a given heat exchanger, the local bulk conditions (concentration and fluid temperature) change from inlet to outlet. As a result, the local rate of fouling deposition will vary along the flow-channel length. Depending upon heating conditions, the local wall temperature will change with time, as the 
fouling deposition grows at a given axial point of the flow channel. For example, consider a condensing heat-transfer media on the shell side of a shell-and-tube heat exchanger for heating organic fluid flowing inside the tubes. The temperature increases from inlet to outlet as the fluid is being heated by the condensing medium. In addition, the precursor formation in the bulk or in the thermal-boundary layer will affect the local rate of fouling deposition downstream. At time $t=0$, when the tube surface is free of fouling deposition, the local rate of fouling deposition will be affected by the change in precursor concentration from inlet to outlet. This concentration gradient can cause nonuniform deposition, which in turn affects the local wall temperature. This interactive process of local fouling deposition and local conditions must be properly modeled to represent the prototype operating conditions.

The modeling approach is to apply the microscopic heat and mass balances for turbulent flow in a single flow channel under various simplifying assumptions. The structure of the models follows that of Himmelblau and Bischoff (1968), who classified a hierarchy of models on the basis of assumptions of the flow field and the transport behavior. The two levels most suitable to the present work are the multiple gradient model and the maximum gradient model. In the former model, radial and axial concentrations are calculated. A velocity distribution is used, and molecular and turbulent contributions to transport parameters along with the axial dispersion effects are included. In the latter model, which was selected for the present work, cross-sectional averages of concentration and temperature are used, and axial dispersion terms are neglected. This approach, adopted as the basic formulation of the fouling process in the flowing stream, was considered sufficiently complex without involving the dispersion effects.

All model calculations include the appropriate conservation equations for the key species and the energy equation, which result in a series of differential equations that are coupled; these equations must be solved together. If one considers a horizontal tube through which fluid with concentration $\mathrm{C}_{\mathrm{i}}$ flows in the $z$ direction, the maximum gradient model yields Equation 5.3 for the conservation of specie $\mathrm{i}$ within a control volume:

$$
\begin{aligned}
& \frac{\partial \mathrm{C}_{\mathrm{i}}}{\partial \mathrm{t}}+\frac{\partial\left(\mathrm{V}_{\mathrm{z}} \mathrm{C}_{\mathrm{i}}\right)}{\partial \mathrm{z}}=\mathrm{r}_{\mathrm{i}}+\mathrm{m}_{\mathrm{i}} \\
& \text { Accumulation Bulk Generation Transport } \\
& \text { transport by reaction through } \\
& \text { boundary }
\end{aligned}
$$

where

$$
\begin{aligned}
r_{i} & =\text { moles of specie } i \text { generated per unit volume per unit time, and } \\
m_{i} & =\text { moles of specie } i \text { transported out of the control volume. }
\end{aligned}
$$


The energy equation is given by Equation 5.4:

$$
\begin{aligned}
& \rho C_{p}\left[\frac{\partial T}{\partial t}+\frac{\partial\left(V_{z} T\right)}{\partial z}\right]=S_{r}+E^{t} \\
& \begin{array}{llll}
\text { Accumulation } & \begin{array}{l}
\text { Bulk } \\
\text { transport }
\end{array} & \begin{array}{l}
\text { Generation } \\
\text { by reaction }
\end{array} & \begin{array}{l}
\text { Transport } \\
\text { through } \\
\text { boundary }
\end{array}
\end{array}
\end{aligned}
$$

The heat generation term due to the reaction is of the form

$$
S_{r}=\sum_{j}\left(-\Delta H_{r j} r_{j}\right)
$$

where $\Delta \mathrm{H}_{\mathrm{rj}}$ is the heat of reaction for reaction $\mathrm{j}$, and the heat transport term is expressed as

$$
E^{t}=h_{f}\left(T_{w}-T_{f}\right) .
$$

Depending upon the heating condition, the wall temperature may or may not be known a priori, and it must be calculated using an appropriate heat-flux condition. Equations 5.3-5.6 are applicable to all reactant species and precursor(s). However, formation of insoluble foulant must be treated separately, as will be discussed later in this section when the equations are formulated for each of the three fouling cases. In addition, the heat- and mass-balance equations are simplified by assuming a quasi-steady-state, as discussed earlier in this section. Under this assumption, initial conditions are known (e.g., clean surface), and integration is started at time $t=0$, when the heat-transfer surface has no deposition. At time interval $\Delta \mathrm{t}$, Equations 5.3-5.4 are integrated along the length of the flow channel ( $\mathrm{z}$ direction). The resulting rate of fouling deposition is assumed to be constant for the time interval of $\Delta t$. The incremental deposition is then calculated by multiplying the rate of deposition by $\Delta t$. In the next cycle of calculation along the flow direction $\mathrm{z}$, the local interfacial temperature is calculated by using the local value for the fouling resistance. This method is applied to all three fouling cases. Note that the heat of reaction is assumed to be negligible and the heat balance equation shown below is common for all three cases:

$$
m V_{z} \frac{d T_{b}}{d z}=h_{f} P\left(T_{i}-T_{b}\right)
$$

where the interfacial temperature $T_{i}$ at a given value of $z$ is calculated using the known local heat flux and the fouling resistance in addition to other heat-transfer coefficients. It is assumed that the fluid-side heat-transfer coefficient is not affected by the presence of fouling film. 
The set of equations developed in this section is applicable to a flow channel with perimeter $P$ and flow area $\overline{\mathbf{a}}$. The initial values at $\mathrm{z}=0$ are set by the inlet conditions below:

$$
\begin{aligned}
C_{a 1 b} & =C_{a 10} \\
C_{a 2 b} & =C_{a 20} \\
C_{p b} & =0 \\
T_{b} & =T_{b 0} .
\end{aligned}
$$

Case 1a. Precursor Generation in Bulk; Foulant Formation at Wall

The equations for Case 1a, with constant composition feed flowing through a flow channel, are shown below (see Figure 5.1a for the control volume for which the mass and heat balance is formulated):

Reactant al

$$
\mathrm{V}_{\mathrm{z}} \frac{\mathrm{d} \mathrm{C}_{\mathrm{a} 1 \mathrm{~b}}}{\mathrm{dz}}=-\mathrm{s}_{\mathrm{a} 1} \mathrm{k}_{1}\left(\mathrm{~T}_{\mathrm{b}}\right) \mathrm{C}_{\mathrm{a} 1 \mathrm{~b}}^{m} \mathrm{C}_{\mathrm{a} 2 \mathrm{~b}}^{n}
$$

Reactant a2

$$
\mathrm{V}_{\mathrm{z}} \frac{\mathrm{dC}_{\mathrm{a} 2 \mathrm{~b}}}{\mathrm{dz}}=-\mathrm{s}_{\mathrm{a} 2} \mathrm{k}_{1}\left(\mathrm{~T}_{\mathrm{b}}\right) \mathrm{C}_{\mathrm{a} 1 \mathrm{~b}}^{m} \mathrm{C}_{\mathrm{a} 2 \mathrm{~b}}^{n}
$$

Precursor

$$
\mathrm{V}_{\mathrm{z}} \frac{\mathrm{dC_{pb }}}{\mathrm{dz}}=\mathrm{s}_{\mathrm{p}} \mathrm{k}_{1}\left(\mathrm{~T}_{\mathrm{b}}\right) \mathrm{C}_{\mathrm{a} 1 \mathrm{~b}}^{m} \mathrm{C}_{\mathrm{a} 2 \mathrm{~b}}^{n}-\mathrm{K}_{\mathrm{mp}}\left(\mathrm{C}_{\mathrm{pb}}-\mathrm{C}_{\mathrm{pi}}\right)
$$

Foulant formation at the wall surface by reaction 2

$$
\mathrm{r}_{2}=\mathrm{k}_{2}\left(\mathrm{~T}_{\mathrm{i}}\right) \mathrm{C}_{\mathrm{pi}}^{l}
$$

Boundary condition at the wall surface

$$
K_{m p}\left(C_{p b}-C_{p i}\right)=k_{2}\left(T_{i}\right) C_{p i}^{l}
$$




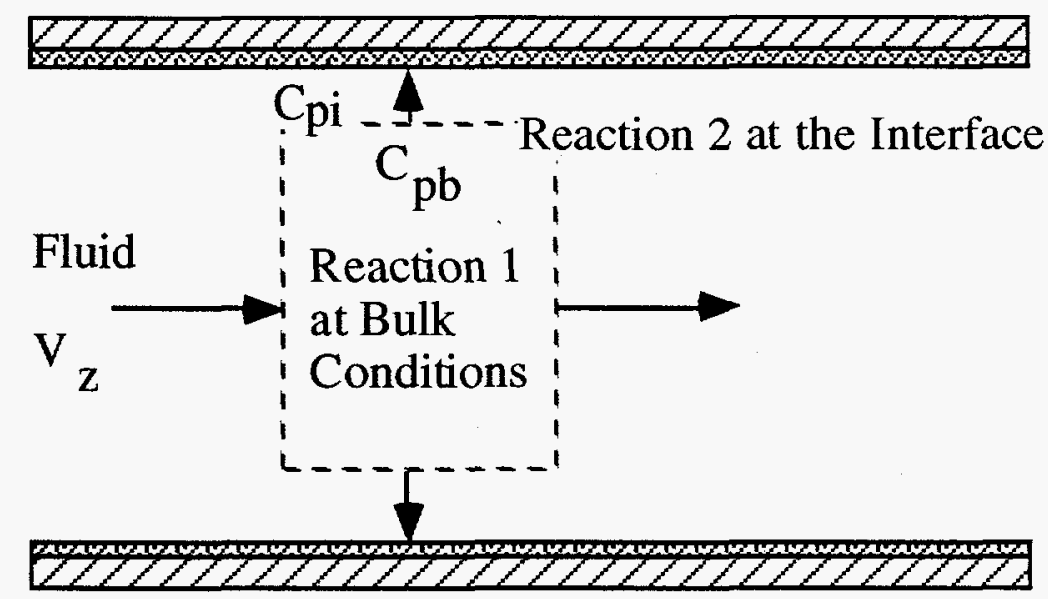

a. Case 1a

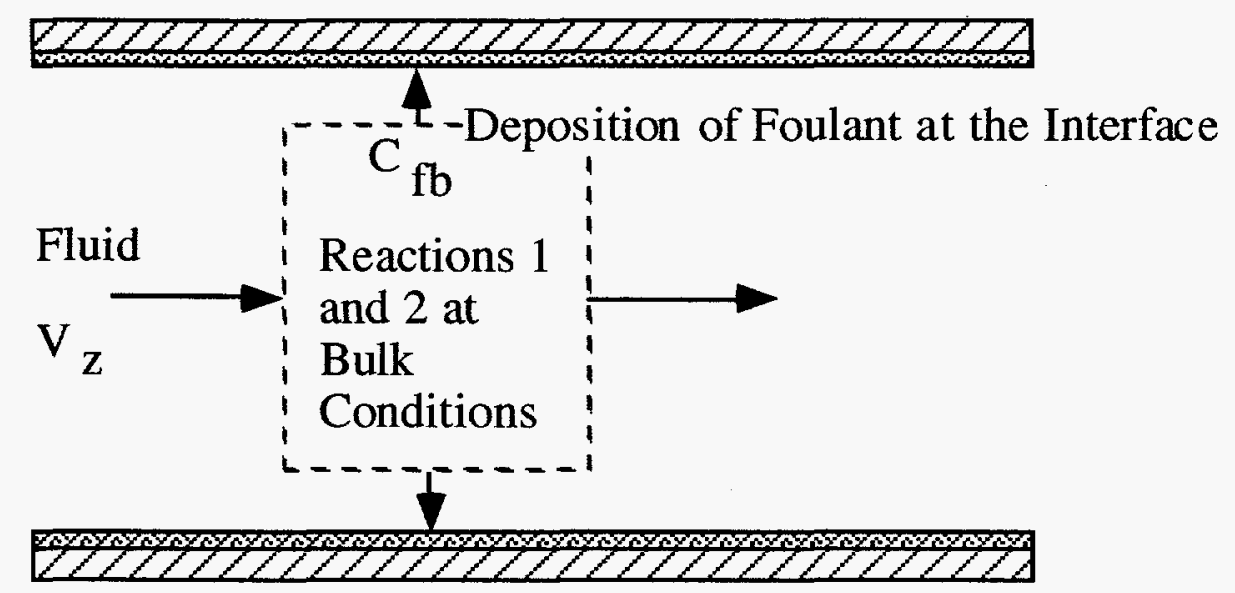

b. Case 1b

FIGURE 5.1 Control Volume for the Case 1 Fouling Models

Case 1b. Precursor Generation in Bulk; Foulant Formation in Bulk

Equations for reactants 1 and 2 for Case $1 \mathrm{~b}$ are the same as those for Case 1a (Equations 5.8 and 5.9), while that for the precursor is shown below (see Figure 5.1b for the control volume for which the mass and heat balance is formulated):

Precursor

$$
\mathrm{V}_{\mathrm{z}} \frac{\mathrm{dC_{ \textrm {pb } }}}{\mathrm{dz}}=\mathrm{s}_{\mathrm{a} 2} \mathrm{k}_{1}\left(\mathrm{~T}_{\mathrm{b}}\right) \mathrm{C}_{\mathrm{a} 1 \mathrm{~b}}^{m} \mathrm{C}_{\mathrm{a} 2 \mathrm{~b}}^{n}-\mathrm{k}_{2}\left(\mathrm{~T}_{\mathrm{i}}\right) \mathrm{C}_{\mathrm{pb}}^{l}
$$


Foulant

$$
\mathrm{V}_{\mathrm{z}} \frac{\mathrm{dC}_{\mathrm{fb}}}{\mathrm{dz}}=\mathrm{s}_{\mathrm{f}} \mathrm{k}_{2}\left(\mathrm{~T}_{\mathrm{b}}\right) \mathrm{C}_{\mathrm{pb}}^{l}-\mathrm{K}_{\mathrm{mf}} \mathrm{C}_{\mathrm{fb}} .
$$

Case 2. Precursor Generation in Boundary Layer; Foulant Formation in Boundary Layer

Since the reaction zone is in the boundary layer, the rate of transport from and to bulk from the boundary layer has to be included in the mass balance equation for each reacting component (see Figure 5.2 for the control volume for which the mass and heat balance equations are formulated):

Reactant a1

$$
\mathrm{V}_{\mathrm{z}} \frac{\mathrm{d} \mathrm{C}_{\mathrm{a} 1 \mathrm{~b}}}{\mathrm{dz}}=-(\mathrm{P} / \overline{\mathrm{a}}) \mathrm{N}_{1}
$$

Reactant a2

$$
\mathrm{V}_{\mathrm{z}} \frac{\mathrm{dC}_{\mathrm{a} 2 \mathrm{~b}}}{\mathrm{dz}}=-(\mathrm{P} / \overline{\mathrm{a}}) \mathrm{N}_{2}
$$

Precursor

$$
\mathrm{V}_{\mathrm{z}} \frac{\mathrm{dC} \mathrm{pb}}{\mathrm{dz}}=-(\mathrm{P} / \overline{\mathrm{a}}) \mathrm{N}_{\mathrm{p}}
$$

where mass fluxes $\left(\mathrm{N}_{1}, \mathrm{~N}_{2}, \mathrm{~N}_{\mathrm{p}}\right)$ at a given value for $\mathrm{z}$ are determined by solving the set of equations for the boundary as described in Section 4.2.

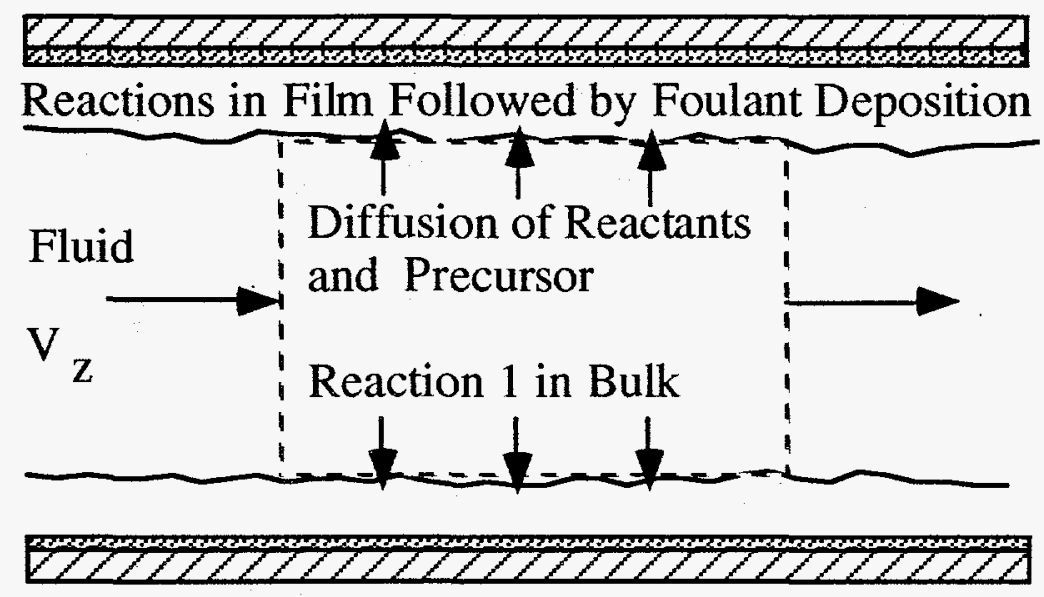

FIGURE 5.2 Control Volume for the Case 2 Fouling Model 
Case 3. Precursor Generation at Wall Surface

The reaction zone for both reactions is at the wall surface; therefore, the mass balance equations are combined with the diffusion rate for a given incremental distance (see Figure 5.3 for the control volume for which the mass and heat balance equations are formulated):

Reactant A1

$$
\mathrm{V}_{\mathrm{z}} \frac{\mathrm{dC}_{\mathrm{alb}}}{\mathrm{dz}}=-(\mathrm{P} / \overline{\mathrm{a}})\left(\mathrm{K}_{\mathrm{m} 1}\right)\left(\mathrm{C}_{\mathrm{alb}}-\mathrm{C}_{\mathrm{ali}}\right)
$$

Reactant A2

$$
\mathrm{V}_{\mathrm{z}} \frac{\mathrm{dC}_{\mathrm{a} 2 \mathrm{~b}}}{\mathrm{dz}}=-(\mathrm{P} / \overline{\mathrm{a}})\left(\mathrm{K}_{\mathrm{m} 2}\right)\left(\mathrm{C}_{\mathrm{a} 2 \mathrm{~b}}-\mathrm{C}_{\mathrm{a} 2 \mathrm{i}}\right)
$$

Precursor

$$
\mathrm{V}_{\mathrm{z}} \frac{\mathrm{dC}_{\mathrm{pb}}}{\mathrm{dz}}=(\mathrm{P} / \overline{\mathrm{a}})\left(\mathrm{K}_{\mathrm{mp}}\right)\left(\mathrm{C}_{\mathrm{pb}}-\mathrm{C}_{\mathrm{pi}}\right)
$$

The rate of formation of precursor and foulant are calculated by using the reaction rate given in Equation 4.16. Note that the interfacial concentration for each component has to be determined by equating the rate of mass transfer with the rate of reaction.

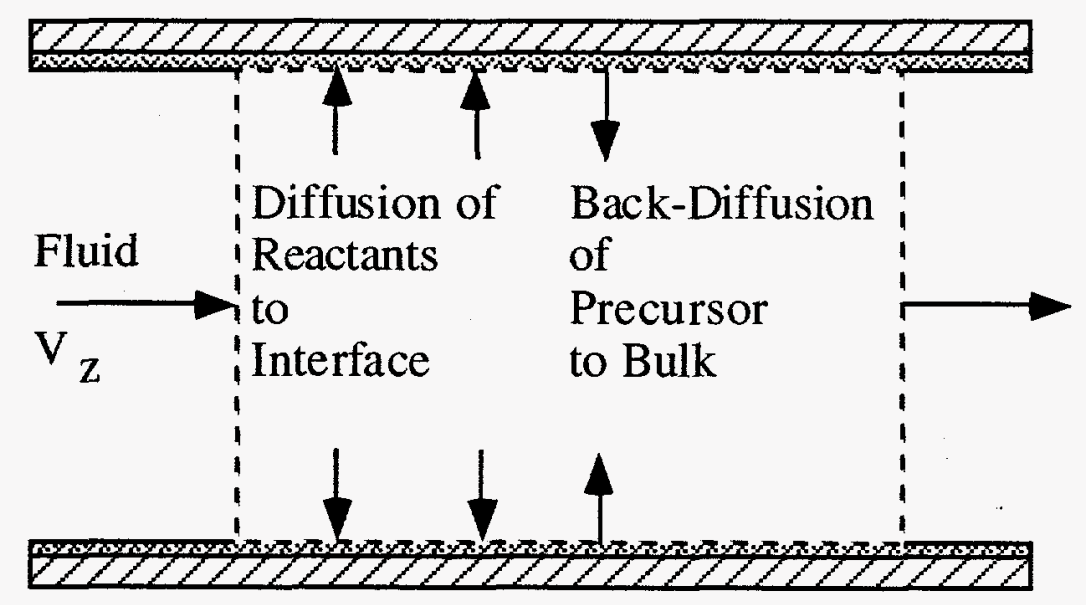

FIGURE 5.3 Control Volume for the Case 3 Fouling Model 


\subsection{Closed-Flow Loop}

The mass- and heat-balance equations formulated in Section 5.1 apply to a flow channel with constant inlet conditions; however, experiments are generally conducted with an apparatus having a closed-flow-loop configuration with a fixed batch of fluid. Therefore, the bulk conditions at any point in the system are both space- and time-dependent. It is important to take into account the time-dependent variation of the fluid composition when validating the fouling model using the laboratory data obtained with a closed-flow-loop apparatus. Detailed descriptions of the two fouling apparatuses being used for the present program are given in Section 7; however, simplified flow diagrams for the ANL and the UBC fouling apparatuses are shown in Figures 5.4 and 5.5. The ANL fouling apparatus has the following major components:

- Cooler (serves as a reservoir),

- Circulation pump,

- Heating coil,

- Heat-transfer monitors at three locations, and

- Tubes.

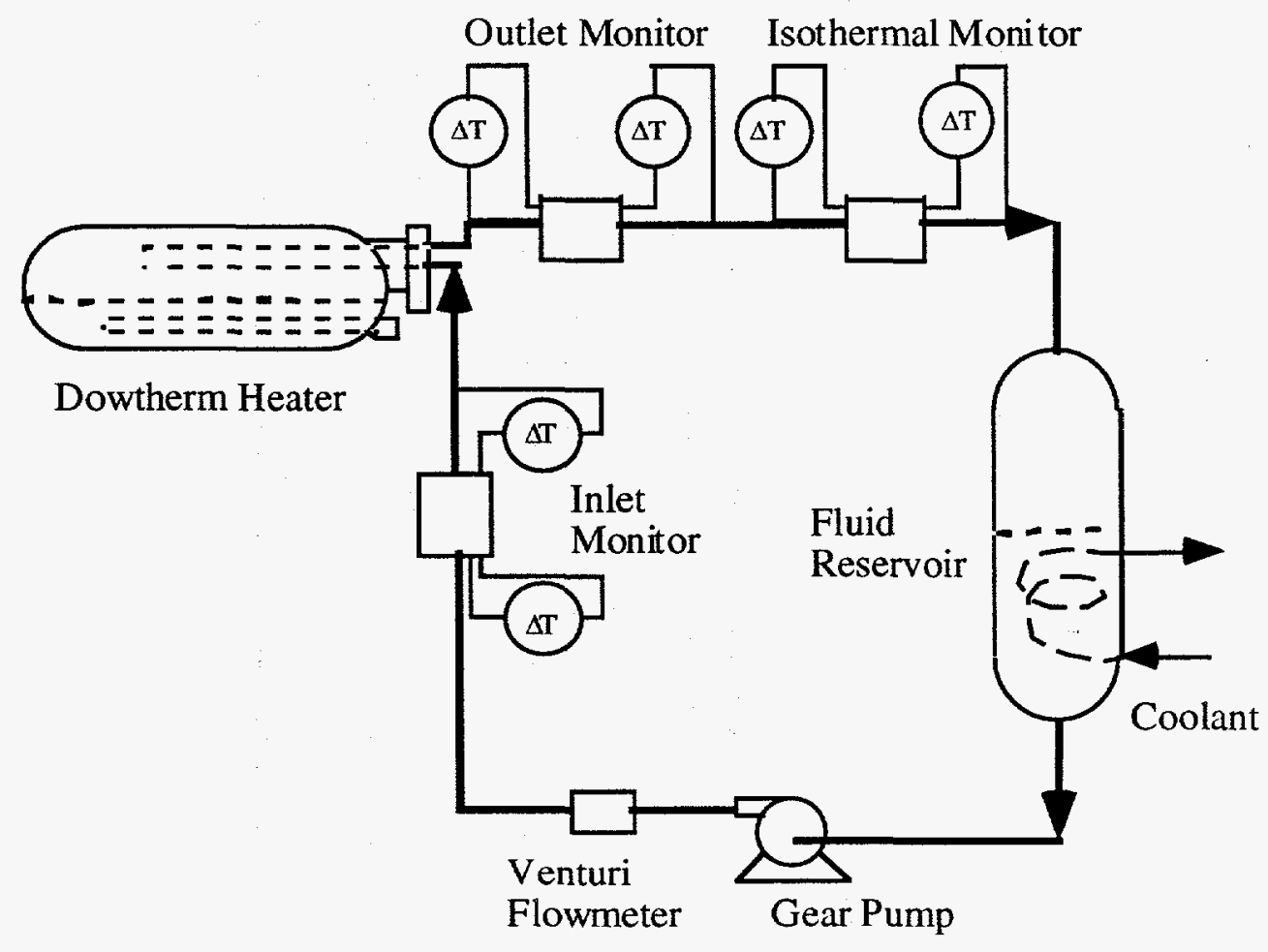

FIGURE 5.4 Flow Schematic Diagram for the ANL Fouling Apparatus 


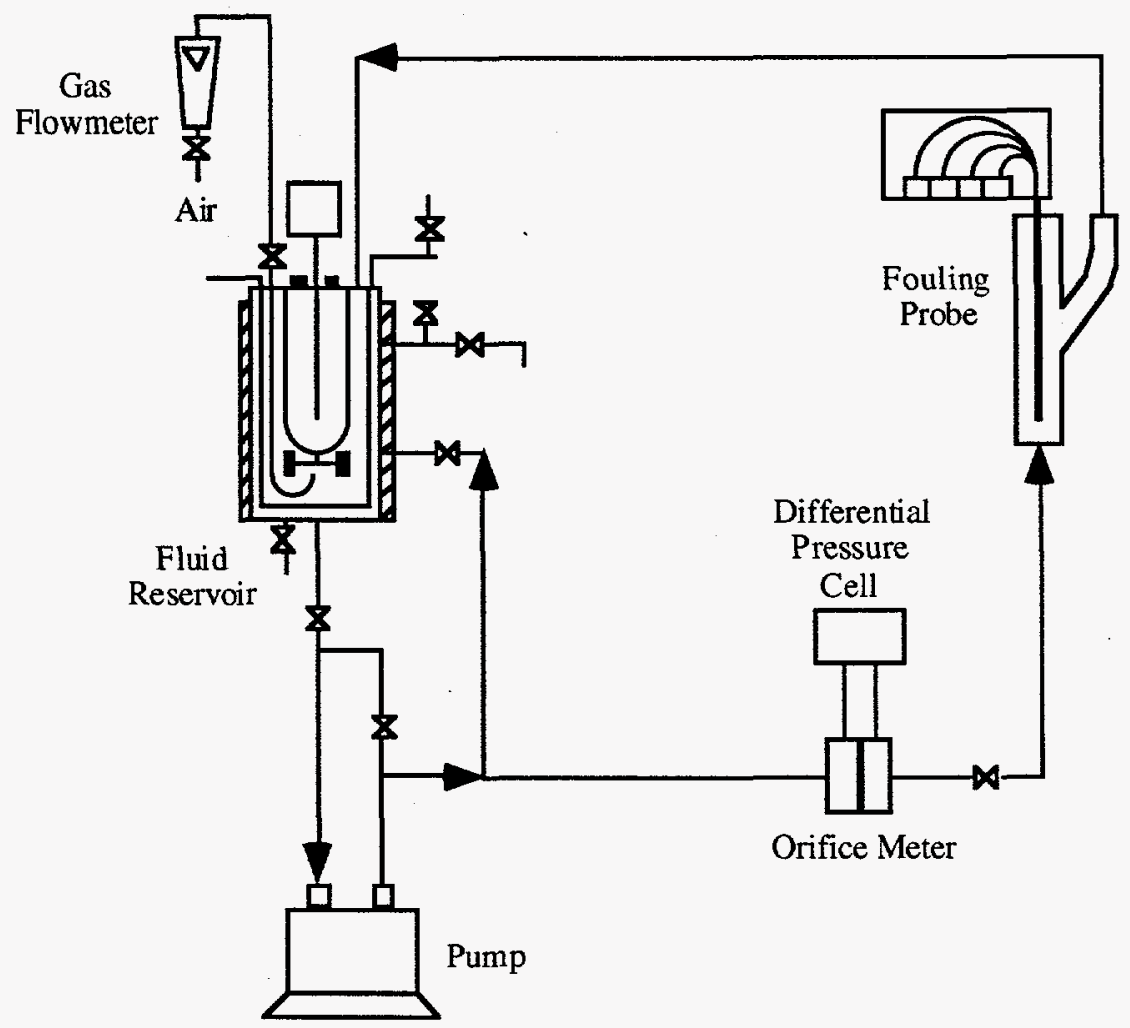

FIGURE 5.5 Flow Schematic Diagram for the UBC Fouling Apparatus

The UBC fouling apparatus has the following major components:

- Cooler (serves as a reservoir),

- Circulation pump,

- Single HTM, and

- Tubes.

The two principal differences between the ANL and the UBC apparatuses in terms of flow simulation are that (1) the ANL apparatus has a heating coil to measure the fouling rate under simulated conditions of heat exchangers and (2) the ANL HTM has in-tube flow while the UBC HTM has annular flow.

If reaction 1 (generation of precursor) takes place either in bulk or in the boundary layer, the precursor concentration will increase with time. In general, it should increase until concentrations of primary reactants drop to such values that the rate of precursor consumption by reaction 2 is greater than the rate of generation of precursor by reaction 1 . The simulation program developed for the fouling model includes rate equations for the reactions occurring at or in each of 
the major components mentioned above. The appropriate rate equation is formulated for each component, and the simulation program follows each component in sequence, as shown below:

1. Cooler, where reaction 1 is allowed to occur,

2. Isothermal tube flow at the temperature of the cooler, allowing reaction 1 to occur,

3. HTM\#1, installed at inlet to heating coil,

4. Heating coil that simulates heat-exchanger tube,

5. HTM\#2, installed at outlet of heating coil,

6. HTM\#3, for determination of isothermal fouling rate, and

7. Isothermal tube flow at heating-coil-outlet temperature.

As mentioned earlier, a quasi-steady-state approach is assumed in the simulation program. In this approach, the rate of precursor generation is calculated starting from the cooler reservoir, and the outlet conditions for a given component are taken as the inlet conditions for the next component. In addition to calculation of the precursor generation, the rates of fouling deposition are calculated for the HTMs and at the heating coil. The cooler reservoir holds most of the fluid; therefore, the total rate of precursor generation occurs in the reservoir. The rate of precursor generation in the cooler reservoir is calculated by integrating the rate equation over the time increment, $\Delta \mathrm{t}$. The simulation continues with the next cycle at time t plus $\Delta \mathrm{t}$, using the new value of the bulk concentration of reactants and precursor concentration.

In the following section, the rate equations for components not discussed earlier are formulated. The formulation is, in general, based on the standard approach used for simulating the overall reaction in such components.

\section{Cooler/Reservoir}

The cooler/reservoir can be treated as a batch reactor in the apparatus; the corresponding equations are given below.

Reactant al

$$
\frac{\mathrm{dC}_{\mathrm{alb}}}{\mathrm{dz}}=\mathrm{G} / \mathrm{Vo}_{\mathrm{o}}\left(\mathrm{C}_{\mathrm{a} 1 \mathrm{i}}-\mathrm{C}_{\mathrm{a} 1 \mathrm{~b}}\right)-\mathrm{s}_{\mathrm{a} 1} \mathrm{k}_{1}\left(\mathrm{~T}_{\mathrm{b}}\right) \mathrm{C}_{\mathrm{alb}}^{m} \mathrm{C}_{\mathrm{a} 2 \mathrm{~b}}^{n}
$$


Reactant a2

$$
\frac{d C_{a 2 b}}{d z}=G / V o\left(C_{a 2 i}-C_{a 2 b}\right)-s_{a 2} k_{1}\left(T_{b}\right) C_{a 1 b}^{m} C_{a 2 b}^{n}
$$

Precursor

$$
\frac{\mathrm{dC}_{\mathrm{pb}}}{\mathrm{dz}}=\mathrm{G} / \mathrm{Vo}_{\mathrm{o}}\left(\mathrm{C}_{\mathrm{pi}}-\mathrm{C}_{\mathrm{pb}}\right)-\mathrm{s}_{\mathrm{a} 2} \mathrm{k}_{1}\left(\mathrm{~T}_{\mathrm{b}}\right) \mathrm{C}_{\mathrm{a} 1 \mathrm{~b}}^{m} \mathrm{C}_{\mathrm{a} 2 \mathrm{~b}}^{n}-\mathrm{s}_{\mathrm{p}} \mathrm{k}_{2}\left(\mathrm{~T}_{\mathrm{i}}\right) \mathrm{C}_{\mathrm{pb}}^{l}
$$

The first terms on the right-hand sides of Equations 5.21-5.23 can be neglected if it is assumed that the liquid holdup in the system is relatively small compared with that for the cooler/reservoir. Equations 5.21-5.23 then represent the batch reaction. In some cases, the concentration of rate-controlling reactant can be maintained at a constant value, e.g., the amount of dissolved oxygen can be kept constant by continuously purging with air. In that case, the left-hand side of Equation 5.22 for the second component is equated to zero. In addition, the foulant formation reaction can be ignored for most cases, except when experiments are conducted at high cooler/reservoir temperatures.

\section{Heat-Exchanger Tube}

Formulation of equations for local foulant deposition in heat-exchanger tubes is identical to that for the once-through flow channel described in Section 5.1. The only difference is that the inlet concentration of reactants changes with time for the closed-loop experimental apparatus. In the ANL fouling apparatus, the tube is heated by condensing Dowtherm vapor. The wall temperature, and hence the fouling-film/fluid interface temperature, is calculated as follows:

- Assume outer wall temperature,

- Calculate the condensate film coefficient (saturation temperature is known),

- Calculate fluid heat-transfer coefficient by using a correlation,

- Calculate the overall heat-transfer coefficient and hence heat flux,

- Calculate the wall and interfacial temperatures, and

- Use the interfacial temperature for calculation of local fouling deposition.

The calculated fluid-side heat-transfer coefficient can be compared with the experimentally measured value by means of the three HTMs. A correction factor is used in the Nusselt correlation 
for calculation of the condensation coefficient. The value for the correction factor is determined by matching the measured outlet-fluid temperature with the calculated outlet temperature. This procedure is applied for time $\mathrm{t}=0$, when the fouling resistance is assumed to be zero, and the same correction factor is applied to the rest of the calculation procedure.

\section{Heat-Transfer Monitor}

The HTM device is considered as a differential unit; therefore, an average fouling rate is calculated by following the procedure described in Section 4 . The interfacial temperature is either given as input or is calculated at time $\mathrm{t}=0$ using the heat flux.

\section{Isothermal Tube Flow}

The rate of reaction for precursor generation in the tube flow is calculated by integrating the following set of rate equations over the length of the tube:

Reactant a1

$$
\mathrm{V}_{\mathrm{z}} \frac{\mathrm{dC_{ \textrm {a } 1 \mathrm { b } }}}{\mathrm{dz}}=-\mathrm{k}_{1}\left(\mathrm{~T}_{\mathrm{b}}\right) \mathrm{C}_{\mathrm{a} 1 \mathrm{~b}}^{m} \mathrm{C}_{\mathrm{a} 2 \mathrm{~b}}^{n}
$$

Reactant a2

$$
\mathrm{V}_{\mathrm{z}} \frac{\mathrm{dC}_{\mathrm{a} 2 \mathrm{~b}}}{\mathrm{dz}}=-\mathrm{s}_{\mathrm{a} 2} \mathrm{k}_{1}\left(\mathrm{~T}_{\mathrm{b}}\right) \mathrm{C}_{\mathrm{a} 1 \mathrm{~b}}^{m} \mathrm{C}_{\mathrm{a} 2 \mathrm{~b}}^{n}
$$

Precursor

$$
\mathrm{v}_{\mathrm{z}} \frac{\mathrm{d} \mathrm{C}_{\mathrm{pb}}}{\mathrm{dz}}=\mathrm{s}_{\mathrm{p}} \mathrm{k}_{1}\left(\mathrm{~T}_{\mathrm{b}}\right) \mathrm{C}_{\mathrm{alb}}^{m} \mathrm{C}_{\mathrm{a} 2 \mathrm{~b}}^{n}-\mathrm{s}_{\mathrm{f}} \mathrm{k}_{2}\left(\mathrm{~T}_{\mathrm{i}}\right) \mathrm{C}_{\mathrm{pb}}^{l}
$$

Note that the bulk temperature is assumed to remain unchanged at a given value; therefore, the kinetic constants are uniform along the tube length. 


\section{Experimental Apparatus and Procedure}

\subsection{Argonne Test Apparatus and Procedure}

\subsubsection{Test Apparatus}

The OFF apparatus at Argonne is a modification of the Organic Rankine Cycle (ORC) apparatus (Cole et al. 1987), in which the thermal stability of organic working fluids was determined under simulated Rankine cycle conditions. The apparatus was modified for the OFF experiments by keeping two major components, the evaporator and the cooler/condenser. Figures 6.1 and 6.2 show overall flow schematic diagrams for the evaporator and cooler sections of the fouling apparatus. The test fluid is circulated in a closed-loop configuration, with the bulk of it residing in a reservoir that also serves as a cooler, by means of a gear pump that is driven by a magnetically coupled motor. The magnetic gear pump eliminates the possibility of fluid leak, and the fluid flow rate can be effectively controlled by adjusting the pump speed. The heat energy from the apparatus is removed by circulating ethylene glycol/water solution in the cooler, which in turn is cooled by the chilled water.

Figure 6.1 shows an overall piping diagram of the flow loop in the evaporator section. The Dowtherm evaporator consists of a horizontal tank with electric immersion heaters located near

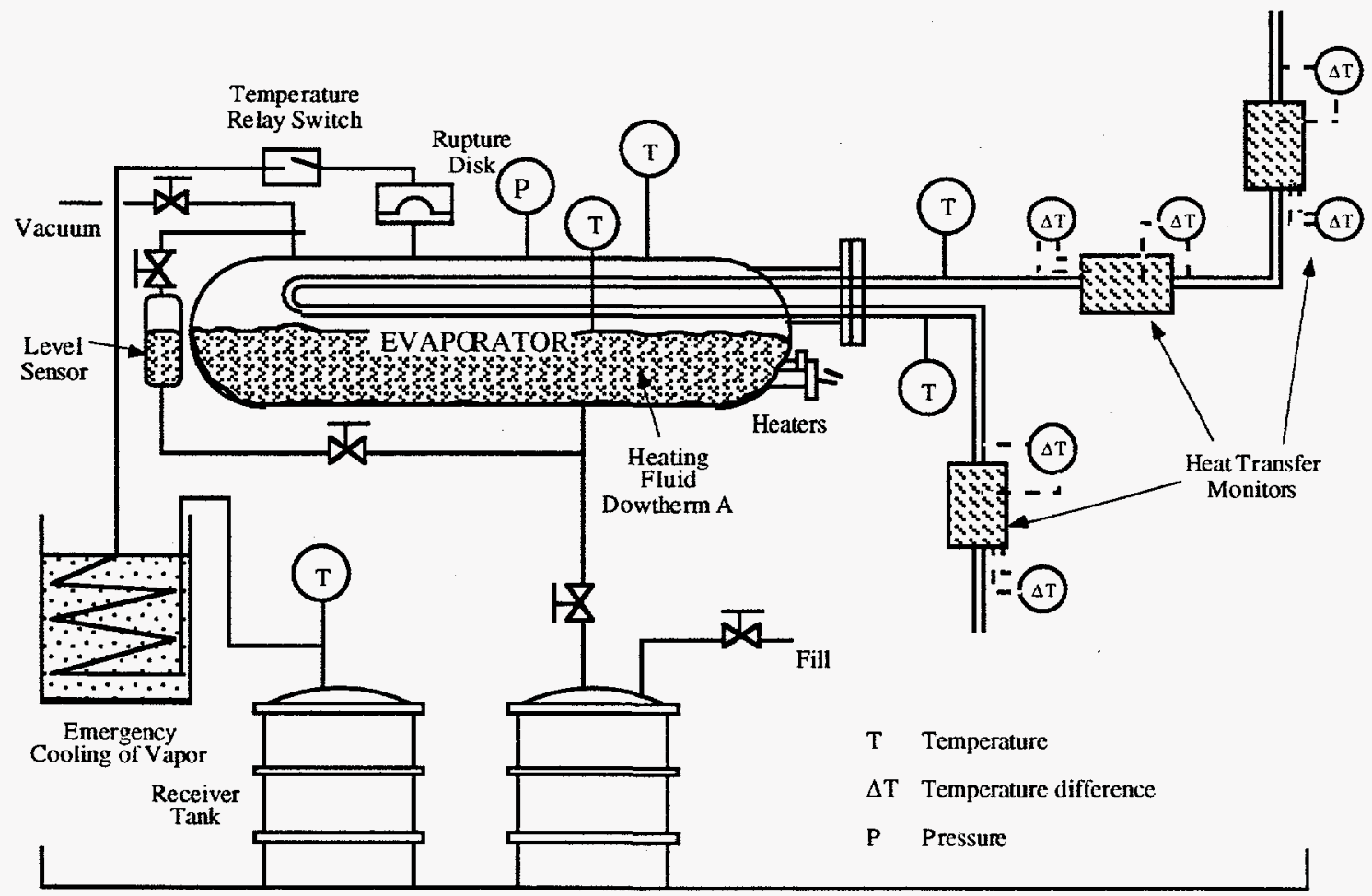

FIGURE 6.1 Process and Instrumentation Diagram for the ANL Fouling Apparatus: Evaporator Section 


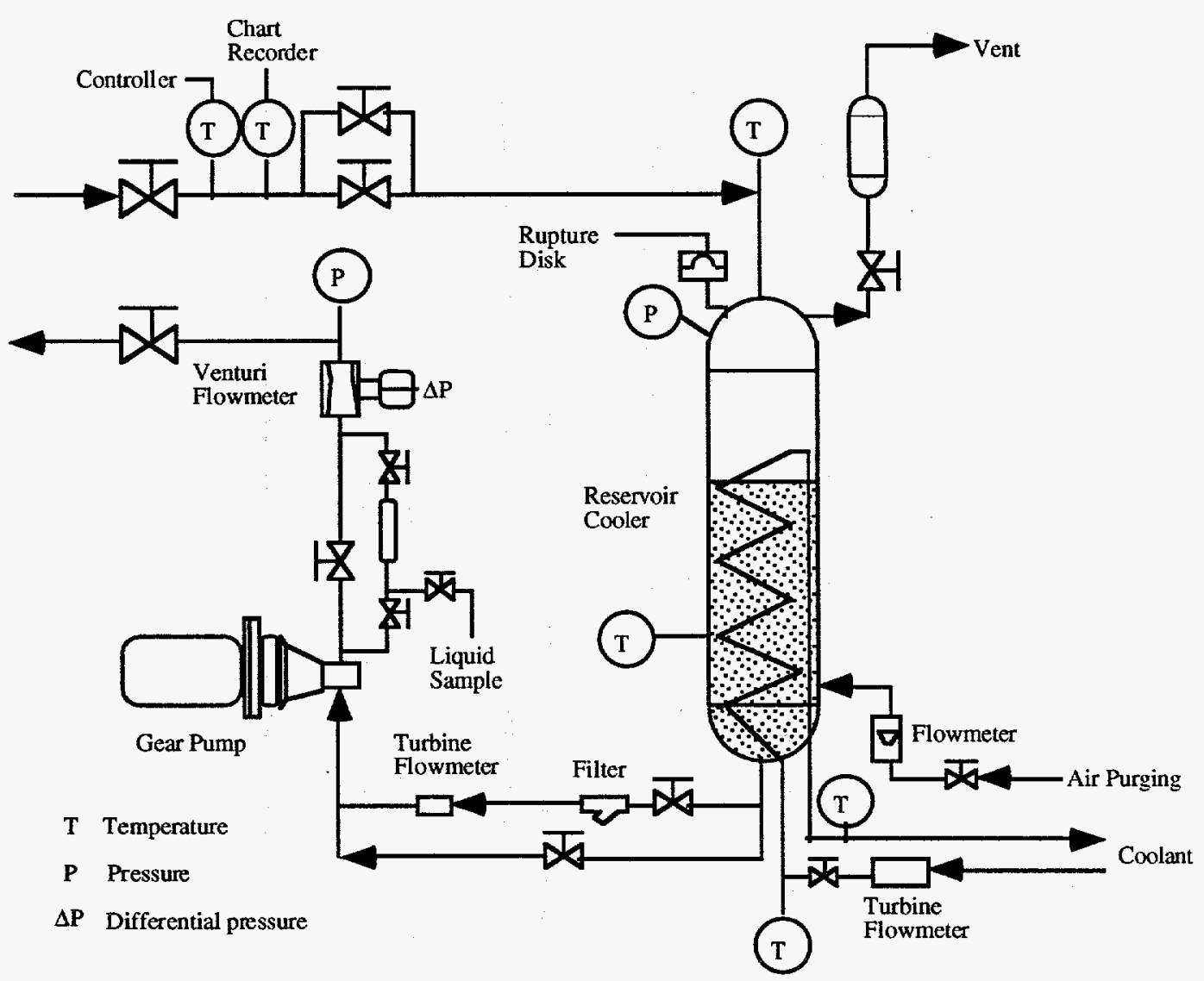

FIGURE 6.2 Process and Instrumentation Diagram for the ANL Fouling Apparatus: Cooler Section

the bottom. Dowtherm-A is used as the heating medium, and a set of electric heaters at different power ratings are used to control the rate of heat transfer. These heaters are powered by $480-\mathrm{V}$ main heaters and $208-\mathrm{V}$ control heaters. The total electric power available to the evaporator is about $12 \mathrm{~kW}$. A control heater is used to maintain constant fluid temperature at the outlet. It is possible to adjust the electric power to any value by means of different power switches and a rheostat. The Dowtherm vapor condenses on the outside of the coil through which the test fluid flows. This heating device provides a heating media of uniform temperature. The overall fouling deposition on the heating-coil surface is determined by measuring the change in the overall heattransfer coefficient. In general, as the fouling deposition occurs on the heat-transfer surface of the heating coil, the Dowtherm pressure increases as a result of the decrease in the overall heat-transfer coefficient.

The cooler section of the fouling apparatus is shown in Figure 6.2. It consists of a reservoir (volume of about $7 \mathrm{~L}$ ) that also serves as a cooler for the test fluid. A cooling coil is installed inside the vessel through which a coolant mixture of ethylene glycol and water is circulated. Provision is made to inject a measured flow of air or other gas into the reservoir to maintain a constant concentration of gas mixture above the test fluid. The cooling system consists of a tank filled with the coolant mixture that is circulated by means of a magnetically driven centrifugal pump. A combination of bypass flow and valve control is used to adjust the flow rate 
to the desired value. The coolant temperature is maintained by controlling the chiller water, which flows through a coil inside the tank. Further temperature control is achieved by heating the coolant with an electric heater that is controlled by a thermostat. In general, coolant temperature can be maintained within one to two degrees of the set temperature.

The local rate of fouling is measured by the HTM, a simple but an accurate device for determining the change in the heat-transfer coefficient caused by the fouling deposition. A schematic view of the HTM device is shown in Figure 6.3. A stainless-steel block is installed on a tube section and is heated by means of an electric heater coil. Two sets of resistance-temperature devices (RTD) are installed at preselected locations (see Table 6.1). The $\Delta \mathrm{T}$ sensor 1 (shown in Figure 6.3) measures the radial temperature gradient, while $\Delta T$ sensor 2 measures the temperature difference between the test fluid and block. These two temperatures and the bulk-fluid temperature are used to calculate the heat-transfer coefficient. As discussed in the data analysis section (Section 6.1.4), the fouling resistance is calculated by measuring the heat-transfer coefficient at time $\mathrm{t}=0$ (clean surface) and at time $\mathrm{t}=\mathrm{t}$.

As shown in Figure 6.1, two HTMs, one on each end of the heating coil, measure the local rate of fouling. These two HTMs are maintained at relatively high heat fluxes to obtain appropriate wall temperatures. In addition, an HTM is installed immediately downstream of the outlet HTM and operates at very low heat flux, providing the fouling characteristics at essentially isothermal conditions (wall temperature equal to fluid bulk temperature). The low-flux HTM is used to determine the rate of fouling under test conditions where the rate of deposition is not dependent on the wall temperature. The two high-flux HTMs determine the local rate of fouling at inlet and outlet conditions of the heating coil. The three HTMs and the heating coil provide a

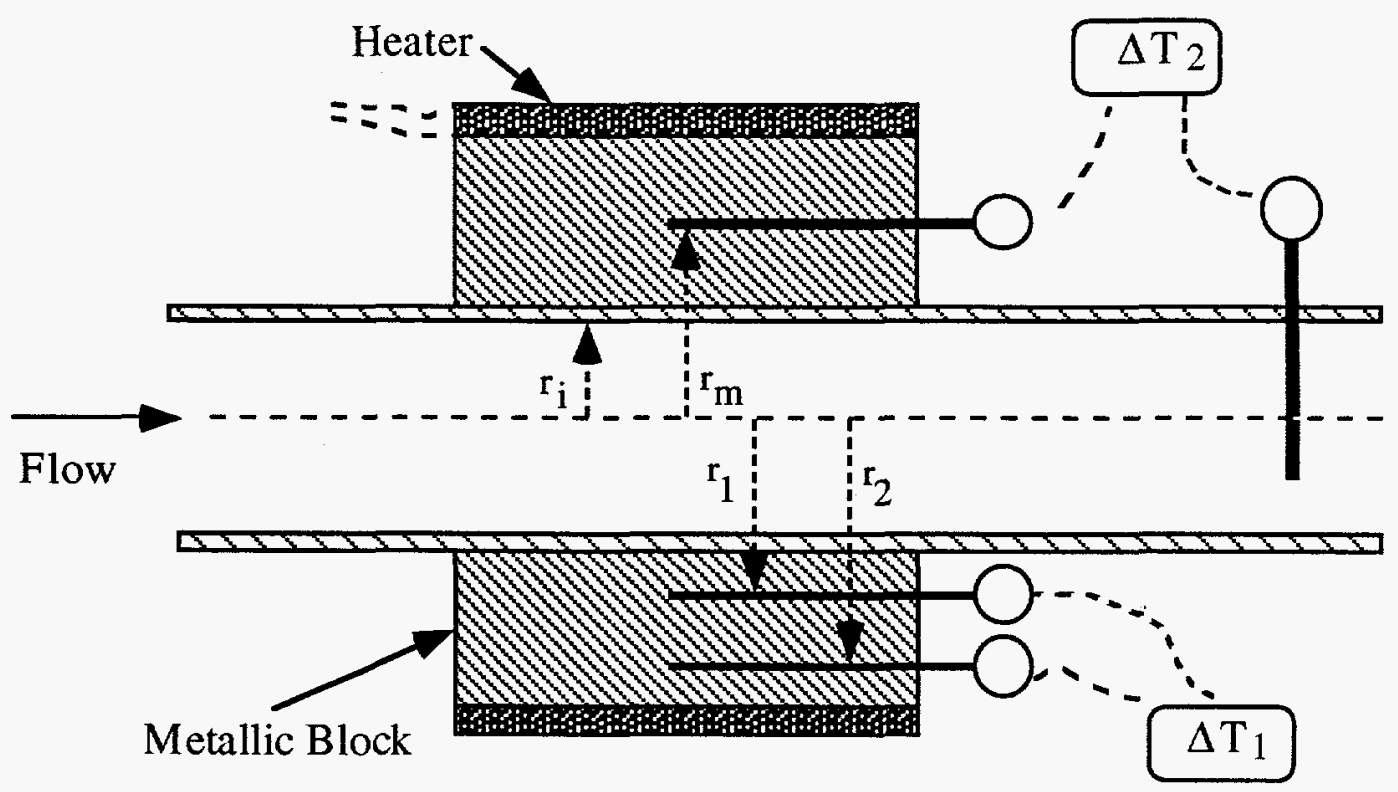

FIGURE 6.3 Schematic Diagram of the ANL Fouling Monitor 
TABLE 6.1 List of Instrumentation for the Argonne Fouling Apparatus

\begin{tabular}{|c|c|c|c|c|c|}
\hline Name & NB\# & INT\# & $\begin{array}{l}\text { Scale } \\
\text { Factor }\end{array}$ & Range & Comments \\
\hline DT-1 & 1 & 48 & 1.8 & $0.5^{\circ} \mathrm{C}$ & mass flowmeter $\Delta T$ \\
\hline DT-2 & 2 & 49 & 72.0 & $0-200^{\circ} \mathrm{C}$ & HTM\#1 wall-to-fluid $\Delta T$ \\
\hline DT-3 & 3 & 50 & 18.0 & $0.50^{\circ} \mathrm{C}$ & HTM\#1 wall $\Delta \mathrm{T}$ \\
\hline DT-4 & 4 & 51 & 3.6 & $0-10^{\circ} \mathrm{C}$ & small loop $\Delta T$ \\
\hline DT-5 & 5 & 52 & 72.0 & $0-200^{\circ} \mathrm{C}$ & HTM\#2 wall-to-fluid $\Delta T$ \\
\hline DT-6 & 6 & 53 & 18.0 & $0-50^{\circ} \mathrm{C}$ & $H T M \# 2$ wall $\Delta T$ \\
\hline DT-7 & 7 & 54 & 3.6 & $0-10^{\circ} \mathrm{C}$ & HTM\#3 wall-to-fluid $\Delta T$ \\
\hline DT -8 & 8 & 55 & 1.8 & $0-5^{\circ} \mathrm{C}$ & $H T M \# 3$ wall $\Delta T$ \\
\hline DT-9 & 9 & & & & spare \\
\hline DT -10 & 10 & & & & spare \\
\hline $\mathrm{TC}-1$ & 11 & 32 & $E$ & & test-fluid evaporator inlet $T$ \\
\hline $\mathrm{TC}-2$ & 12 & 33 & $\bar{E}$ & & test-fluid evaporator middle $T$ \\
\hline $\mathrm{TC}-\overline{3}$ & 13 & 34 & $\bar{E}$ & & test-fluid evaporator outlet $T$ \\
\hline $\mathrm{TC}-4$ & 14 & 35 & $\mathrm{E}$ & & Dowtherm liquid $T$ \\
\hline TC-5 & 15 & 36 & $E$ & & Dowtherm vapor $T$ \\
\hline TC-6 & 16 & & & & spare \\
\hline TC-7 & 17 & & & & spare \\
\hline TC-8 & 18 & & & & spare \\
\hline TC-9 & 19 & & & & spare \\
\hline TC-10 & 20 & & & & spare \\
\hline TC-11 & 21 & 37 & $E$ & & test-fluid condenser inlet $T$ \\
\hline TC-12 & 22 & 38 & E & & test-fluid condenser outlet $T$ \\
\hline TC-13 & 23 & 47 & E & & coolant condenser inlet $T$ \\
\hline TC-14 & 24 & 40 & $E$ & & coolant condenser outlet $T$ \\
\hline TC-15 & 25 & & & & spare \\
\hline TC-16 & 26 & & & & spare \\
\hline TC-17 & 27 & & & & spare \\
\hline TC-18 & 28 & & & & spare \\
\hline TC-19 & 29 & & & & spare \\
\hline TC-20 & 30 & & & & spare \\
\hline EP-1 & 31 & 16 & 201.0 & $2,750-3,450 \mathrm{kPa}$ & test-fluid evaporator outlet $P$ \\
\hline EP-2 & 32 & 17 & 10.065 & $0-345 \mathrm{kPa}$ & Dowtherm pressure \\
\hline CP-3 & 33 & 20 & 201.0 & $1,380-3,450 \mathrm{kPa}$ & test-fluid condenser $P$ \\
\hline EDP-4 & 34 & 18 & 5.000 & $0-34.5 \mathrm{kPa}$ & test-fluid evaporator coil $1 \Delta P$ \\
\hline EDP-5 & 35 & 19 & 5.000 & $0-34.5 \mathrm{kPa}$ & test-fluid evaporator coil $2 \Delta P$ \\
\hline FM-3 & 36 & 31 & 6.7566 & $0-858 \mathrm{~mm}$ & flowmeter DP \\
\hline$P-7$ & 37 & & & & spare \\
\hline$F M-1$ & 38 & 27 & 1.000 & $0-7.5 \mathrm{~L} / \mathrm{m}$ & test-fluid flow rate \\
\hline FM-2 & 39 & 28 & 1.114 & $0-19 \mathrm{~L} / \mathrm{m}$ & coolant flow rate \\
\hline FM-3 & 40 & & 0.3322 & $0-7.5 \mathrm{~L} / \mathrm{m}$ & test-fluid flow rate \\
\hline HTM1-V & 41 & & & & spare \\
\hline HTM1-A & 42 & & & & spare \\
\hline HTM2-V & 43 & & & & spare \\
\hline HTM2-A & 44 & & & & spare \\
\hline НTM3-V & 45 & 29 & 11.0 & & HTM\#3 voltage \\
\hline HTM3-A & 46 & 42 & 100.0 & & HTM\#3 current \\
\hline
\end{tabular}


complete set of fouling data for validation of the fouling model. The additional information required is related to the change in fluid chemistry (i.e., reactant and precursor concentrations as functions of time).

\subsubsection{Instrumentation of the Data-Acquisition System}

Two sets of instruments are used for the fouling apparatus: one set accurately measures the rate of fouling at a given set of test conditions and the other set operates and controls the apparatus. Table 6.1 lists all the instruments installed. The fluid temperatures are measured with type $\mathrm{E}$ (chromel-constantan) thermocouples located at key positions. These thermocouples were initially checked against the quartz thermometer (accuracy of about $0.02^{\circ}$ ), which showed that the measurement accuracy was about $0.5^{\circ}$. As discussed earlier, temperature differences for the HTM device are directly measured with the differential RTD. In this system, the two RTD sensors measuring the temperature difference are part of the same signal-processing circuit. As a result, the RTD provides a more accurate temperature difference measurement as compared with the measurement of temperatures and taking the difference. All $\Delta \mathrm{T}$ sensors are calibrated at Argonne by using the quartz-temperature sensor for which temperature difference is directly measured. In the calibration procedure, the RTD and quartz probes are put in two temperature baths. The lowtemperature bath is ice slurry at $0^{\circ} \mathrm{C}$. The high-temperature bath is a copper block maintained at the desired temperature by a controlled heating device. This copper block assembly has been used to investigate the measurement accuracy and the stability of quartz and thermistor sensors (Seren et al. 1983). The estimated calibration accuracy for the $\Delta \mathrm{T}$ sensors is about $0.2^{\circ}$.

The flow rate of the fluid had been measured with a turbine flowmeter that had an estimated measurement accuracy of $5 \%$ of the reading. The flowmeter had been calibrated at Argonne by using a calibrated tank. However, the turbine flowmeter was sensitive to the presence of particulates and foulant gum in the fluid stream. Under severe fouling conditions, it stopped. Therefore, a venturi flowmeter has been installed in its place. The pressure-drop sensor for the venturi flowmeter is calibrated by applying a known level of liquid column and using the factorysupplied coefficient factor. The resulting calculation showed that the two flowmeters agreed in the range of 2 to $6 \%$, depending on the flow rate. The fluid pressure is measured with strain-gauge sensors having a factory-calibrated accuracy of about $0.5 \%$ of the operating range, which is adequate for the fouling experiments because the pressure does not enter directly into the fouling calculation.

The data-acquisition system (DAS) consists of signal conditioning and a microcomputerbased system. The sensor input is converted to a $0-5-\mathrm{V}$ dc signal and fed to an IBM/PS2 computer containing an analog to digital conversion (AVD) board manufactured by Metrabite and a corresponding expansion board giving access to 128 differential channels. All channels can be individually addressed, and they can be scanned in a fraction of a second. It is possible to employ gain on each expansion board (Metrabite EXP-16) so that the sensor output can be closely matched with $5 \mathrm{~V} \mathrm{dc}$, which gives maximum possible resolution in reading the data. The calibration method in general included end-to-end reading; therefore, the electronic system was included in the overall calibration. However, if it is necessary to calibrate the sensor separately, the electronic 
system can be calibrated by applying standard input to the signal conditioning and computer systems.

A commercial software, $\mathrm{LabTec}$, was used for reading and processing the output from the instrument sensors. The test data were stored on the disk in engineering units for each channel as a required frequency. For the averaging techniques, a number of samples were taken over a given period of time and their arithmetic average was calculated. All experimental data were routinely transferred onto floppy disks for permanent storage. The data were also transferred to another computer for detailed analysis. This computer has the capability to graphically display the data, which is used to see the trend for selected sensors.

\subsubsection{Procedure}

Typical operation of the fouling apparatus consists of the following steps:

1. Preparing the test fluid,

2. Loading the test fluid into the aerator,

3. Aerating the test fluid for a predetermined period,

4. Transferring the test fluid to the flow loop,

5. Startup and establishing steady state,

6. Setting HTM power to achieve proper wall temperature,

7. Continuing fouling experiment for up to $40 \mathrm{~h}$,

8. Taking liquid sample(s),

9. Stopping the test run when sufficient fouling data are obtained, and

10. Preparing the apparatus for the next run.

The test fluid mixture is prepared by weighing the constituents on a balance and combining them in a glass beaker. Air saturation is achieved by using the aerator/calibration vessel, which allows gaseous saturation at any pressure up to 150 psia. The initial, nonaerated mixture is loaded into the aerator by a vacuum-drawing technique, and gas is injected at the bottom of the vessel 
through a sieve. Upon completion of the aeration, it is essential to maintain the saturation pressure in order to guarantee a known amount of oxygen in the test fluid.

The test fluid is loaded into a clean flow loop by pressurized transfer from the aerator column to the flow loop. Special precautions are taken at this point to be certain that dissolved gas does not come out of solution and that additional gas is not absorbed. A certain concentration of dissolved gas is an important experimental parameter. During the filling process, the test-fluid pump is turned on to assure a gas-free flow loop.

The test fluid is circulated by means of a gear pump that has no seals, which is driven by magnetic coupling. The pump is powered by a dc motor with variable speed controls. Flow is controlled by adjusting the motor-speed knob in the control room, and the maximum flow is $5 \mathrm{~L} / \mathrm{m}$. In a previous configuration, an ac motor was used, and the flow rate was controlled using a flow bypass on the pump.

Once the fluid is loaded and the flow is established, Dowtherm heating, HTM heating at low power, and the cooling system are started. In general, any evaporator power can be arbitrarily set, and the system will eventually reach a stable condition (provided the coolant flow rate is sufficient to remove the system heat). However, for consistent results, the initial stabilization time must be limited. The key parameters contributing to the stabilization period are Dowtherm temperature and coolant tank temperature. In order to avoid prolonged exposure of the test fluid to an unstable thermal cycle, the Dowtherm and coolant are preheated. The set values for temperatures, as well as other important parameters, are determined from a combination of heatload calculations and operator experience. A typical stabilization time for the apparatus is about $1 \mathrm{~h}$.

After stable temperature and flow rate are achieved, the HTMs can be set at the desired power. The total HTM power can be as high as $1,200 \mathrm{~W}$; therefore, the evaporator power must be adjusted. Because of the large thermal mass of the HTMs and the convective heat transfer to the fluid from the inner surface, $15-45 \mathrm{~min}$ are required to establish stable HTM operation. Assuming a value for the heat-transfer coefficient, the HTM power can be calculated for a given value of wall temperature. However, the heat-transfer coefficient cannot be accurately calculated; therefore, it is necessary to make adjustments by using the experimental data. At specified times during a test run, small samples of the test fluid must be retrieved for chemical analysis in order to note the progression of chemical changes. Figure 6.1 shows the piping arrangement provided to allow withdrawal of the test fluid with no resulting system disturbance.

Completion of a run is determined by the degree of fouling; a typical run lasts $40-60 \mathrm{~h}$. Data are periodically taken and analyzed, and the run is terminated after the fouling trend is determined. Because of the limited test-fluid volume, bulk changes in the test-fluid chemistry do not permit meaningful long-term runs. Once a run is completed, maintenance commences, including cooling the system, draining and disposing of the spent test fluid, flushing the system with solvent (acetone), brushing the HTM surfaces to remove fouling deposits, and evacuating the flow loop. 


\subsubsection{Data Analysis}

The fouling resistance is calculated from the two $\Delta \mathrm{T}$ measurements made with the HTM device. The analysis shown below gives a step-by-step procedure for calculating the fouling resistance (refer to Figure 6.3 for the locations of the temperature sensors in the HTM):

Heat flux

$$
\dot{\mathrm{q}}=\frac{2 \mathrm{k} \Delta \mathrm{T}_{1}}{\mathrm{~d} \ln \left(\mathrm{r}_{2} / \mathrm{r}_{1}\right)}
$$

Heat transfer rate

$$
\mathrm{Q}=\frac{2 \pi \mathrm{L} k \Delta \mathrm{T}_{1}}{\ln \left(\mathrm{r}_{2} / \mathrm{r}_{1}\right)}
$$

Mean temperature difference

$$
\Delta \mathrm{T}_{\mathrm{mtd}}=\Delta \mathrm{T}_{2}-\Delta \mathrm{T}_{\mathrm{f}}-\Delta \mathrm{T}_{\mathrm{m}}
$$

Heat-transfer coefficient

$$
\mathrm{h}=\dot{\mathrm{q}} / \Delta \mathrm{T}_{\mathrm{mtd}}
$$

Fouling resistance

$$
R_{f}=(1 / h)_{t=t}-(1 / h)_{t=0}
$$

where

$$
\begin{aligned}
\Delta \mathrm{T}_{\mathrm{f}} & =\text { change in fluid temperature as it flows through the HTM } \\
& =\mathrm{Q} / \dot{\mathrm{m}}_{\mathrm{f}} \mathrm{C}_{\mathrm{p}} \text {, and } \\
\Delta \mathrm{T}_{\mathrm{m}} & =\Delta \mathrm{T}_{1} \frac{\ln \left(\mathrm{r}_{\mathrm{m}} / \mathrm{r}_{\mathrm{i}}\right)}{\ln \left(\mathrm{r}_{2} / \mathrm{r}_{1}\right)}
\end{aligned}
$$

Experiments are conducted at constant heat flux for a given test run; therefore, $\Delta \mathrm{T}_{1}$ and $\Delta \mathrm{T}_{\mathrm{f}}$ are relatively constant. In addition, if the fluid flow rate is maintained constant, Equation 6.5 simplifies to the expression shown in Equation 6.8.

$$
R_{f}=\frac{\left[\left(\Delta T_{2}\right)_{t=t}-\left(\Delta T_{2}\right)_{t=0}\right] \ln \left(r_{2} / r_{1}\right)}{2 k \Delta T_{1} / d}
$$

The $\Delta \mathrm{T}$ sensors were calibrated for an accuracy of $0.2^{\circ}$. When this measurement accuracy is applied to Equation 6.8 , the uncertainty in $R_{f}$ is about $0.001 \mathrm{~m}^{2} \mathrm{~K} / \mathrm{kW}$ for a typical set of test conditions. 


\subsection{UBC Test Apparatus}

\subsubsection{Test Apparatus}

The UBC fouling test apparatus consists of a stainless steel flow loop in which an annular probe and a hot-wire probe are mounted in parallel for simultaneous measurement of the heat transfer from the cylindrical rod and from the coiled wire. A flow diagram and construction data are given in Figure 6.4 and Table 6.2, respectively. Table 6.3 lists the instrumentation and the accuracy of readings.

The fluid is pumped from the pressurized 9.45-L reservoir tank through orifice flowmeters to the probes. The tank is heated by a $500-\mathrm{W}$ immersion heater and a $600-\mathrm{W}$ external heating tape connected to a temperature controller. A motorized stirrer mixes the fluid in the tank. A cooling coil within the tank allows water flow to cool the contents.

The heating rod for the annular fouling measurements was supplied by Heat Transfer Research Inc. (HTRI). The rod consists of a stainless-steel-sheathed, resistance heater that has four thermocouples located close to the heating surface. The bulk temperature is measured by thermocouples located in the mixing chambers upstream and downstream of the annulus.

The coiled, stainless-steel-wire probe, which is mounted in a rectangular duct normal to the flow, is heated electrically. The heat flux supplied by the wire is calculated from the current and voltage. The wire temperature is determined by means of the known change of electrical resistance with wire temperature. The bulk temperature around the hot-wire probe is measured by two thermocouples, one located $19 \mathrm{~mm}$ upstream and one located $19 \mathrm{~mm}$ downstream from the coil. The liquid flow for the hot-wire probe is generally laminar. In the annulus, flow is turbulent except when high viscosity carrier fluids are used.

\subsubsection{Procedure}

The general procedure for fouling tests includes system cleaning, saturation of fluid with air, fouling test, and data analysis. The detailed procedure is given below.

1. System Cleaning: To obtain the same initial condition of the test system for each fouling test, the supply tank and pipeline are cleaned using acetone solvent and washed with pure kerosene. The whole system is cleaned again by repeating the procedure. 


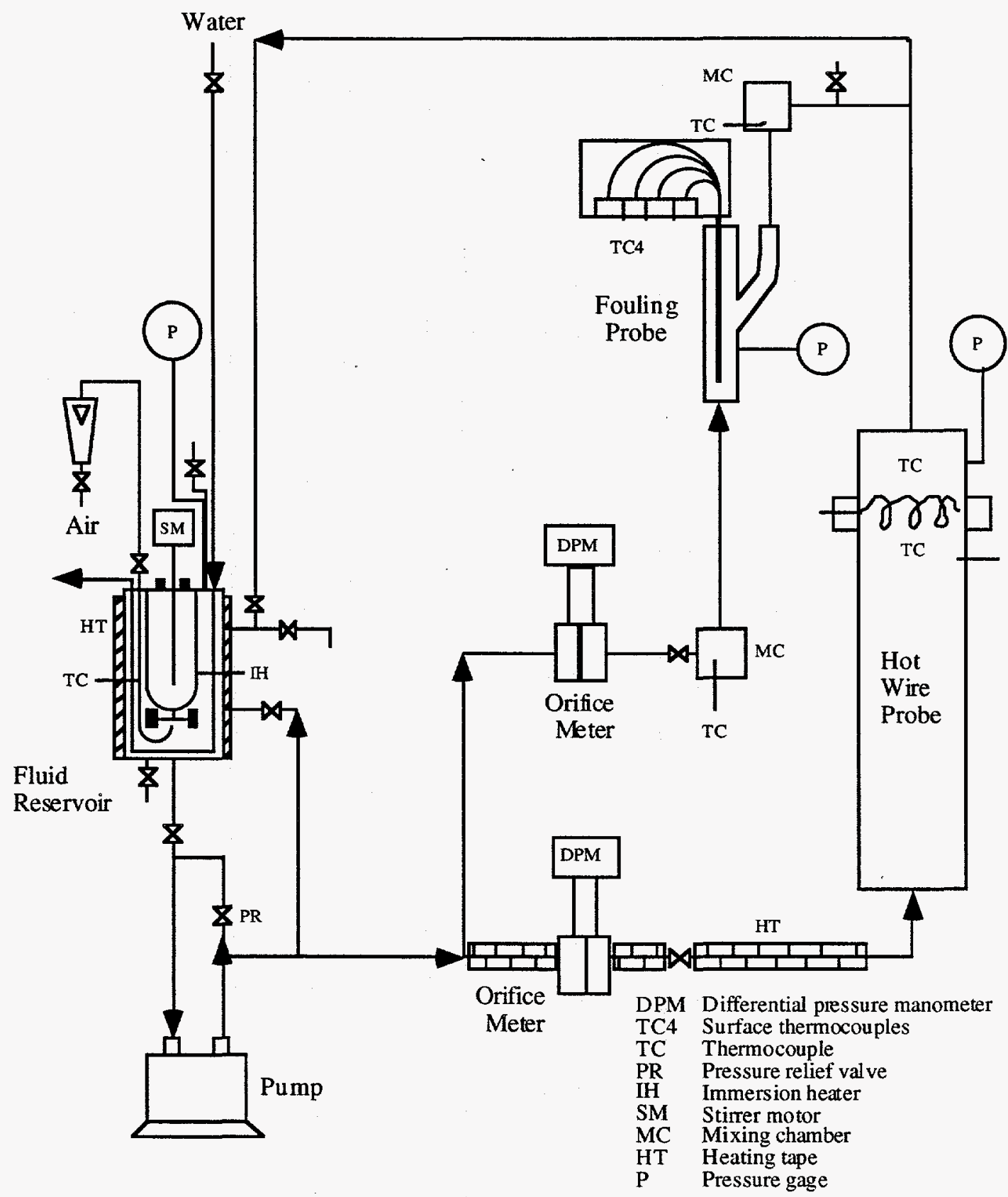

FIGURE 6.4 Flow Diagram for the UBC Fouling Apparatus

2. Fluid Saturation: Before filling the system with test fluid, the annular probe and hot-wire coil are inserted into their respective test sections. The supply tank is then partially filled with kerosene. The volume of fluid used is normally $10 \mathrm{~L}$. In the case of the oxygenated runs, air is bubbled into the supply tank while the kerosene is circulated by the pump. During the saturation process, the stirrer is activated, and the tank is pressurized to about $410 \mathrm{kPa}$ (abs). The fluidsaturation step takes about $12 \mathrm{~h}$. 
TABLE 6.2 Design Specifications for Fouling Probes

\begin{tabular}{|c|c|c|c|}
\hline \multicolumn{2}{|l|}{ Annular } & \multicolumn{2}{|l|}{ Hot Wire } \\
\hline Parameter & Value & Parameter & Value \\
\hline Material & SS 316 & Material & SS 410 \\
\hline Diameter $(\mathrm{mm})$ & 10.7 & Wire diameter $(\mathrm{mm})$ & 0.2 \\
\hline Annulus outer diameter $(\mathrm{mm})$ & 25.4 & Wire length (mm) & 125 \\
\hline Heated length $(\mathrm{mm})$ & 102.0 & Coil diameter $(\mathrm{mm})$ & 1.25 \\
\hline $\begin{array}{l}\text { Heated length to thermo- } \\
\text { couple location }(\mathrm{mm})\end{array}$ & 78.0 & Number of coils & 25 \\
\hline $\begin{array}{l}\text { Length from entrance to } \\
\text { thermocouple location }(\mathrm{mm})\end{array}$ & 294.0 & Duct cross section (mm) & $40 \times 13$ \\
\hline
\end{tabular}

TABLE 6.3 Instrumentation for the UBC Fouling Apparatus

\begin{tabular}{llll}
\hline \multicolumn{1}{c}{ Parameter } & \multicolumn{1}{c}{ Instrument } & \multicolumn{1}{c}{ Range } & Accuracy \\
\hline Temperature measurement & Digital thermometer 670 & $-100^{\circ}$ to $\sim 870^{\circ} \mathrm{C}$ & $\pm 1.0^{\circ} \mathrm{C}$ \\
Temperature measurement & Digitrend 235 & $-217.0^{\circ} \mathrm{C}$ to & $\pm 0.1^{\circ} \mathrm{C}$ \\
& & $\sim 1002.5^{\circ} \mathrm{C}$ & \\
Temperature controller & Thermo Electric 100 & 0 to $\sim 1000^{\circ} \mathrm{C}$ & $\pm 1^{\circ} \mathrm{C}$ \\
Hot-wire power & Data Precision 2480 & voltage 0 to $\sim 10 \mathrm{~V}$ & $\pm 1 \mathrm{mV}$ \\
& Current 0 to $\sim \mathrm{A}$ & $\pm 0.1 \mathrm{~mA}$ \\
Electric power & Digitrend 235 & voltage 0 to $\sim 1 \mathrm{~V}$ & $\pm 1 \mathrm{mV}$ \\
Pressure measurement & Marsh 100-355 & 0 to $\sim 200 \mathrm{psi}$ & $\pm 2 \mathrm{psi}$ \\
Differential pressure measurement & U-tube manometer & 0 to $\sim 30 \mathrm{in} . \mathrm{Hg}$ & $\pm 0.1 \mathrm{in}$. $\mathrm{Hg}$ \\
Fluid flow rate & Orifice & $\mathrm{d}_{2}=15.8 \mathrm{~mm}$ & \\
& & $\mathrm{C}_{\mathrm{d}}=0.6102$ & \\
Water flow rate & Rotameter & 0 to $\sim 5.0 \mathrm{gal} / \mathrm{min}$ & $\pm 0.1 \mathrm{gal} / \mathrm{min}$ \\
& & & \\
\hline
\end{tabular}

3. Fouling Test: After the liquid is well-saturated, the olefin is added to the system. The flow rate and temperatures (bulk and surface) are then set to the required values. The data recorder (datalogger) is started with a specified time interval between readings. During a fouling test, fluid samples are taken through the sample port (Figure 6.4) at suitable times in order that a proper analysis of the data can be obtained. Normally, a fouling test is stopped when the surface temperature of the annular probe is in excess of $300^{\circ} \mathrm{C}$. 


\subsubsection{Data Analysis}

The heat-transfer coefficient is defined as

$$
h=(Q / A)\left(T_{s}-T_{b}\right)
$$

For the annular probe, $T_{s}$ is calculated from the wall temperature, $T_{W}$, measured at distance $s$ below the surface of the metal:

$$
\mathrm{T}_{\mathrm{s}}=\mathrm{T}_{\mathrm{w}}-\frac{\mathrm{S}}{\mathrm{k}_{\mathrm{m}}} \frac{\mathrm{Q}}{\mathrm{A}}
$$

where the volume $S / \mathrm{k}_{\mathrm{m}}$ is given by the manufacturer of the probe and $\mathrm{Q}$ is determined directly from voltage and resistance measurements through an ac/dc conversion circuit.

For the hot wire probe,

$$
\mathrm{T}_{\mathrm{s}}=\left[\frac{\mathrm{R}-\mathrm{R}_{\mathrm{ext}}}{\mathrm{R}_{\mathrm{o}}-\mathrm{R}_{\mathrm{ext}}}-1\right] \frac{1}{\alpha}+\mathrm{T}_{\mathrm{b}}
$$

and

$$
\mathrm{Q}=\mathrm{I}^{2}\left(\mathrm{~V} / \mathrm{I}-\mathrm{R}_{\mathrm{ext}}\right) .
$$

The fouling resistance for both probes is given by

$$
R_{f}=\frac{1}{h}-\frac{1}{h_{t=0}} .
$$




\section{Validation of the Model}

The objective of the analytical work is to evaluate the fouling model to identify the governing mechanisms of the fouling process. In this phase of the research program, several series of experiments were carried out at ANL and at UBC to characterize the effects of physical parameters. The major objective of the experimental program was to obtain reproducible data under controlled conditions. Key observations made during this phase of the experimental program are summarized below:

- The reactant becomes depleted and the concentration of the foulant precursor builds up in the closed-loop apparatus; therefore, care must be taken in applying the laboratory data to industrial conditions.

- The wall temperature of the HTM surface can reach a level above the boiling point of the test fluid; appropriate fluid pressure must applied for a given wall temperature to suppress subcooled boiling.

- The fouling characteristics of the subcooled-boiling test fluid are significantly different from those occurring under single-phase, convective, heat-transfer conditions.

- Appropriate pressure must be applied to minimize to the effect of changes in the solubility of the reacting dissolved gas (e.g., oxygen) near the wall surface.

- The long-term fouling characteristics of the test fluid are affected by the aging process of the fouling deposition; therefore, the fouling resistance during the initial period (typically, the first $8-40 \mathrm{~h}$ ) should be used for validating the fouling model.

In this section of the report, the rate of fouling predicted by the fouling model is compared with the experimentally measured fouling rate. A chemical system of olefin-based fouling was selected to evaluate the fouling model for its ability to predict the fouling rate and to identify the controlling mechanism(s). The previous work at UBC (Asomaning and Watkinson 1990) and the literature data have identified several olefins that produce polyperoxides in the presence of dissolved oxygen. Indene $\left(\mathrm{C}_{8} \mathrm{H}_{9}\right)$ was selected as an impurity, and odorless kerosene was used as a test fluid. It was experimentally shown that kerosene does not produce foulant deposition for the range of test conditions used in the present experimental program.

\subsection{Determination of Kinetic Data}

The fouling model contains several kinetic and physical constants that must be determined. A baseline test run obtained at ANL is used to determine the kinetic constant required in the fouling 
model. The kinetic constant for the first reaction between indene and oxygen was derived from the batch-reaction data of Russell (1957). The results are summarized in Table 7.1. The reaction rate equation used for the autoxidation of indene is shown below:

$$
\mathrm{r}_{1}=\mathrm{k}_{1}[\mathrm{I}]^{1.5}\left[\mathrm{O}_{2}\right]^{0.5}
$$

where the reaction constant $\mathrm{k}_{1}$ is expressed in the Arrhenius form as follows:

$$
\mathrm{k}_{1}=\mathrm{a}_{1} \mathrm{e}^{(-\mathrm{E} / \mathrm{RT})}
$$

Russell's data include only one temperature; therefore, the activation energy could not be calculated for indene. The autoxidation data of styrene (Russell 1957) were used to determine the activation constant, and it was assumed to be the same value for indene. The assumption is justified on the basis that the autoxidation reaction mechanism for indene is similar to that for styrene.

No kinetic study has been reported for the second reaction, where precursor(s) reacts to form insoluble foulant. The fouling data obtained at ANL were used to determine the kinetic constant. Four test runs were obtained at the average test conditions and physical parameters shown in Table 7.2.

TABLE 7.1 Batch-Reaction Data and Calculated Reaction Results

\begin{tabular}{lc}
\hline \multicolumn{1}{c}{ Parameter } & Value \\
\hline & \\
Reaction Conditions & \\
& \\
Reaction temperature $\left({ }^{\circ} \mathrm{C}\right)$ & 60 \\
Oxygen pressure $(\mathrm{mm})$ & 730 \\
Oxygen consumed $(\mathrm{moles} / 12 \mathrm{~h})$ & 0.153 \\
Indene (moles) & 0.53 \\
Indene $(\mathrm{L})$ & 0.0634 \\
Indene density ( $\mathrm{g} / \mathrm{mol})$ & 0.9696 \\
& \\
Calculated Results & \\
& \\
Rate of reaction $(\mathrm{mol} / \mathrm{h} \cdot \mathrm{L})$ & 0.0342 \\
Oxygen concentration $(\mathrm{mol} / \mathrm{L})$ & 0.0086 \\
Indene concentration $(\mathrm{mol} / \mathrm{L})$ & 8.35 \\
Reaction constant $(\mathrm{L} / \mathrm{mol} \cdot \mathrm{h})$ & 0.01528 \\
Activation energy $(\mathrm{kJ} / \mathrm{mol})$ & 96.3 \\
Frequency constant $(\mathrm{L} / \mathrm{mol} \cdot \mathrm{h})$ & $6.516 \times 10^{13}$ \\
Frequency constant $\left(\mathrm{m}^{3} / \mathrm{kmol} \cdot \mathrm{s}\right)$ & $1.81 \times 10^{10}$ \\
& \\
\hline
\end{tabular}


TABLE 7.2 Average Test Conditions and Physical Parameters for the Baseline Test Runs at ANL

\begin{tabular}{|c|c|c|c|c|c|}
\hline \multirow[b]{2}{*}{$\begin{array}{l}\text { Test Conditions } \\
\text { and Parameters }\end{array}$} & \multicolumn{5}{|c|}{ Test Run No. } \\
\hline & 1 & 2 & 3 & 4 & Average \\
\hline \multicolumn{6}{|l|}{ Test Conditions } \\
\hline Concentration of indene (wt\%) & 10 & 10 & 10 & 10 & 10 \\
\hline \multicolumn{6}{|l|}{ Concentration of indene } \\
\hline $\begin{array}{l}\left(\mathrm{kmol} / \mathrm{m}^{3}\right) \\
\text { System pressure }(\mathrm{kPa})\end{array}$ & $\begin{array}{ll}0.71 \\
417\end{array}$ & $\begin{array}{l}0.71 \\
429\end{array}$ & $\begin{array}{l}0.71 \\
428\end{array}$ & $\begin{array}{l}0.71 \\
421\end{array}$ & $\begin{array}{l}0.71 \\
424\end{array}$ \\
\hline Oxygen concentration $\mathrm{a}\left(\mathrm{kmol} / \mathrm{m}^{3}\right)$ & 0.0057 & 0.0059 & 0.0058 & 0.0057 & 0.0058 \\
\hline Fluid velocity $(\mathrm{m} / \mathrm{s})$ & 1.04 & 1.0 & 0.95 & 0.92 & 0.98 \\
\hline Fluid temperature at $\mathrm{HTM} \# 1\left({ }^{\circ} \mathrm{C}\right)$ & 82.5 & 82.9 & 82.7 & 82.4 & 82.6 \\
\hline Fluid temperature at $\mathrm{HTM} \# 2\left({ }^{\circ} \mathrm{C}\right)$ & 99.2 & 98.9 & 98.6 & 98.4 & 98.8 \\
\hline Wall temperature of $\mathrm{HTM} \# 1\left({ }^{\circ} \mathrm{C}\right)$ & 191.8 & 194.7 & 191.6 & 196.4 & 193.6 \\
\hline Wall temperature of $\mathrm{HTM} \# 2\left({ }^{\circ} \mathrm{C}\right)$ & 187.7 & 193.5 & 189.9 & 193.5 & 191.1 \\
\hline \multicolumn{6}{|l|}{ Physical Parameters } \\
\hline Foulant density $\left(\mathrm{kg} / \mathrm{m}^{3}\right)$ & ....... & - & 1000 & $\ldots$ & (......... \\
\hline Foulant molecular weight & (............. & (............. & $\cdots \quad 2,368$ & $\cdots \cdots$ & $\ldots$ \\
\hline $\begin{array}{l}\text { Foulant thermal conductivity } \\
(\mathrm{kW} / \mathrm{m} \cdot \mathrm{K})\end{array}$ & - n & $\ldots . . .$. & $\cdots \quad 0.0002$ & $\cdots+\cdots$ & $\ldots$ \\
\hline
\end{tabular}

a Oxygen concentration calculated by using the ASTM 3827 standard.

The molecular weight for foulant was determined on the basis of solubility data for polyperoxide reported by Russell (1957). It was found that the prediction was not significantly affected when the molecular weight was varied in the range of 1,480 and 4,760. Thermal conductivity was calculated by using the fouling resistance and the film thickness measured at $\mathrm{UBC}$; although the value may not be accurately measured, it agrees with the literature data for polymeric films. The foulant density shown in Table 7.2 is also a typical value for polymeric films. All three parameters - molecular weight, density, and thermal conductivity - are used in a product term; therefore, a single uncertainty value can be used for the combined error of their values. This uncertainty was integrated into the kinetic constant, since the frequency constant for the second reaction was determined by using the fouling data, as discussed below.

The reaction equation for foulant formation is shown below:

$$
\mathrm{r}_{2}=\mathrm{k}_{2}[\mathrm{p}]
$$


where the reaction constant $\mathrm{k}_{2}$ is expressed in the Arrhenius form as follows:

$$
k_{2}=a_{2} e^{(-E / R T)}
$$

The activation energy for reaction $r_{2}$ was assumed to be the same as for reaction $r_{1}$ (i.e., $96.3 \mathrm{~kJ} / \mathrm{mol}$ ). The kinetic constant $\mathrm{a}_{2}$ was then varied until a reasonable agreement was achieved between the experimental and predicted fouling resistance. The analysis of the experimental data indicated that the fouling deposition occurring between 8 and $20 \mathrm{~h}$ after testing began represents a defined trend for the baseline set of conditions shown in Table 7.2; therefore, the predicted fouling resistance matched the experimental value at about $14 \mathrm{~h}$. Data from a set of four test runs at baseline conditions are shown in Figures 7.1 and 7.2 for the Case 2 fouling mechanism; these figures show the reproducibility of the data and the good agreement with the predictions for HTM\#1 and HTM\#2, respectively. In two of the test runs, variation in the operating conditions seemed to have caused reduction in the fouling resistance for a part of the test period. However, the visual analysis of the data show that the rate of deposition represented by the slope (dRf $/ d t)$ between the test period of 12 and $20 \mathrm{~h}$ is comparable for all four test runs for HTM\#1. A slightly lower wall temperature for HTM\#2 for part of the test period caused lower fouling rates for two test runs. The resulting value for a from this analysis was $9.6 \times 10^{7} \mathrm{~m}^{3} / \mathrm{s}$. These two kinetic constants, $a_{1}$ and $a_{2}$, were used for comparing the experimental data with predictions in this section and in analyzing the parametric effects in Section 8.

Figures 7.1 and 7.2 show that the rate of fouling was relatively low for about $8 \mathrm{~h}$, which was then followed by a rapid rate of fouling deposition. The initial period of low fouling has a special significance for determination of threshold conditions. The scope of the present work did not include investigation of the initial period; it is a part of the next phase of the research investigation. The fouling behavior during the initial period was reproducible for most test runs. Note that chemical analysis of the test fluid is essential to determine the amount of precursor formation, in order to understand the fouling behavior during the initial period.

The fouling resistance for HTM\#3 (isothermal conditions) for the set of four baseline test runs is shown in Figure 7.3. The fouling resistance was essentially zero; however, the apparent indication of fouling resistance during the first $5 \mathrm{~h}$ is believed to be due to system operation. It was observed that the flow rate increases and then decreases during the first 5-8 $\mathrm{h}$. This variation is probably caused by the combination of buildup of soluble gum in the fluid and the characteristics of the gear pump. Since HTM\#3 operates with small temperature differences $\left(<5^{\circ} \mathrm{C}\right)$, measurement of the fouling resistance is sensitive to the change in local fluid temperature. The other two HTMs did not show such behavior. The negative values for two test runs are partly due to the value of the reference heat-transfer coefficient at time $t=0$ that was used for calculating the fouling resistance and partly due to some deposition that produced roughness, giving a higher heattransfer coefficient as compared with the value for a clean surface. In any case, the fouling resistance did not change after the initial period of about $4 \mathrm{~h}$. 


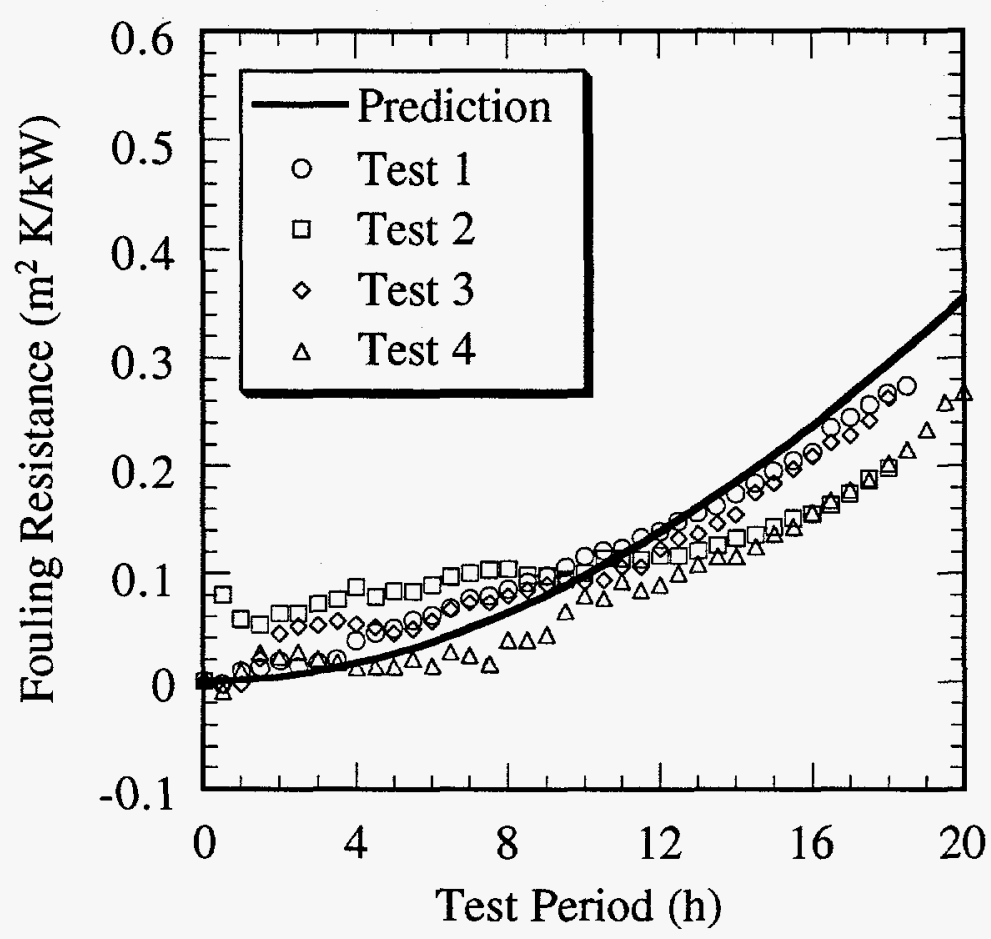

FIGURE 7.1 Fouling Resistance for HTM\#1 for Baseline Conditions and Comparison with the Case 2 Prediction

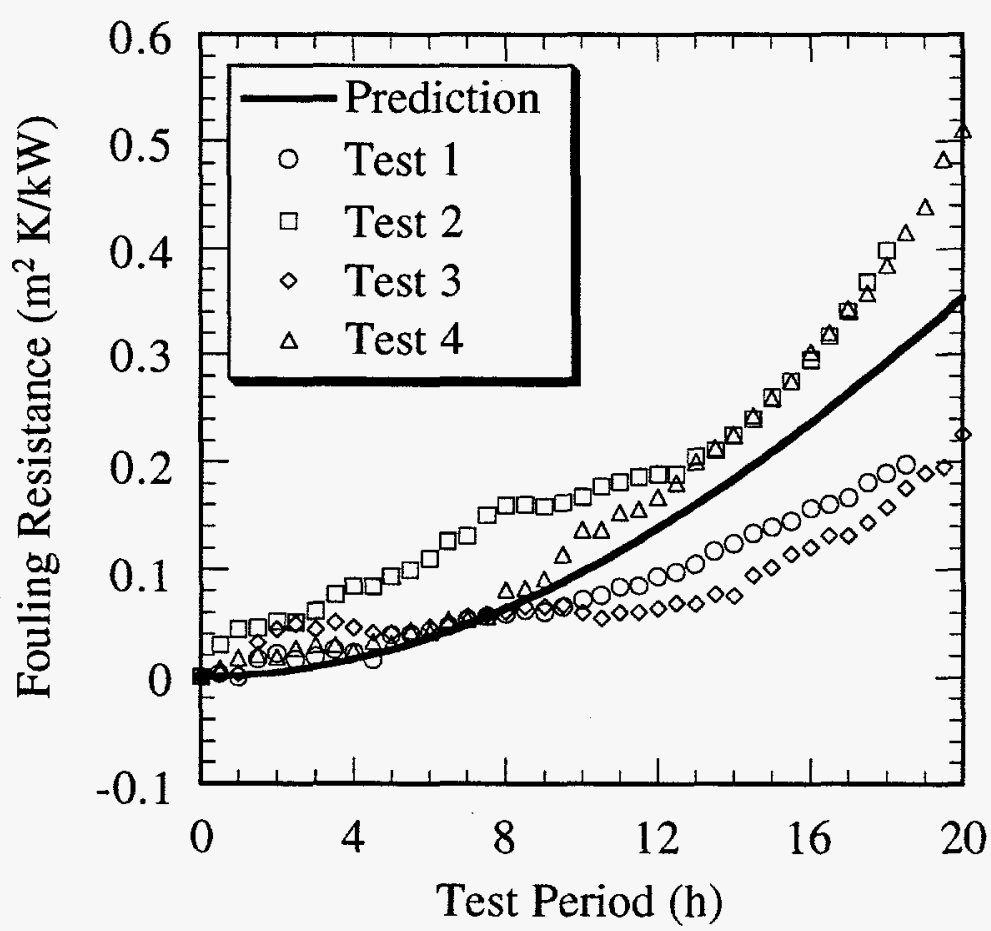

FIGURE 7.2 Fouling Resistance for HTM\#2 for Baseline Conditions and Comparison with the Case 2 Prediction 


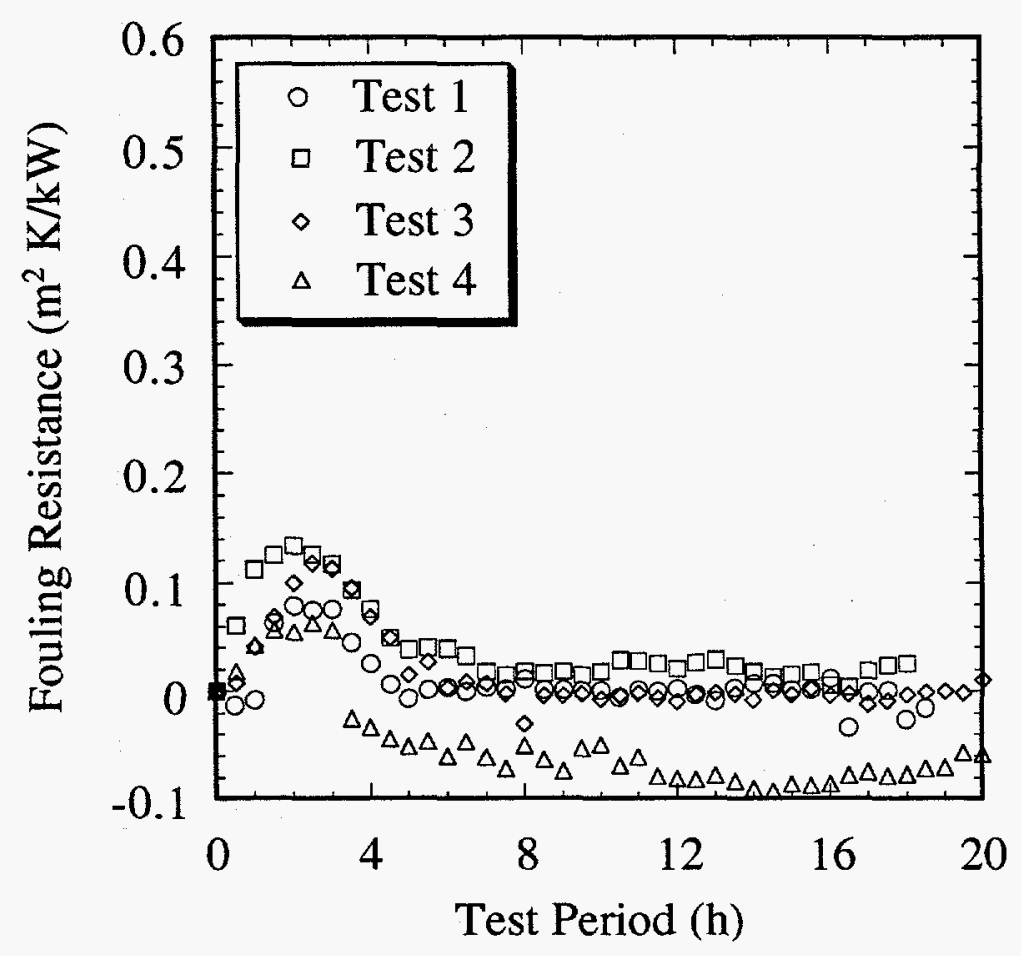

FIGURE 7.3 Fouling Resistance for HTM\#3 for Baseline Conditions

In the Case 1a fouling mechanism, the second reaction occurs at the wall surface. In order to convert the reaction rate from per unit volume to per unit surface area, parameter â is introduced in Equation 7.5:

$$
\mathbf{r}_{2}=\hat{a} k_{2}[\mathrm{p}] \text {. }
$$

The frequency constant a 2 was kept the same as that for Case 2 ; however, the parameter â was varied until the predicted fouling resistance agreed with the experimental value after a test period of $14 \mathrm{~h}$, as shown in Figure 7.4 for the HTM\#1 data. The resulting value for the parameter â was 0.012. The HTM\#2 data are shown in Figure 7.5. For a given test run, the wall temperatures for the two HTMs were comparable, but the bulk temperature for HTM\#2 was about $17 \mathrm{C}^{\circ}$ higher than for HTM\#1 (see Table 7.2). The Case 1a model does not take into account the bulk temperature for the second reaction. As a result, the predicted rate of fouling for HTM\#2 was slightly lower than that for the Case 2 predictions after both models were validated with the HTM\#1 data.

The experimental data shown in Figure 7.3 clearly indicate that the fouling process is not controlled by particulate deposition of insoluble foulant formed in the bulk, which is represented by the Case $1 \mathrm{~b}$ fouling mechanism. The effect of particulate size on the fouling resistance at the end of the 15-h test period is shown in Figure 7.6 for the baseline test conditions. The fouling resistance drops sharply as the particulate size increases from about 0.1 to $10 \mu \mathrm{m}$. Since the 


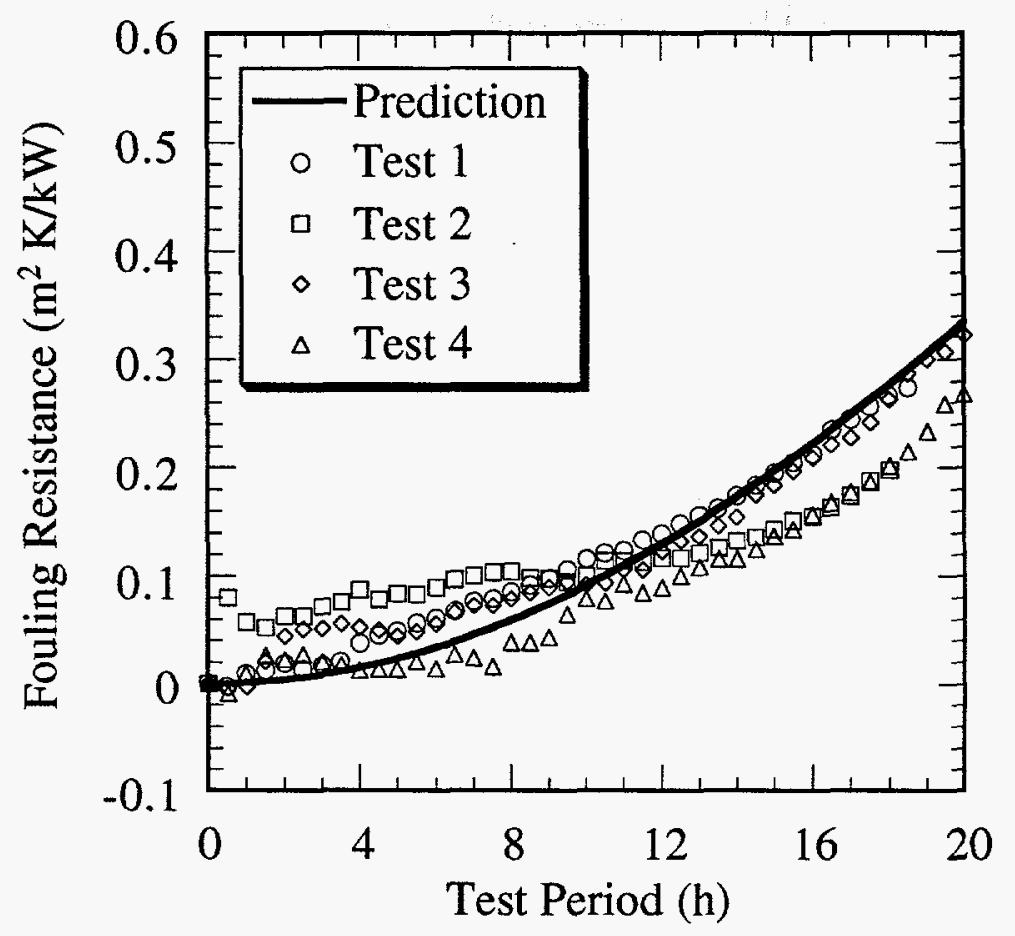

FIGURE 7.4 Fouling Resistance for HTM\#1 for Baseline Conditions and Comparison with Case 1a Prediction

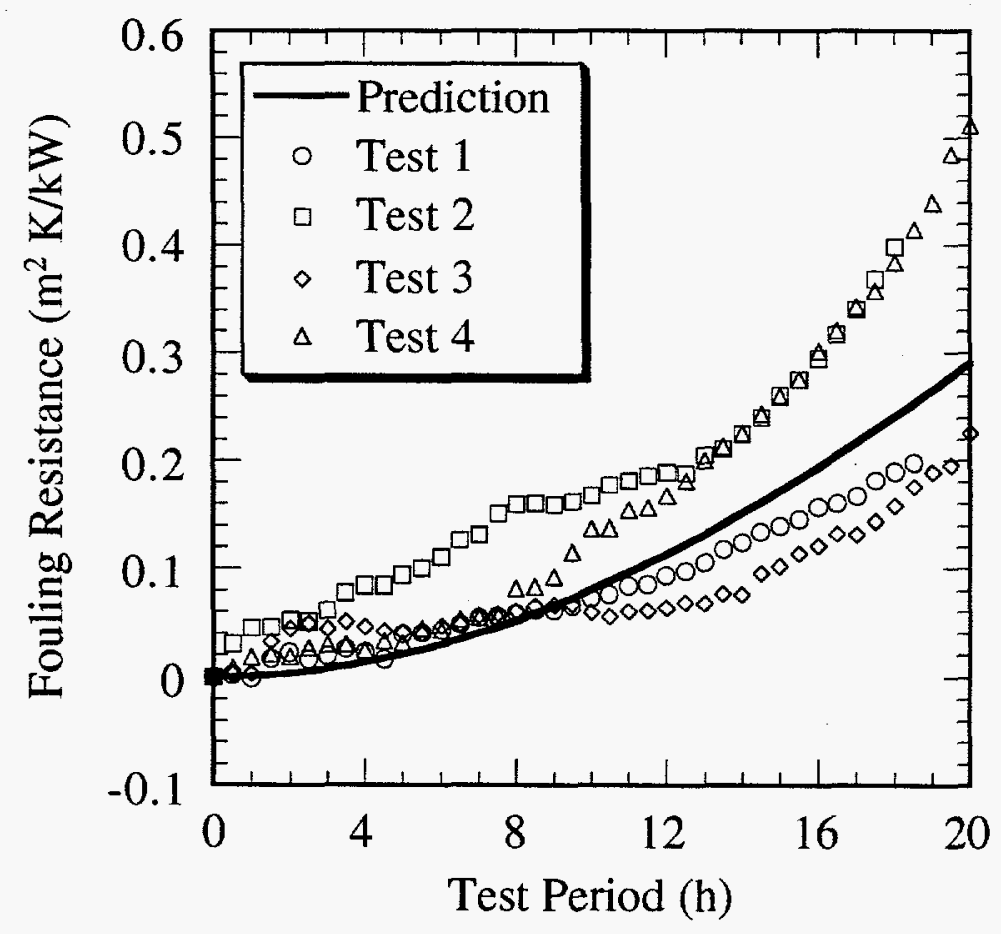

FIGURE 7.5 Fouling Resistance for HTM\#2 for Baseline Conditions and Comparison with Case 1a Prediction 


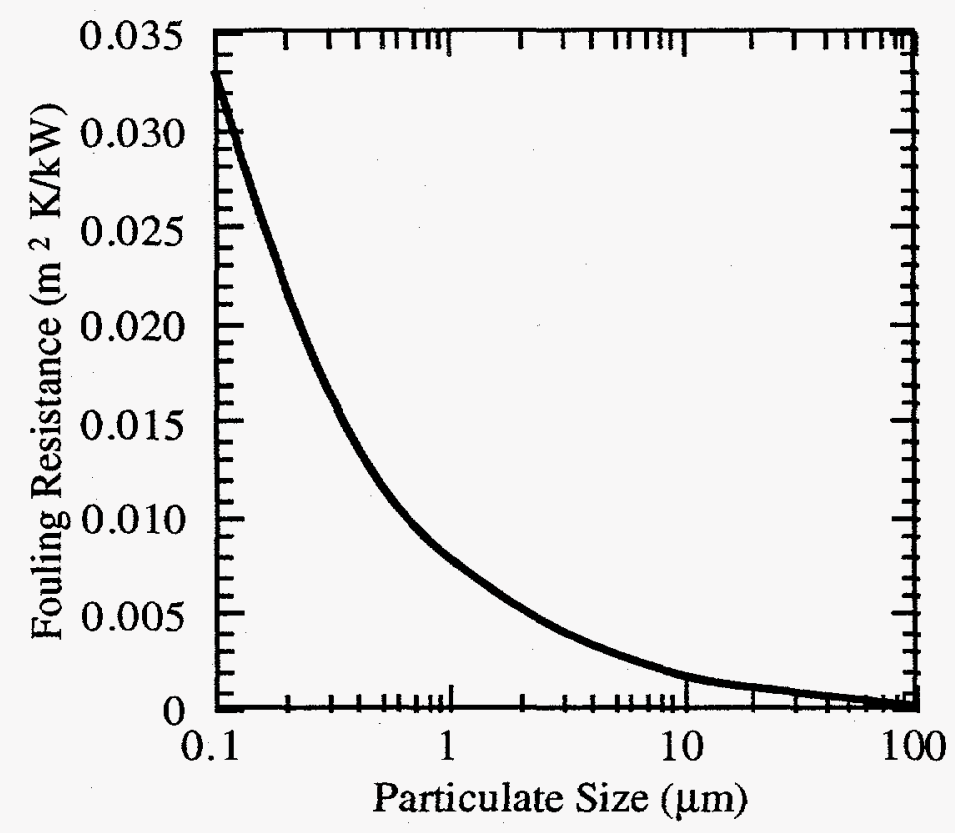

FIGURE 7.6 Effect of Foulant Particulate Size on the Fouling Resistance at $15 \mathrm{~h}$ for Case $1 \mathrm{~b}$

stickiness factor (refer to Chapter 4) is assumed to be 1.0, the controlling step is transport of particulate from bulk to the wall surface. The isothermal HTM\#3 showed negligible fouling deposition; therefore, it was concluded that, if the foulant particulates are formed in the bulk, they are larger in size than $10 \mu \mathrm{m}$. Moreover, the rate of fouling for Case $1 \mathrm{~b}$ is independent of the wall temperature, which is contrary to the experimental observation. On the basis of the two observed results, it was concluded that the fouling deposition is not controlled by the Case $1 \mathrm{~b}$ mechanism; therefore, it is not included in further analysis of the data.

In the Case 3 fouling mechanism, both reactions are assumed to occur at the fluid/wall interface. The precursor formed in the first reaction diffuses in the bulk flow. In order to separate the Case 3 fouling mechanism from that for Case $1 \mathrm{~b}$, precursor formation in the reservoir and in pipe flow was not included in the fouling model. The reaction constants in general are determined on the basis of unit reaction volume; therefore, the reaction rate needs to be expressed in terms of unit wall surface. A common parameter â was used for both reactions, as expressed by Equation 7.5. As for Case 1 and Case 2, the baseline fouling data for HTM\#1 were used to determine the value of 0.00025 for parameter â. This value corrects for the assumption that reaction is taking place at wall temperature in a small volume near the wall surface. Figures 7.7 and 7.8 show a comparison of the experimental fouling resistances and the resistances predicted by Case 3 for the set of baseline test runs for HTM\#1 and HTM\#2. 


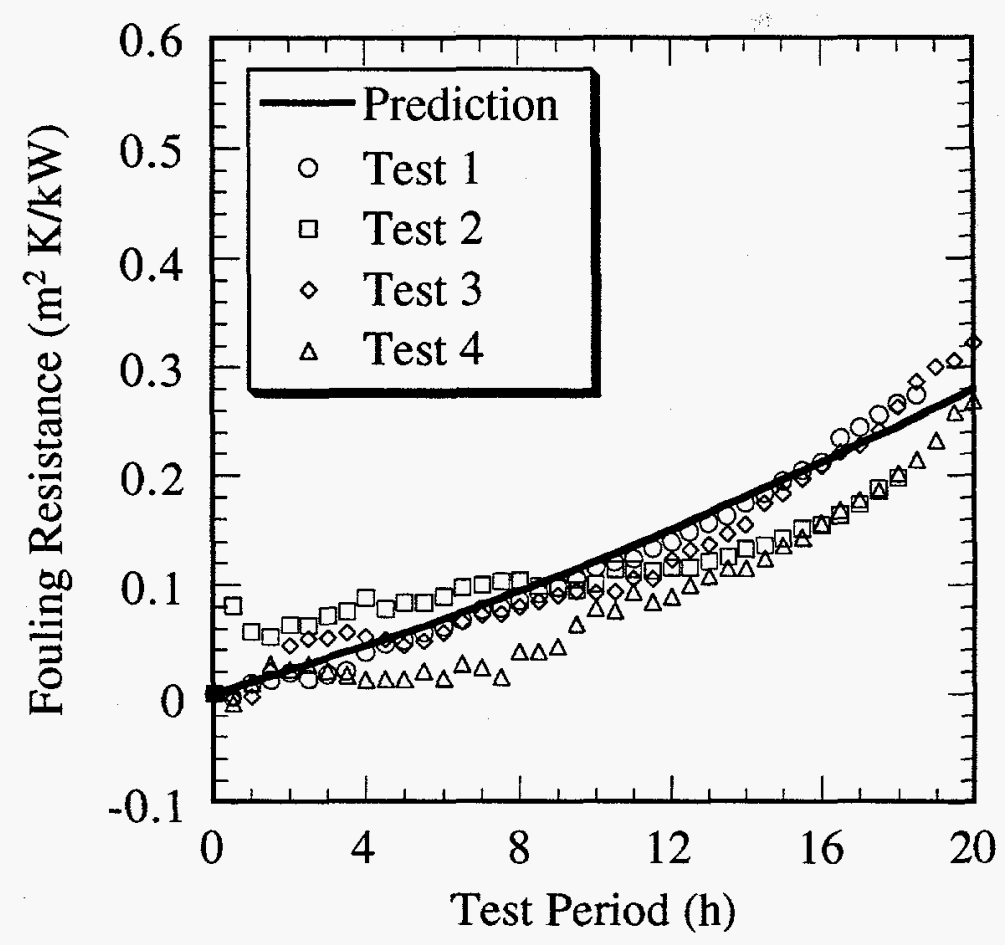

FIGURE 7.7 Fouling Resistance for HTM\#1 for Baseline Conditions and Comparison with the Case 3 Prediction

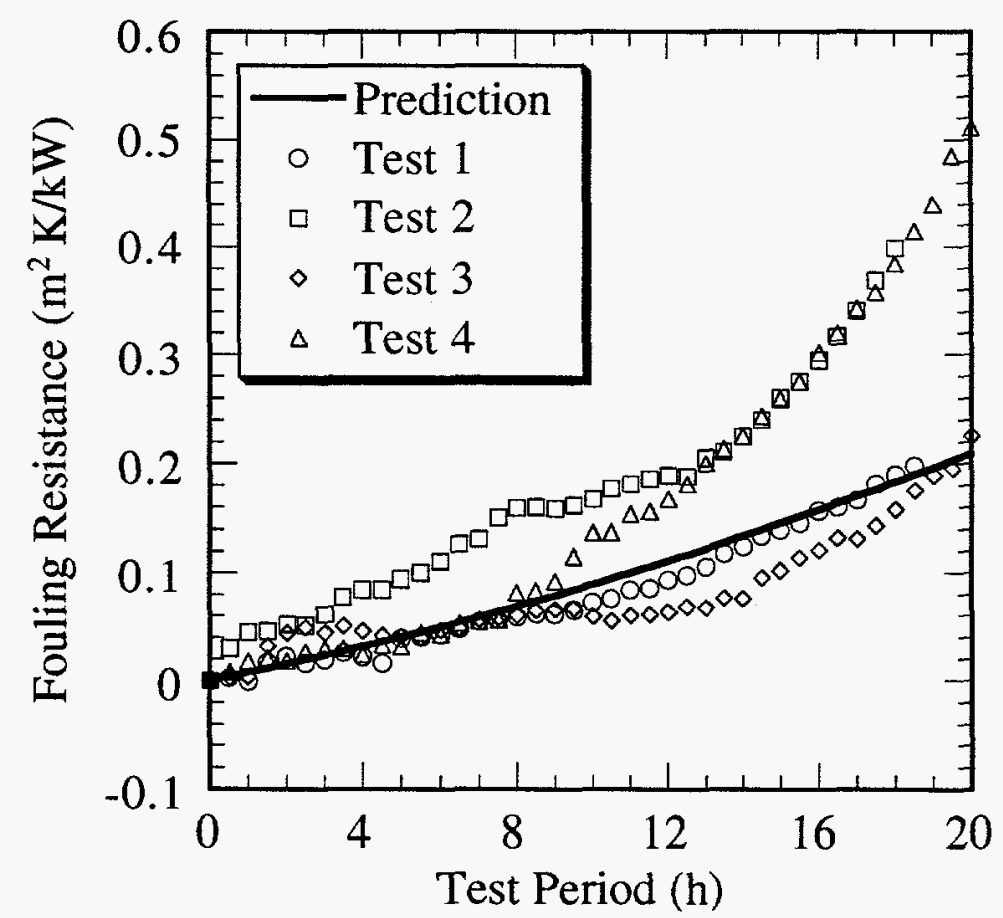

FIGURE 7.8 Fouling Resistance for HTM\#2 for Baseline Conditions and Comparison with the Case 3 Prediction 
The predicted rate of fouling resistance for Case 3 is relatively linear, as compared to the rates for Case 1 and Case 2 predictions. The linear rate of fouling is mainly due to the fact that both reactions are assumed to occur at the interface and not in the bulk flow; therefore, the consumption of reactants and the concentration buildup of precursor is relatively low. Most experimental data show a low initial rate of fouling, followed by a larger rate; therefore, the Case 3 fouling mechanism may not represent the fouling mechanism observed in the present set of experimental conditions.

In summary, the kinetic constants for the two-step reaction were determined by baseline data comprising the batch-reaction data of Russell and the fouling resistance data. Case 2 seems to follow the fouling trend observed experimentally. No fouling deposition was observed for the isothermal HTM, indicating that the Case $1 \mathrm{~b}$ fouling mechanism has a negligibly small contribution to the overall fouling process. The Case 1 a mechanism comes close to the predicted trend of Case 2 and the experimental data. The nearly linear rate of fouling predicted by the Case 3 fouling mechanism does not seem to predict the observed fouling trend. Further confirmation of the model will be examined in Section 7.2, where the effects of varying the physical parameters are analyzed.

\subsection{Effects of Physical Parameters}

Once the kinetic constants are determined, it is possible to analyze the effects of the physical parameters on the rate of fouling as predicted by the three fouling mechanisms and to compare the predicted effects with the experimental data. The major parameters analyzed were

- Flow geometry (tube flow vs. annular flow),

- Wall temperature,

- Concentration of dissolved oxygen, and

- Concentration of indene.

In the present analysis, a limited number of the tests carried out in the Phase I experimental program are included to characterize the effects of physical parameters. The objective is to analyze the relative effects of the physical parameters on the rate of fouling predicted by the three cases of fouling mechanisms and to compare these predicted effects with the experimental results. 


\subsubsection{Flow Geometry}

The ANL experiments were conducted for flow inside a tube section, while the UBC apparatus has an annular flow geometry. The effects of flow-passage geometry on the rate of fouling and the prediction capability of the fouling model were determined by comparing the two sets of fouling data. In the Phase 1 experimental program at $\mathrm{UBC}$, two experimental data points were obtained at two temperatures, as shown in Table 7.3. The conditions for test 1 were close to those used for the baseline experiment at ANL. The kinetic constants determined for the ANL baseline test were kept the same for analyzing the UBC data; however, heat- and mass-transfer correlations were changed for annular flow. The predicted fouling resistances for the three cases are shown in Figures 7.9, 7.10, and 7.11 for Case 1a, Case 2 and Case 3, respectively, along with the UBC and the ANL data.

The fouling resistance at any given time for the ANL data and for the UBC data were comparable up to about $10 \mathrm{~h}$ into the test period; however, after about $10 \mathrm{~h}$, the fouling rate for the UBC data was higher than that for the ANL data. The Case 1a fouling model predicted a significantly high rate of fouling for the UBC test. A closer examination of the model suggests that the ratio of the volume to the heat-transfer area for the HTM at UBC (value equal to 12.4) is higher than that for the HTM at ANL (value equal to 1.9). The ratio is used to combine the diffusion

TABLE 7.3 Average Test Conditions and Physical Parameters for the Baseline Test Runs at UBC

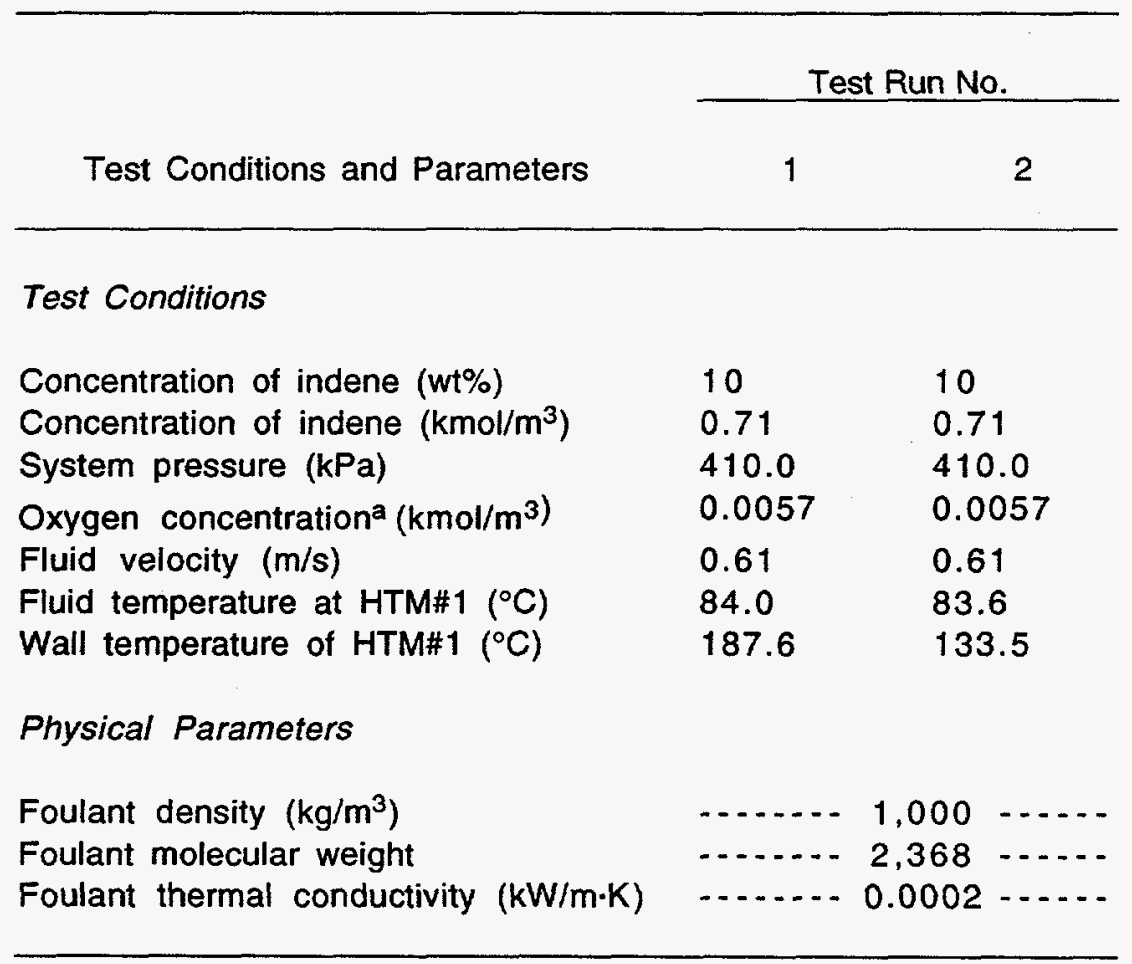

a Oxygen concentration calculated by using the ASTM 3827 standard. 


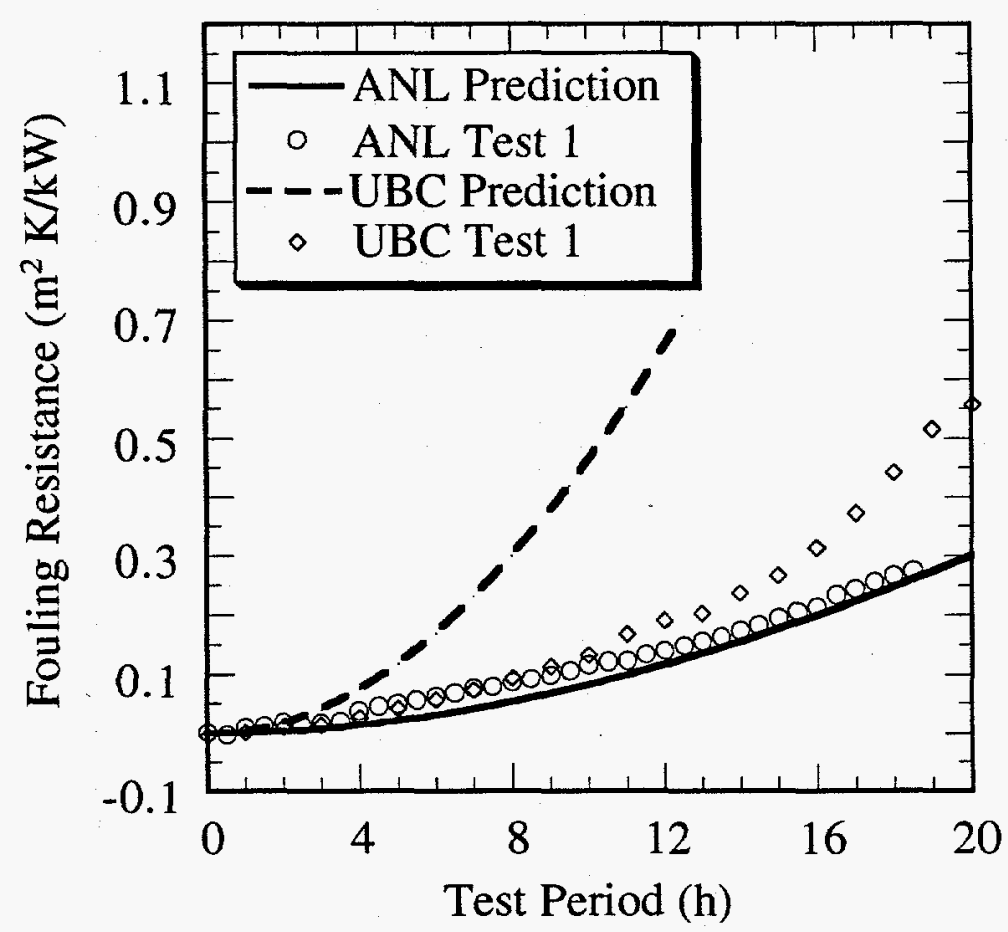

FIGURE 7.9 Comparison of the Fouling Resistance for In-Tube and Annular Flow Monitors and Comparison with the Case 1a Prediction

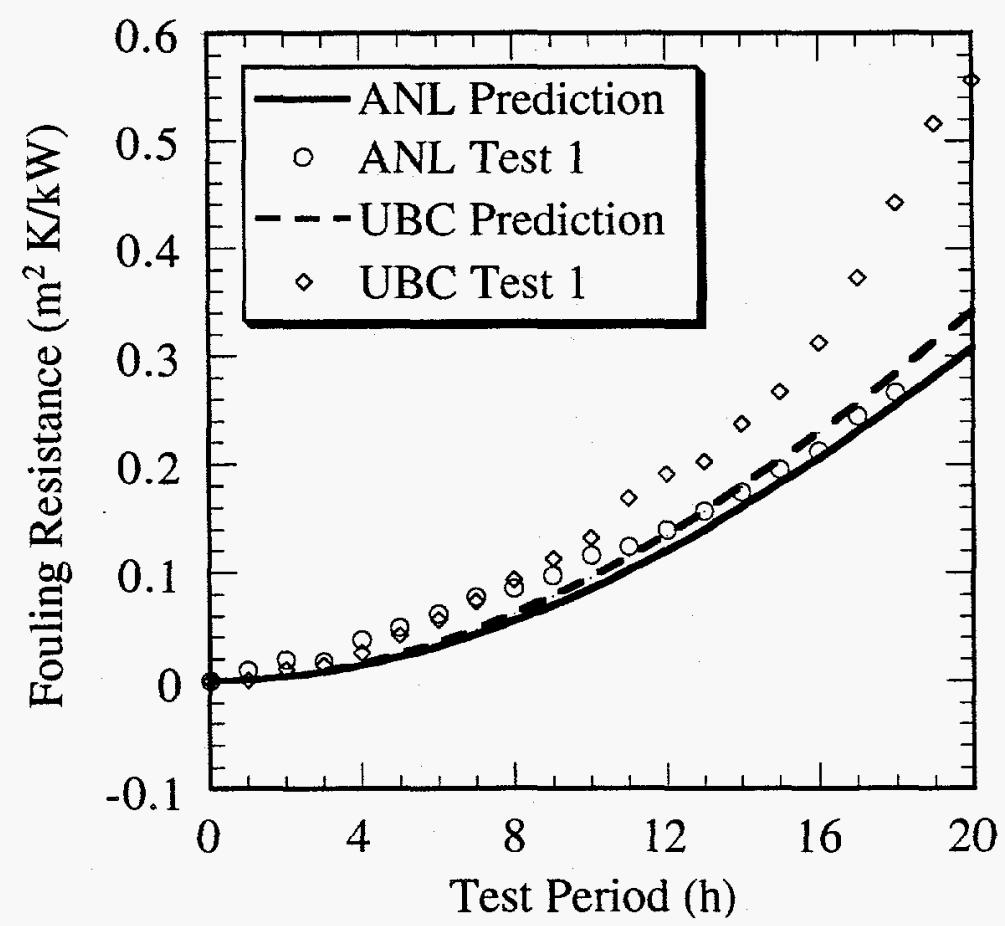

FIGURE 7.10 Comparison of the Fouling Resistance for In-Tube and Annular Flow Monitors and Comparison with the Case 2 Prediction 


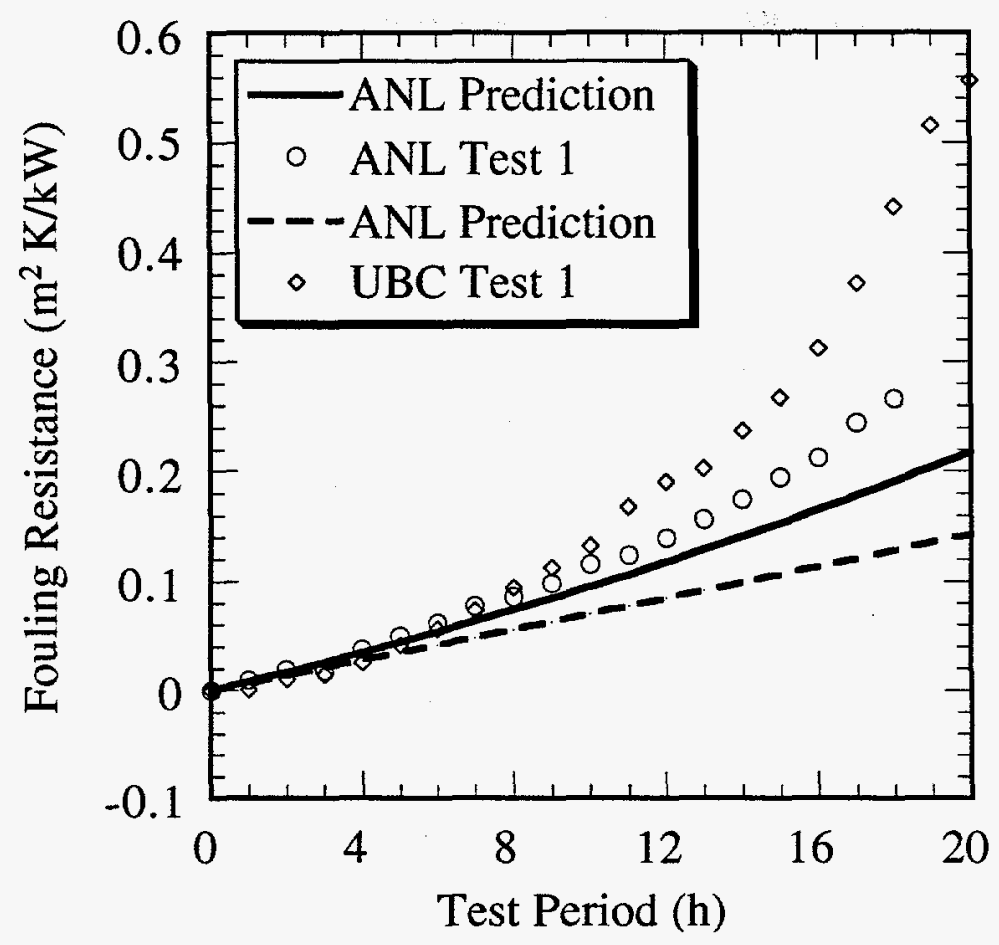

FIGURE 7.11 Comparison of the Fouling Resistance for In-Tube and Annular Flow Monitors and Comparison with the Case 3 Prediction

equation for the precursor with the foulant-formation reaction at the wall surface. The results show that the Case 1a model may not be able to show the effects of flow geometry, including the effects of tube diameter. The fouling data in Figure 7.10 show that the Case 2 model appropriately predicted the fouling trend for both sets of data. A slightly higher fouling rate for the UBC data than for the ANL data is predicted by the Case 2 model. The results in Figure 7.11 show that the Case 3 model incorrectly predicted the fouling trend for the UBC data, as compared with the prediction for the ANL data. The predicted fouling rate for Case 3 is nearly linear; therefore, the experimental data diverge from the predicted values when the test period exceeds $10 \mathrm{~h}$.

Those results suggest that the Case 2 fouling model is able to predict the effects of flow geometry more accurately than the other two fouling model cases. Additional data at different flow conditions are required before a definite conclusion can be drawn. However, the initial results are encouraging, especially for extrapolation of the laboratory data to industrial heat-exchangers, where tube diameter may not be the same as used for experiments.

\subsubsection{Wall Temperature}

The effect of wall temperature was determined by varying the heat flux for the HTMs while keeping the bulk temperature and the flow rate at the baseline conditions. Tables 7.3 and 7.4 show 
TABLE 7.4 Test Conditions for ANL Experiments to Determine the Effects of Interface Temperature

\begin{tabular}{|c|c|c|c|}
\hline \multirow[b]{2}{*}{ Test Conditions } & \multicolumn{3}{|c|}{ Test Run No. } \\
\hline & 1 & 5 & 6 \\
\hline Concentration of indene ( $w t \%$ ) & 10 & 10 & 10 \\
\hline Concentration of indene $\left(\mathrm{kmol} / \mathrm{m}^{3}\right)$ & 0.71 & 0.71 & 0.71 \\
\hline System pressure $(\mathrm{KPa})$ & 417 & 432 & 417 \\
\hline Oxygen concentration ${ }^{\mathrm{a}}\left(\mathrm{kmol} / \mathrm{m}^{3}\right)$ & 0.0057 & 0.0059 & 0.0057 \\
\hline Fluid velocity $(\mathrm{m} / \mathrm{s})$ & 1.04 & 0.99 & 0.97 \\
\hline Fluid temperature at $\mathrm{HTM} \# 1\left({ }^{\circ} \mathrm{C}\right)$ & 82.5 & 82.7 & 82.8 \\
\hline Fluid temperature at $\mathrm{HTM} \# 2\left({ }^{\circ} \mathrm{C}\right)$ & 99.2 & 99.1 & 98.6 \\
\hline Wall temperature of $\mathrm{HTM} \# 1\left({ }^{\circ} \mathrm{C}\right)$ & 191.8 & 182.2 & 199.8 \\
\hline Wall temperature of $\mathrm{HTM} \# 2\left({ }^{\circ} \mathrm{C}\right)$ & 187.7 & 181.6 & 198.7 \\
\hline
\end{tabular}

a Oxygen concentration calculated by using the ASTM 3827 standard.

a summary of the test conditions for the UBC and the ANL experiments, respectively. By using the set of kinetic constants determined from the baseline data, the fouling models for the three cases were used to predict the fouling resistance for a given set of wall temperatures. As shown by the ANL data in Figures 7.12 through 7.17 , there were significant changes in the fouling rate as the wall temperatures were reduced from 197 to $165^{\circ} \mathrm{C}$ for $\mathrm{HTM \# 1}$ and from 195 to $165^{\circ} \mathrm{C}$ for HTM\#2. The predicted fouling resistance for the Case 1a fouling mechanism is compared with the experimental data in Figures 7.12 and 7.13 for HTM\#1 and HTM\#2, respectively. The predicted effect of the wall temperature was less significant than that observed experimentally for both HTM\#1 and HTM\#2. Precursor formation occurs in the bulk - mostly in the reservoir and the foulant formation reaction occurs at the wall surface. Therefore, the predicted effect of precursor concentration at the wall surface and wall temperature combined is not as significant as was seen in the experimental data.

Figures 7.14 and 7.15 show a comparison of the Case 2 fouling mechanisms for HTM\#1 and HTM\#2, respectively. As occurred for the Case 1a comparison, the predicted rate of fouling was less sensitive to the wall temperature than was the experimental data. The foulant formation reaction is assumed to occur in the thermal-boundary layer. Therefore, the effects of the precursor diffusion and the local rate of reaction in the thermal-boundary layer are reflected in the predicted rate of fouling. However, the overall comparison is similar to that for Case 1a as shown in Figures 7.12 and 7.13 .

In Case 3, both reactions are assumed to occur at the wall surface; therefore, the predicted rate of fouling is expected to be more sensitive to the wall temperature for Case 3 than for the other 


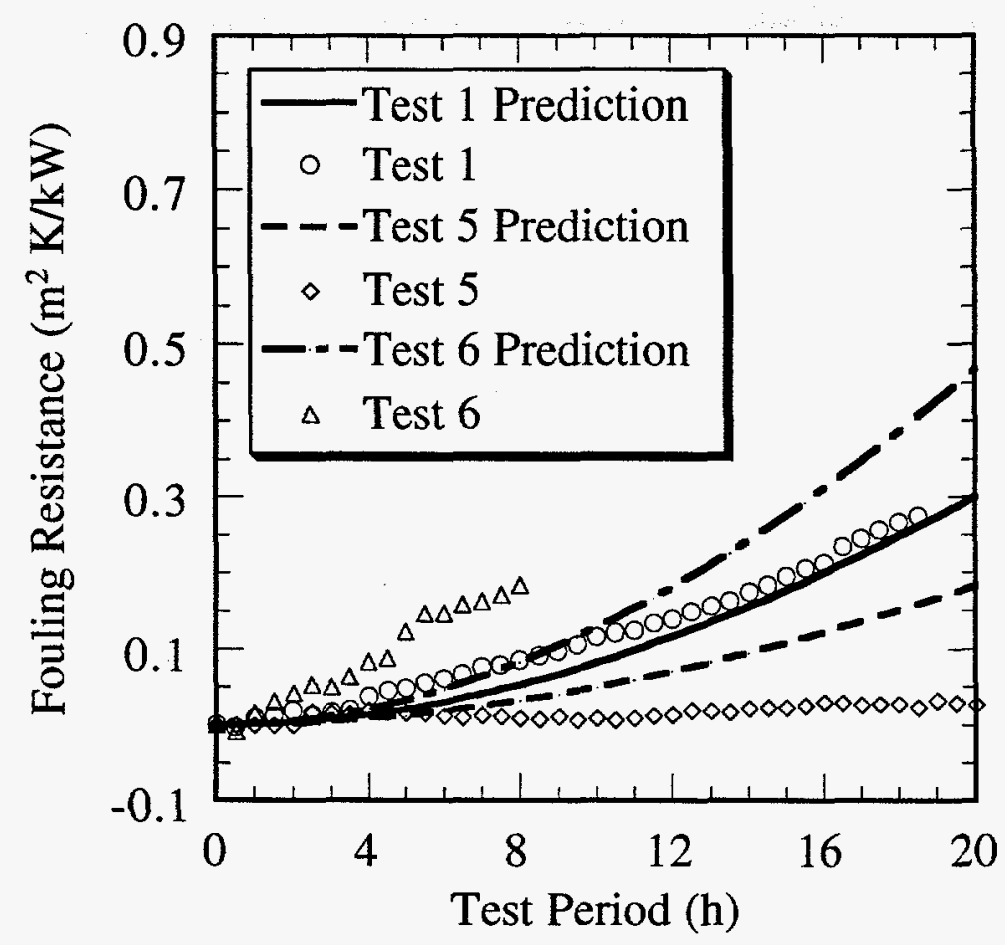

FIGURE 7.12 Effect of Interface Temperature for HTM\#1 in ANL Experiments and Comparison with the Case 1a Prediction

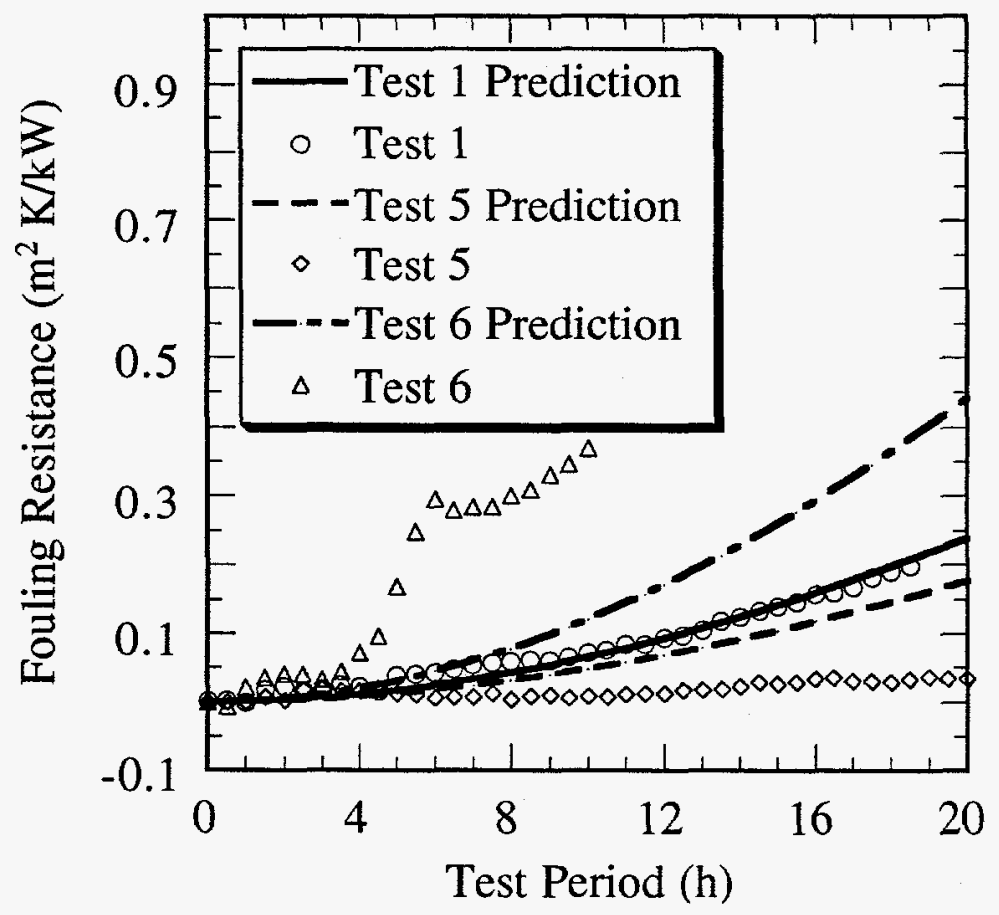

FIGURE 7.13 Effect of Interface Temperature for HTM\#2 in ANL Experiments and Comparison with the Case 1a Prediction 


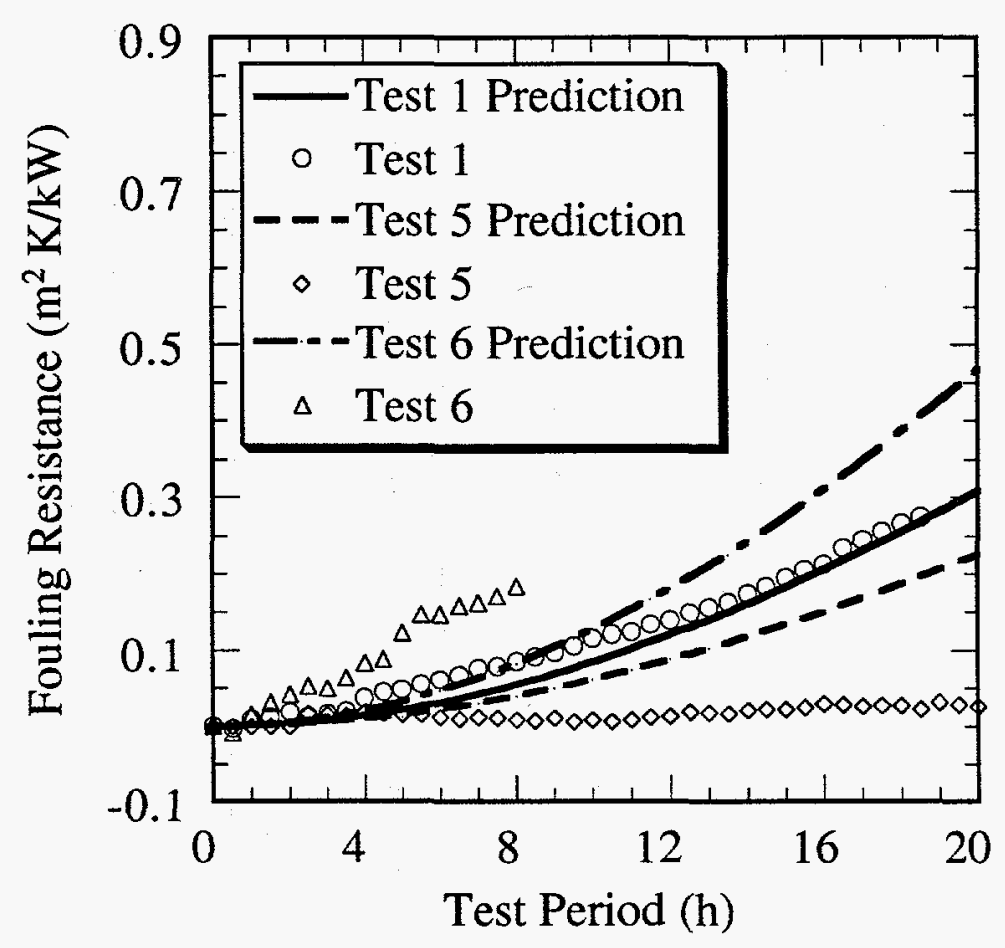

FIGURE 7.14 Effect of Interface Temperature for HTM\#1 in ANL Experiments and Comparison with the Case 2 Prediction

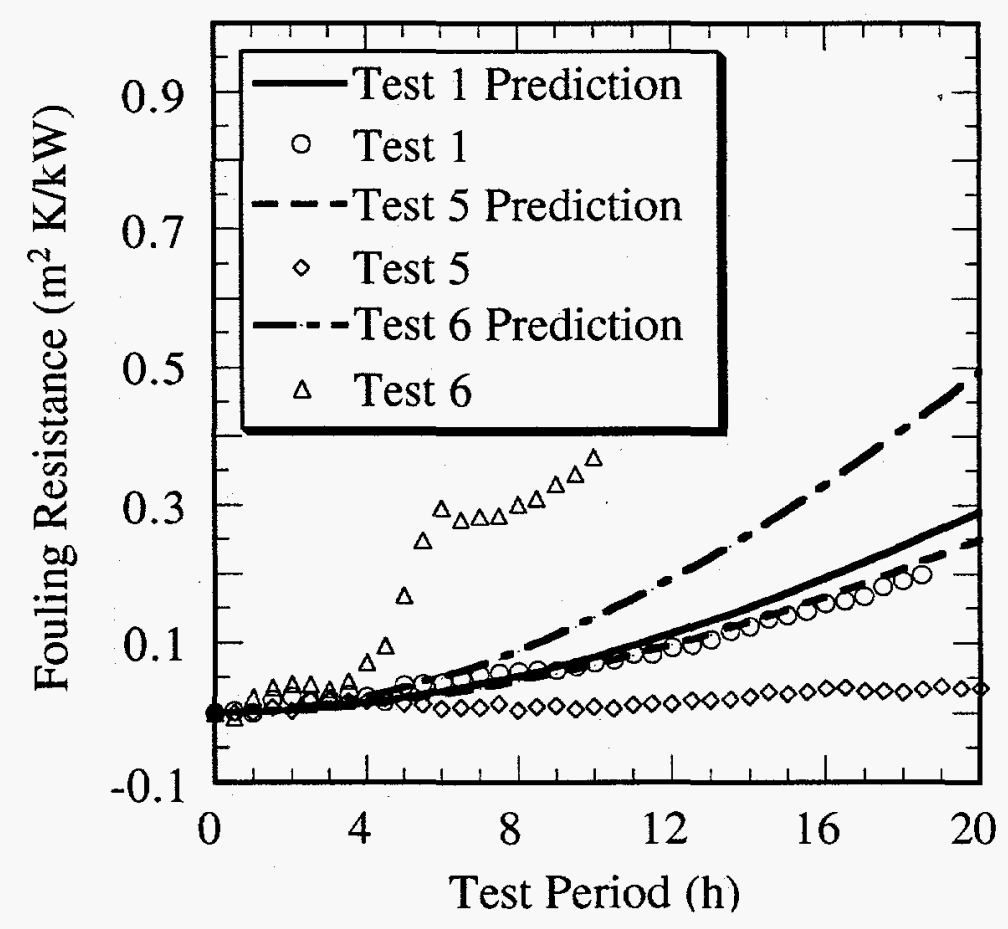

FIGURE 7.15 Effect of Interface Temperature for HTM\#2 in ANL Experiments and Comparison with the Case 2 Prediction 


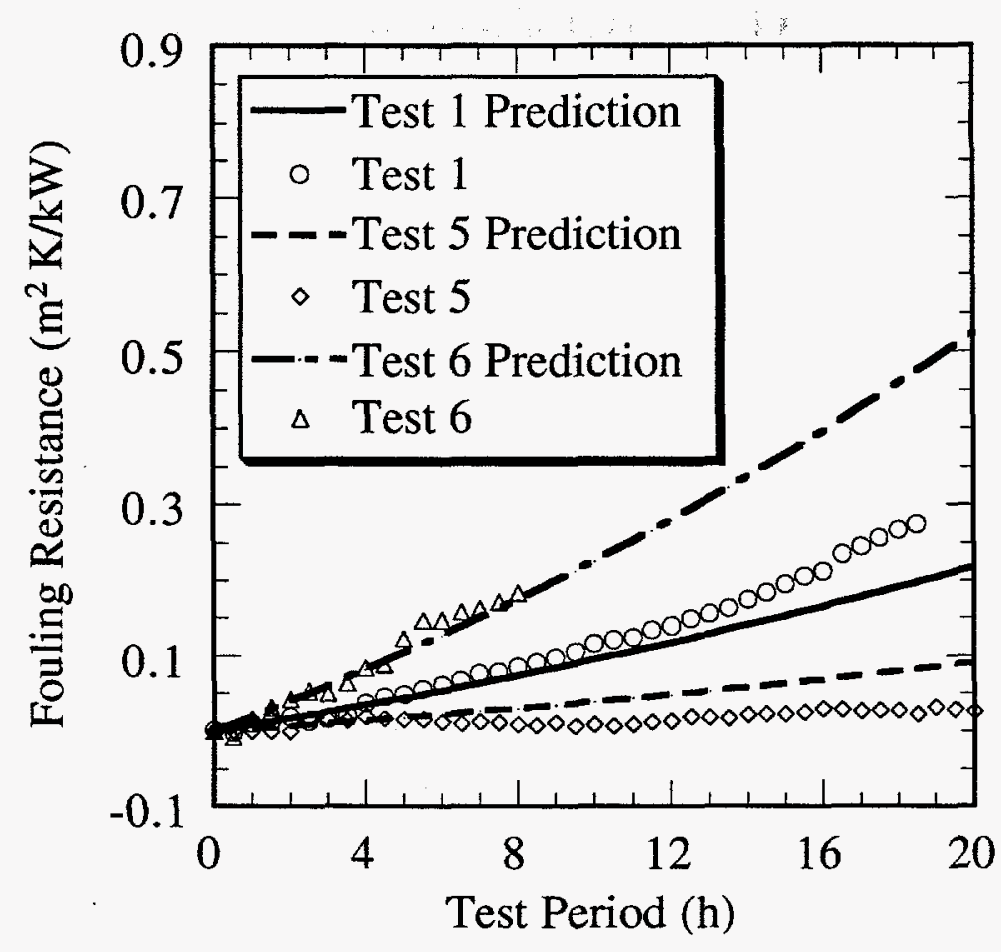

FIGURE 7.16 Effect of Interface Temperature for HTM\# 1 in ANL Experiments and Comparison with the Case 3 Prediction

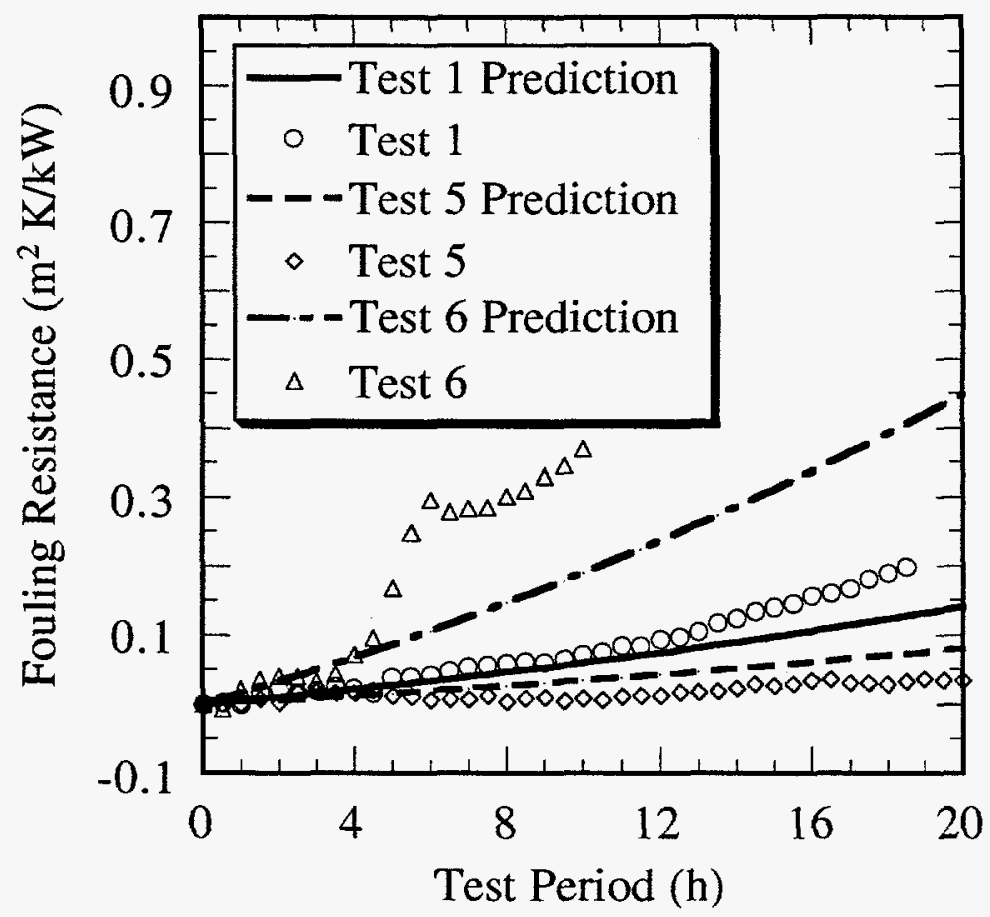

FIGURE 7.17 Effect of Interface Temperature for HTM\#2 in ANL Experiments and Comparison with the Case 3 Prediction 
two cases. The results in Figures 7.16 and 7.17 show that the predicted fouling resistance agrees with the experimental data better for Case 3 than for the other two cases. Note that the predicted rate of fouling for Case 3 is nearly linear, showing no initial period of slow fouling deposition.

UBC conducted two experiments at wall temperatures of $188^{\circ}$ (Test 1 ) and $133^{\circ} \mathrm{C}$ (Test 2). The experimental results and predictions for the three fouling cases are shown in Figures 7.18-7.20. The Case 1a prediction was higher than the experimental data for both temperatures, but the fouling trend was predicted with reasonable accuracy. The Case 2 fouling model was able to predict the effect of wall temperature more accurately than the other two models; the better agreement obtained for the UBC data as compared with that for the ANL data will require verification through additional experimental work at comparable conditions. Figure 7.20 shows a comparison of predicted rate and experimental results for the Case 3 fouling model. The predicted fouling rate is lower than the experimental data for both test runs. The predicted rate of fouling was negligibly small for the wall temperature of $133^{\circ} \mathrm{C}$, indicating that no significant fouling buildup would occur for an extended period of time. However, the experimental results showed a slow growth of the fouling resistance.

In conclusion, the predicted effects of wall temperature were inconclusive for the ANL data; however, the Case 2 fouling model predicted the UBC data with reasonable accuracy.

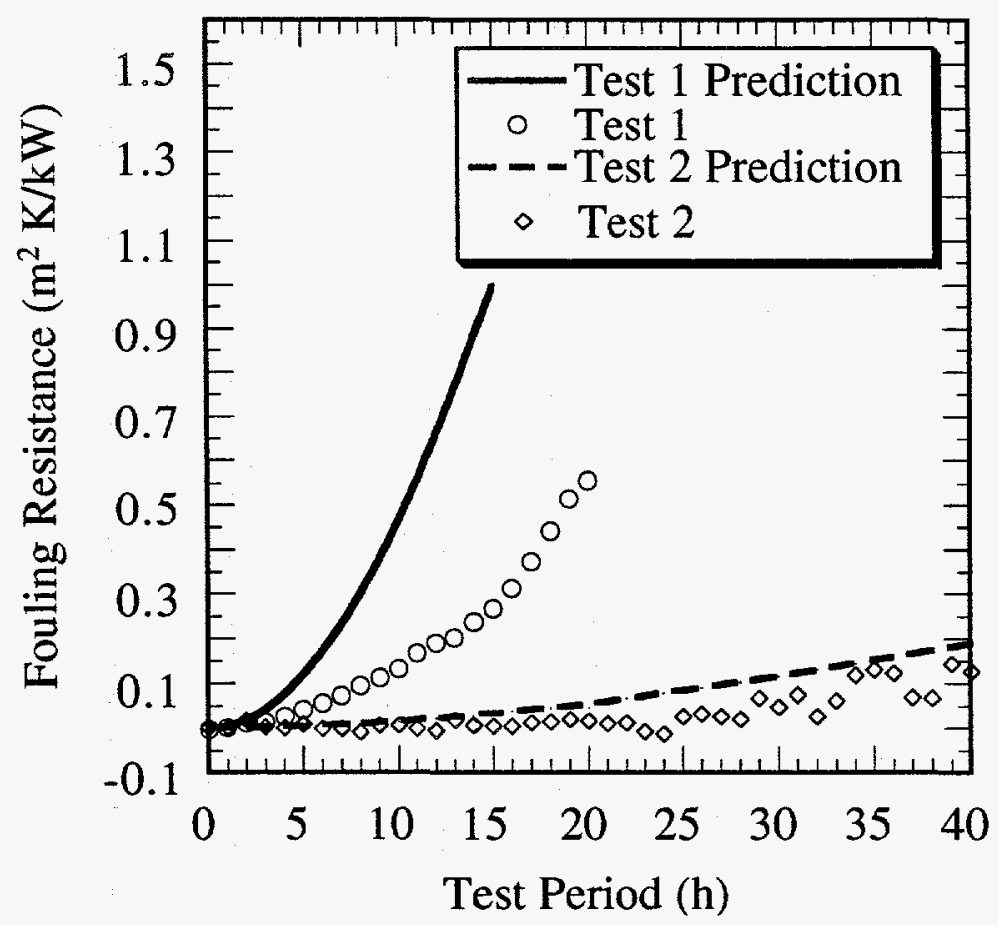

FIGURE 7.18 Effect of Interface Temperature for UBC

Experiments and Comparison with the Case 1a Prediction 


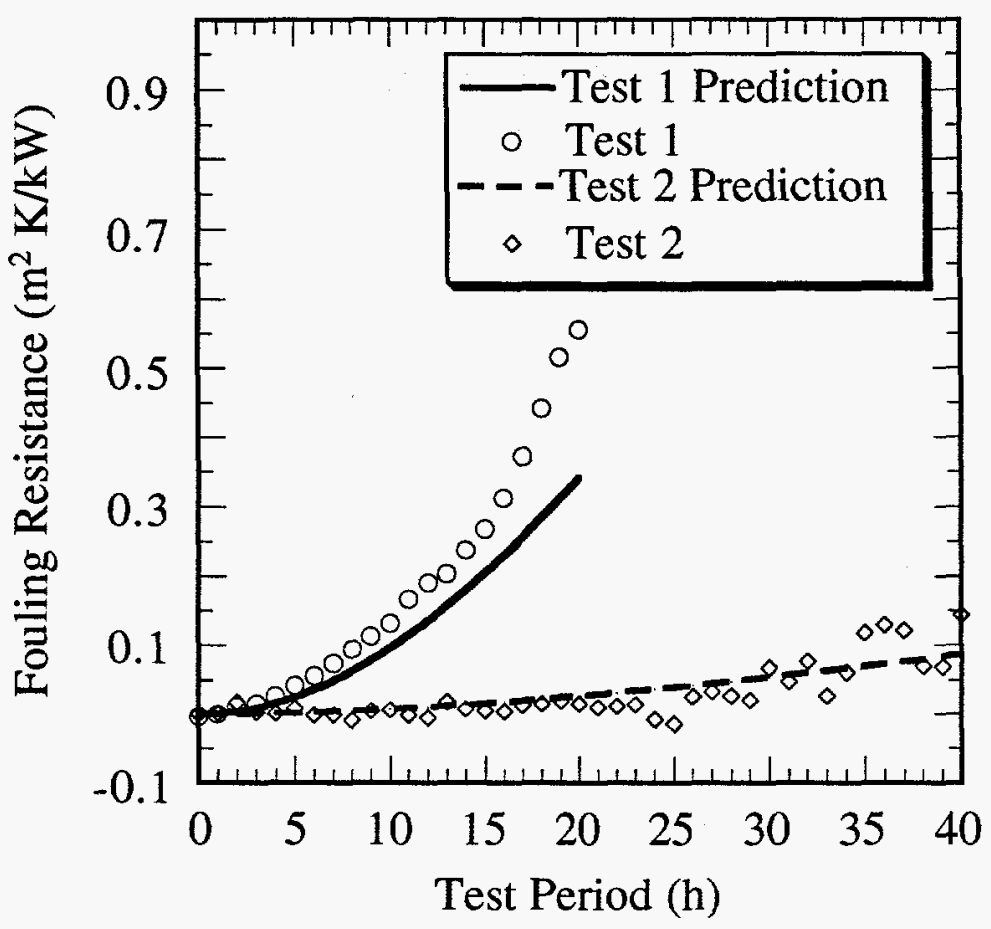

FIGURE 7.19 Effect of Interface Temperature for UBC Experiments and Comparison with the Case 2 Prediction

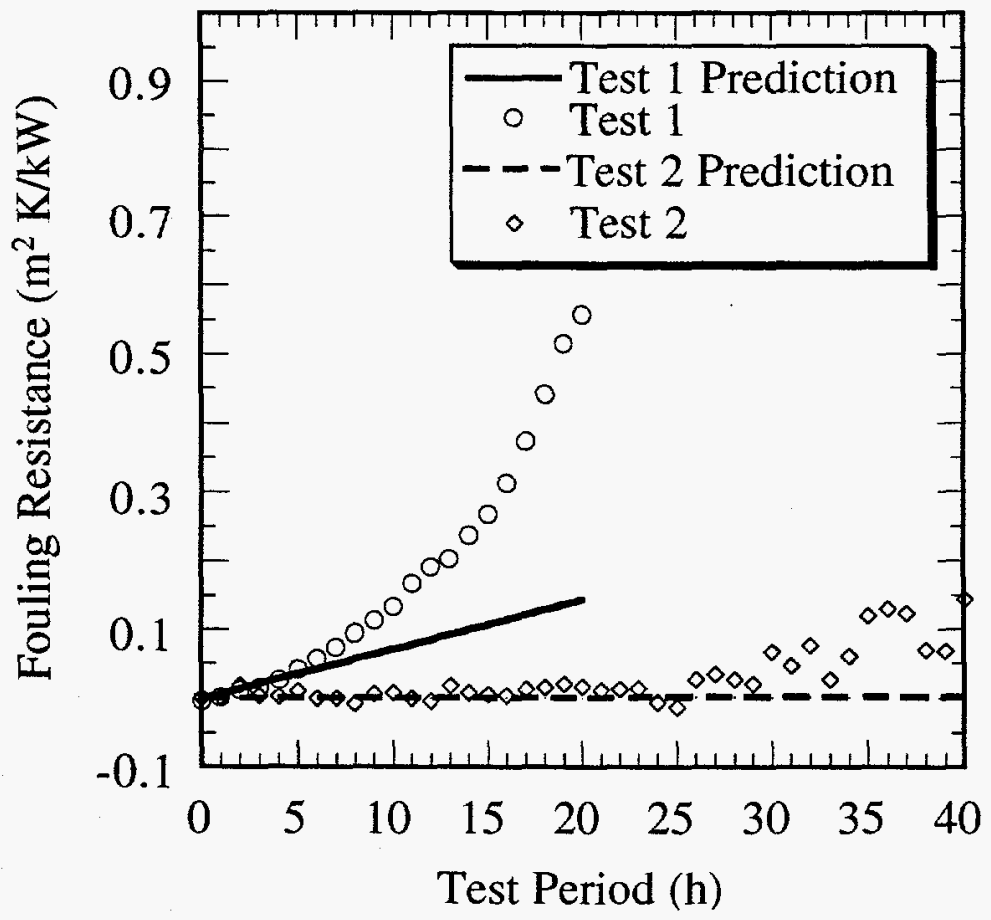

FIGURE 7.20 Effect of Interface Temperature for UBC Experiments and Comparison with the Case 3 Prediction 


\subsubsection{Reactant Concentration}

According to the kinetic model, the effects of concentration of indene and dissolved oxygen are reflected by the reaction order ( 1.5 for indene and 0.5 for oxygen as per Equation 7.1 ). However, the overall rate of fouling deposition depends on the combined effects of the diffusion of chemical species, the temperature gradient, and the foulant formation reaction in the thermalboundary layer or at the wall surface. Table 7.5 shows test conditions used to determine the effects of reactant concentration. The experimental data shown in Figures 7.21 through 7.26 show the effects of dissolved oxygen at two pressures, $417 \mathrm{kPa}$ (Test 1) and $318 \mathrm{kPa}$ (Test 7). The effects of pressure on the rate of fouling for these two test runs were relatively small. The lower fouling resistance for HTM\#1, shown in Figure 7.21, can be attributed to the lower wall temperature $\left(188.2^{\circ} \mathrm{C}\right.$ for $318 \mathrm{kPa}$ vs. $191.8^{\circ} \mathrm{C}$ for $\left.417 \mathrm{kPa}\right)$ rather than to the lower system pressure. The HTM\#2 data (wall temperatures of 187.7 and $188^{\circ} \mathrm{C}$ ) show that the fouling resistance was slightly higher for Test 7 than for Test 1 , possibly because of a slightly higher fluid flow for the $417-\mathrm{kPa}$ test run $(2.94 \mathrm{~L} / \mathrm{m})$ than for the $318-\mathrm{kPa}$ test run $(2.76 \mathrm{~L} / \mathrm{m})$.

All three fouling models predicted relatively small effects of oxygen concentration for the two system pressures of the 318 and $417 \mathrm{kPa}$ used in the present study. For HTM\#1, the predicted fouling resistance was lower for the $318-\mathrm{kPa}$ test run than for the $417-\mathrm{kPa}$ test run, which is in agreement with the experimental data. The Case 3 fouling model showed a better agreement than the other two models, which could be attributed to the fact that the Case 3 model shows stronger effects of the wall temperature. The fouling resistances predicted by all three fouling models for HTM\#2 were comparable, as seen in Figures 7.22, 7.24, and 7.26.

The effects of indene concentration are shown in Figures 7.27 through 7.32 . The predicted results for the Case 1a and Case 2 models show good agreement with the experimental

TABLE 7.5 Test Conditions for ANL Experiments to Determine the Effects of Reactant Concentration

\begin{tabular}{|c|c|c|c|}
\hline \multirow[b]{2}{*}{ Test Conditions } & \multicolumn{3}{|c|}{ Test Run No. } \\
\hline & 1 & 7 & 8 \\
\hline Concentration of indene (wt \%) & 10 & 10 & 5 \\
\hline Concentration of indene $\left(\mathrm{kmol} / \mathrm{m}^{3}\right)$ & 0.71 & 0.71 & 0.305 \\
\hline System pressure (kPa) & 417 & 318 & 432 \\
\hline Oxygen concentration ${ }^{a}\left(\mathrm{kmol} / \mathrm{m}^{3}\right)$ & 0.0057 & 0.0044 & 0.0059 \\
\hline Fluid velocity $(\mathrm{m} / \mathrm{s})$ & 1.04 & 0.98 & 0.95 \\
\hline Fluid temperature at $\mathrm{HTM} \# 1\left({ }^{\circ} \mathrm{C}\right)$ & 82.5 & 82.9 & 82.7 \\
\hline Fluid temperature at $\mathrm{HTM} \# 2\left({ }^{\circ} \mathrm{C}\right)$ & 99.2 & 98.9 & 99.1 \\
\hline Wall temperature of $\mathrm{HTM} \# 1\left({ }^{\circ} \mathrm{C}\right)$ & 191.8 & 189.2 & 196.2 \\
\hline Wall temperature of $\mathrm{HTM} \# 2\left({ }^{\circ} \mathrm{C}\right)$ & 187.7 & 188.0 & 194.6 \\
\hline
\end{tabular}

a Oxygen concentration calculated by using the ASTM 3827 standard. 
data for both HTMs. In Case 1a and Case 2, the precursor-forming reaction is assumed to take place in bulk (particularly in the reservoir), as compared to Case 3, for which the reaction is assumed to take place at the wall surface of the HTMs. Therefore, the Case 3 model predicted a relatively smaller effect of the indene concentration on the rate of fouling than was observed experimentally.

In conclusion, the effect of oxygen concentration for two system pressures of 318 and $417 \mathrm{kPa}$ was relatively small for both the experimental data and the predicted results. In future experiments, the oxygen concentration needs to be varied over a wide range, in order to observe the effect in a significant manner. The effect of indene concentration on the rate of fouling can be determined by considering the first reaction taking place in the bulk, as is done in the Case 1a and Case 2 fouling models.

\subsubsection{Fluid Bulk Temperature}

The effects of bulk temperature on the rate of fouling are shown in Figures 7.33 through 7.38 for the ANL in-tube flow monitors. These figures also show the predicted fouling resistance for Cases 1a, 2, and 3. The interfacial temperature and fluid velocity were maintained nearly constant for the three tests as shown in Table 7.6; therefore, the observed rate of fouling showed the effects of precursor generation at the bulk temperature. Both the Case 1a and Case 2 models predicted the effects of the bulk temperature with reasonable accuracy; however, the Case 3 model failed to predict the trend of fouling as a function of bulk temperature. The predicted rate of fouling was closer to the experimental data for the Case 2 model prediction than for the Case 1a model. The bulk reaction is neglected in the Case 3 model; as a result, the predicted rate of fouling stayed nearly the same for the three bulk temperatures. The predicted results and the experimental data clearly show that the bulk temperature must be considered along with the interfacial temperature in analyzing the effects of temperature on the rate of fouling for a closed-flow-loop apparatus. This observation is quite important in the application of experimental data obtained with a closed-flow-loop apparatus to industrial processes of once-through flow systems. The level of uncertainty associated with the commonly used method of correlating the fouling rate with the interfacial temperature and calculating the corresponding activation energy is unknown. 


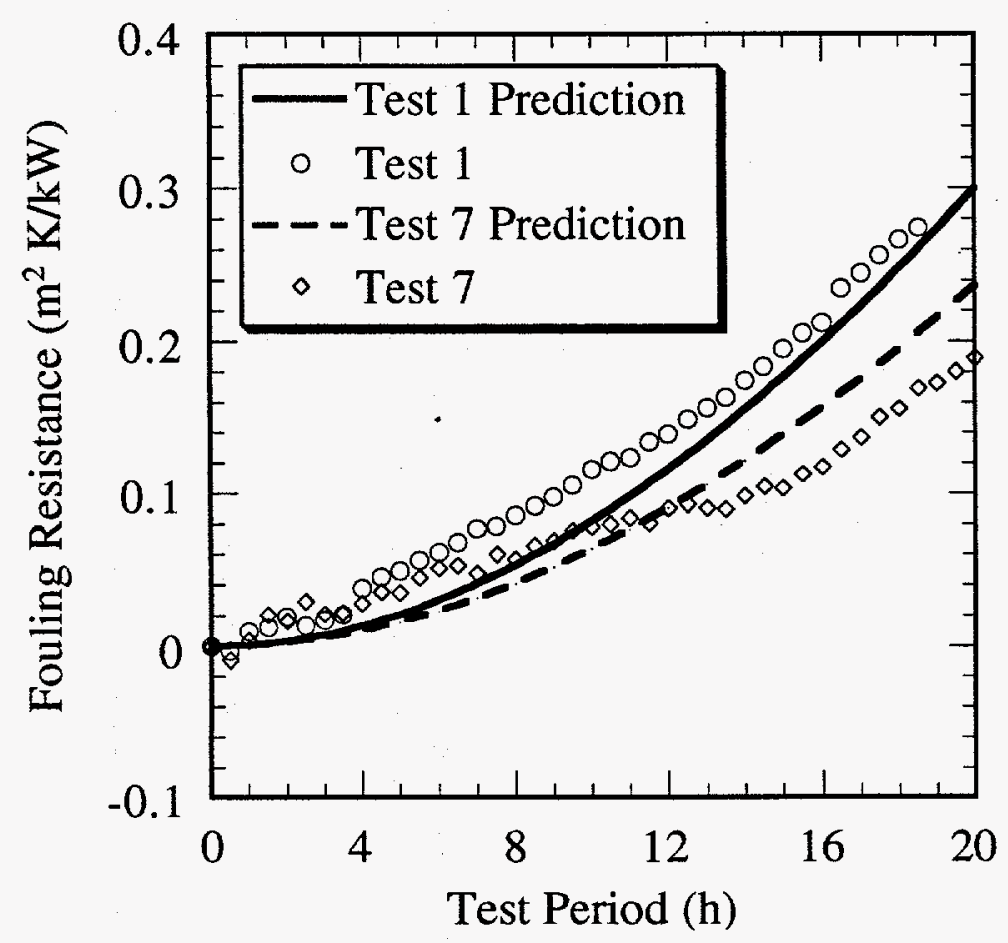

FIGURE 7.21 Effect of Oxygen Concentration for HTM\#1 in ANL Experiments and Comparison with the Case 1a Prediction

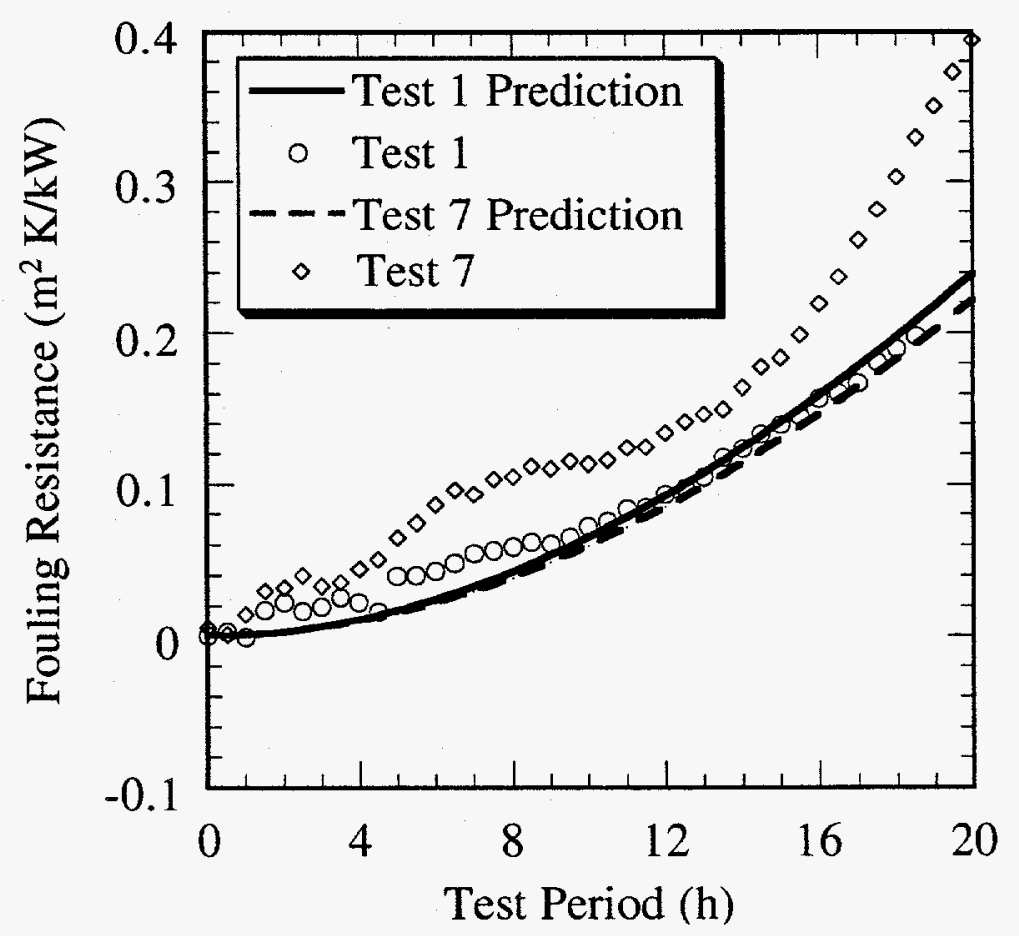

FIGURE 7.22 Effect of Oxygen Concentration for HTM\#2 in ANL Experiments and Comparison with the Case 1a Prediction 


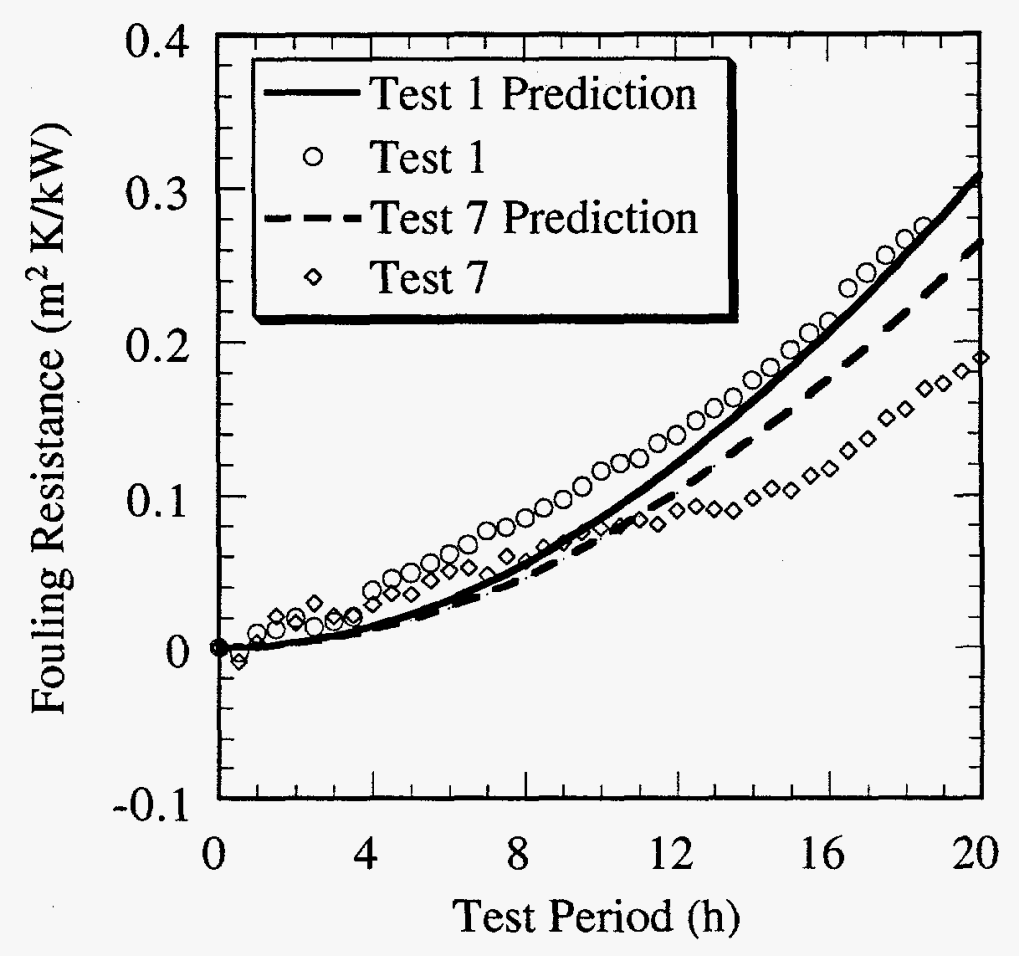

FIGURE 7.23 Effect of Oxygen Concentration for HTM\#1 in ANL Experiments and Comparison with the Case 2 Prediction

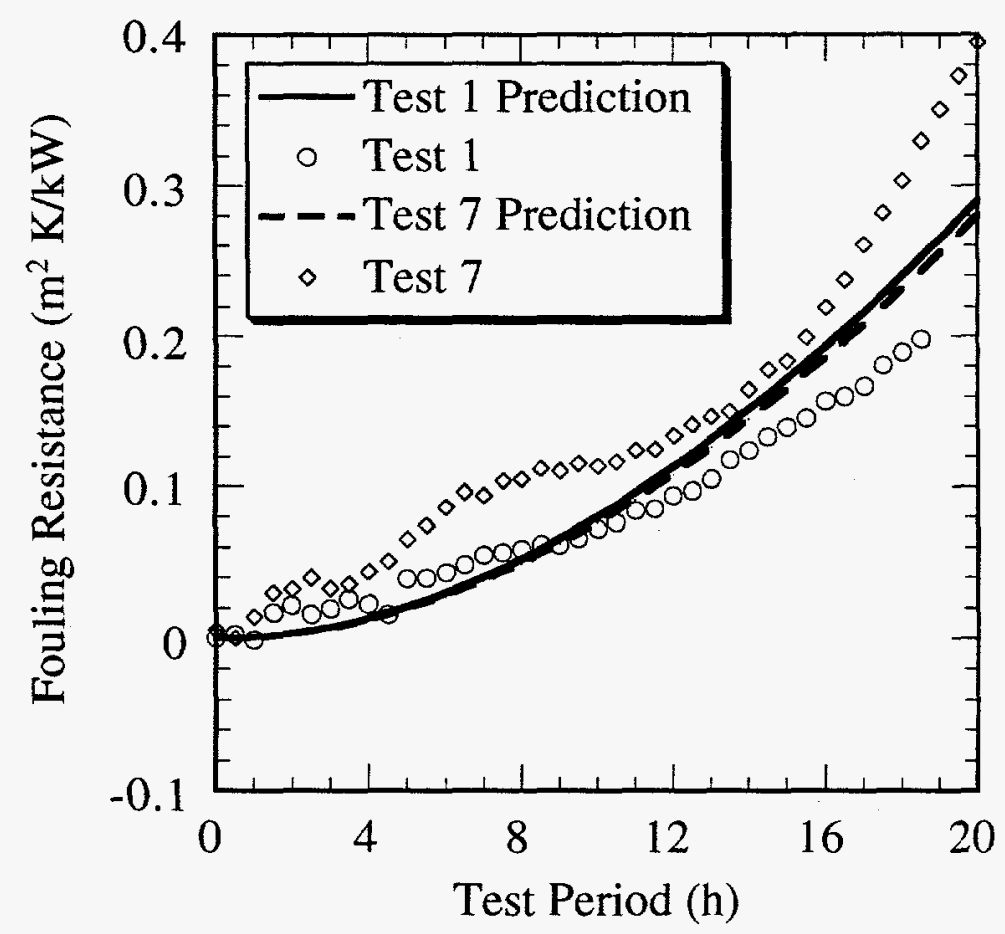

FIGURE 7.24 Effect of Oxygen Concentration for HTM\#2 in ANL Experiments and Comparison with the Case 2 Prediction 


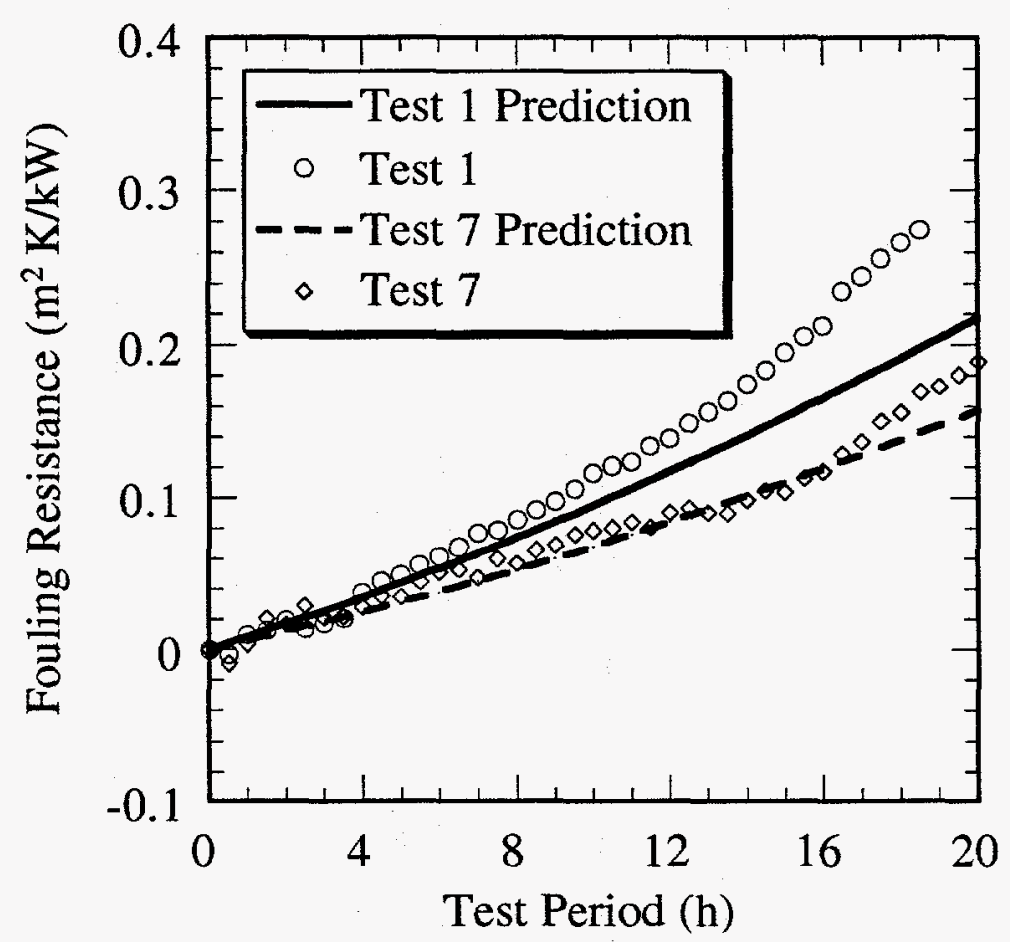

FIGURE 7.25 Effect of Oxygen Concentration for HTM\#1 in ANL Experiments and Comparison with the Case 3 Prediction

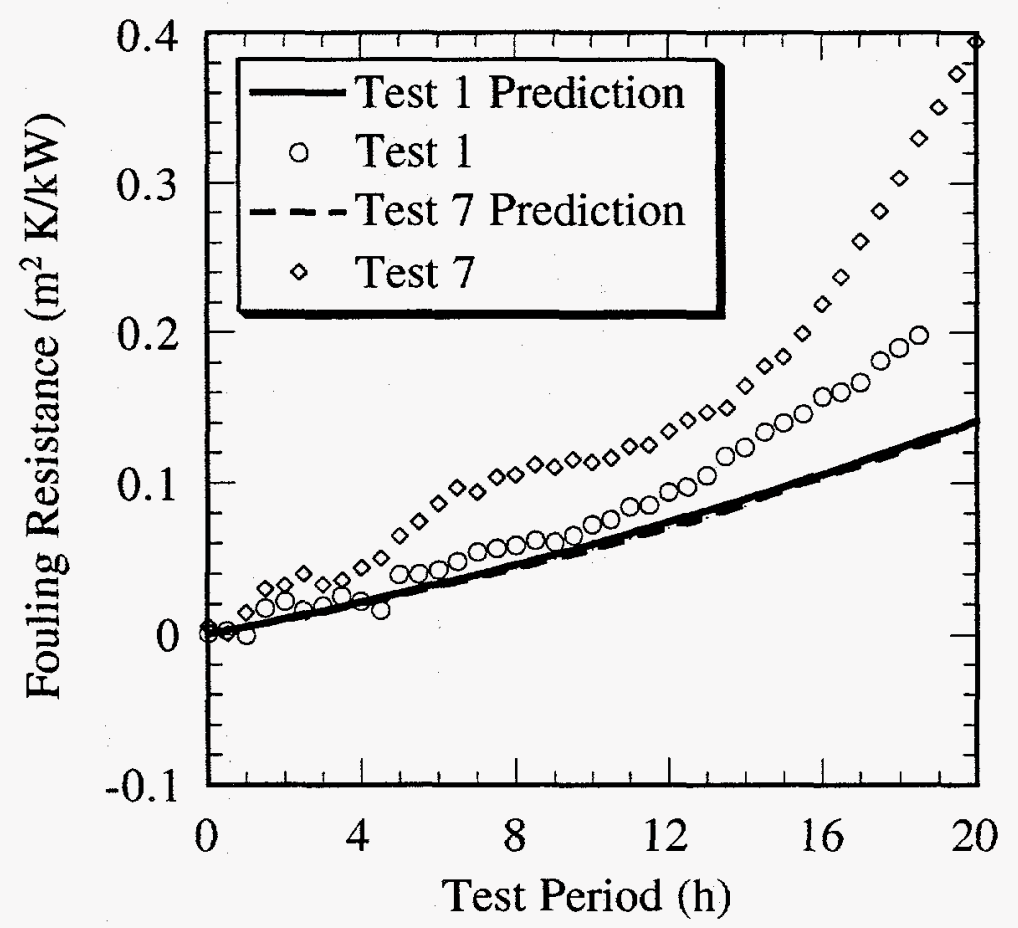

FIGURE 7.26 Effect of Oxygen Concentration for HTM\#2 in ANL Experiments and Comparison with the Case 3 Prediction 


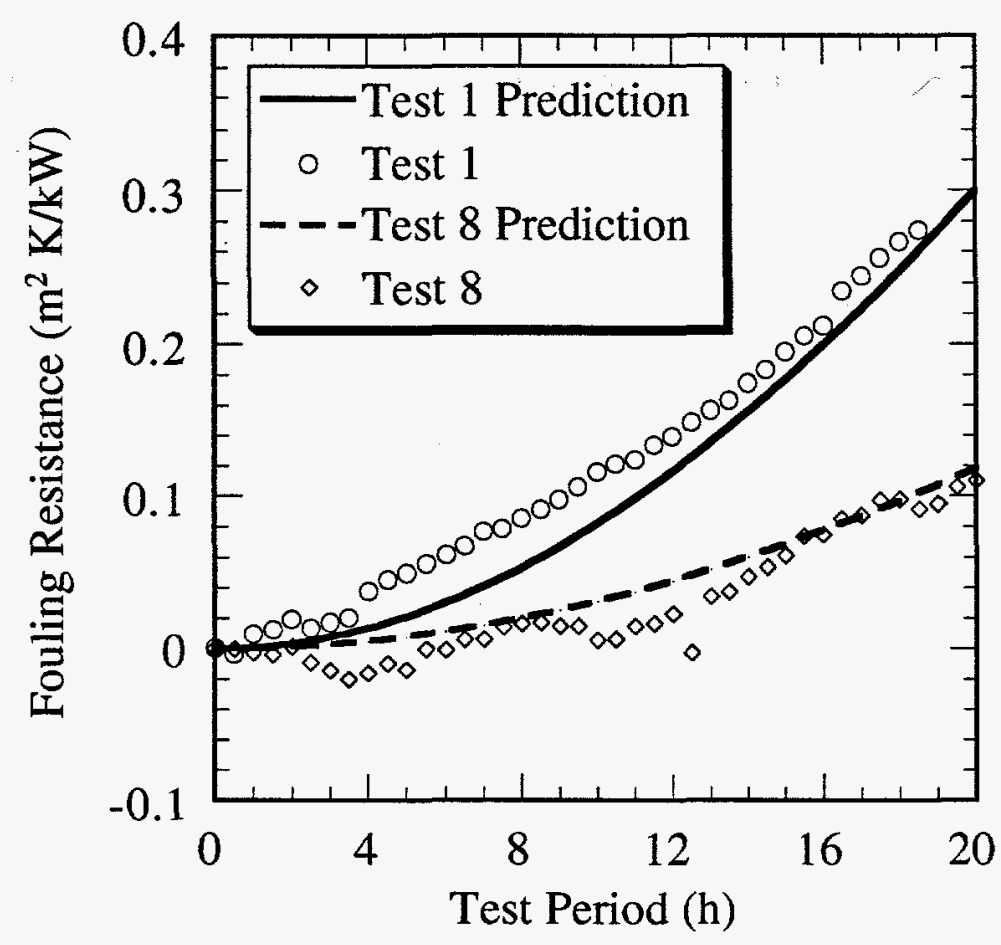

FIGURE 7.27 Effect of Indene Concentration for HTM\#1 in ANL Experiments and Comparison with the Case 1a Prediction

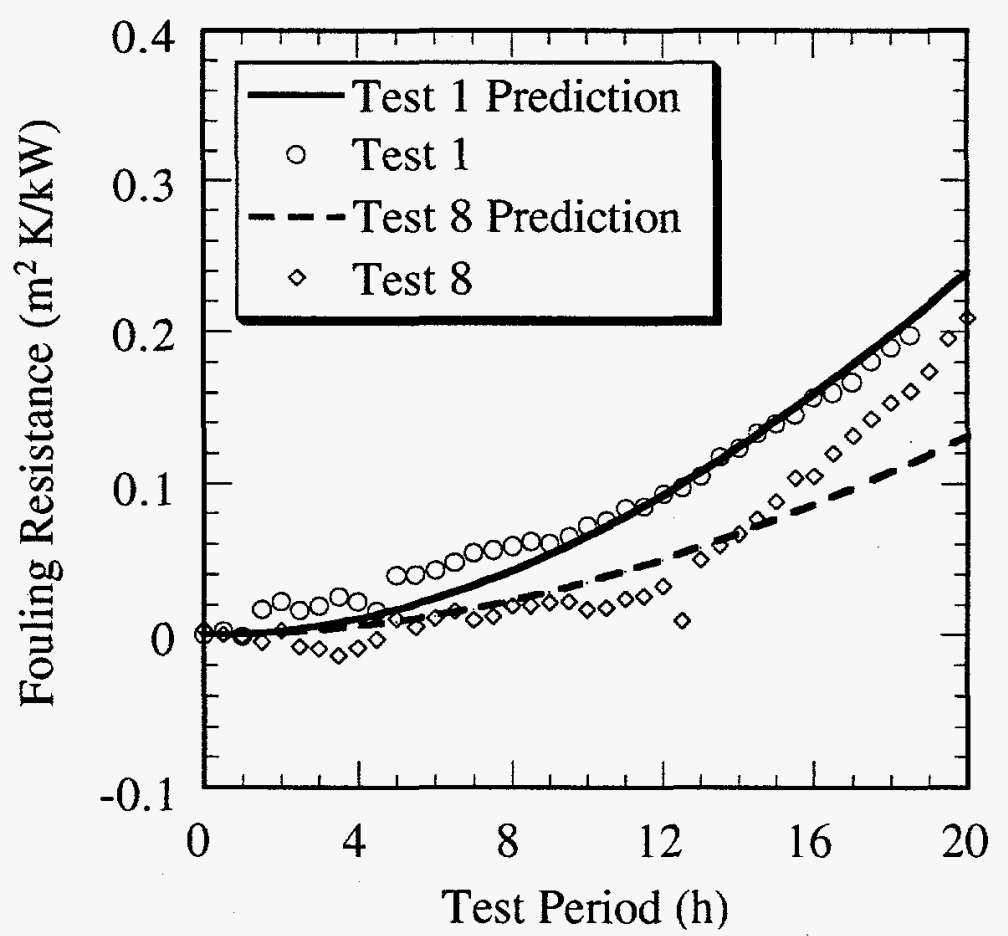

FIGURE 7.28 Effect of Indene Concentration for HTM\#2 in ANL Experiments and Comparison with the Case 1a Prediction 


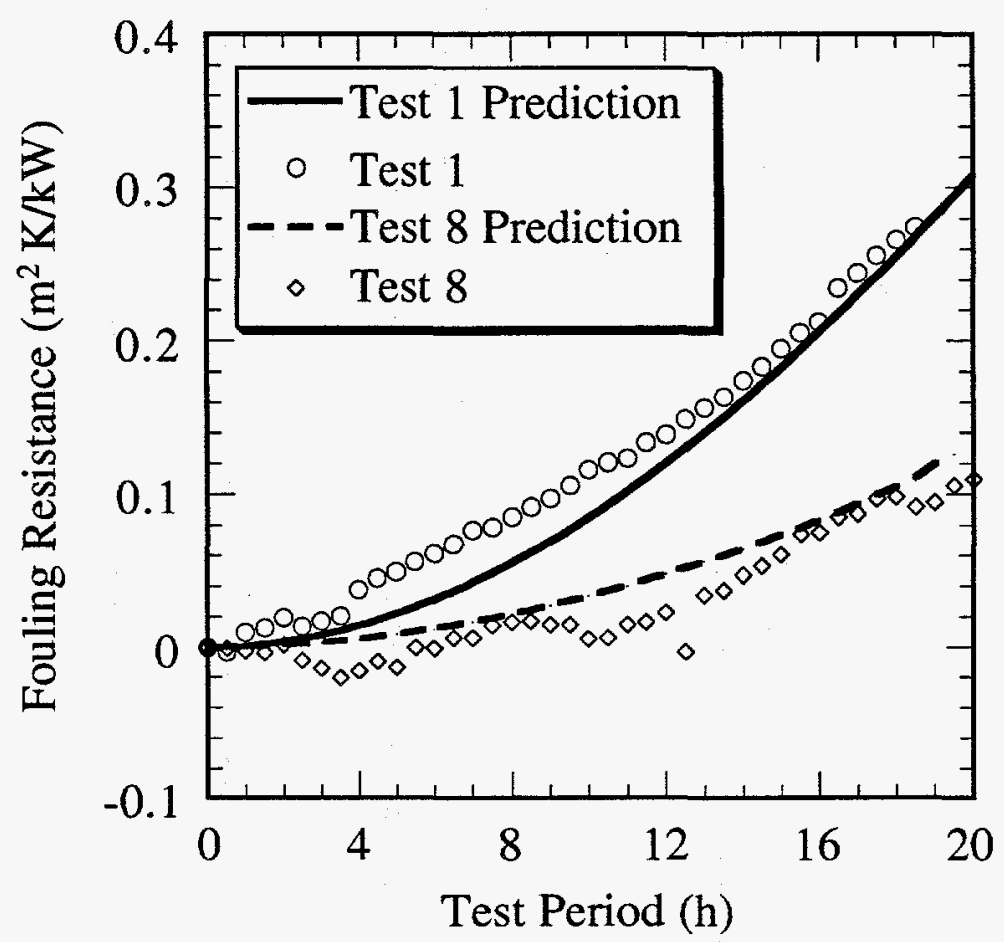

FIGURE 7.29 Effect of Indene Concentration for HTM\#1 in ANL Experiments and Comparison with the Case 2 Prediction

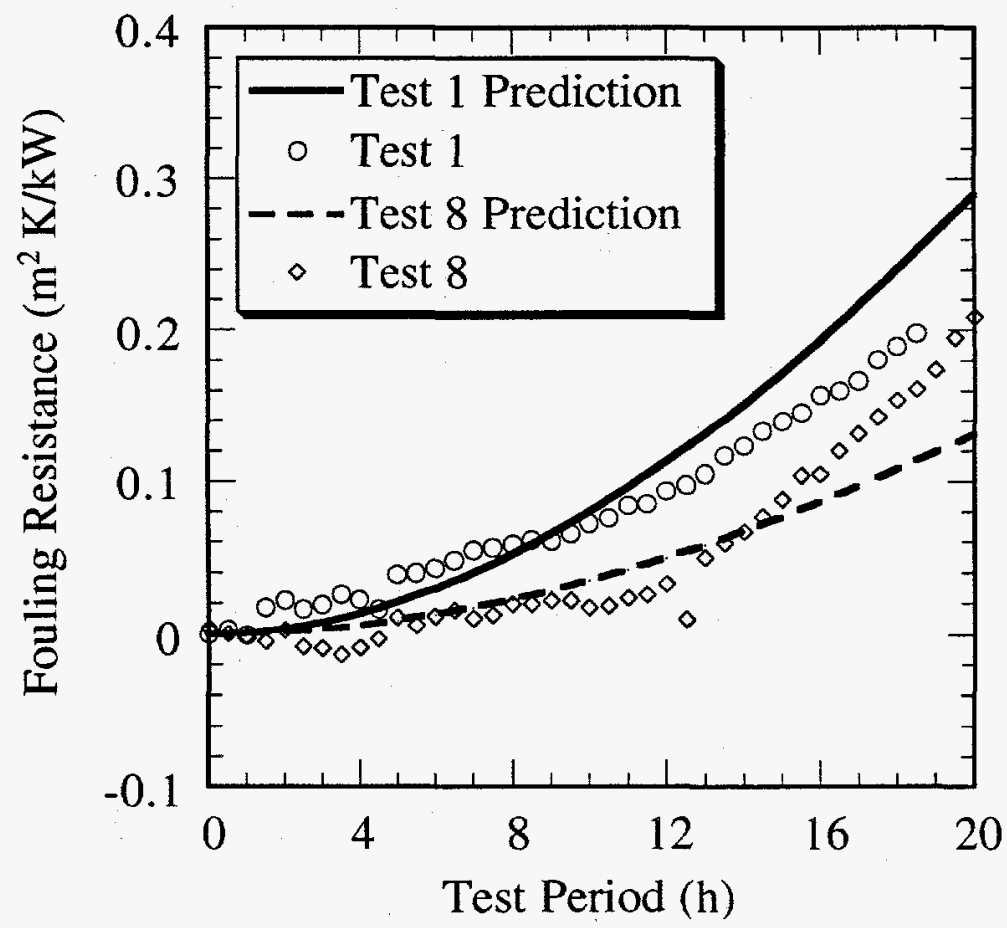

FIGURE 7.30 Effect of Indene Concentration for HTM\#2 in ANL Experiments and Comparison with the Case 2 Prediction 


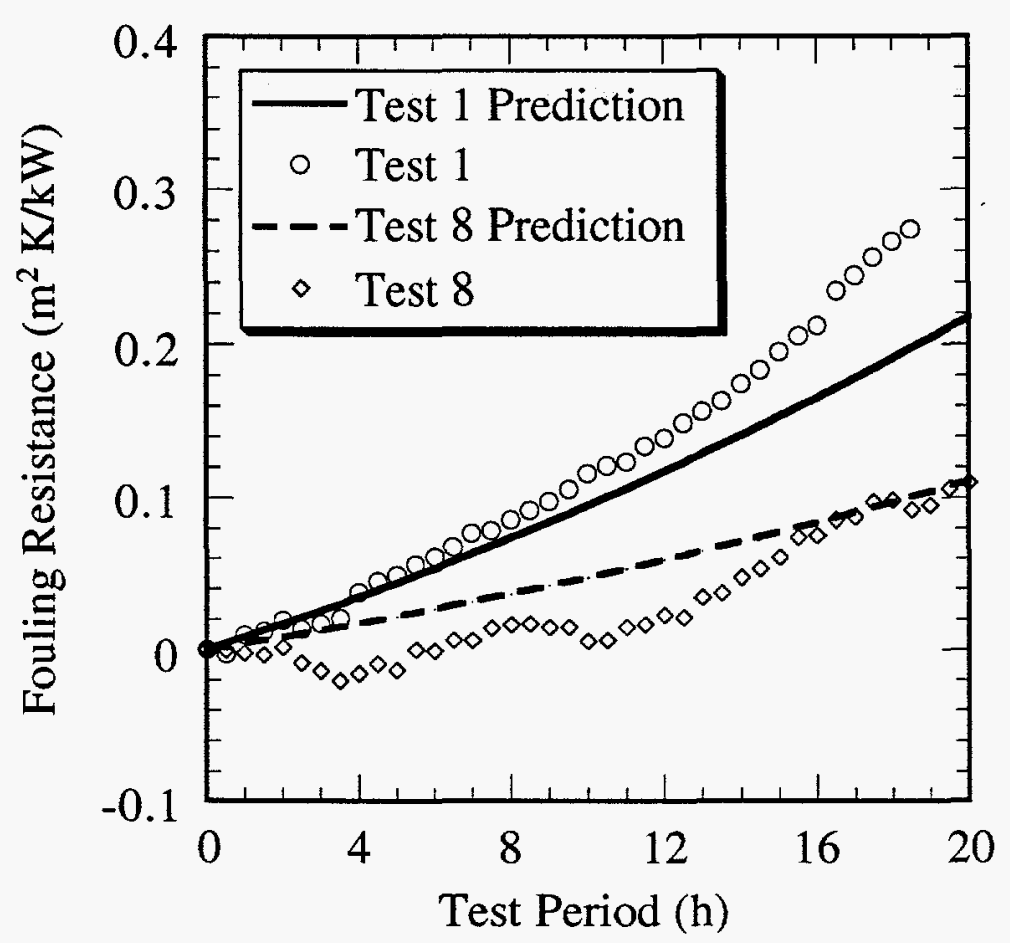

FIGURE 7.31 Effect of Indene Concentration for HTM\#1 in ANL Experiments and Comparison with the Case 3 Prediction

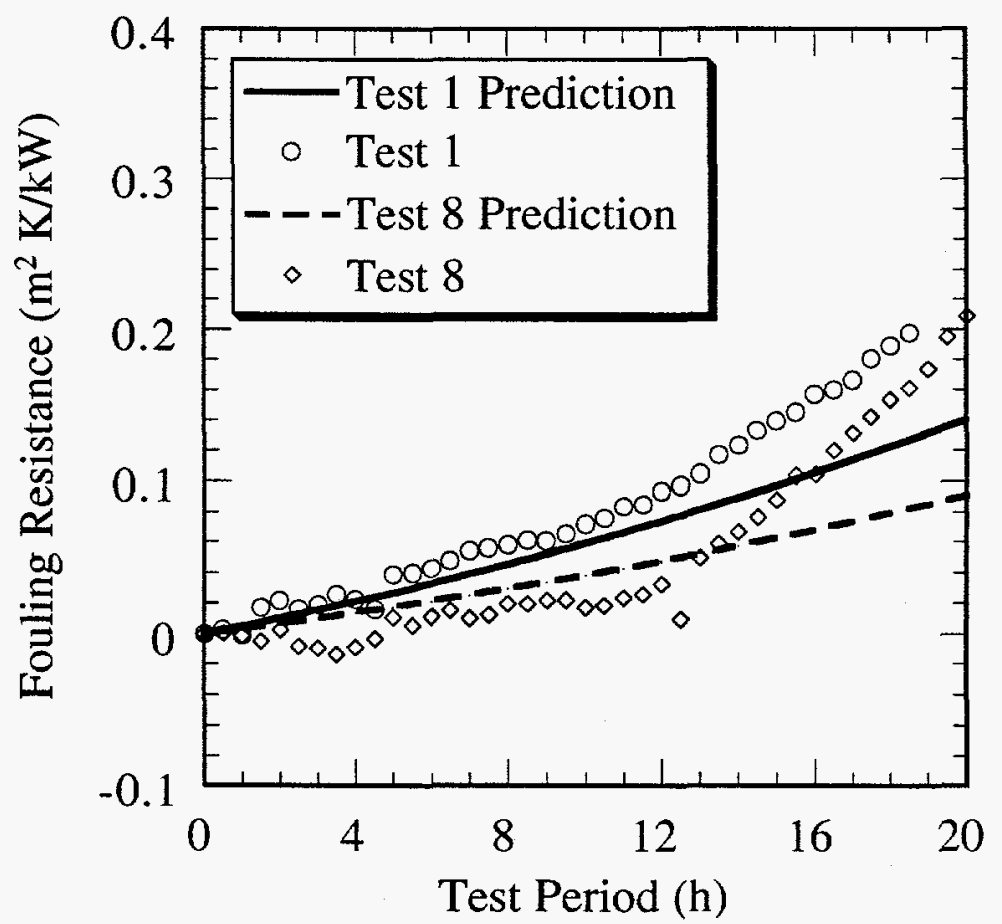

FIGURE 7.32 Effect of Indene Concentration for HTM\#2 in ANL Experiments and Comparison with the Case 3 Prediction 


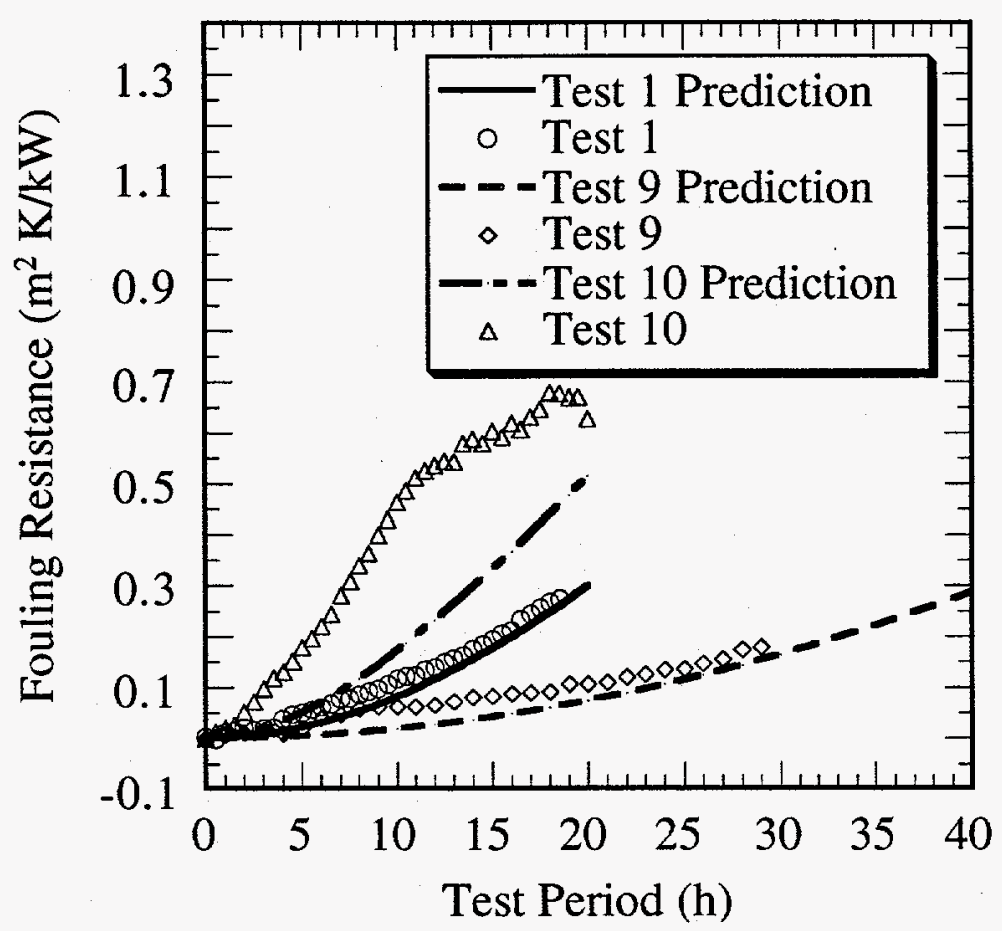

FIGURE 7.33 Effect of Bulk Fluid Temperature for HTM\#1 in ANL Experiments and Comparison with the Case 1a Prediction

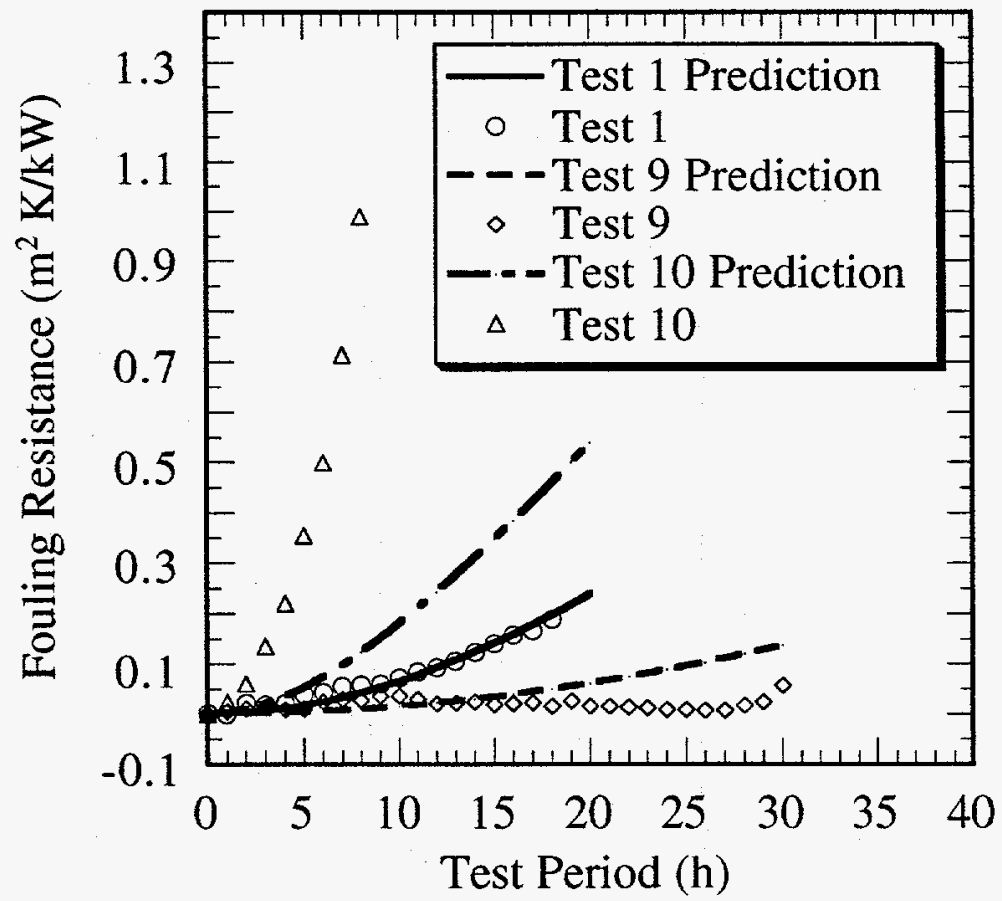

FIGURE 7.34 Effect of Bulk Fluid Temperature for HTM\#2 in ANL Experiments and Comparison with the Case 1a Prediction 


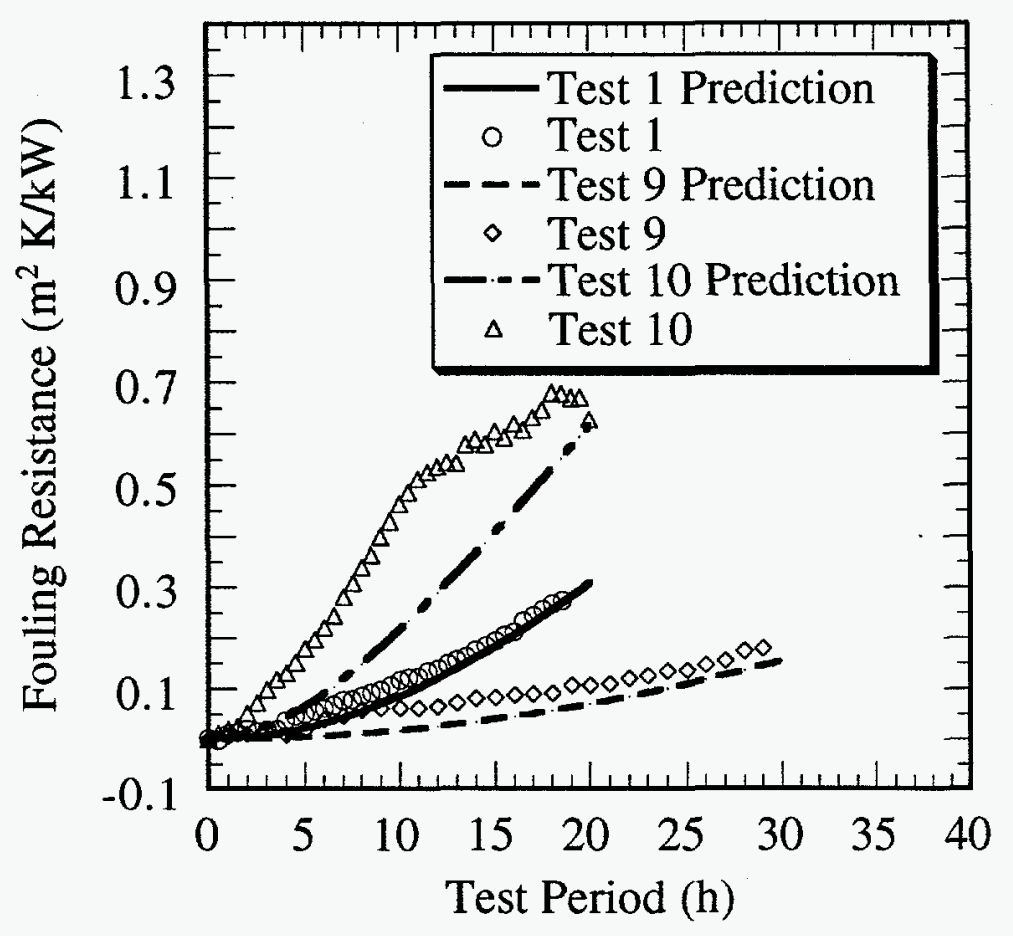

FIGURE 7.35 Effect of Bulk Fluid Temperature for HTM\#1 in ANL Experiments and Comparison with the Case 2 Prediction

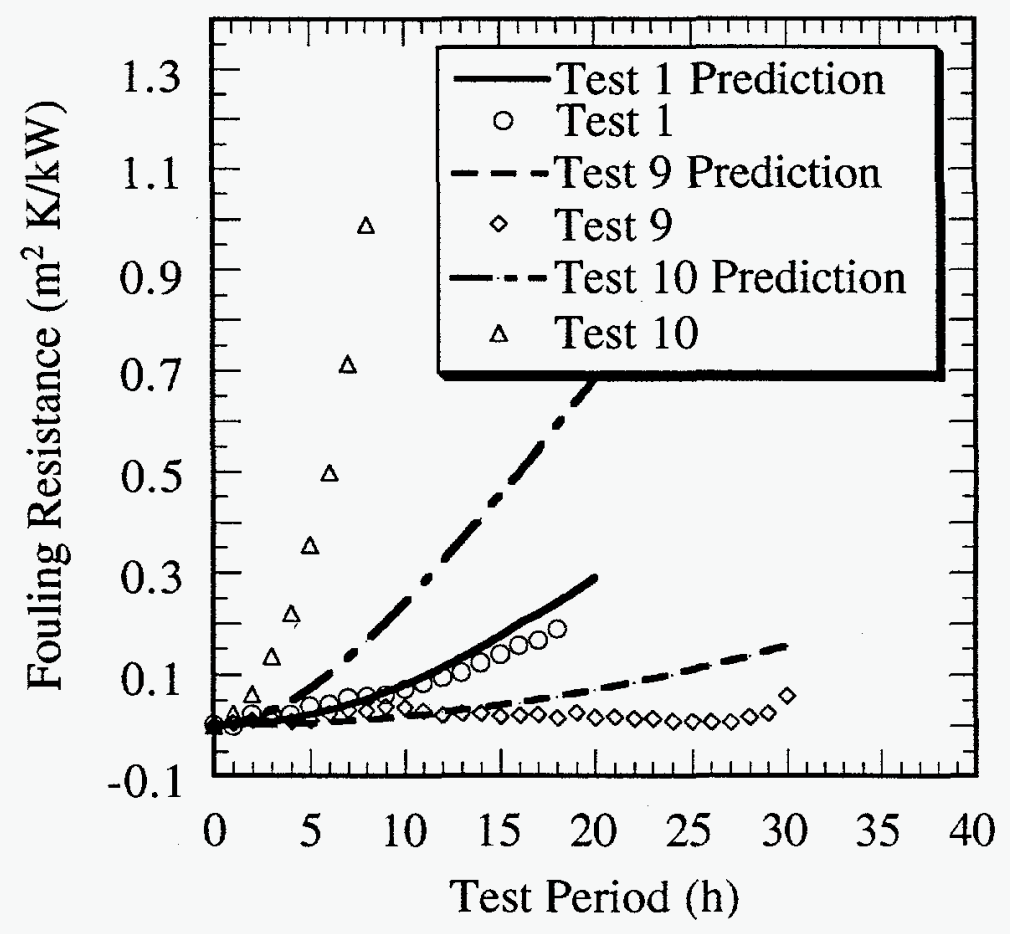

FIGURE 7.36 Effect of Bulk Fluid Temperature for HTM\#2 in ANL Experiments and Comparison with the Case 2 Prediction 


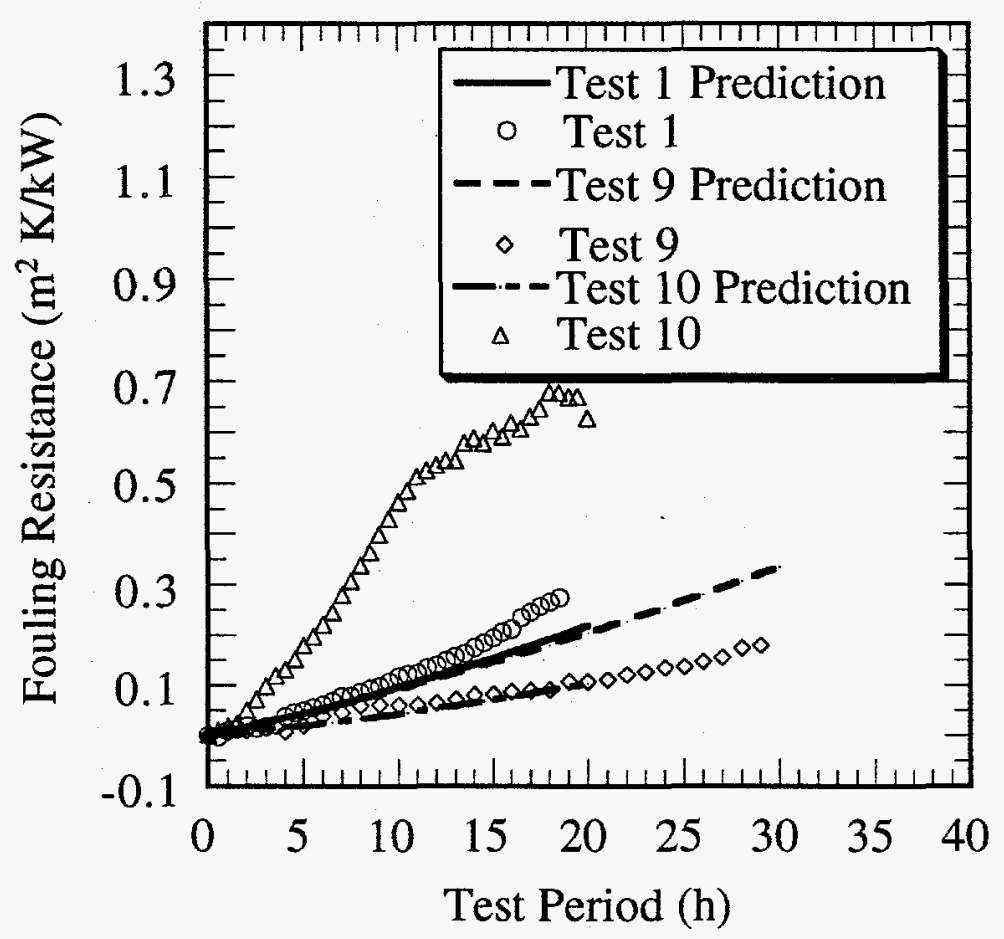

FIGURE 7.37 Effect of Bulk Fluid Temperature for HTM\#1 in ANL Experiments and Comparison with the Case 3 Prediction

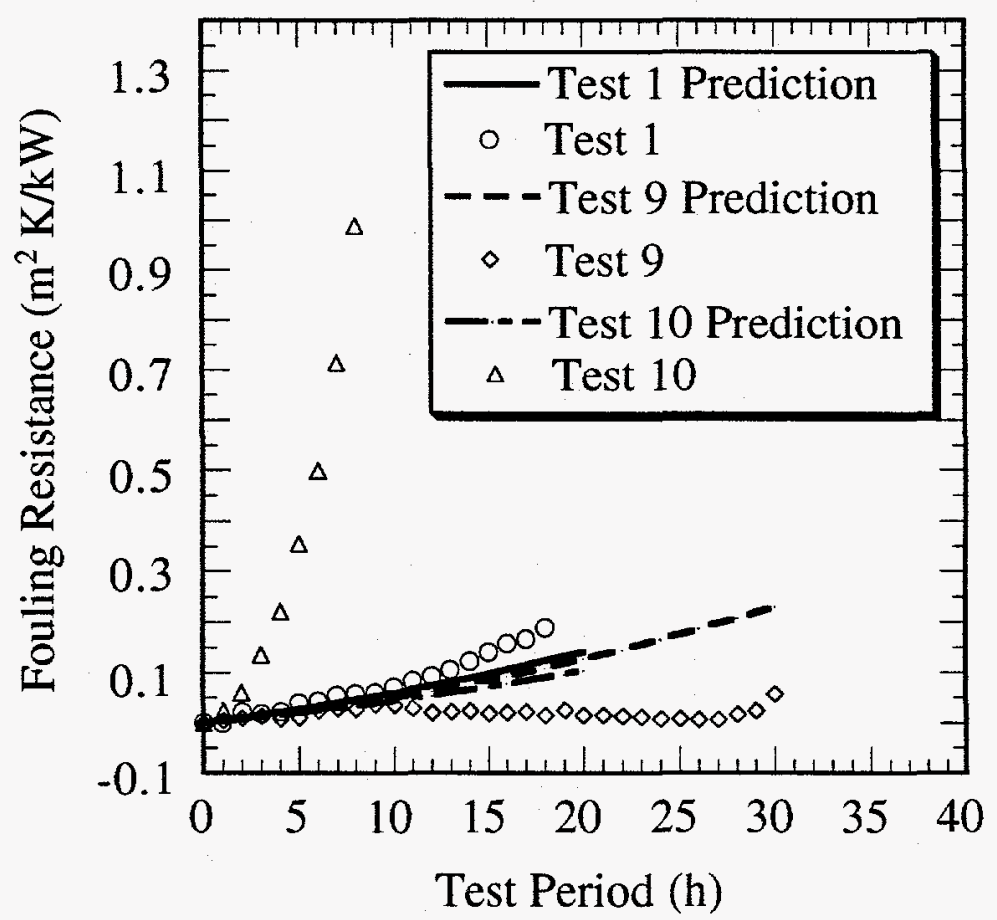

FIGURE 7.38 Effect of Bulk Fluid Temperature for HTM\#2 in ANL Experiments and Comparison with the Case 3 Prediction 
TABLE 7.6 Test Conditions for ANL Experiments to Determine the Effects of Fluid Temperature

Test Run No.

Test Conditions

Concentration of indene (wt\%)

Concentration of indene $\left(\mathrm{kmol} / \mathrm{m}^{3}\right)$

System pressure $(\mathrm{KPa})$

Oxygen concentration ${ }^{\mathrm{a}}\left(\mathrm{kmol} / \mathrm{m}^{3}\right)$

Fluid velocity $(\mathrm{m} / \mathrm{s})$

Fluid temperature at $\mathrm{HTM \# 1}\left({ }^{\circ} \mathrm{C}\right)$

Fluid temperature at HTM\#2 $\left({ }^{\circ} \mathrm{C}\right)$

Wall temperature of HTM\#1 $\left({ }^{\circ} \mathrm{C}\right)$

Wall temperature of $\mathrm{HTM} \# 2\left({ }^{\circ} \mathrm{C}\right)$

\begin{tabular}{ccc}
\multicolumn{3}{c}{ Test Run No. } \\
\hline 1 & 9 & 10 \\
& & \\
10 & 10 & 10 \\
0.71 & 0.71 & 0.305 \\
417 & 412 & 432 \\
0.0057 & 0.0057 & 0.0059 \\
1.04 & 1.02 & 0.95 \\
82.5 & 67.0 & 82.7 \\
99.2 & 99.2 & 99.1 \\
191.8 & 190.6 & 196.2 \\
187.7 & 187.2 & 194.6 \\
\hline
\end{tabular}

a Oxygen concentration calculated using ASTM 3827 standard. 


\section{Parametric Analysis}

In Section 7, the effects of physical parameters were analyzed within the range of experimental data. In this section, the analysis is expanded to consider the effects of physical parameters as predicted by the three fouling cases. Moreover, the rate of fouling for once-through flow is analyzed to determine the effects of physical parameters on industrial processes. The key technical objective is to develop a methodology for applying the experimental data to industrial conditions. For example, the wall temperature is directly related to the heat flux for a given fluid velocity and bulk temperature. Some of the literature data are reported in terms of heat flux without specifying the wall temperature. Conclusions from such data cannot be easily interpreted, and the experimental data cannot be easily applied to industrial processes. The three parameters essential to interpretation of the fouling data for a given system of chemical composition are fluid velocity, bulk temperature, and wall temperature. For the sake of continuity, the system of indene in kerosene that was used for experimental work is considered for the parametric analysis.

\subsection{Closed-Loop Flow}

The experimental apparatus, in general, has a closed-loop flow arrangement; therefore, buildup of the precursor concentration and depletion of reactants with time affect the fouling rate. Therefore, the effects of physical parameters on the rate of fouling must be determined by isolating one parameter at a time. It was not possible to maintain the parameters constant except for the one of interest in collecting the experimental data discussed in Section 7; therefore, the effects of certain parameters were not clearly resolved. In this section, the fouling models for the three cases are used to calculate the fouling resistance after a test period of $15 \mathrm{~h}$ to determine the effects of the physical parameters. The relative effects for the in-tube flow (ANL apparatus) and for the annulus flow (UBC apparatus) were comparable; therefore, the calculated data for the ANL apparatus only is included in the analysis. The nominal conditions used for the baseline case are shown in Table 8.1.

\subsubsection{Fluid Velocity}

The effects of fluid dynamics and associated heat- and mass-transfer processes on the chemical reaction can be analyzed by keeping the wall temperature constant and varying the fluid velocity. Some of the experiments reported in the literature were carried out under constant heat-flux conditions, where varying the fluid velocity would also change the wall temperature. Without knowing the exact wall temperature, it is not possible to differentiate the effect of
TABLE 8.1 Baseline Test Conditions for the Parametric Analysis for Closed-Loop Flow

\begin{tabular}{lc}
\hline \multicolumn{1}{c}{ Parameter } & Value \\
\hline & \\
Fluid velocity $(\mathrm{m} / \mathrm{s})$ & 1.0 \\
Fluid temperature $\left({ }^{\circ} \mathrm{C}\right)$ & 82.2 \\
Wall temperature for $\mathrm{HTM}\left({ }^{\circ} \mathrm{C}\right)$ & 191.0 \\
Indene concentration $\left(\mathrm{kmol} / \mathrm{m}^{3}\right)$ & 0.71 \\
Air pressure $(\mathrm{kPa})$ & 414.0 \\
\hline
\end{tabular}




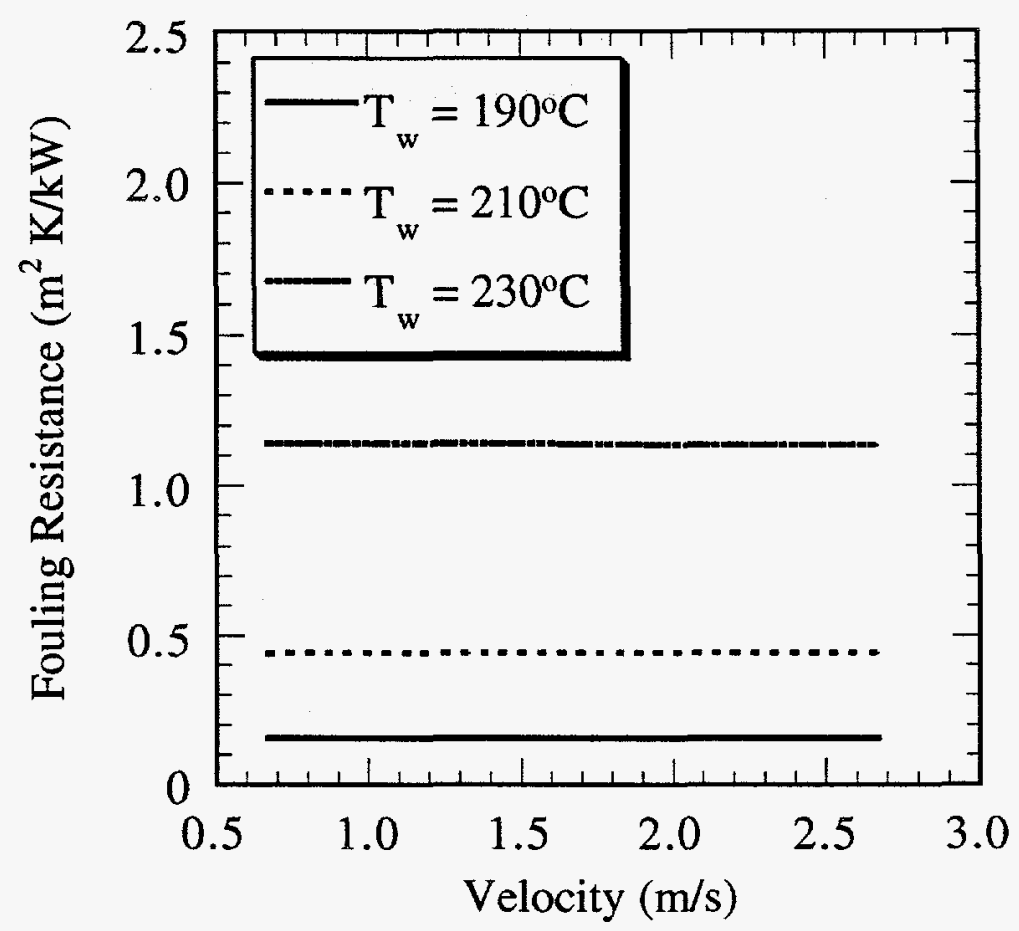

FIGURE 8.1 Effect of Fluid Velocity on the Fouling Resistance at $15 \mathrm{~h}$ as Predicted by Case 1a

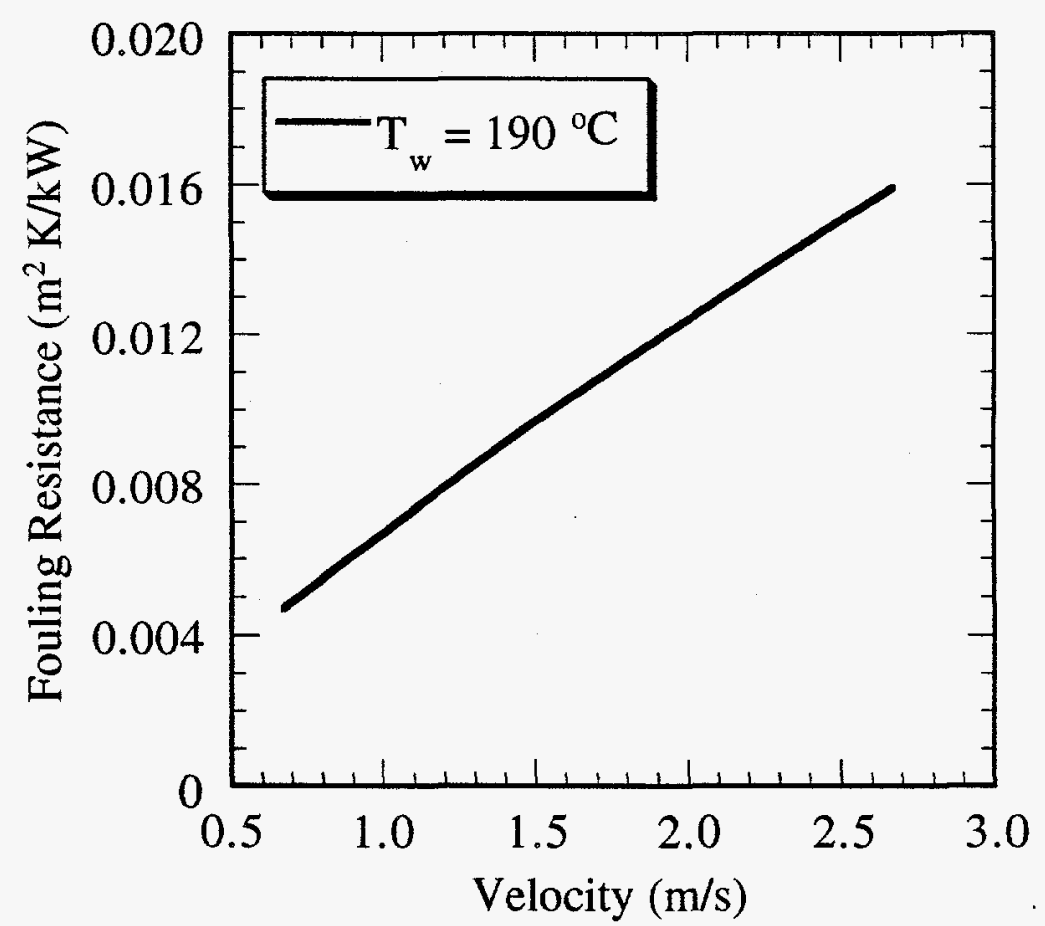

FIGURE 8.2 Effect of Fluid Velocity on the Fouling Resistance at $15 \mathrm{~h}$ as Predicted by Case $1 \mathrm{~b}$ 
fluid velocity from that of wall temperature. In Figures 8.1 through 8.4 , the effect of fluid velocity, with the wall temperature as a parameter, is shown for each of the three fouling cases.

In Case 1a, where the precursor formation reaction takes place in bulk and formation of foulant occurs at the wall surface, only the mass transport of precursor to the wall surface is velocity dependent. The computed results in Figure 8.1 indicate that diffusion is not a controlling step for the three wall temperatures; however, the numerical values indicate that the fouling rate increases slightly with fluid velocity. The effect of fluid velocity should become significant at higher temperatures, where reaction kinetics are not the controlling step in the overall process. The effect of fluid velocity on the fouling resistance is significant for the Case $1 \mathrm{~b}$ fouling mechanism, as seen in Figure 8.2. In this case, insoluble foulant particulates are formed in the bulk, followed by their transport to the wall surface. A particulate size of $1 \mu \mathrm{m}$ was used, and the sticking probability was assumed to be unity (i.e., all particulates reaching the wall surface are deposited). As discussed in Section 7, the Case $1 \mathrm{~b}$ fouling mechanism does not depend on the wall temperature, as is shown by a single curve in Figure 8.2. These results followed an expected trend of the particulate fouling mechanism; however, note that the fouling resistance value is relatively low compared with that for the other fouling cases.

The effect of fluid velocity on the fouling resistance for the Case 2 fouling mechanism is shown in Figure 8.3 for the three wall temperatures. As expected, the effect of fluid velocity decreases as the wall temperature is reduced from 230 to $190^{\circ} \mathrm{C}$. The effect of fluid velocity in the Case 2 fouling mechanism has two elements: thickness of the thermal-boundary layer and mass diffusion. The mass diffusion, in turn, includes two effects: diffusion of reactants into the thermal-boundary layer and back-diffusion of precursor into the bulk. As the fluid velocity is increased, the thickness of the thermal-boundary layer decreases, but the rate of mass diffusion increases. The resultant effects are, therefore, dependent on the wall temperature for a given bulk temperature. At the wall temperature of $230^{\circ} \mathrm{C}$, the reaction rate is relatively high, and the rapid decrease in the fouling resistance is primarily caused by reduction in the thickness of the thermalboundary layer, where the controlling reaction takes place. At the low temperature of $190^{\circ} \mathrm{C}$, the reaction rate and hence the fouling rate is relatively low, and the reduction in the thermal-boundary layer is counterbalanced by the increase in the mass diffusion rate.

The effect of fluid velocity on the rate of fouling deposition as predicted by the Case 3 model is shown in Figure 8.4. As for the Case 2 results, the fouling resistance decreases as the fluid velocity is increased, and the effect of fluid velocity diminishes at low wall temperatures. The major effect of the fluid velocity in the Case 3 fouling mechanism is on the back-diffusion of precursor from the wall surface. The mass-flux balance between the reaction and the mass diffusion at the fluid/wall interface determines the concentration of reactants and precursor. As the fluid velocity is increased, the mass diffusion of reactants to the wall surface increases, but the rate of back-diffusion of precursor also increases, which reduces the rate of fouling deposition. The computed results show that the back-diffusion of precursor plays an important role in the Case 3 fouling mechanism. 


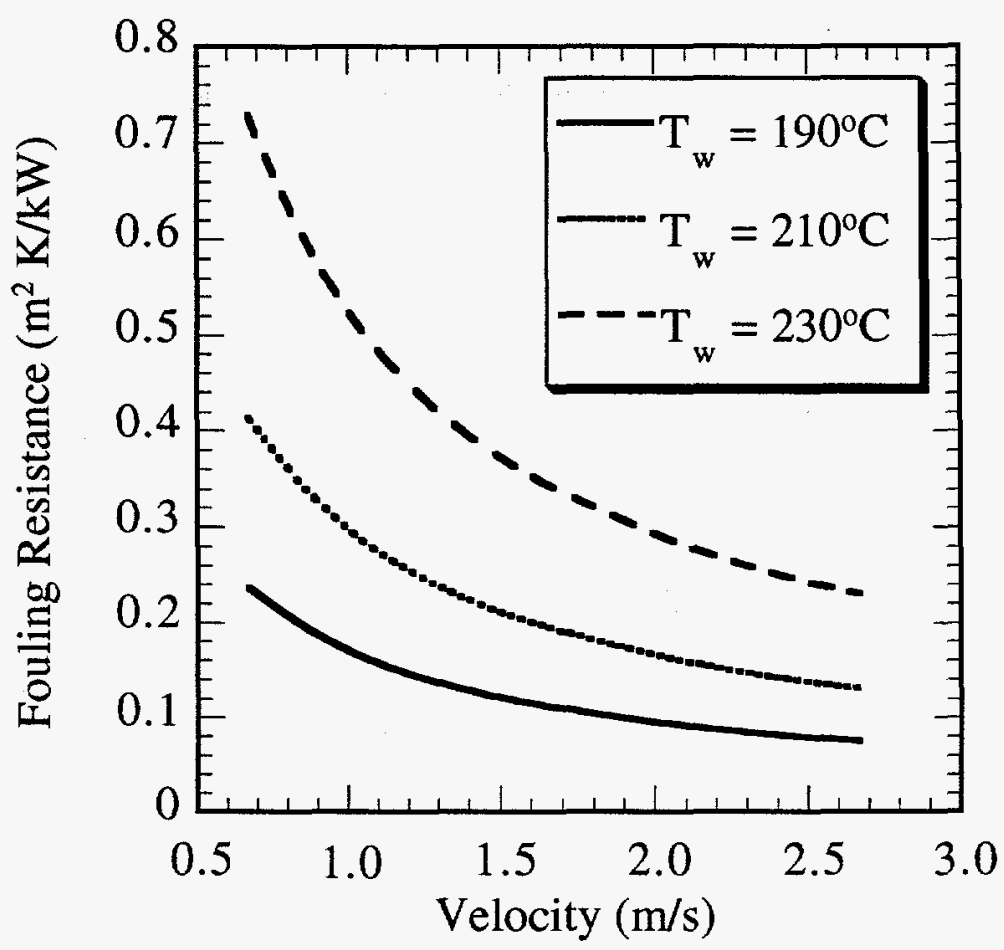

FIGURE 8.3 Effect of Fluid Velocity on the Fouling Resistance at $15 \mathrm{~h}$ as Predicted by Case 2

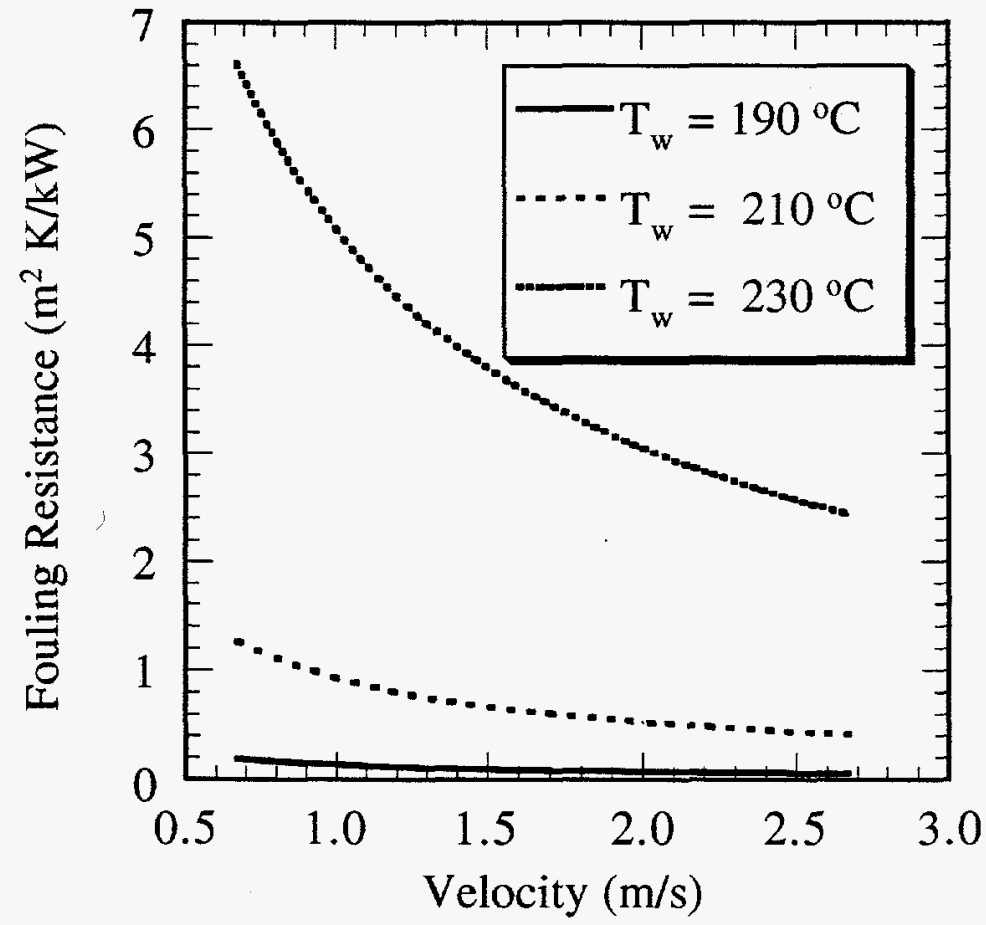

FIGURE 8.4 Effect of Fluid Velocity on the Fouling Resistance at $15 \mathrm{~h}$ as Predicted by Case 3 
The critical review study by Watkinson (1988) indicated that the experimental data reported in the literature showed different effects of the fluid velocity; however, no rigorous analysis of the literature data has been carried out. The three fouling cases of the present investigation may provide an explanation for the observed trend of fouling in the literature results. The fluid velocity is a key parameter for determining threshold conditions for fouling in industrial processes. Therefore, the present analysis will be continually refined to determine the effect of fluid velocity under different operating conditions.

\subsubsection{Wall Temperature}

For a given bulk temperature and fluid velocity, the HTM wall temperature increases with increase in the heat flux. The bulk conditions, including the concentration of precursor for Case 1 and Case 2 fouling mechanisms, remain constant at a given time. Therefore, the computed results discussed in this section show the rate of fouling for the three fouling mechanisms as a function of wall temperature, without having the effect masked by other parameters.

In the Case 1a fouling mechanism, the foulant-forming reaction takes place at the wall surface; therefore, the wall temperature has a significant effect on the rate of fouling, as is seen in Figure 8.5. Because the effect of fluid velocity is negligible, only one set of results at fluid velocity of $0.75 \mathrm{~m} / \mathrm{s}$ is shown in Figure 8.5 . The Case $1 \mathrm{~b}$ fouling mechanism is independent of the wall temperature, as seen in Figure 8.6. In the present range of experimental conditions, the rate of fouling varies with the wall temperature, which indicates that Case $1 b$ is not a governing mechanism for the present set of test conditions.

The effect of the HTM wall temperature on the deposition rate for the Case 2 fouling mechanism is shown in Figure 8.7 for three fluid velocities. The effect of the wall temperature on the deposition rate is less significant for Case 2 than for the Case 1a fouling mechanism. In the Case 2 fouling mechanism, the reaction zone is in the thermal-boundary layer, where the prevailing temperature gradient is used to calculate the local rate of reaction, while in Case 1a the foulant-forming reaction takes place at the wall surface. Because the bulk temperature is kept constant, the effect of wall temperature on the rate of fouling for Case 1a is expected to be larger than the effect for Case 2. The effect of wall temperature for Case 3 is even greater, as seen in Figure 8.8 , because both the precursor and the foulant-forming reactions take place at the wall surface.

The effect of wall temperature, $T_{\mathrm{w}}$, is generally presented as an Arrhenius plot, and the activation energy is calculated from the slope. The following correlation represents the Arrhenius plot:

$$
\text { Rate of fouling }=k \exp \left(-E / R T_{W}\right)
$$




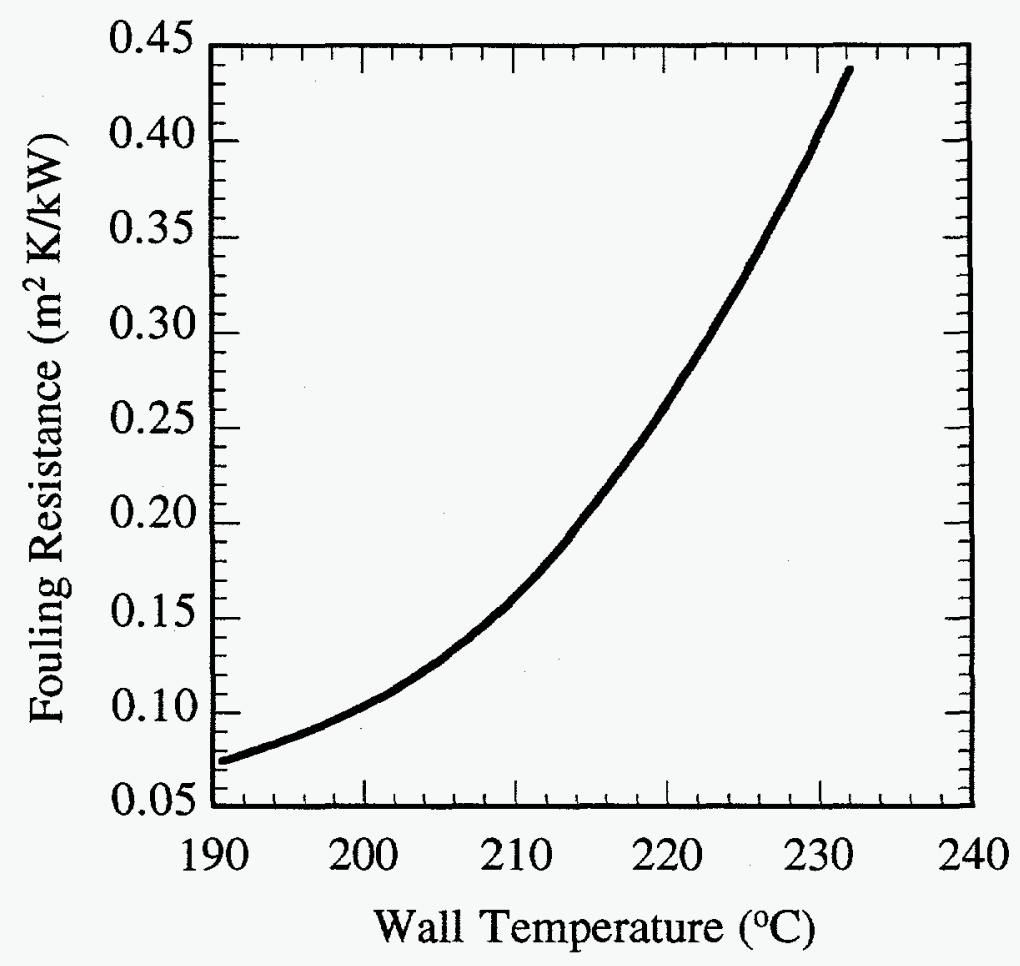

FIGURE 8.5 Effect of HTM Wall Temperature on the Fouling Resistance at $15 \mathrm{~h}$ as Predicted by Case $1 \mathrm{a}$

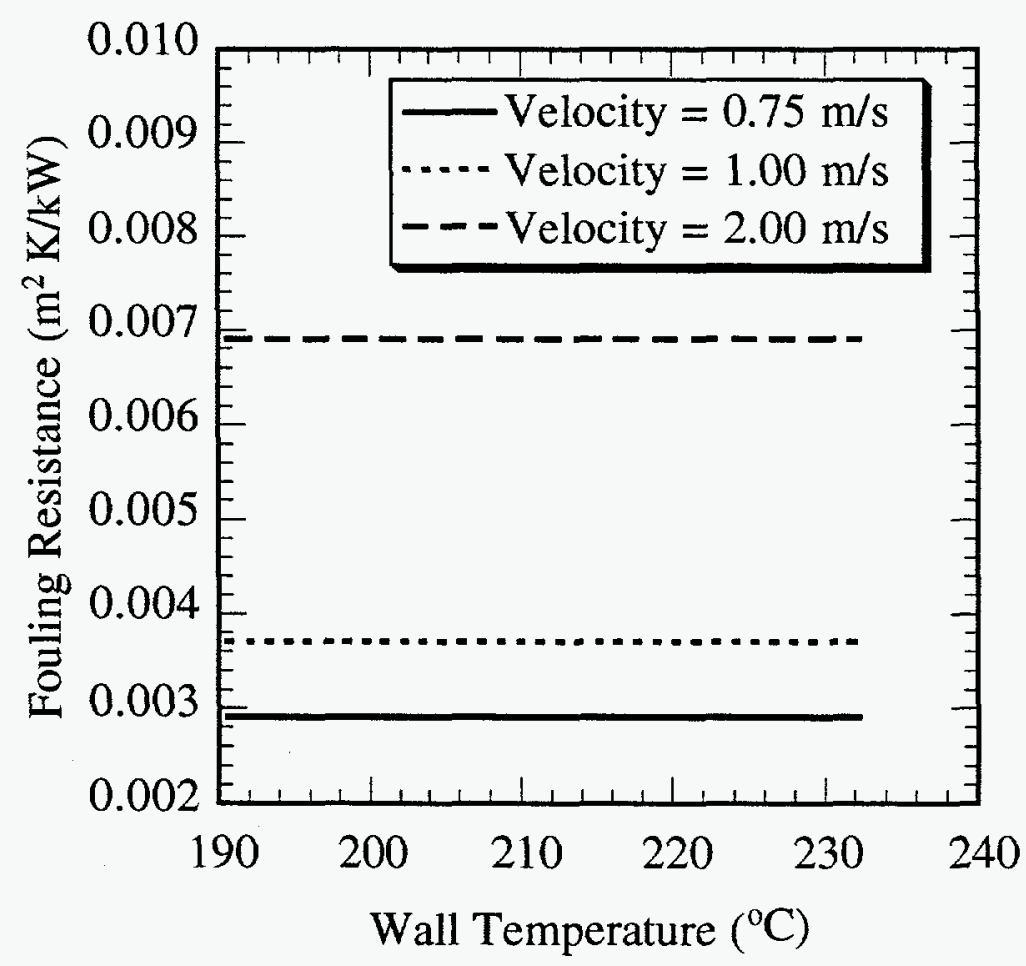

FIGURE 8.6 Effect of HTM Wall Temperature on the Fouling Resistance at $15 \mathrm{~h}$ as Predicted by Case $1 \mathrm{~b}$ 


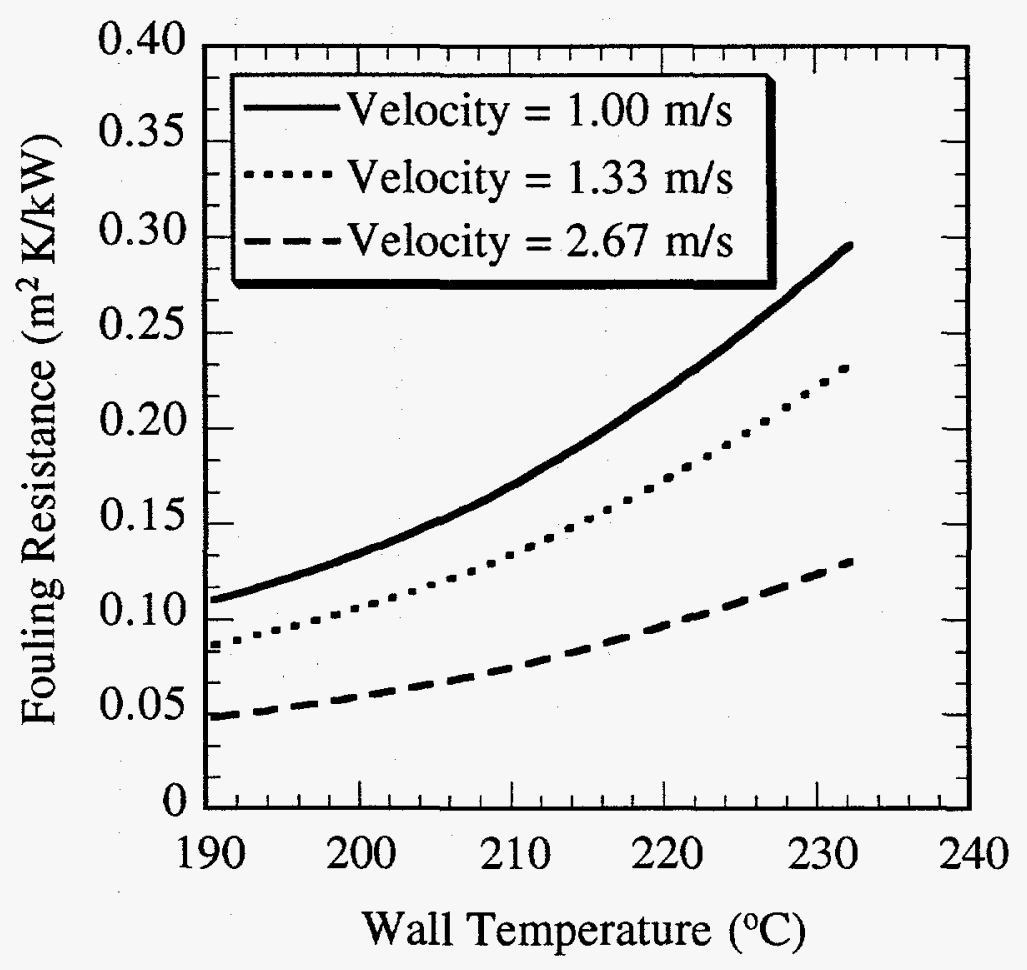

FIGURE 8.7 Effect of HTM Wall Temperature on the Fouling Resistance at $15 \mathrm{~h}$ as Predicted by Case 2

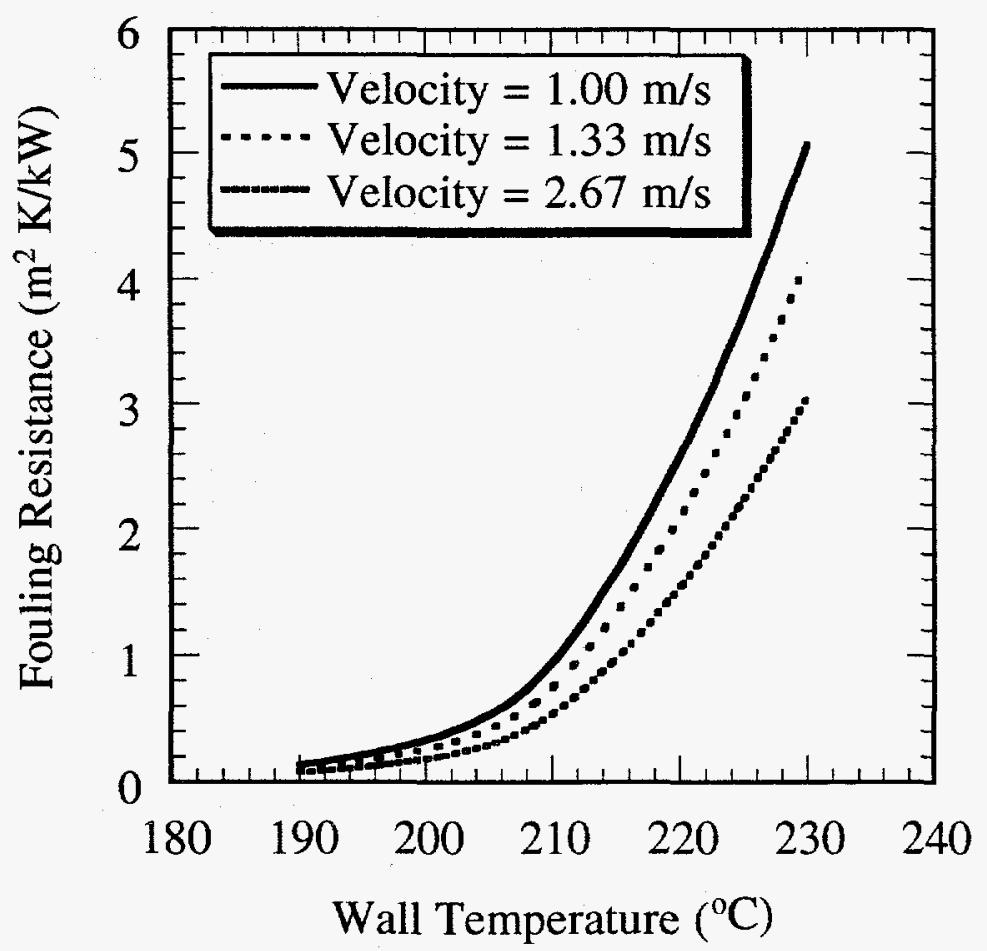

FIGURE 8.8 Effect of HTM Wall Temperature on the Fouling Resistance at $15 \mathrm{~h}$ as Predicted by Case 3 
Note that Equation 8.1 is based on the assumption that the mass diffusion and the reaction can be lumped together. Therefore, the activation energy calculated from the overall fouling results depends on the governing fouling mechanism and the physical parameters (i.e., fluid velocity and bulk temperature), which is evident from the computed results shown in Figures 8.5 through 8.8. The results are reported in the form of Arrhenius plots in Figures 8.9, 8.10, and 8.11 for Cases 1a, 2, and 3, respectively. In the present range of test conditions, the individual plots are nearly linear. However, the calculated activation energies are not the same for the three cases:

\section{Case 1a: $\quad 83.1 \mathrm{~kJ} / \mathrm{kmol}$ \\ Case 2: $\quad 46.5 \mathrm{~kJ} / \mathrm{kmol}$ \\ Case 3: $\quad 178.0 \mathrm{~kJ} / \mathrm{kmol}$.}

The activation energy used for both reactions was $96.3 \mathrm{~kJ} / \mathrm{kmol}$. It is evident that an unknown level of uncertainty would be introduced if the experimental data are extrapolated to industrial conditions where a correction for the wall temperature is required. The uncertainty would be even greater if the fouling mechanism shifts from laboratory to industrial applications, because of different operating conditions. The values of the activation energy also show that Case 2 is more dependent on the diffusion process and the fluid dynamics than the other two cases. Note that the activation energy for the Case 3 fouling mechanism is greater than that for the individual chemical reaction, which indicates that if both reactions occur at the wall surface, the fouling process becomes quite sensitive to the wall temperature.

\subsubsection{Bulk Temperature}

The bulk fluid temperature is a key parameter for a closed-flow-loop system because the precursor generation occurs in the bulk, specifically in the fluid reservoir, and the rate of foulant formation is a strong function of the precursor concentration. In order to extrapolate the closedloop experimental data to industrial conditions where the fluid temperature may be different, it is essential to characterize the effect of fluid temperature. In the past, the wall temperature was used to calculate the energy of activation, which could be erroneous if the bulk temperature affects the rate of fouling for a given wall temperature. As was the case for the effects caused by parameters such as fluid velocity and wall temperature, the relative effects of fluid temperature differ, depending upon the controlling fouling mechanism.

In the Case 1a fouling mechanism, the precursor generation occurs in the bulk, while the foulant formation occurs at the wall surface. Figure 8.12 shows a significant increase in the fouling resistance for a fluid temperature change from about $65^{\circ}$ to $130^{\circ} \mathrm{C}$. The effect of fluid temperature is more significant for the wall temperature of $230^{\circ} \mathrm{C}$ than for $190^{\circ} \mathrm{C}$. At fluid temperatures greater than $110^{\circ} \mathrm{C}$, the primary reactant, indene, was consumed, yielding an 


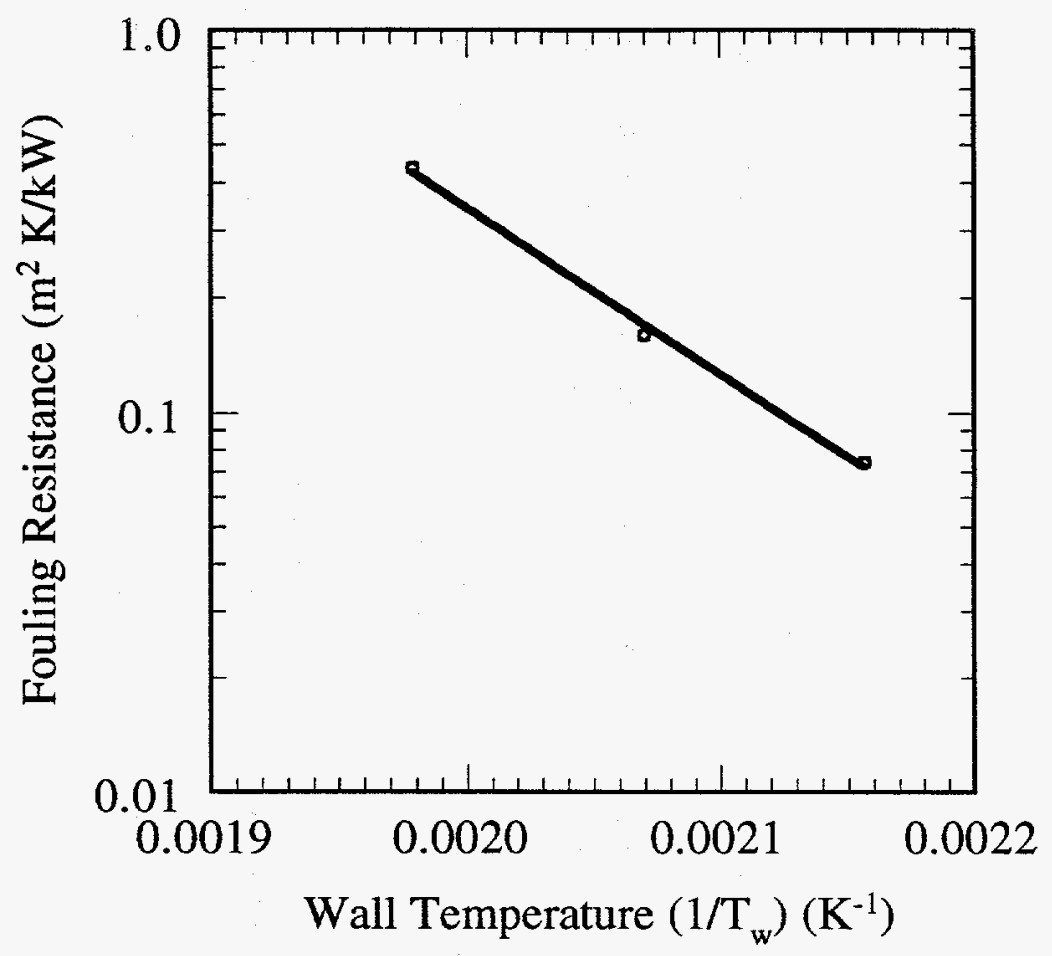

FIGURE 8.9 Effect of HTM Wall Temperature on the Fouling Resistance at $15 \mathrm{~h}$ as Predicted by Case 1a, Presented as an Arrhenius Plot

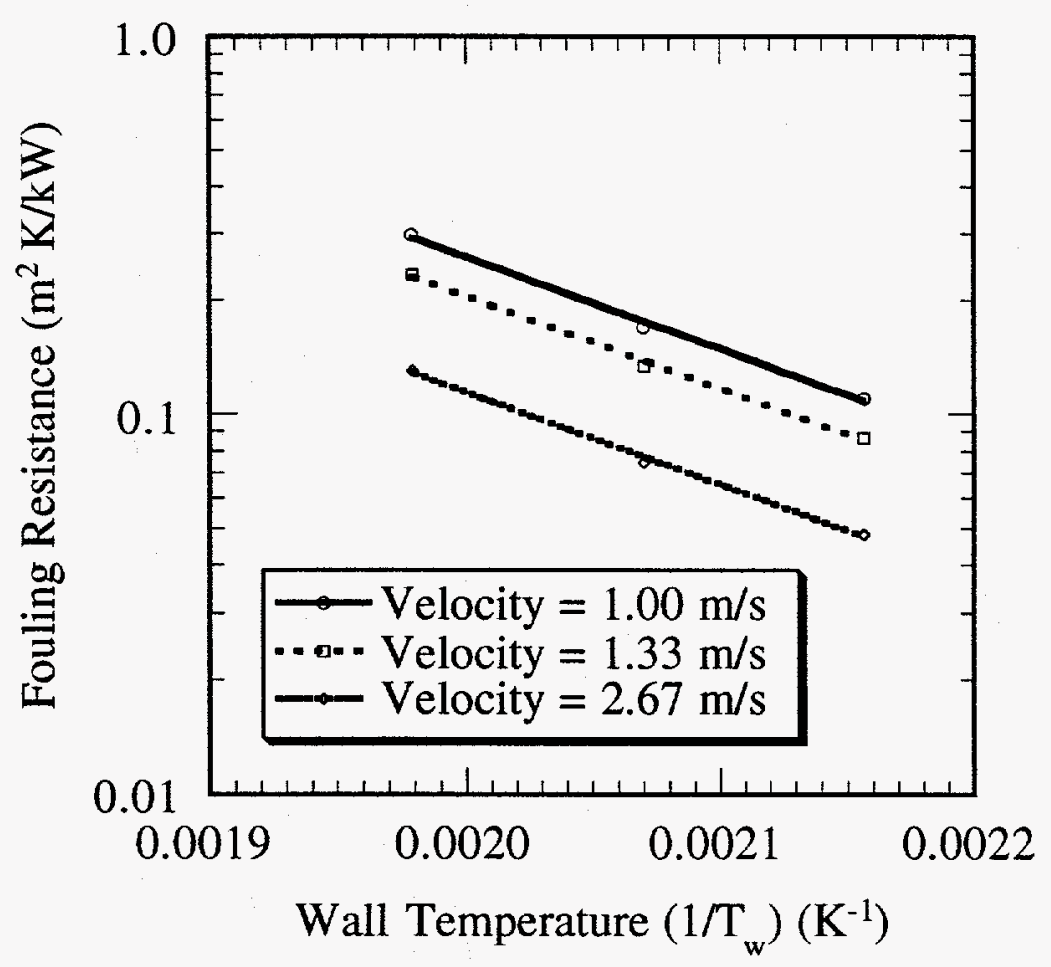

FIGURE 8.10 Effect of HTM Wall Temperature on the Fouling Resistance at $15 \mathrm{~h}$ as Predicted by Case 2, Presented as an Arrhenius Plot 


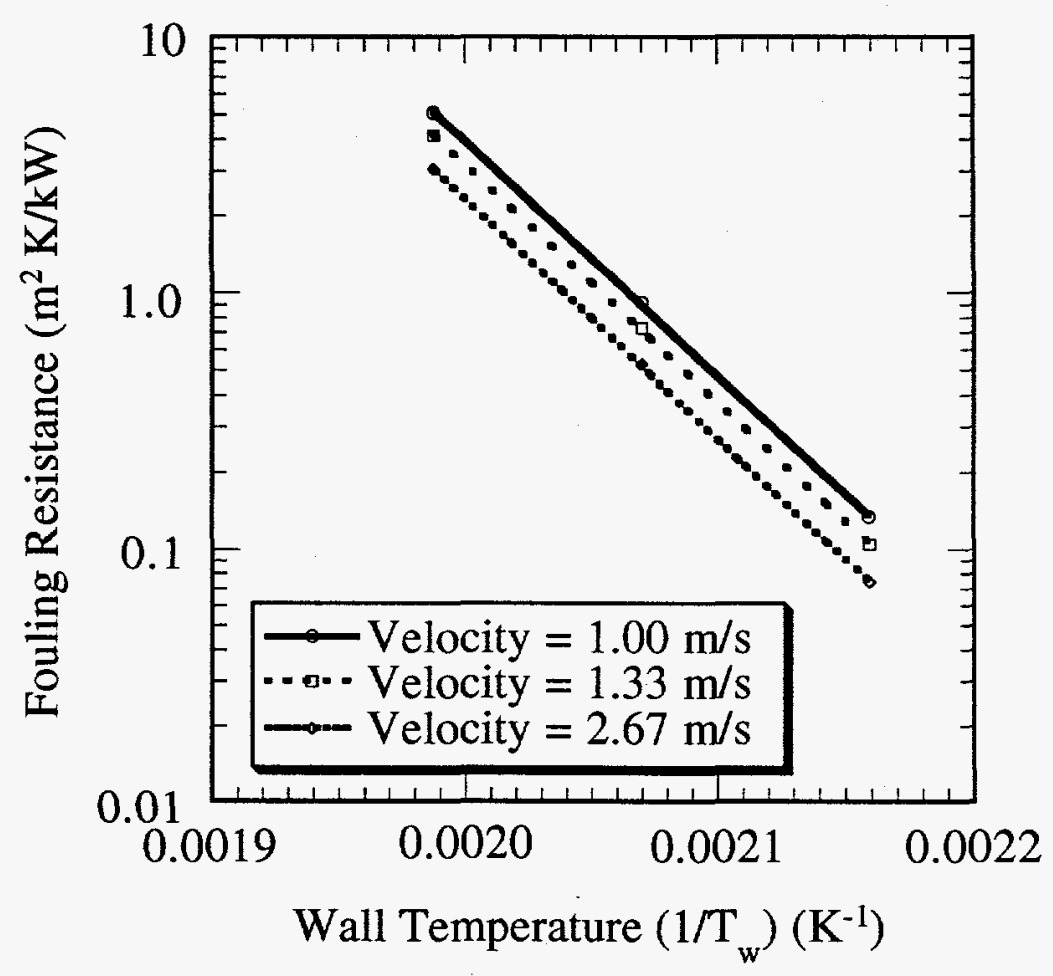

FIGURE 8.11 Effect of HTM Wall Temperature on the Fouling Resistance at $15 \mathrm{~h}$ as Predicted by Case 3, Presented as an Arrhenius Plot

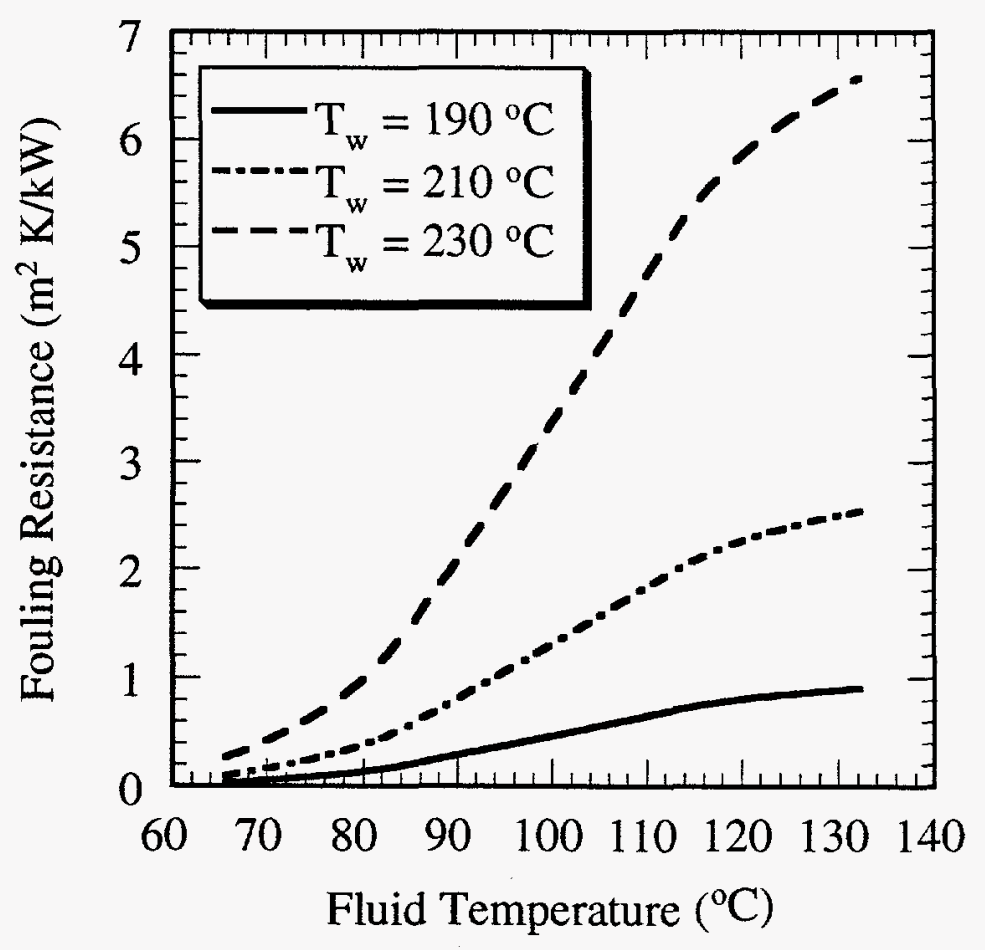

FIGURE 8.12 Effect of Fluid Temperature on the Fouling Resistance at $15 \mathrm{~h}$ as Predicted by Case 1a 
asymptotic value of the fouling resistance. As a result, the plot of the fouling resistance at $15 \mathrm{~h}$ vs. fluid temperature (Figure 8.12) shows an asymptotic trend, although such a trend is not observed at a lower time scale. The fouling deposition does not depend upon the wall temperature in the Case 1b fouling mechanism; therefore, the results are shown in Figure 8.13 for only one wall temperature. In Case $1 \mathrm{~b}$, a continuous increase in the rate of fouling is observed as the fluid temperature is increased. Note that at fluid temperatures below about $100^{\circ} \mathrm{C}$, the Case $1 \mathrm{~b}$ fouling mechanism may not be important for the kerosene/indene system being studied in the present investigation, as was experimentally observed and discussed in Section 7. However, the Case 1b fouling mechanism may become important for high fluid temperatures. These results further prove that the controlling fouling mechanism could shift, depending upon the operating conditions, for a given chemical system of fluid and reactants.

The computed results for the Case 2 fouling mechanism are shown in Figure 8.14. Because the overall fouling process depends significantly on the precursor concentration in the bulk, the effects of fluid temperature on the rate of fouling for the Case 2 fouling mechanism are similar to those for Case 1a. As mentioned earlier, indene was nearly consumed in $15 \mathrm{~h}$ (initial concentration of $0.71 \mathrm{~mol} / \mathrm{L}$ ) at fluid temperatures greater than $100^{\circ} \mathrm{C}$. The precursor concentration peaked at an intermediate time, which gave an asymptotic value for the fouling resistance. The results can be explained on the basis of reactions occurring in the bulk. In the Case 2 fouling mechanism, both reactions for precursor and foulant formation occur in the bulk as well as in the thermal-boundary layer. As foulant formation continues in the bulk, precursor concentration drops after most of the primary reactant (indene) is consumed. As per the Case 2 assumption, the foulant formed in the bulk does not deposit on the wall surface. If the results for Case $1 \mathrm{~b}$ and Case 2 are combined, the resulting fouling resistance shows an expected fouling trend.

In the Case 3 fouling mechanism, both reactions occur at the wall surface; therefore, the effects of fluid temperature are expected to be small, as is seen in Figure 8.15. The slight reduction in the fouling resistance at $15 \mathrm{~h}$ is mostly due to an increase in back-diffusion of precursor caused by changes in the physical properties. Because the bulk reaction is not considered in the Case 3 fouling mechanism (i.e., the foulant concentration in the bulk is negligible), the Case 3 prediction cannot be combined with the Case $1 \mathrm{~b}$ prediction to give an overall rate of fouling.

The results discussed in this section clearly identify differences in the effect of fluid temperature on the fouling rate for the three fouling cases. The closed-flow-loop experimental data must be carefully applied to industrial conditions, even though the same fluid system may be used in both systems. In the present experimental work, the fluid temperature was not varied; therefore, it is not possible to identify the controlling fouling mechanism on the basis of the fluid temperature. 


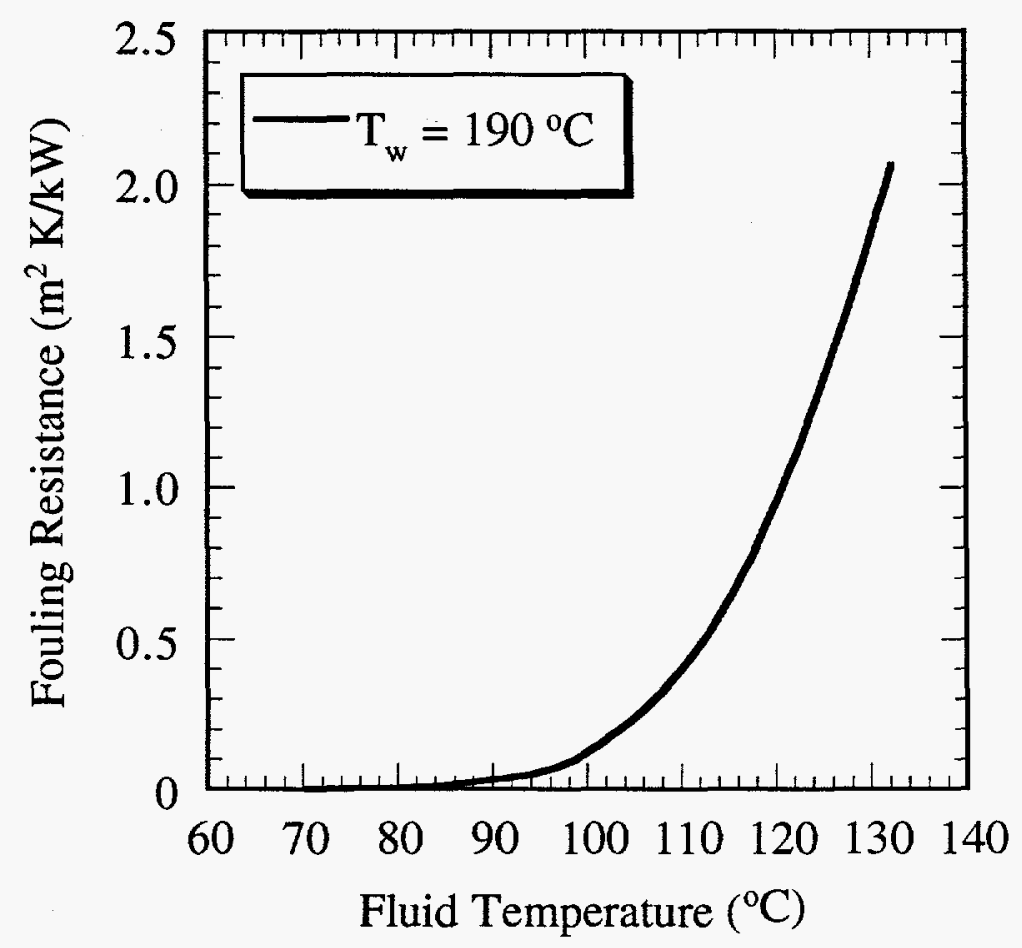

FIGURE 8.13 Effect of Fluid Temperature on the Fouling Resistance at $15 \mathrm{~h}$ as Predicted by Case $1 \mathrm{~b}$

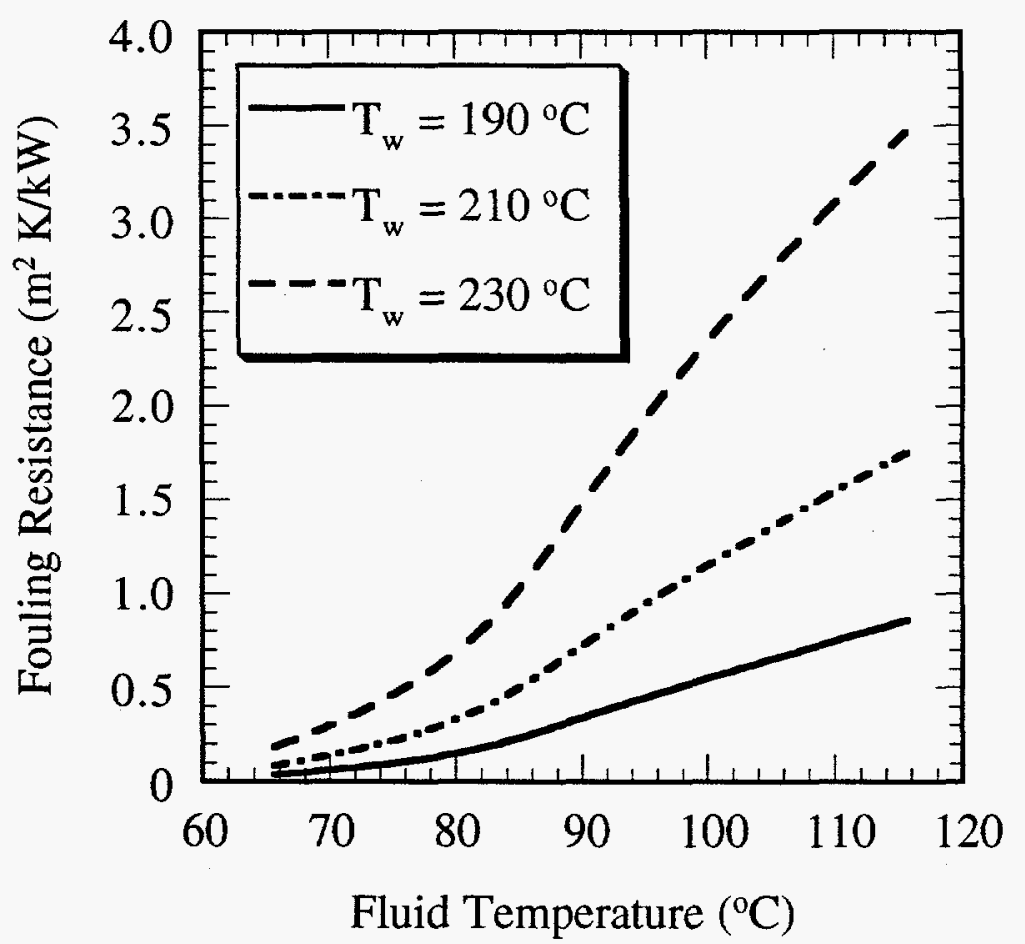

FIGURE 8.14 Effect of Fluid Temperature on the Fouling Resistance at $15 \mathrm{~h}$ as Predicted by Case 2 


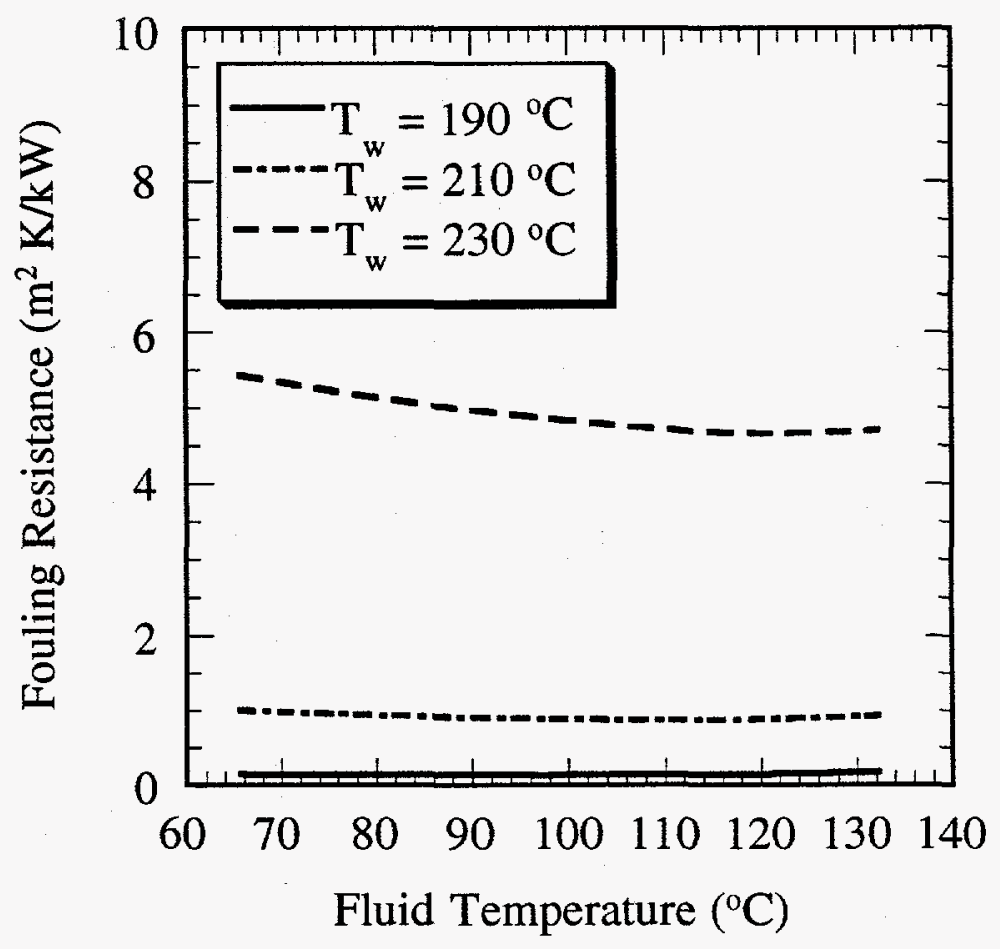

FIGURE 8.15 Effect of Fluid Temperature on the Fouling Resistance at $15 \mathrm{~h}$ as Predicted by Case 3

\subsubsection{Indene Concentration}

The effect of indene concentration on the fouling resistance at $15 \mathrm{~h}$ is shown in Figure 8.16 for the three fouling mechanisms. Other parameters, including fluid velocity, wall and fluid temperatures, and oxygen concentration, were kept at nominal values. Because indene is consumed during the fouling process, the results shown in Figure 8.16 are integral effects for the period of $15 \mathrm{~h}$. On the basis of the reaction mechanism, the rate of precursor generation is indene concentration raised to a power of 1.5. The effective power on the basis of the calculated fouling data is about 1.44 for Cases 1a, 2, and 3, and about 1.47 for Case $1 \mathrm{~b}$. However, the effects of mass transfer and local temperature distribution may alter the effect of indene concentration. The computed results show that the relative effects of indene concentration for Cases 1a, 2, and 3 are comparable. The effect is more significant for the Case 2 fouling model than for the other two cases. The Case $1 \mathrm{~b}$ fouling mechanism is governed by both reactions occurring in the bulk; therefore, the relative effect of indene concentration on the fouling deposition can be easily estimated by calculating the rate of reaction at bulk conditions.

The three fouling cases differ in the interactive effects of fluid dynamics, which affect the heat and mass transfer and the governing chemical reaction. For the given fluid dynamic conditions and the rate of chemical reaction, the results in Figure 8.16 show the difference in the effects of reactant concentration. The results cannot be generalized for a wide range of operating conditions, because the relative effects of the heat and mass transfer and chemical reaction vary 


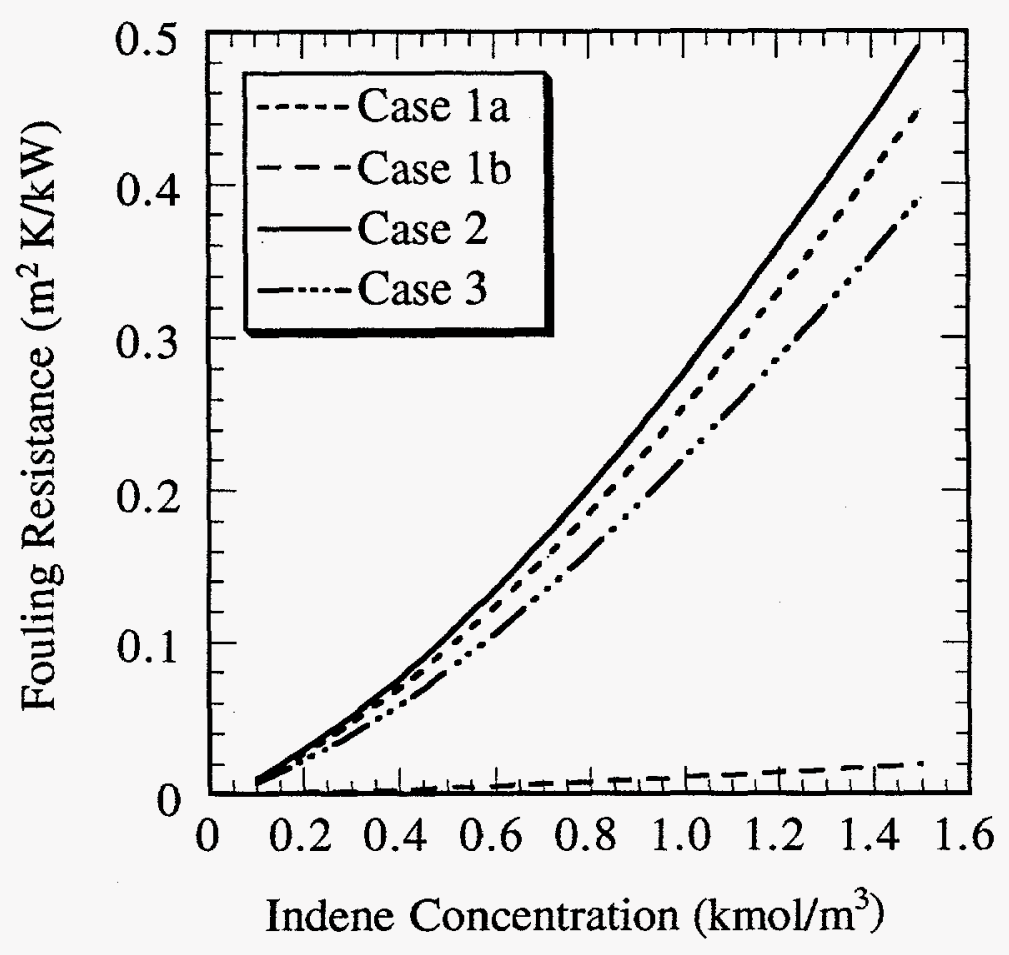

FIGURE 8.16 Effect of Indene Concentration on the Fouling Resistance at $15 \mathrm{~h}$ as Predicted by the Three Fouling Cases

with the operating conditions. For example, the differences between the three fouling cases are expected to widen significantly as the fluid and wall temperatures are increased, because at higher temperatures, the heat and mass transfer become more significant than the chemical reaction rate.

\subsubsection{Oxygen Concentration}

The effect of oxygen concentration on the fouling resistance at $15 \mathrm{~h}$ is shown in Figure 8.17. Oxygen concentration is assumed constant during the fouling cycle, while indene is being consumed; therefore, the results are based on constant oxygen concentration during the fouling process. The reaction kinetics for the precursor formation show that the rate is proportional to the oxygen concentration raised to a power of 0.5 . The results in Figure 8.17 show that the effective power is about 0.45 for Cases $1 \mathrm{a}, 2$ and 3 , while the power is about 0.52 for Case 1b. The effects of heat and mass transfer, although small for the given set of conditions, are clearly identified in these results.

The experimental fouling data reported in the literature (Watkinson 1988) show that the dissolved oxygen is an important parameter for the fouling process where autoxidation is the governing chemical mechanism. The experimental work with industrial fluids (Taylor et al. 1974) showed that the rate of fouling was negligible when oxygen was removed from the fluid. No 


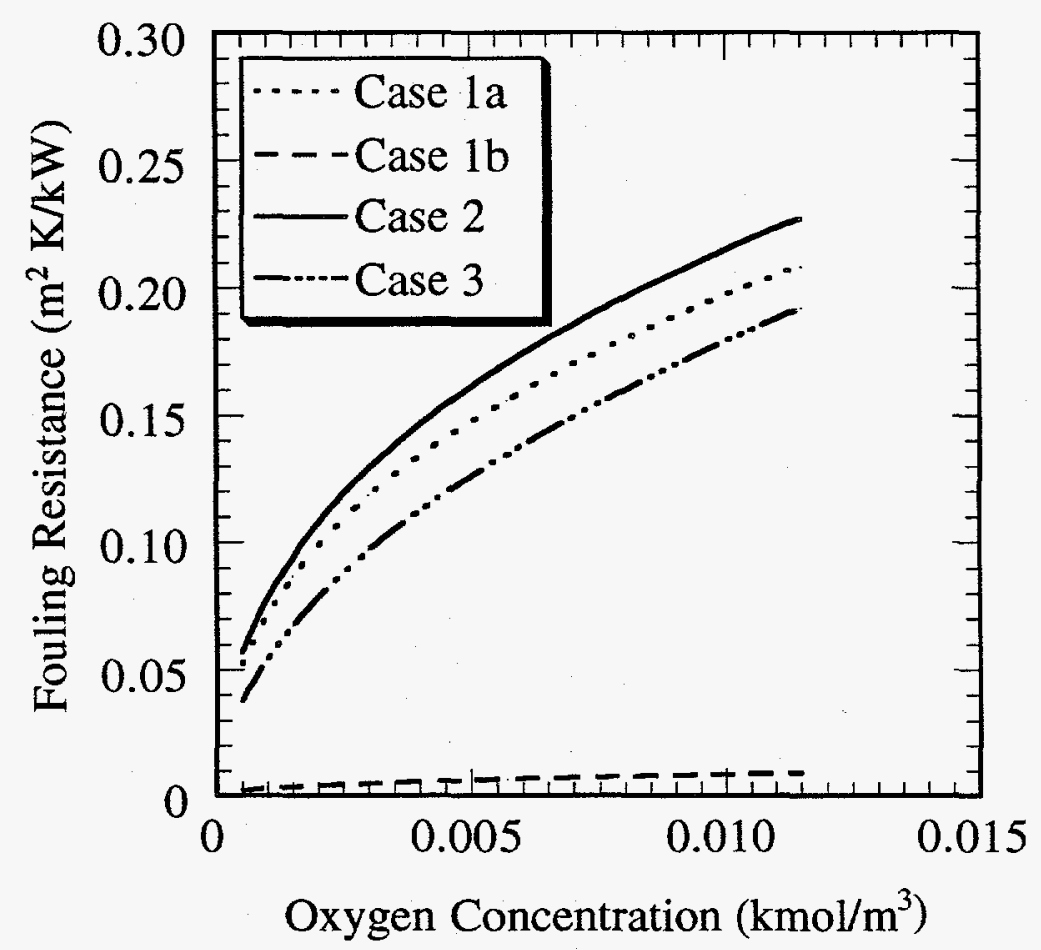

FIGURE 8.17 Effect of Oxygen Concentration on the Fouling Resistance at $15 \mathrm{~h}$ as Predicted by the Three Fouling Cases

systematic study has been carried out to determine the threshold concentration of dissolved oxygen below which the rate of fouling would not follow the fouling curve shown in Figure 8.17. This investigation will require a better understanding of the initiation mechanism for fouling deposition.

\subsection{Once-Through Flow}

Once-through flow is encountered in most industrial applications; therefore, an analysis was carried out to determine the local fouling deposition along the length of a flow passage representative of a heat exchanger. The chemical system of indene in kerosene, used for the closed-loop flow in Section 8.1, is considered for once-through flow calculations. As stated in Section 1 , one of the objectives of the analysis is to show the applicability of the fouling model to industrial conditions. The fouling models for the three cases were validated for the same set of experimental data obtained for the closed-loop flow apparatus. The results show differences in the ability of each of the three fouling mechanisms to extrapolate the closed-loop data to the oncethrough flow conditions typical of industrial applications.

The inlet conditions shown in Table 8.2 are similar to the baseline conditions used for the ANL fouling experiments. However, the outlet conditions at any time vary, depending on the local rate of fouling at a given axial length. The heating-media temperature is kept constant during the 
TABLE 8.2 Baseline Test Conditions for the Parametric Analysis for Once-Through Flow

\begin{tabular}{lc}
\hline \multicolumn{1}{c}{ Parameter } & Value \\
& \\
\hline & \\
Fluid velocity $(\mathrm{m} / \mathrm{s})$ & 1.0 \\
Fluid temperature at inlet $\left({ }^{\circ} \mathrm{C}\right)$ & 82.2 \\
Heating-media temperature $\left({ }^{\circ} \mathrm{C}\right)$ & 300.0 \\
Heating-media heat-transfer coefficient $\left(\mathrm{kW} / \mathrm{m}^{2} \cdot \mathrm{K}\right)$ & 8.0 \\
Indene concentration at inlet $\left(\mathrm{kmol} / \mathrm{m}^{3}\right)$ & 0.71 \\
Oxygen concentration at inlet $\left(\mathrm{kmol} / \mathrm{m}^{3}\right)$ & 0.0057 \\
Precursor concentration at inlet $\left(\mathrm{kmol} / \mathrm{m}^{3}\right)$ & 0.0 \\
Tube diameter $(\mathrm{mm})$ & 7.75 \\
Tube length $(\mathrm{m})$ & 3.0 \\
& \\
\hline
\end{tabular}

period of buildup of fouling deposition. As a result of the fouling deposition, the overall rate of heat transfer decreases with time, which lowers the outlet-fluid temperature. The conditions described above represent a typical set of industrial conditions in which a condensing heat source is used for heating the fluid stream. In order to bring the fluid temperature to the process condition, additional heating is required to compensate for the loss due to fouling.

The local fouling resistance at $15 \mathrm{~h}$ as predicted by each of the three fouling models is shown in Figure 8.18. Because the precursor concentration at the inlet is zero and the Case 1a and Case 2 fouling mechanisms are based on generation of the precursor in the bulk, the predicted fouling resistance at the inlet is negligibly small. Along the tube length, increases in the interface (between the fluid and the fouling film) temperature and the precursor concentration result in increasingly higher fouling resistance. However, the Case 3 fouling mechanism does not depend on the bulk conditions; therefore, the fouling resistance starts from the inlet, and the increase in the fouling resistance along the length of the tube is mostly caused by higher wall temperature. The results in Figure 8.18 clearly indicate that, if the fouling mechanism is controlled by either Case 1a or Case 2, fouling deposition occurs predominantly in the outlet part of the heat exchanger; the precursor concentration increases from zero at the inlet to about $0.001 \mathrm{kmol} / \mathrm{m}^{3}$ at the outlet. On the other hand, if the fouling mechanism is controlled by Case 3, the fouling deposition would be throughout the heat exchanger. The bulk and the interface temperature profiles at time zero and at time $15 \mathrm{~h}$ are shown in Figures 8.19 and 8.20 , respectively. The outlet bulk temperature at time zero was $213.7^{\circ} \mathrm{C}$, which decreased to $210.7,208.2$, and $165.7^{\circ} \mathrm{C}$ at time $15 \mathrm{~h}$, as predicted by the Case 1a, Case 2, and Case 3 fouling mechanisms, respectively. The heat duty that cannot be provided by a given heat exchanger because of fouling buildup is supplied either by providing a make-up heat-exchange unit (e.g., gas-fired heat exchanger) or by raising the temperature (e.g., higher steam pressure) of the heating media. In either case, there is a net loss of energy for the overall system. 


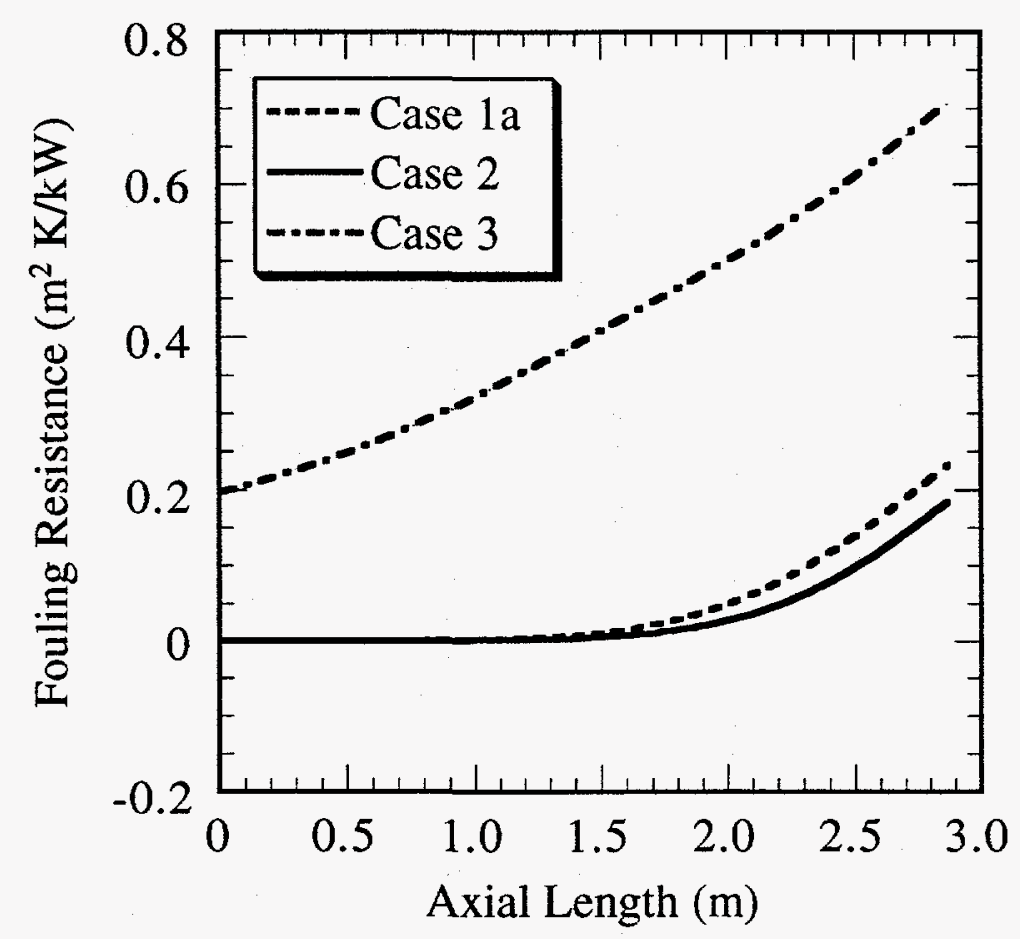

FIGURE 8.18 Distribution of the Fouling Resistance along the Heat-Exchanger Length at $15 \mathrm{~h}$ as Predicted by the Three Fouling Cases: Zero Precursor Concentration at the Inlet

The interface temperatures, shown in Figure 8.20, provide a general view of the operation of the heat exchanger as fouling builds up in a given area. As the fouling deposition occurs locally, the heat flux decreases, leading to lower interfacial temperature. In such a case, the local rate of fouling drops, and the heat duty is redistributed. Because of the similarity of the Case la and Case 2 fouling mechanisms, the predicted fouling trend and the outlet temperature for these two cases are similar, whereas they differ for the Case 3 fouling mechanism. The set of conditions used for the analysis may have given an accelerated fouling deposition; however, similar overall behavior is expected for industrial heat exchangers. The fouling resistance at the outlet end of the heat-exchanger tube as a function of time is shown in Figure 8.21. This figure shows that the fouling deposition takes place gradually for Case 1a and Case 2, but the fouling deposition for Case 3 is rapid initially, which lowers the interfacial temperature; consequently, the rate of fouling is relatively low. However, by the time the rate of fouling levels off, the thermal performance of the heat-exchanger becomes unacceptable, and cleaning of the heat-exchanger is required.

In many cases, the precursor can be generated in a heat exchanger or a reactor upstream of the heat exchanger, where serious fouling can occur. The fouling resistance along the tube length for the case where the inlet concentration of the precursor is $0.01 \mathrm{kmol} / \mathrm{m}^{3}$ is shown in Figure 8.22. As expected, the overall fouling deposition is significantly greater than that for zero inlet precursor concentration. As for the case of zero inlet precursor concentration, the rate of 


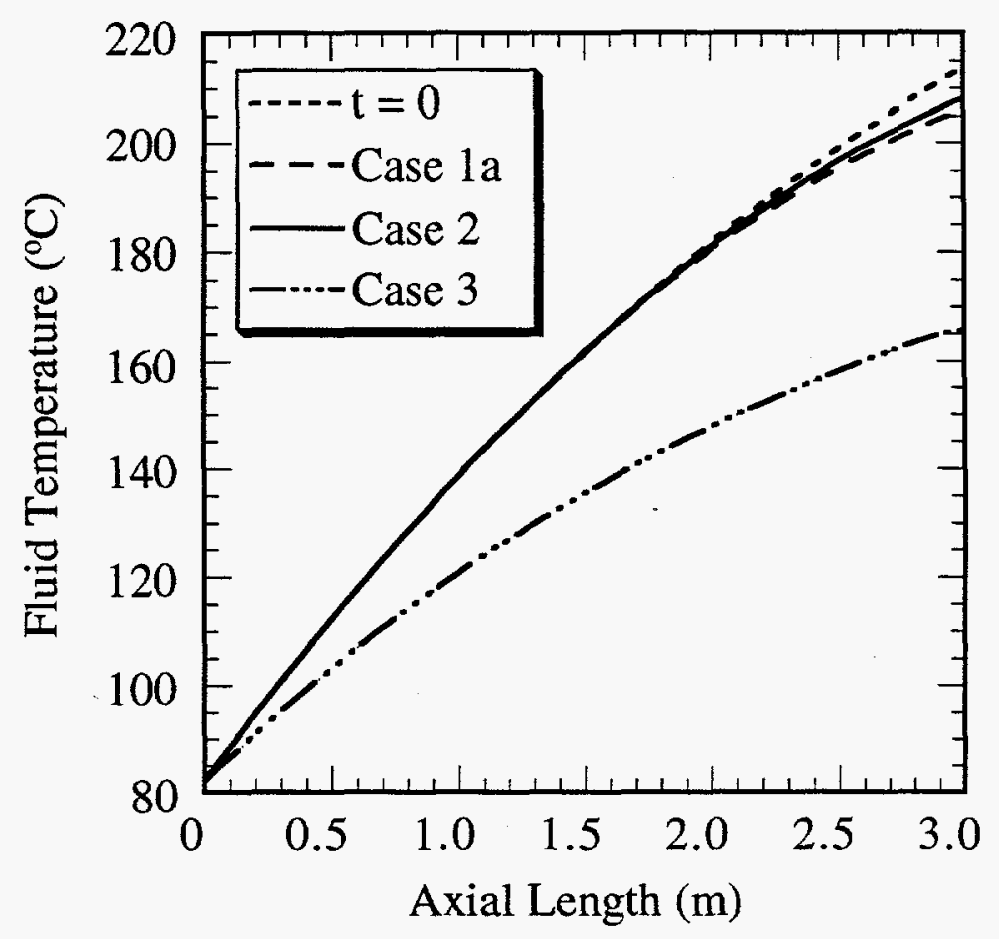

FIGURE 8.19 Distribution of the Fluid Temperature along the Heat-Exchanger Length at Time 0 and $15 \mathrm{~h}$ as Predicted by the Three Fouling Cases: Zero Precursor Concentration at the Inlet

fouling for Case 3 was greater than that for Case 1a and Case 2. The corresponding change in the fluid-temperature and interfacial-temperature profiles are shown in Figures 8.23 and 8.24, respectively. The significant drop in the outlet temperature indicates that the thermal performance of a heat exchanger can be seriously affected by fouling deposition caused by precursor generated in some other part of the industrial process (e.g., upstream heat-exchanger or chemical reactor). Because of the significant drop in the heat flux caused by the fouling deposition, the interfacial temperature decreased. However, the effects of lower interfacial temperature on the local rate of fouling were offset by the higher precursor concentration, giving a relatively high fouling rate. The fouling resistance at the outlet end of the heat-exchanger tube as a function of time is shown in Figure 8.25. The general trend of the results shown in Figure 8.25 is similar to that shown in Figure 8.21 for zero inlet precursor concentration. However, the fouling resistance for inletprecursor concentration of $0.01 \mathrm{kmol} / \mathrm{m}^{3}$ is significantly large as compared to that for zero inlet precursor concentration.

The results discussed in this section were intended to show the expected fouling behavior of a typical heat-exchanger. In addition, this section provided an overview of how one can apply the laboratory data to industrial conditions with the help of a fouling model to account for the physical and chemical processes associated with the fouling process. 


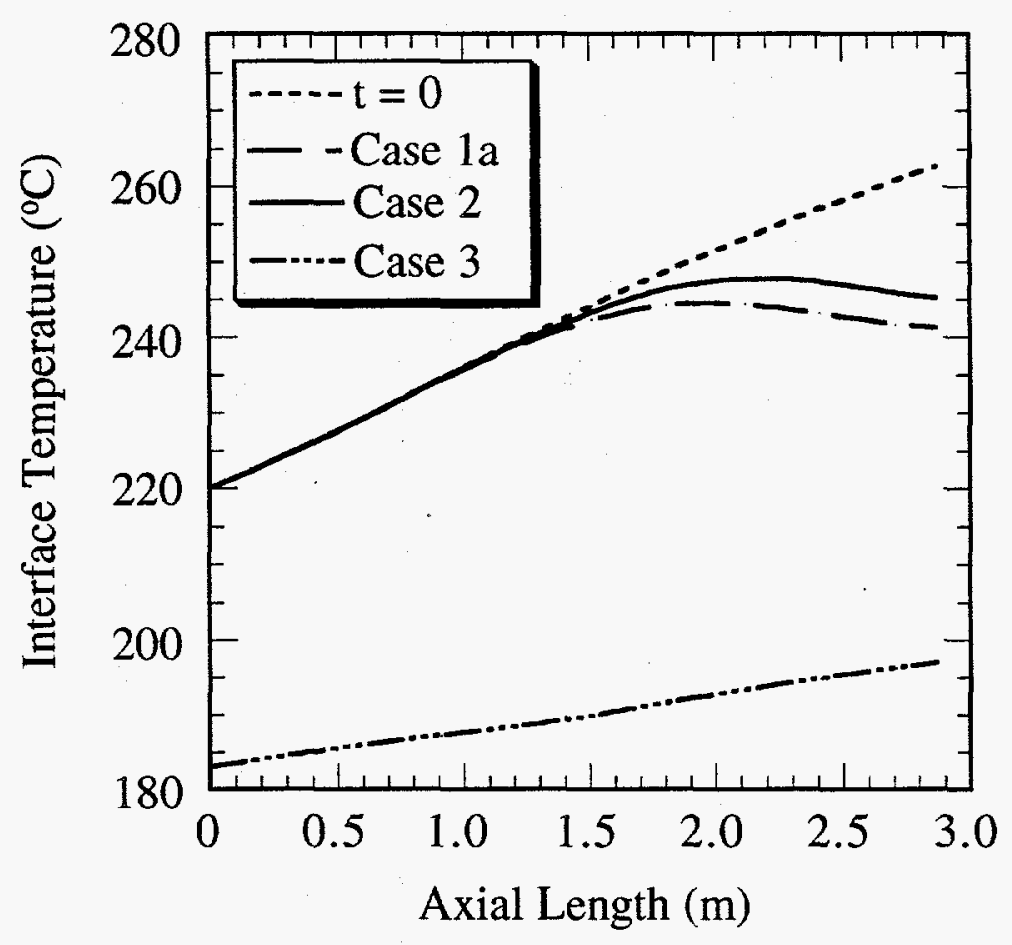

FIGURE 8.20 Distribution of the Interface Temperature along the Heat-Exchanger Length at Time 0 and $15 \mathrm{~h}$ as Predicted by the Three Fouling Cases: Zero Precursor Concentration at the Inlet

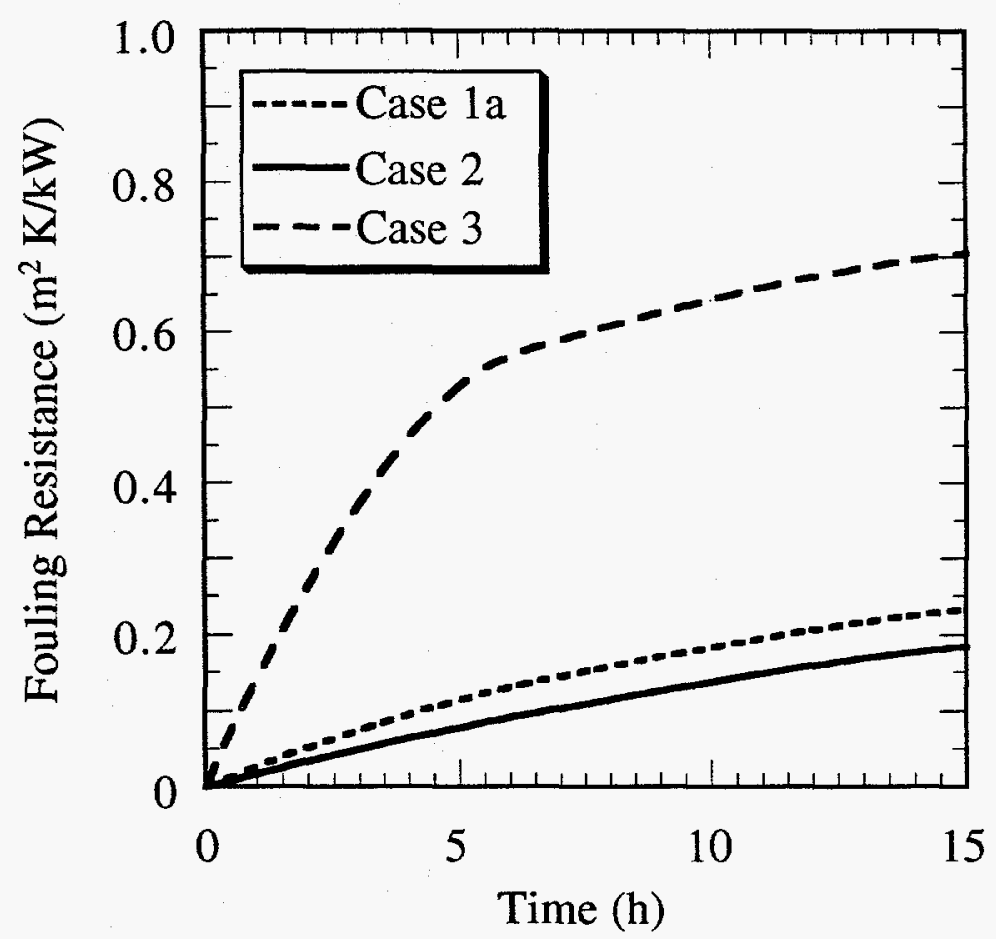

FIGURE 8.21 Fouling Resistance at the Outlet as a Function of Time as Predicted by the Three Fouling Cases: Zero Precursor Concentration at the Inlet 


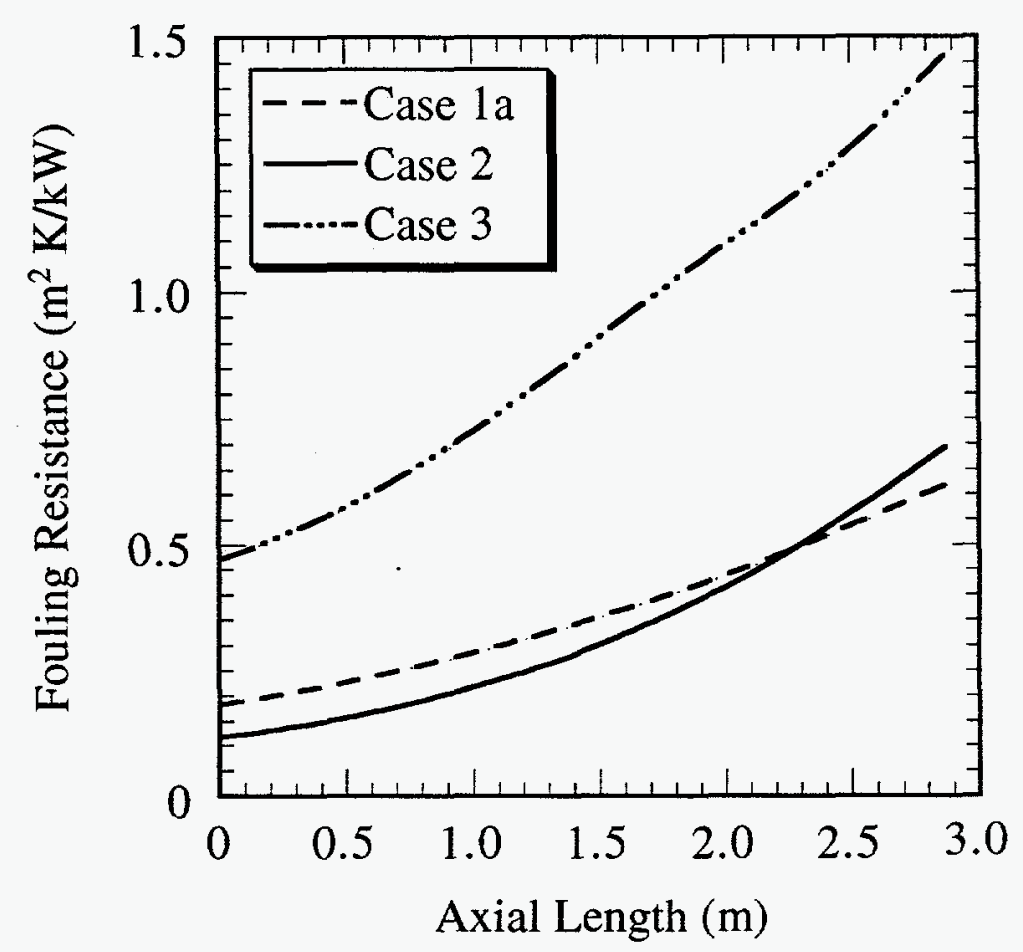

FIGURE 8.22 Distribution of the Fouling Resistance along the Heat-Exchanger Length at $15 \mathrm{~h}$ as Predicted by the Three Fouling Cases: Inlet Precursor Concentration of $0.01 \mathrm{kmol} / \mathrm{m}^{3}$

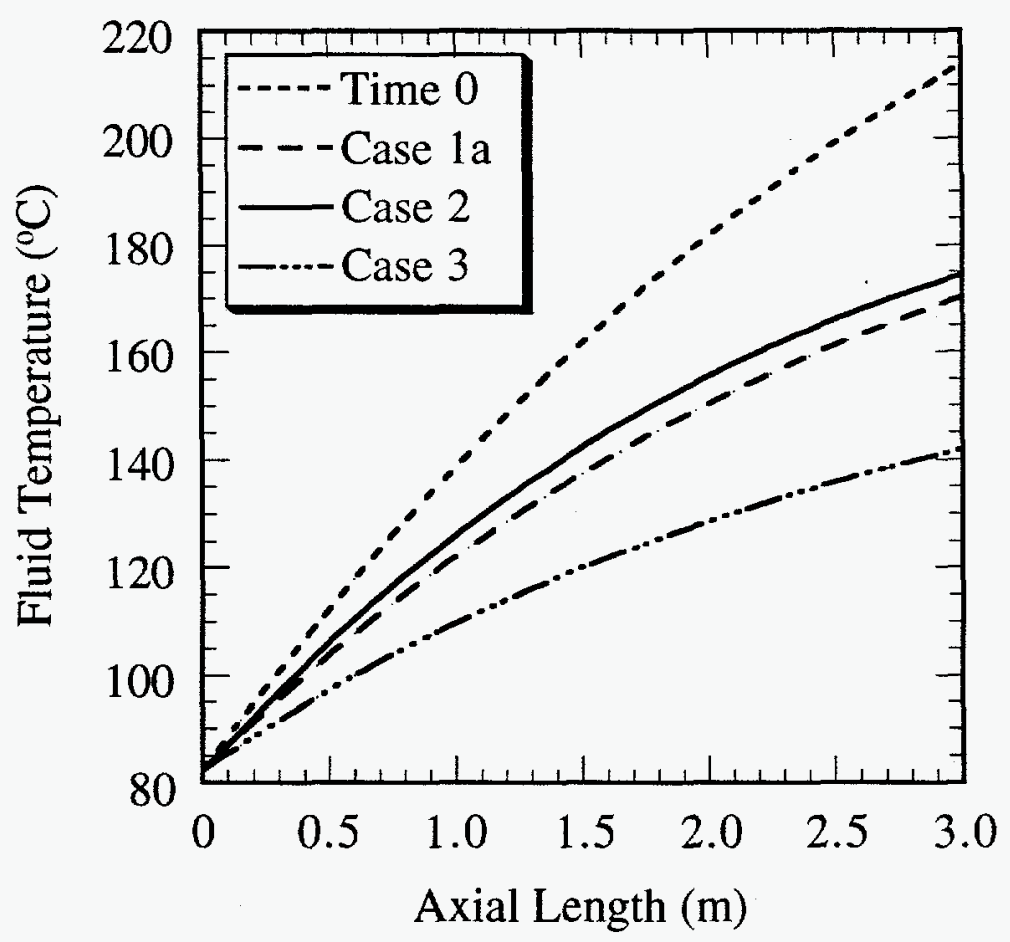

FIGURE 8.23 Distribution of the Fluid Temperature along the Heat-Exchanger Length at Time 0 and $15 \mathrm{~h}$ as Predicted by the Three Fouling Cases: Inlet Precursor Concentration of $0.01 \mathrm{kmol} / \mathrm{m}^{3}$ 


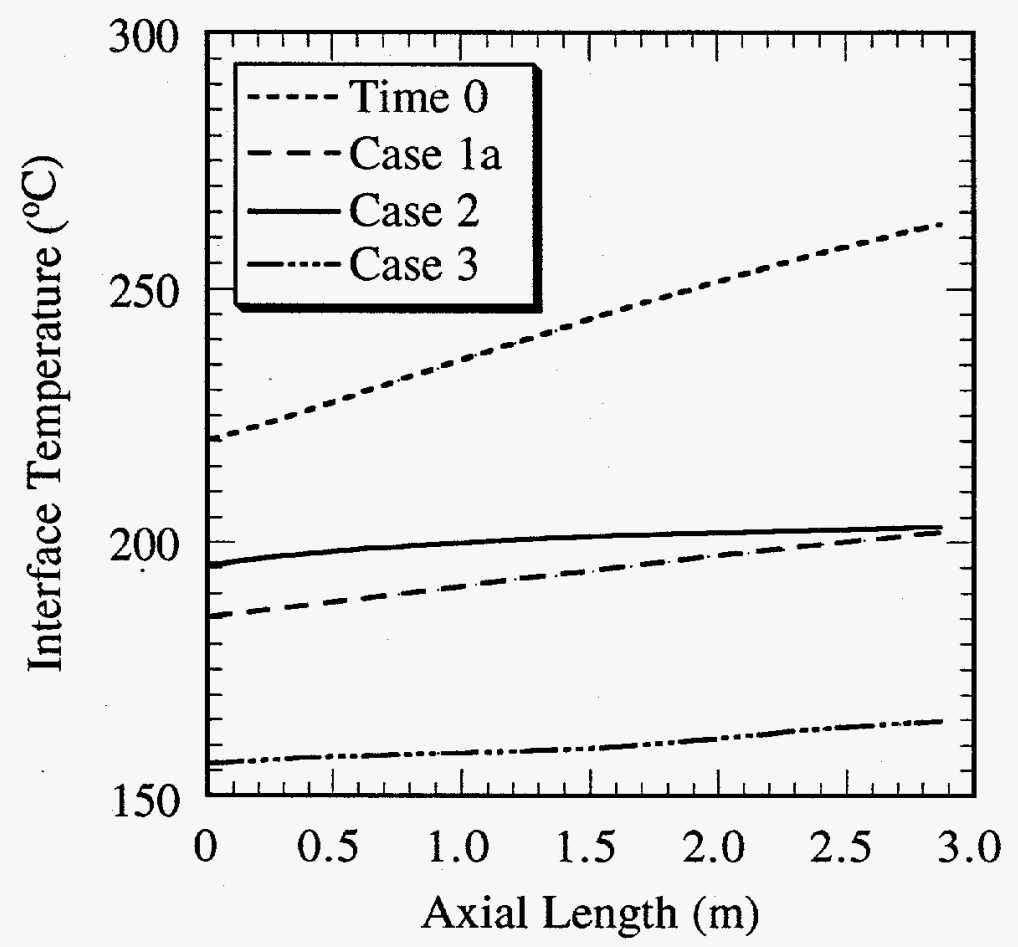

FIGURE 8.24 Distribution of the Interface Temperature along the Heat-Exchanger Length at Time 0 and $15 \mathrm{~h}$ as Predicted by the Three Fouling Cases: Inlet Precursor Concentration of $0.01 \mathrm{kmol} / \mathrm{m}^{3}$

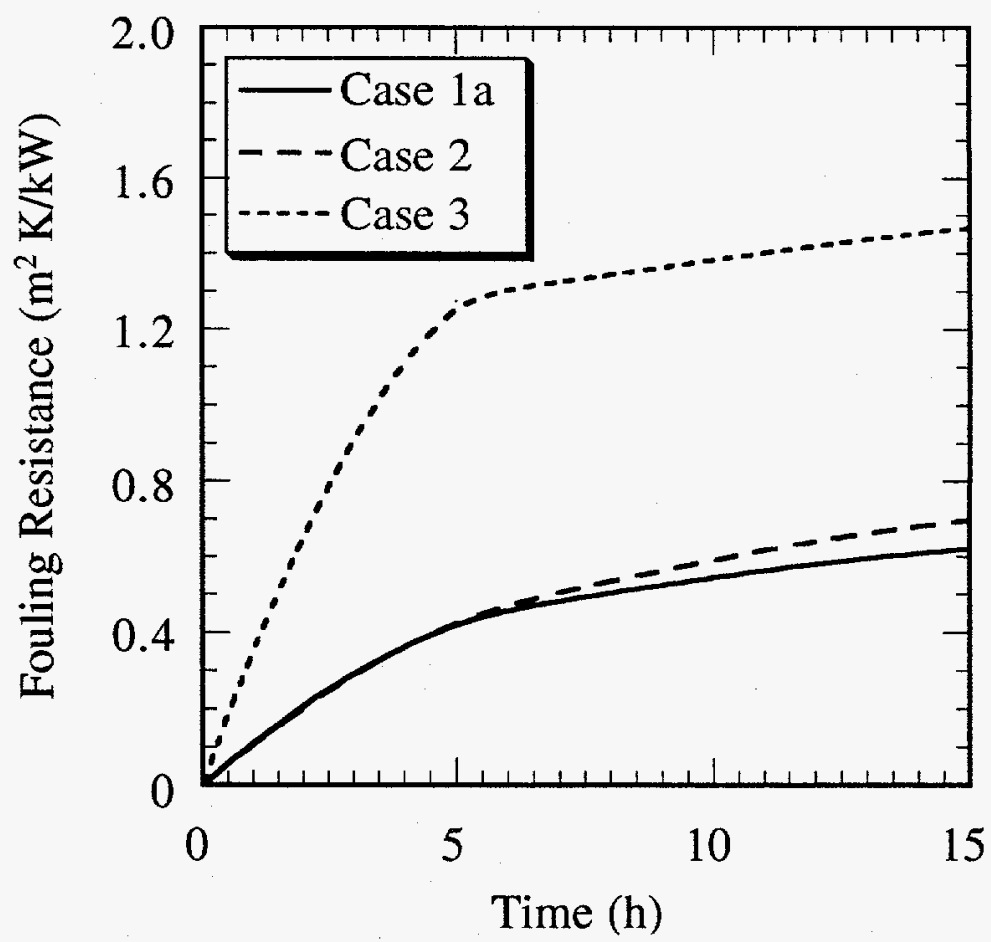

FIGURE 8.25 Fouling Resistance at the Outlet as a Function of Time as Predicted by the Three Fouling Cases: Inlet Precursor Concentration of $0.01 \mathrm{kmol} / \mathrm{m}^{3}$ 


\section{Computer Program}

The fouling model was coded into a computer program to calculate the rate of fouling. The computer program was specifically developed for the analysis of the experimental data taken with the test apparatus at ANL and UBC. However, the program was modified for general use. Two versions of the program are described in this section: closed-flow loop and once-through flow. In both cases, the user can pick one of the three fouling cases described in this report. The computer program was developed as a research tool; therefore, it should not be used as part of a design code.

\subsection{Calculation Algorithms}

The overall structure of the program is shown in Figure 9.1. The main program takes the input data and calculates the results. It calls the TIME subroutine to integrate the rate of reaction and fouling deposition and to calculate changes in bulk conditions for each component. The resulting calculation gives the fouling resistance as a function of time for HTM and HXTUBE. The HTM subroutine calculates the fouling resistance for a small section. On the other hand, the HXTUBE subroutine calculates the local fouling resistance by considering the change in bulk conditions along the tube length. For the once-through flow system, HXTUBE is the main subroutine. The CSTR subroutine is used for a closed-flow-loop system. In the CSTR subroutine, the bulk reaction is allowed to occur in a batch-reaction mode. The TUBE subroutine calculates the bulk reaction in a given length of tube under isothermal conditions at a given temperature. The TIME subroutine can be modified to interconnect different components for a given experimental system. The once-through flow system consists of HXTUBE only, and the closed-flow-loop system is set up as follows:

$$
\text { CSTR } \Rightarrow \text { TUBE } \Rightarrow \text { HTM } \Rightarrow \text { TUBE } \Rightarrow \text { CSTR. }
$$

The list of input parameters required for the once-through flow system is shown in Table 9.1. The heat flux along the tube length can be assumed to be constant at a given value or constant temperature for a condensing heating media. For the latter, it is necessary to provide the heat-transfer coefficient for the condensing media. Olefin, oxygen, and polyperoxide (precursor) concentrations are provided at the inlet, along with temperature and flow rate. Foulant properties are required to convert the results from deposition rate in terms of moles per unit time per unit area to fouling resistance. It may be difficult to measure experimentally or to estimate the foulant properties; therefore, a set of fouling data are required for validating the fouling model. Such a validation can be done with a small laboratory-scale test apparatus; afterward the fouling model can be applied to industrial conditions. A set of typical values is given in Table 9.1 for the baseline case used in Section 7.

The input data required for the fouling model for a closed-flow-loop system are shown in Table 9.2. It is assumed that a cooling system is provided for maintaining the reservoir temperature and that heat flux is maintained constant. One can provide either the wall temperature 


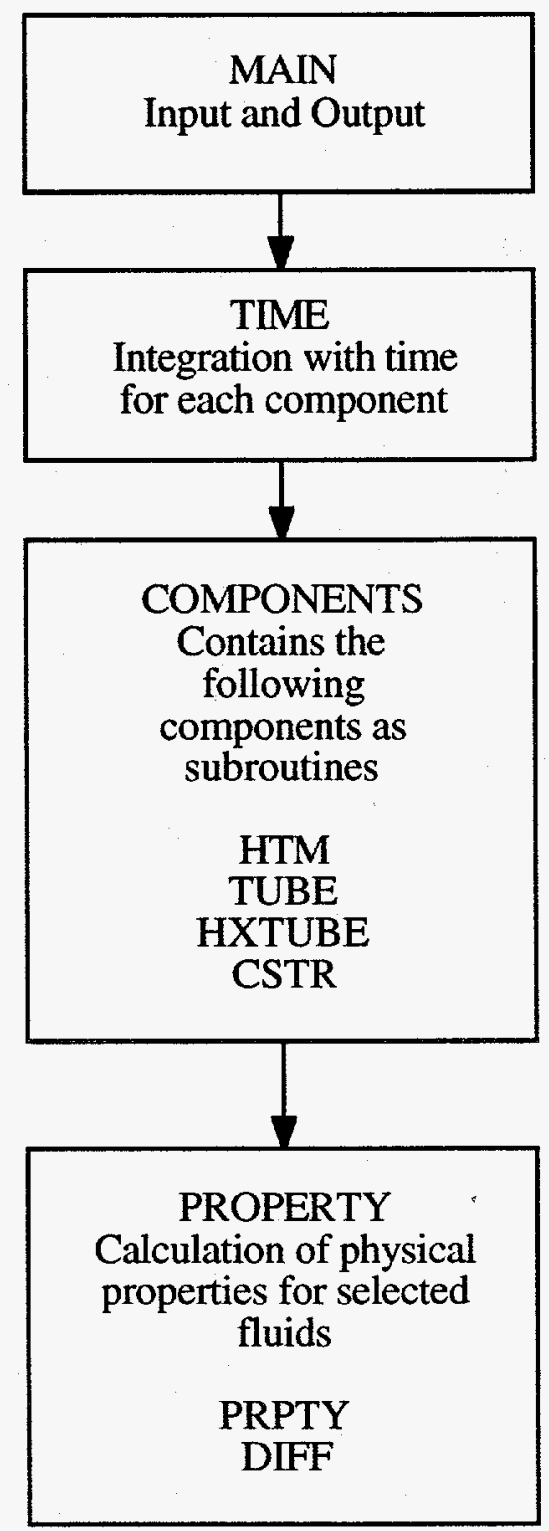

FIGURE 9.1 Overall

Structure of the Computer

Program for the Fouling Model 
TABLE 9.1 Input Parameter List for Once-Through-Flow System

\begin{tabular}{|c|c|c|}
\hline Parameter & $\begin{array}{l}\text { Computer } \\
\text { Code Name }\end{array}$ & $\begin{array}{l}\text { Typical } \\
\text { Value }\end{array}$ \\
\hline \multicolumn{3}{|l|}{ System } \\
\hline Tube diameter $(\mathrm{m})$ & TUBED & 0.00775 \\
\hline Tube length $(m)$ & TUBEL & 3.0 \\
\hline Wall resistance $(\mathrm{m} \cdot \mathrm{K} / \mathrm{kW})$ & RWALL & 0.06 \\
\hline Heat flux (optional) $\left(\mathrm{kW} / \mathrm{m}^{2}\right)$ & QFLUX & 160.0 \\
\hline $\begin{array}{l}\text { Heat transfer coefficient for heating media } \\
\left(\mathrm{kW} / \mathrm{m}^{2} \cdot \mathrm{K}\right)\end{array}$ & HHEAT & 5.0 \\
\hline Temperature of heating media $\left({ }^{\circ} \mathrm{C}\right)$ & THEAT & 150.0 \\
\hline Time for computing fouling (h) & TIMEF & 40.0 \\
\hline Time increment for integration (h) & DELTAT & 0.5 \\
\hline \multicolumn{3}{|l|}{ Inlet Conditions } \\
\hline Flow rate $\left(\mathrm{m}^{3} / \mathrm{s}\right)$ & GFLUID & 0.000048 \\
\hline Inlet temperature $\left({ }^{\circ} \mathrm{C}\right)$ & TFIN & 82.0 \\
\hline Olefin concentration at inlet $\left(\mathrm{kmol} / \mathrm{m}^{3}\right)$ & CR10 & 0.71 \\
\hline Oxygen concentration at inlet $\left(\mathrm{kmol} / \mathrm{m}^{3}\right)$ & CR2O & 0.0057 \\
\hline Polyperoxide concentration $\left(\mathrm{kmol} / \mathrm{m}^{3}\right)$ & CRPO & 0.0 \\
\hline \multicolumn{3}{|l|}{ Foulant Properties } \\
\hline Density $\left(\mathrm{kg} / \mathrm{m}^{3}\right)$ & FRHO & $1,000.0$ \\
\hline Conductivity $(\mathrm{kW} / \mathrm{m} \cdot \mathrm{K})$ & FCOND & 0.0002 \\
\hline Molecular weight & FMW & $2,368.0$ \\
\hline
\end{tabular}

for the HTM or the heat flux (then the wall temperature is internally calculated). The flow geometry for the HTM can be either tubular or annular. By inputting a zero value for HTMOD, one can indicate that tubular HTM is being analyzed. Oxygen concentration is calculated by using the ASTM D3827-92 standard. One can either assume depleting (OPTION = 1) or constant $(\mathrm{OPTION}=0$ ) oxygen concentration in the reservoir. A set of typical values is given in Table 9.2 for the baseline case used in Section 7.

Reaction constants to be provided by the user are shown in Table 9.3. As discussed earlier, the reaction path is assumed to be olefin reacting with oxygen to form polyperoxide (soluble gum as precursor), which will then further polymerize to form insoluble polyperoxide (foulant). A typical set of reaction constants is given in Table 9.3 for the autoxidation of indene. The constants for reaction 1 are derived from the batch data of Russell (1957), and the constants for reaction 2 are derived from the fouling data as discussed in Section 7. 
TABLE 9.2 Input Parameter List for Closed-Flow-Loop System

\begin{tabular}{|c|c|c|}
\hline Parameter & $\begin{array}{l}\text { Computer } \\
\text { Code Name }\end{array}$ & $\begin{array}{l}\text { Typical } \\
\text { Value }\end{array}$ \\
\hline \multicolumn{3}{|l|}{ System } \\
\hline Tube diameter - inlet to HTM (m) & TUBECD & 0.00775 \\
\hline Tube length - inlet to HTM (m) & TUBECL & 6.0 \\
\hline Tube diameter - outlet to HTM (m) & TUBEHD & 0.00775 \\
\hline Tube length - outlet to HTM (m) & TUBEHL & 6.0 \\
\hline Tube diameter for HTM (m) & HTMD & 0.00775 \\
\hline Outer tube diameter for annular probe $(\mathrm{m})$ & HTMOD & 0.0 \\
\hline Liquid volume in reservoir $\left(\mathrm{m}^{3}\right)$ & CSTRV & 0.0045 \\
\hline Option to maintain constant oxygen concentration & OPTION & 0.0 \\
\hline Time for computing fouling $(\mathrm{h})$ & TIMEF & 40.0 \\
\hline Time increment for integration $(h)$ & DELTAT & 0.5 \\
\hline \multicolumn{3}{|l|}{ Initial Operating Conditions } \\
\hline Flow rate $\left(\mathrm{m}^{3} / \mathrm{s}\right)$ & GFLUID & 0.000048 \\
\hline Olefin concentration $\left(\mathrm{kmol} / \mathrm{m}^{3}\right)$ & CR10 & 0.71 \\
\hline Oxygen concentration $\left(\mathrm{kmol} / \mathrm{m}^{3}\right)$ & CR2O & 0.0057 \\
\hline HTM wall temperature $\left({ }^{\circ} \mathrm{C}\right)$ & TWHTM & 187.0 \\
\hline Heat flux for HTM (optional) $\left(\mathrm{kW} / \mathrm{m}^{2}\right)$ & QFLUX & 160.0 \\
\hline Fluid temperature in reservoir $\left({ }^{\circ} \mathrm{C}\right)$ & TFLUID & 82.0 \\
\hline \multicolumn{3}{|l|}{ Foulant Properties } \\
\hline Density $\left(\mathrm{kg} / \mathrm{m}^{3}\right)$ & FRHO & $1,000.0$ \\
\hline Conductivity $(\mathrm{kW} / \mathrm{m} \cdot \mathrm{K})$ & FCOND & 0.0002 \\
\hline Molecular weight & FMW & $2,368.0$ \\
\hline
\end{tabular}


TABLE 9.3 Reaction Parameters

\begin{tabular}{|c|c|c|}
\hline Parameter & $\begin{array}{l}\text { Computer } \\
\text { Code Name }\end{array}$ & $\begin{array}{l}\text { Typical } \\
\text { Value }\end{array}$ \\
\hline Reaction 1 kinetic constant $\left(\mathrm{m}^{3} / \mathrm{kmol} \cdot \mathrm{s}\right)$ & ALFA1 & $1.81 \times 10^{10}$ \\
\hline Reaction 2 kinetic constant (L/s) & ALFA2 & $9.6 \times 10^{7}$ \\
\hline Reaction 1 activation energy $(\mathrm{kJ} / \mathrm{mol})$ & E1 & 96.3 \\
\hline Reaction 2 activation energy $(\mathrm{kJ} / \mathrm{mol})$ & E2 & 96.3 \\
\hline Stoichiometric parameter for olefin & s1 & 1.0 \\
\hline Stoichiometric parameter for oxygen & S2 & 1.0 \\
\hline $\begin{array}{l}\text { Stoichiometric parameter for polyperoxide in } \\
\text { reaction } 1\end{array}$ & S3 & 0.25 \\
\hline $\begin{array}{l}\text { Stoichiometric parameter for polyperoxide in } \\
\text { reaction } 2\end{array}$ & SP & 0.25 \\
\hline Reaction order for olefin & RM & 1.5 \\
\hline Reaction order for oxygen & RN & 0.5 \\
\hline Reaction order for polyperoxide & RL & 1.0 \\
\hline $\begin{array}{l}\text { Gas constant in matching units with activation } \\
\text { energy }(\mathrm{kJ} / \mathrm{mol} \cdot \mathrm{K})\end{array}$ & $\mathbf{R}$ & 0.008314 \\
\hline
\end{tabular}

\subsection{Physical Properties}

The physical properties for kerosene are calculated from the literature data. The effects of olefin on the physical properties are not included. Correlations used for calculating the physical properties are summarized below.

\subsubsection{Liquid Density}

The Hankinson-Brobst-Thomson correlation reported in Properties of Gases and Liquids by Reid, Prausnitz, and Poling (1987) was used to calculate the molar volume, $\mathrm{V}_{\mathrm{s}}$ :

$$
\frac{V_{s}}{V^{*}}=V_{R}(0)\left[1-\omega_{S R K} V_{R}(5)\right]
$$

where

$$
\begin{aligned}
& \mathrm{V}_{\mathrm{R}}(0)=1+\mathrm{a}(1-\mathrm{Tr})^{1 / 3}+\mathrm{b}(1-\mathrm{Tr})^{2 / 3}+\mathrm{c}(1-\mathrm{Tr})+\mathrm{d}(1-\mathrm{Tr})^{4 / 3} \\
& \text { when } 0.25<\mathrm{Tr}<0.95
\end{aligned}
$$


$\operatorname{Tr}=\mathrm{T} / \mathrm{Tc}$

$\mathrm{V}_{\mathrm{R}}(5)=\left[\mathrm{e}+\mathrm{f} \operatorname{Tr}+\mathrm{g} \operatorname{Tr}^{2}+\mathrm{h} \operatorname{Tr}^{3}\right] /(\operatorname{Tr}-1.00001)$,

when $0.25<\operatorname{Tr}<1.0$; and

where the values of the constants are as follows:

$$
\begin{aligned}
\mathrm{V}^{*} & =0.6674 \mathrm{~m}^{3} / \mathrm{kmol} \\
\omega_{\text {SRK }} & =0.4783 \\
\mathrm{Tc} & =664.30 \mathrm{~K} \\
\mathrm{a} & =-1.52816 \\
\mathrm{~b} & =1.43907 \\
\mathrm{c} & =-0.81446 \\
\mathrm{~d} & =0.190454 \\
\mathrm{e} & =-0.296123 \\
\mathrm{f} & =0.386914 \\
\mathrm{~g} & =-0.0427258 \\
\mathrm{~h} & =0.0480645
\end{aligned}
$$

The molar volume is converted to density, $\rho$ (in units of $\mathrm{kg} / \mathrm{m}^{3}$ ), by the equation,

$$
\rho=\mathrm{Wm} / \mathrm{V}_{\mathrm{s}}
$$

where the molecular weight of the liquid, $\mathrm{Wm}$, has a value of 166 . 


\subsubsection{Heat Capacity}

The following correlation, from the Petroleum Processing Handbook (McKetta 1992), was used for calculating heat capacity, $C_{p}$ (in units of $\mathrm{kJ} / \mathrm{kg} \cdot \mathrm{K}$ ):

$$
C_{p}=1.8748+3.7559 \times 10^{-3} \mathrm{t}
$$

where temperature $\mathrm{t}$ is in degrees Celsius.

\subsubsection{Viscosity}

The following correlation was used for calculating viscosity, $\mu$, where the constants were evaluated by using the experimental data reported in the Technical Data Book (1977). The correlation is shown in Equation 9.8, and a comparison of predicted and experimental viscosities (in units of Pa.s) is shown in Table 9.4.

$$
\mu=1.3277 \times 10^{-5} \exp (1393.35 / \mathrm{T})
$$

where $\mathrm{T}$ is the temperature in kelvin.

\subsubsection{Thermal Conductivity}

The following correlation was used for calculating thermal conductivity, $\mathrm{k}$, where the constants were determined by using the experimental data reported in the Technical Data Book. The correlation is shown in Equation 9.9, and a comparison of predicted and experimental thermal conductivities (in units of $\mathrm{W} / \mathrm{m} \cdot{ }^{\circ} \mathrm{C}$ ) is shown in Table 9.5:

$$
\mathrm{k}=0.1311-1.4123 \times 10^{-4} \mathrm{t}
$$

where the temperature $t$ is in degrees Celsius. 
TABLE 9.4 Predicted and Experimental Viscosities

\begin{tabular}{|c|c|c|}
\hline \multirow[b]{2}{*}{ Temperature $(\mathrm{K})$} & \multicolumn{2}{|c|}{ Viscosity $\left(10^{-4} \mathrm{~Pa} \cdot \mathrm{s}\right)$} \\
\hline & Measured & Predicted \\
\hline 317.65 & 10.617 & 10.668 \\
\hline 327.65 & 9.361 & 9.332 \\
\hline 337.65 & 8.299 & 8.227 \\
\hline 347.65 & 7.264 & 7.307 \\
\hline 357.65 & 6.516 & 6.532 \\
\hline 367.65 & 5.882 & 5.875 \\
\hline
\end{tabular}

TABLE 9.5 Predicted and Experimental Thermal Conductivities

\begin{tabular}{ccc}
\hline & $\begin{array}{c}\text { Thermal Conductivity } \\
\left(10^{-4} \mathrm{~W} / \mathrm{m} \cdot{ }^{\circ} \mathrm{C}\right)\end{array}$ \\
\cline { 2 - 3 } Temperature $\left({ }^{\circ} \mathrm{C}\right)$ & Measured & Predicted \\
& & \\
\hline & & \\
50 & 0.1255 & 0.1255 \\
60 & 0.1241 & 0.1240 \\
70 & 0.1227 & 0.1226 \\
80 & 0.1213 & 0.1212 \\
90 & 0.1199 & 0.1198 \\
& 0.1184 & 0.1184 \\
\hline
\end{tabular}

\subsubsection{Oxygen Solubility}

The calculation of the concentration of dissolved air in the test fluid uses the ASTM Standard D3827-92, Standard Method for Estimation of Solubility of Gases in Petroleum and Other Organic Liquids. The calculation is shown below.

1. Determination of parameters for Ostwald coefficient:

$$
\begin{aligned}
& \delta_{1}=12.03 \rho+7.36 \\
& \delta_{2}=7.75 \text { (given for oxygen) }
\end{aligned}
$$

where $\rho$ is the fluid density at $15.5^{\circ} \mathrm{C}$ (in units of $g / \mathrm{mL}$ );

2. Calculation of Ostwald coefficient, L:

$$
\mathrm{L}=\exp \left[\left(0.0395\left(\delta_{1}-\delta_{2}\right)^{2}-2.66\right)(1-273 / \mathrm{T})-0.303 \delta_{1}-0.0241\left(17.6-\delta_{2}\right)^{2}+5.731\right]
$$

where $\mathrm{T}$ is fluid temperature (in kelvin);

3. Calculation of Bunsen coefficient, B:

$$
B=2697 F\left(p-p_{v}\right) L / T
$$


where

$$
\begin{aligned}
F & =\text { fuel factor for a distillate fuel or halogenated solvent } \\
& =1.28 \text { for oxygen } \\
p & =\text { partial pressure of oxygen (in units of } \mathrm{MPa} \text { ) } \\
\mathrm{p}_{\mathrm{v}} & =\text { vapor pressure of fluid (if } \mathrm{p}_{\mathrm{v}}<<\mathrm{p}, \text { it can be neglected) (in units of } \mathrm{MPa} \text { ); }
\end{aligned}
$$

4. Calculation of solubility:

$$
\mathrm{C}_{\mathrm{a} 2}=\mathrm{B} / 22.4
$$

where $C_{a 2}$ is oxygen concentration (in units of $\mathrm{mol} / \mathrm{L}$ or $\mathrm{kmol} / \mathrm{m}^{3}$ ).

\subsubsection{Diffusion Coefficient}

The diffusion coefficient for a dissolved species in a given liquid is calculated by using the Wilke-Chang equation (1955) as shown below:

$$
D=\frac{7.4 \times 10^{-8}(\Phi \mathrm{Wm})^{1 / 2} \mathrm{~T}}{\mu \mathrm{V}_{\mathrm{A}}^{0.6}}
$$

where

$$
\begin{aligned}
D & =\text { diffusivity }\left(\mathrm{cm}^{2} / \mathrm{s}\right) \\
\Phi & =\text { association factor of liquid } \\
\mathrm{Wm}_{\mathrm{m}} & =\text { molecular weight of liquid } \\
\Phi & =\text { association factor of liquid } \\
\mathrm{T} & =\text { temperature }(\mathrm{K}) \\
\mu & =\text { viscosity of liquid }(\mathrm{cP}) \text { and } \\
\mathrm{V}_{\mathrm{A}} & =\text { molar volume of solute } \mathrm{A} \text { at its normal boiling point }\left(\mathrm{cm}^{3} / \mathrm{mol}\right) .
\end{aligned}
$$




\section{Conclusions and Recommendations}

The scope of this report is to document the organic-fluid fouling model and to show its capabilities for predicting the effects of physical parameters on the rate of fouling for a fluid containing a known chemical that can produce foulant. The process of organic-fluid fouling is complex and difficult to formulate with a mathematical model. However, a mechanistic model is essential to identify the controlling mechanism(s) and to determine the effects of physical parameters. Such a fouling model can be the basis for the development of methodology to determine threshold conditions. For many complex fluid systems, it may not be possible to develop a detailed chemical-reaction model. However, a basic fouling model can be a good tool to determine the effects of physical parameters, thereby facilitating the application of laboratory data to industrial conditions. In addition, the fouling model, supported by experimental data for selected conditions, can be used to determine the effectiveness of chemical treatments.

\subsection{Conclusions}

On the basis of the predicted results and experimental data obtained in this phase of work, the following conclusions have been derived:

1. The experimental data showed a trend of increasing fouling rate with time. The experimental data confirmed the predicted results obtained with the Case 1a and Case 2 fouling models, in which the bulk reaction was included.

2. On the basis of conclusion 1, proper care must be taken when applying the experimental data obtained with a closed-flow-loop apparatus to industrial oncethrough-flow systems.

3. The results from the fouling model indicated that it is not always possible to use the wall temperature to determine the activation energy and then to apply the laboratory data to industrial conditions where the fluid and wall temperatures are different from laboratory conditions.

4. The Case 2 model predicted the results obtained with the annular-flow monitor more accurately than did the other models (after their validation with the data for the in-tube monitor); this result suggests that the Case 2 model more correctly represented the fluid dynamics for the present set of conditions.

5. The analysis of the once-though-flow system (typical of industrial heat exchangers) indicated that precursor generated upstream of the heat exchanger could have a more significant effect than precursor generated in the heat exchanger itself. Therefore, the fouling mitigation methods must take into 
account other process units connected to the heat exchanger having the severe fouling problem.

\subsection{Recommendations}

The organic-fluid fouling model is documented in this report, and further validation of the model is expected to be presented in a follow-up report. The research program can be directed to the next step of the four-step approach described in Section 1. Specific recommendations for the next phase of work are as follows:

1. The fouling model should be applied to enhanced surfaces to determine the effects of enhancing the heat- and mass-transfer processes on the local rate of fouling. It will help to examine the test data that showed significantly reduced rates of fouling for certain enhanced surfaces.

2. As follow-up research to recommendation 1 , the fouling model should be used to determine which enhanced surfaces may have minimum fouling propensities.

3. The fouling model should be developed for fluid mixtures, where several species react interactively to produce a fouling precursor.

4. The experimental program should be focused on fluid mixtures in support of the fouling model.

5. Using the fouling model as a base, a model should be developed to determine threshold conditions for fouling. 


\section{References}

Asomaning, S., and A.P. Watkinson, 1990, "The Role of Olefins in Fouling in Heat Exchangers," paper presented at the American Institute of Chemical Engineers Summer National Meeting, San Diego, Calif.

Cole, R.L., J.C. Dimirgian, and J.W. Allen, 1987, Organic Rankine-Cycle Power Systems Working Fluid Study: Topical Report No. 2 - Toluene, ANL/CNSV-TM-192, Argonne National Laboratory, Argonne, Ill.

Crittenden, B.D., S.T. Kolaczkowski, and S.A. Hout, 1987, "Modeling Hydrocarbon Fouling," Chemical Engineering Research \& Design 65:171-179.

Epstein, N., 1987, "Particulate Fouling of Heat Transfer Surfaces," in Fouling Science and Technology, L.F. Melo, T.R. Bott, and C.A. Bernardo (editors), NATO Advanced Science Institutes, Martinus Nijiholff, Holland, pp. 143-164.

Himmelblau, D.M., and K.B. Bishoff, 1968, Process Analysis and Simulation, John Wiley and Sons, Inc., New York, N.Y.

Kern, D.Q., and R.E. Seaton, 1959, "Theoretical Analysis of Thermal Surface Fouling," British Chemical Engineering 4:258-262.

McKetta, J. (editor), 1992, Petroleum Processing Handbook, Marcel Dekker Inc., New York, N.Y.

Nelson, W.L., 1934, "Fouling of Heat Exchangers," Refiner and Natural Gasoline Manufacturer 13(7):271.

Nijsing, R., 1964, Diffusional and Kinetic Phenomena Associated with Fouling, Euratom Report, EUR 543.

Paterson, W.R., and P.J. Fryer, 1988, "A Reaction Engineering Approach to the Analysis of Fouling," Chemical Engineering Science 43:1714-1717.

Rebello, W.J., 1987, Assessment of Heat Transfer Enhancement and Fouling in Industrial Heat Exchangers, DOE/CE/40716-3, Department of Energy, Washington, D.C.

Reid, C.R., J.M. Prausnitz, and B.E. Poling, 1987, Properties of Gases and Liquids, McGrawHill Book Company, New York, N.Y. 
Russell, G.A., 1957, "Oxidation of Unsaturated Compounds," Journal of the American Chemical Society 79:1035-1040.

Seren, L., C.B. Panchal, and D. Rote, 1982, Study of Accuracy and Stability of Temperature Sensors for Low Temperature and Management Applications, ANL/OTEC-PS-12, Argonne National Laboratory, Argonne, Ill.

Somerscales, E.F.C., 1981, "Corrosion Fouling," in Fouling in Heat Exchanger Equipment, J. Chenoweth and M. Impagliozzo (editors), American Society of Mechanical Engineers Publication, HTD-Vol. 17, New York, N.Y., pp. 17-27.

Taborek, J., T. Akoi, R.B. Ritter, J.W. Palen, and J.G. Knudsen, 1972, "Fouling - The Major Unsolved Problem in Heat Transfer," Chemical Engineering Progress 68(2):59-67 and 68(7):69-78.

Taylor, W.F., et al., 1974, "Deposit Formation from De-Oxygenated Hydrocarbons - General Features," Industrial \& Engineering Chemistry Product Research and Development 12:133-138.

Taylor, W.F., et al., 1980, "Deposit Formation from De-Oxygenated Hydrocarbons - Studies in Pure Compound Systems," Industrial \& Engineering Chemistry Product Research and Development 17:65-70.

Technical Data Book, Petroleum Refining, 1977, American Petroleum Institute, Division of Refining, Washington, D.C.

Van Nostrand Jr., W.L., S.H. Leach, and J.L. Haluska, 1981, "Fouling of Refinery Heat Transfer Equipment," in Fouling of Heat Transfer Equipment, E. Somerscales and J.G. Knudsen (editors), Hemisphere Publishing Corp., Washington, D.C., pp. 619-643.

Watkinson, A.P., 1988, Critical Review of Organic Fluid Fouling, ANL/CNSV-TM-208, Argonne National Laboratory, Argonne, Ill.

Watkinson, A.P., and N. Epstein, 1970, "Particulate Fouling of Sensible Heat Exchangers," Proceedings, 4th International Heat Transfer Conference, Paris, France, Vol. 1, paper 1.6.

Wilke, C.R., and P. Chang, 1955, "Correlation of Diffusion Coefficients in Dilute Solutions," AIChE Journal, 1:264-270. 